NLT

National Institute of Standards and Technology

Technology Administration, U.S. Department of Commerce
Office of Applied Economics

Building and Fire Research Laboratory

Gaithersburg, Maryland 20899

\title{
Benefits and Costs of Research:
}

\section{A Case Study of Construction Systems}

\section{Integration and Automation Technologies in}

\section{Commercial Buildings}

\section{Robert E. Chapman}

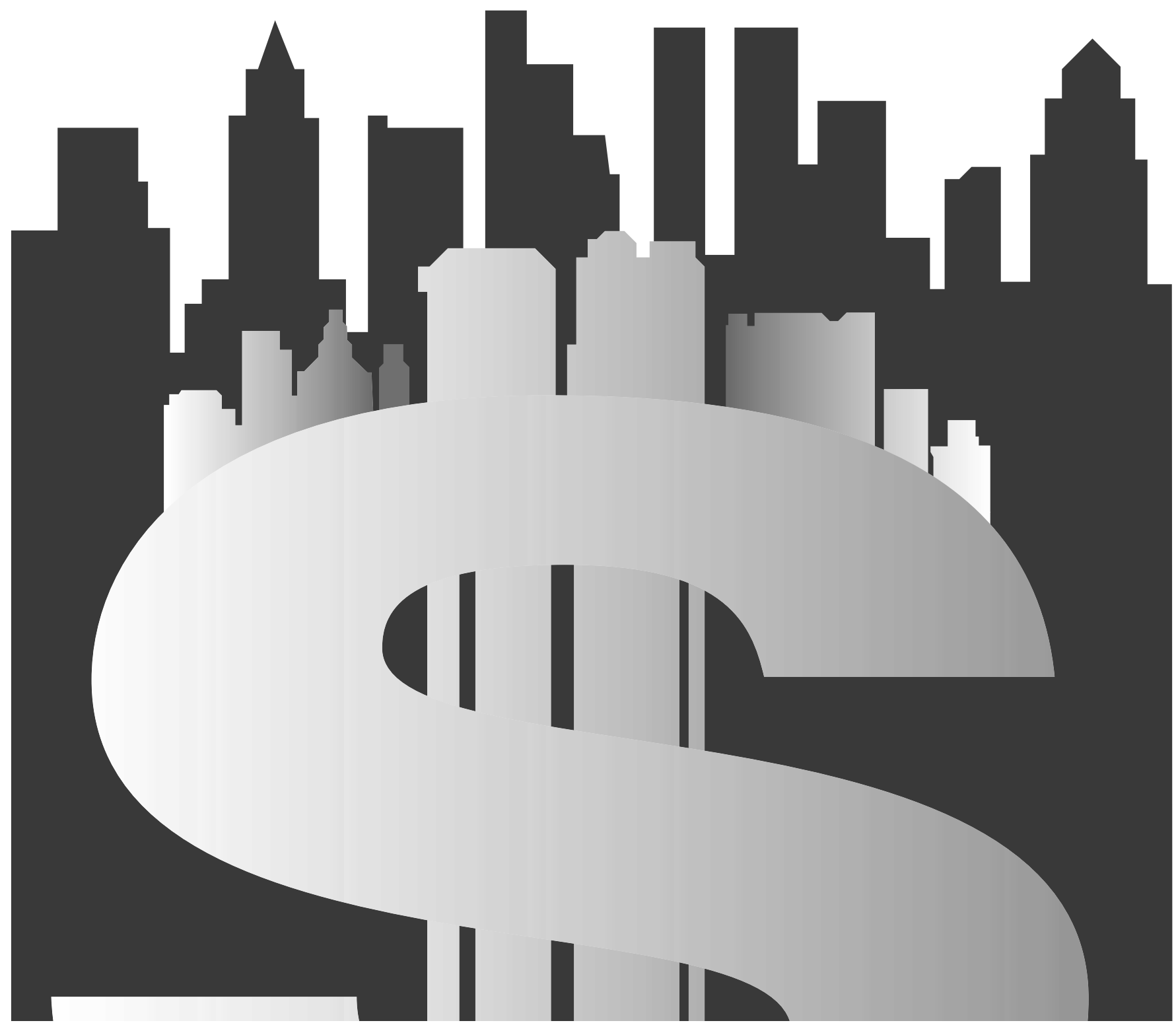



U.S. Department of Commerce

Technology Administration

National Institute of Standards and Technology
Office of Applied Economics

Building and Fire Research Laboratory Gaithersburg, MD 20899

\title{
Benefits and Costs of Research: A Case Study of Construction Systems Integration and Automation Technologies in Commercial Buildings
}

\author{
Robert E. Chapman
}

Sponsored by:

National Institute of Standards and Technology

Building and Fire Research Laboratory

December 2001
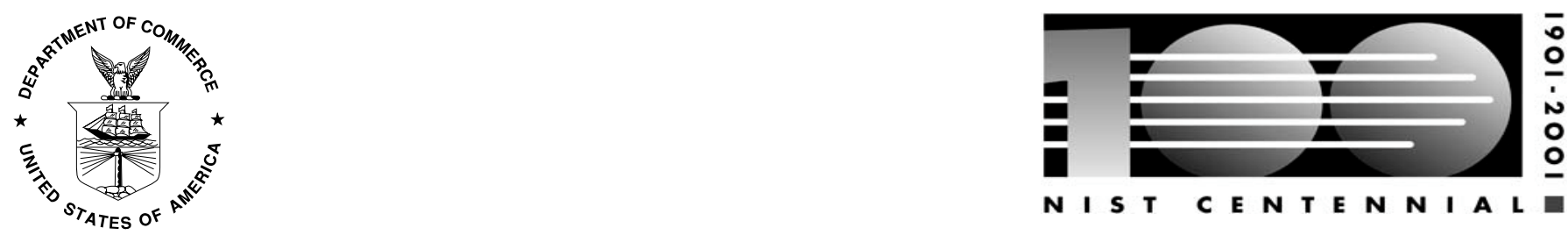

U.S. DEPARTMENT OF COMMERCE

Donald L. Evans, Secretary

\section{TECHNOLOGY ADMINISTRATION}

Philip J. Bond, Under Secretary for Technology

NATIONAL INSTITUTE OF STANDARDS AND TECHNOLOGY

Arden L. Bement, Jr., Director 



\begin{abstract}
The National Institute of Standards and Technology (NIST) is improving its resource allocation process by doing "microstudies" of its research impacts on society. This report is one of a series of microstudies prepared by NIST's Building and Fire Research Laboratory (BFRL).

This report focuses on a critical analysis of the economic impacts of past, ongoing, and planned research on BFRL's construction systems integration and automation technologies (CONSIAT) program. The CONSIAT program is an interdisciplinary research effort within BFRL - in collaboration with the Construction Industry Institute, the private sector, other federal agencies, and other laboratories within NIST - to develop key enabling technologies, standard communication protocols, and advanced measurement technologies needed to deliver fully-integrated and automated project process (FIAPP) products and services to the construction industry.
\end{abstract}

This case study of BFRL's CONSIAT-related research, development, and deployment effort illustrates how to apply in practice a series of standardized methods to evaluate and compare the economic impacts of alternative research investments. It is presented in sufficient detail to understand the basis for the economic impact assessment and to reproduce the results. It is based on past, ongoing, and planned research efforts. Thus, it includes CONSIAT-related investment costs that have already occurred along with estimates of future investment costs and cost savings due to the use of FIAPP products and services.

The results of this study demonstrate that the use of FIAPP products and services will generate substantial cost savings to the owners and managers of commercial buildings and to contractors engaged in the construction of those buildings. The present value of savings nationwide expected from the use of FIAPP products and services is nearly $\$ 1.4$ billion (measured in 1997 dollars). Furthermore, because of BFRL's involvement, FIAPP products and services are expected to be commercially available in 2005. If BFRL had not participated in the development of FIAPP products and services, the commercial introduction of FIAPP products and services is expected to be delayed until 2009. Consequently, potential cost savings accruing to commercial building owners and managers and to contractors over the period 2005 through 2008 would have been foregone. The present value of these cost savings is approximately $\$ 120$ million. These cost savings measure the value of BFRL's contribution for its CONSIAT-related investment costs of approximately $\$ 29.1$ million. Stated in present value terms, every public dollar invested in BFRL's CONSIAT-related research, development, and deployment effort is expected to generate $\$ 4.13$ in cost savings to the public.

\title{
Keywords
}

Building economics; commercial buildings; construction; delivery time; economic analysis; impact evaluation; integration and automation; life-cycle costing; safety 


\section{Preface}

This study was conducted by the Office of Applied Economics in the Building and Fire Research Laboratory (BFRL) at the National Institute of Standards and Technology (NIST). The study is designed to estimate the economic impacts resulting from BFRL research and to estimate the return on BFRL's research investment dollars. The intended audience is the National Institute of Standards and Technology as well as other government and private research groups that are concerned with evaluating how efficiently they allocated their past, present, and future research budgets.

The measurement of economic impacts of research is a major interest of BFRL and of NIST. Managers need to know the impact of their research programs in order to achieve the maximum social benefits from their limited budgets. The standardized methods for measuring economic impacts employed in this study are essential to support BFRL's effort to evaluate the cost effectiveness of completed and ongoing research projects. As additional experience is gained with the application of these standardized methods, their use will enable BFRL to select the "best" among competing research programs for future funding, to evaluate how cost effective are existing research programs, and to defend or terminate programs on the basis of their economic impact. This need for measurement methods exists across programs in BFRL, in NIST, and in other research laboratories. 


\section{Acknowledgements}

The author wishes to thank all those who contributed so many excellent ideas and suggestions for this report. They include Dr. Shyam Sunder of the Structures Division at NIST's Building and Fire Research Laboratory (BFRL), manager of BFRL's construction systems integration and automation technologies (CONSIAT) product development effort, for his technical guidance, suggestions, and support. The author wishes to thank the Construction Industry Institute (CII) for providing an aggregated, project-level data set covering the industrial and commercial sectors. Special thanks are extended to Dr. Stephen R. Thomas, CII Associate Director for Benchmarking, for his stimulating discussions on the uses of these data. Special appreciation is extended to Drs. Harold E. Marshall and Sieglinde K. Fuller of BFRL's Office of Applied Economics for the thoroughness of their reviews and for their many insights and to Mrs. J'amie L. Maynard for her assistance in preparing the manuscript for review and publication. Special appreciation is extended to Ms. Christine A. Izzo who helped immensely with the data collection and analysis effort and who provided numerous technical and editorial comments on earlier drafts of this report. Thanks are due to the entire BFRL CONSIAT product development team for their assistance in formulating this research effort. And special thanks are due each of the CONSIAT project leaders-Dr. Kent A. Reed, Mr. Mark E. Palmer, Mr. Robert R. Lipman, Dr. William C. Stone, Ms. Geraldine S. Cheok, and Ms. Karen M. Furlani-for their assistance in identifying CONSIAT-related benefits and costs and for their helpful comments on an earlier draft of this report. The report has also benefited from the review and technical comments provided by Dr. Christoph Witzgall of NIST's Information Technology Laboratory. 


\section{Table of Contents}

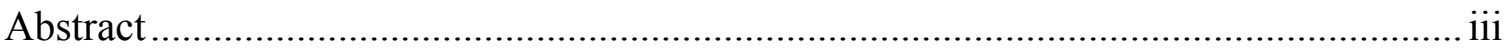

Preface

Acknowledgements ................................................................................................. vii

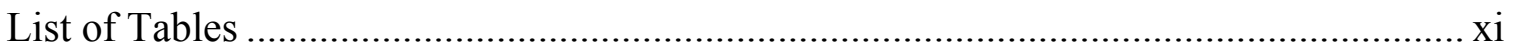

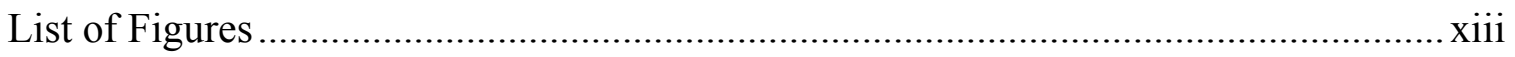

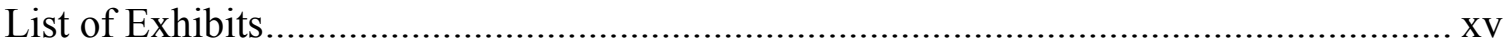

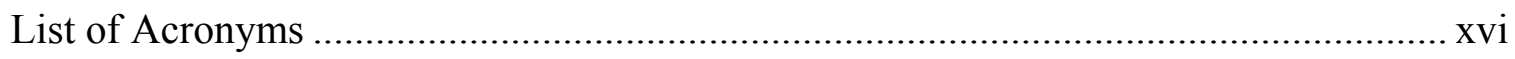

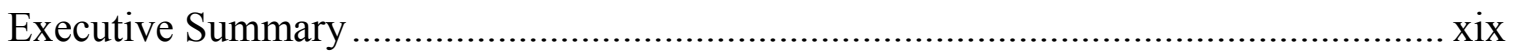

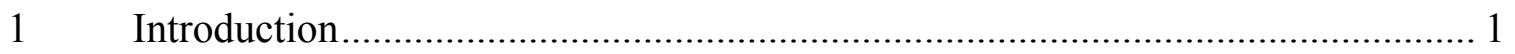

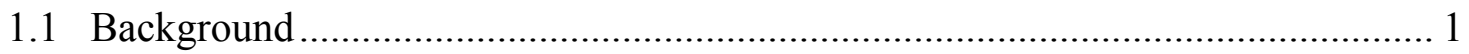

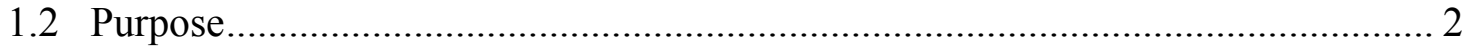

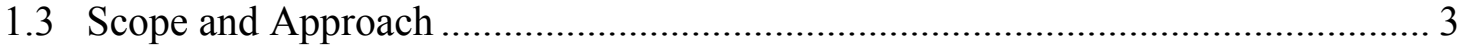

2 A Methodology for Analyzing Economic Impacts .............................................. 5

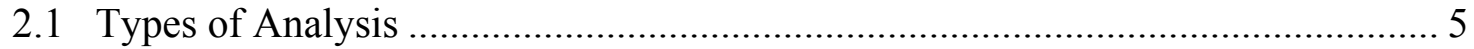

2.1.1 Baseline Analysis......................................................................... 5

2.1.2 Sensitivity Analysis ………………………........................................ 5

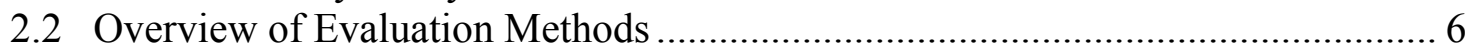

2.2.1 Present Value of Net Benefits and Present Value of Net Savings.................. 7

2.2.2 Benefit-to-Cost Ratio and Savings-to-Investment Ratio .................................. 8

2.2.3 Adjusted Internal Rate of Return .........................................................

2.2.4 Summary of Methods......................................................................... 10

2.3 Presentation and Analysis of the Results of an Economic Impact Assessment.... 12

2.3.1 Significance of Research Effort ............................................................ 12

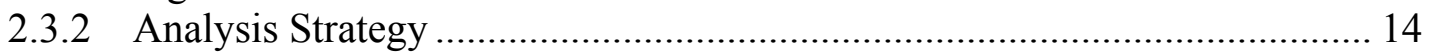

2.3.3 Calculation of Benefits, Costs, and Additional Measures ............................. 15

3 Building and Fire Research Laboratory's CONSIAT Program ............................ 17

3.1 Fully-Integrated and Automated Project Processes: What They Are and What

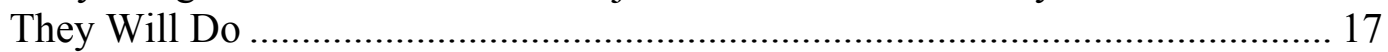

3.2 The FIATECH Consortium: A Vehicle for Delivering Fully-Integrated and Automated Project Processes to the Construction Industry .................................. 20

3.3 Key Components of BFRL's CONSIAT Program ……………............................ 21

3.3.1 Project Information Management System Technologies............................... 25 
3.3.2 Advanced Graphical User Interfaces for Construction Project Delivery

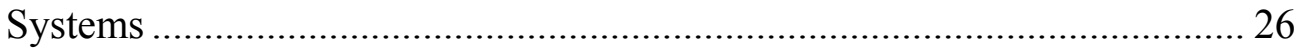

3.3.3 Product Data Standards for Industrial Facilities ........................................ 28

3.3.4 Site Measurement System Communication Standards and Practices ........... 29

3.3.5 Procedures and Metrics for Construction Range Imaging and Registration. 31

3.3.6 Measurement Processes and Metrics for Construction Component Tracking ............................................................................................... 32

3.3.7 Enhanced Construction Object Recognition Through Sensor Fusion .......... 34

3.3.8 Economic Analysis of FIAPP Products and Services................................... 35

$4 \quad$ Market for FIAPP Products and Services ………….......................................... 37

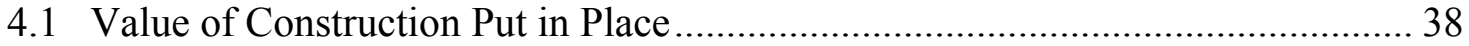

4.2 Overview of the Commercial Sector................................................................... 44

4.3 Characteristics of Commercial Buildings ......................................................... 48

$5 \quad$ Strategy for Identifying, Collecting, and Measuring FIAPP-Related Benefits

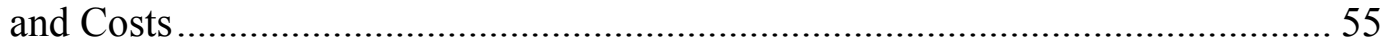

5.1 Identification of Key Stakeholders ………………........................................... 55

5.2 Classification of FIAPP-Related Benefits and Cost Savings................................. 56

5.3 Classification of FIAPP-Related Cost Increases and Benefit Reductions ............. 64

5.4 How FIAPP-Related Benefits and Costs Accrue to Stakeholders ......................... 68

6 Data and Assumptions for the CONSIAT Economic Impact Assessment ........... 73

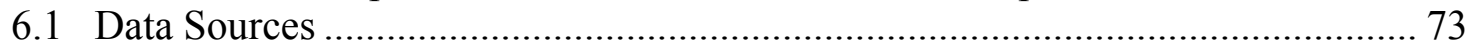

6.1.1 Baseline Measures of Construction Industry Practices................................. 73

6.1.2 The CII Benchmarking and Metrics Database............................................... 74

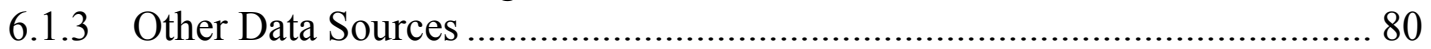

6.2 Defining the Base Case and the FIAPP Alternative ……………………….......... 83

6.3 Estimating Significant FIAPP-Related Benefits and Costs ................................... 84

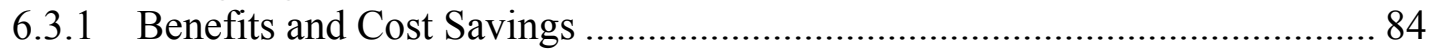

6.3.1.1 Reduced First Costs...................................................................... 85

6.3.1.2 Reduced Maintenance and Repair Costs .......................................... 86

6.3.1.3 Reductions in Construction-Related Accidents................................. 87

6.3.1.4 Reductions in Delivery Time …………………............................. 90

6.3.1.5 Higher Net Income for Contractors.................................................. 90

6.3.2 Cost Increases and Benefit Reductions....................................................... 91

6.3.2.1 New-Technology Introduction Costs .............................................. 92

6.3.2.2 Increased Research and Development Costs ................................... 92

6.4 Key Assumptions and Analysis Issues ................................................................ 94

6.4.1 Base Year for Computing Benefits and Costs ............................................ 94

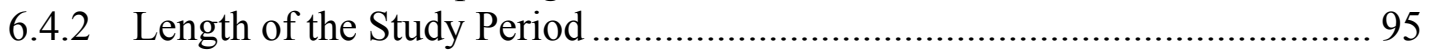

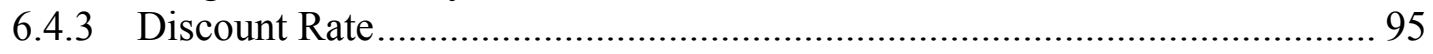

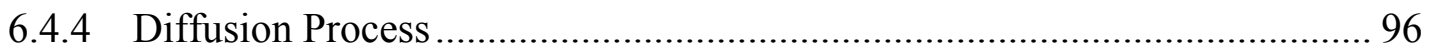

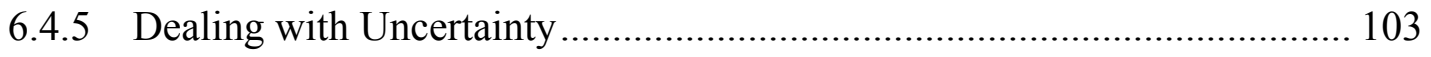

6.4.6 Measuring BFRL's Contribution ............................................................... 104 
$7 \quad$ Baseline Analysis of Economic Impacts........................................................ 107

7.1 BFRL Summary Impact Statement .............................................................. 110

7.2 Cost Savings Nationwide ........................................................................... 110

7.3 Measuring the Value of BFRL's Contribution and the Return on BFRL's CONSIAT-Related Investments ................................................................... 119

8 Sensitivity Analysis of Economic Impacts ………......................................... 125

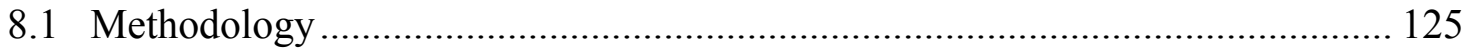

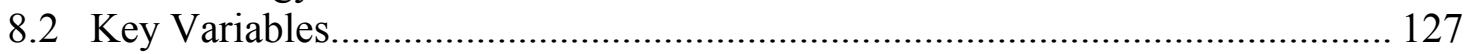

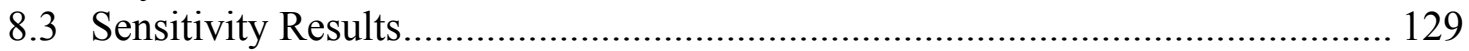

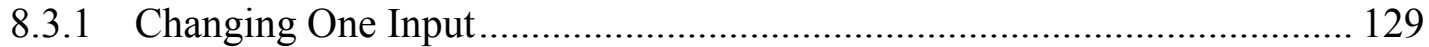

8.3.2 Changing All Eleven Inputs in Combination............................................. 139

9 Summary and Suggestions for Further Research........................................... 155

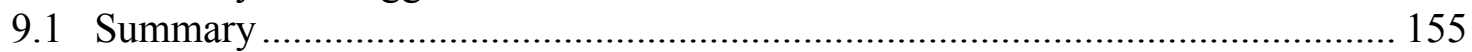

9.2 Suggestions for Further Research ........................................................... 158

9.2.1 The Development of a Standard Classification of Research Benefits and

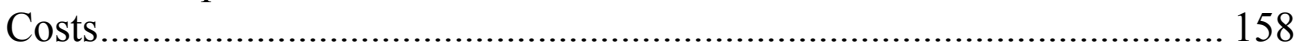

9.2.2 Factors Affecting the Diffusion of New Technologies................................ 159

9.2.3 Conducting Ex Ante Evaluations with Scheduled Follow-ups .................... 159

9.2.4 Evaluations Based on Multiattribute Decision Analysis ............................. 160

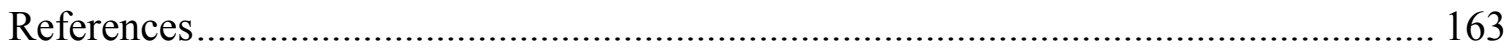

Disclaimer:

Certain trade names and company products are mentioned in the text in order to adequately specify the technical procedures and equipment used. In no case does such identification imply recommendation or endorsement by the National Institute of Standards and Technology, nor does it imply that the products are necessarily the best available for the purpose.

\section{List of Tables}

Table 2-1. Summary of Appropriateness of Each Standardized Evaluation Method for Each Decision Type

Table 4-1. Value of Construction Put in Place in Millions of Constant 1997 Dollars .....40

Table 4-2. Value of Construction Put in Place in Millions of Current Dollars

Table 4-3. Value of Construction Put in Place: Sector Totals and Sum Total in Millions of Constant 1997 Dollars.

Table 4-4. Value of Construction Put in Place: Sector Totals and Sum Total in Millions of Current Dollars. 
Table 5-1. Hierarchy of FIAPP Stakeholders by Groups and Classes of Individual FIAPP Stakeholders

Table 5-2. Assignment of Classes of Individual FIAPP Stakeholders to FIAPP Stakeholder Groups

Table 5-3. FIAPP-Related Benefits (or Cost Savings) for All Stakeholders .60

Table 5-4. FIAPP-Related Cost Increases (or Benefit Reductions) for All Stakeholders .66

Table 5-5. Types of FIAPP-Related Benefits (or Cost Savings) Classified by Stakeholder Group

Table 5-6. Types of FIAPP-Related Cost Increases (or Benefit Reductions) Classified by Stakeholder Group

Table 6-1. Summary of Selected Results from the Statistical Analyses of the CII Project Data. .80

Table 6-2. Average Costs of Construction Site Injuries: 1997 . .89

Table 6-3. BFRL Investment Costs by Fiscal Year..... .93

Table 6-4. Baseline Case of $\mathrm{P}_{\eta}(\mathrm{t})(\alpha=4.0, \beta=0.5, \eta=0.4)$ 101

Table 6-5. Estimated Investment Costs as a Function of the Year of First Commercial Use 106

Table 7-1. Baseline Values for the Diffusion Models and of FIAPP-Related Investments and Installations by Year: $1993-2017$

Table 7-2. Baseline Cost Savings by Category and in Total in Millions of 1997 Dollars by Year: 1993-2017.

Table 7-3. Baseline Computation of Present Value Cost Savings Nationwide in Millions of 1997 Dollars: 1993-2017

Table 7-4. Summary of BFRL Research Investments: 1993-2017.

Table 7-5. Estimated Cost Savings in Millions of 1997 Dollars Attributable to BFRL

Table 8-1. Baseline and Extreme Values of the Eleven Input Variables Used in the Sensitivity Analysis 
Table 8-2. Summary Statistics Due to Changes in the Input Variable Alpha.................130

Table 8-3. Summary Statistics Due to Changes in the Input Variable Beta ...................131

Table 8-4. Summary Statistics Due to Changes in the Input Variable Eta .....................132

Table 8-5. Summary Statistics Due to Changes in the Input Variable Discount Rate....133

Table 8-6. Summary Statistics Due to Changes in the Input Variable First Cost Savings.

Table 8-7. Summary Statistics Due to Changes in the Input Variable Maintenance and Repair Cost Savings

Table 8-8. Summary Statistics Due to Changes in the Input Variable Reductions in Delivery Time

Table 8-9. Summary Statistics Due to Changes in the Input Variable Higher Contractor Net Income.

Table 8-10. Summary Statistics Due to Changes in the Input Variable NewTechnology Introduction Costs ....

Table 8-11. Summary Statistics Due to Changes in the Input Variable Time of First Use 136

Table 8-12. Summary Statistics Due to Changes in the Input Variable Length of Delay

Table 8-13. Results of the Deterministic Sensitivity Analysis for the Combined Effects Due to Changes of the Input Variables "Targeted" Time of First Use and the Length of the Delay

Table 8-14. Summary Statistics Due to Changes in All of the Input Variables

Table 8-15. Percentiles for Statistical Measures Due to Changes in All of the Input Variables.

\section{List of Figures}

Figure 3-1. Information Flows Model for Commercial Buildings and Industrial

Facilities 
Figure 3-2. Schematic Diagram of BFRL's CONSIAT Program ..................................23

Figure 4-1. 1997 Breakdown of \$657 Billion Construction Market.................................44

Figure 4-2. 1997 Breakdown of \$206 Billion Commercial Sector .................................46

Figure 4-3. Total Number of Commercial Buildings by Size Category: 1995 .................50

Figure 4-4. Total Commercial Floorspace by Building Size Category: 1995 ..................50

Figure 4-5. Total Commercial Floorspace by Building Size Category and Number of

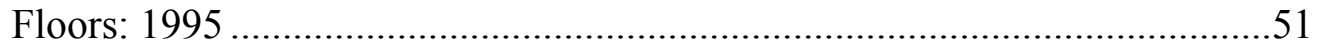

Figure 4-6. Total Number of Commercial Buildings by Year of Construction: 1995 .......52

Figure 4-7. Total Commercial Floorspace by Year of Construction: 1995 .....................52

Figure 4-8. Total Commercial Floorspace by Year of Construction and Number of Floors: 1995

Figure 6-1. CII Database by Respondent Type...............................................................77

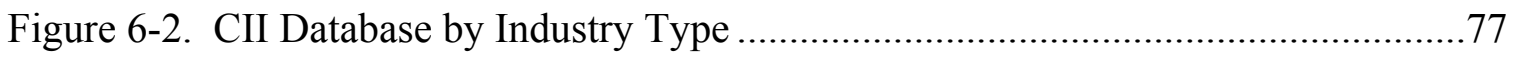

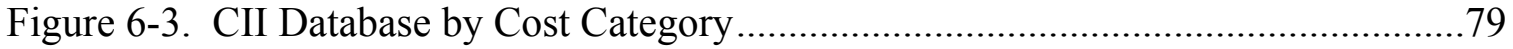

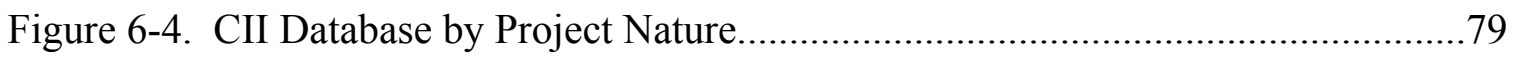

Figure 6-5. Recordable Incidence Rate and Lost Workday Case Incidence Rate for Years 1989-1997.

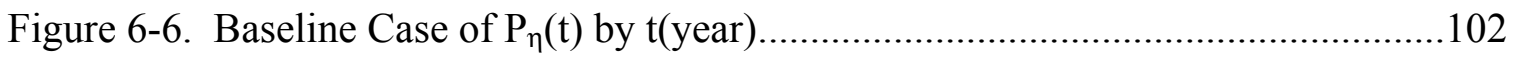

Figure 8-1. Present Value of Cost Savings Nationwide in Millions of 1997 Dollars.....145

Figure 8-2. Present Value of Cost Savings Attributable to BFRL in Millions of 1997 Dollars

Figure 8-3. Present Value of BFRL's Investment Costs in Millions of 1997 Dollars....147

Figure 8-4. Present Value of Net Savings Attributable to BFRL in Millions of 1997 Dollars

Figure 8-5. Savings to Investment Ratio on BFRL's Research and Development Investment 
Figure 8-6. Adjusted Internal Rate of Return on BFRL's Research and Development

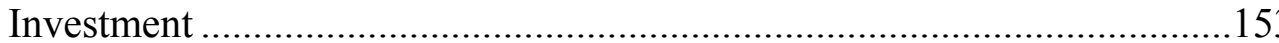

\section{List of Exhibits}

Exhibit 2-1. Format for Summarizing the Economic Impacts of BFRL Research Efforts

Exhibit 7-1. Summary of Economic Impacts of BFRL Research on Construction Systems Integration and Automation Technologies in Commercial Buildings 


\section{List of Acronyms}

\begin{tabular}{|l|l|}
\hline Acronym & \\
\hline AHP & Analytical Hierarchy Process \\
\hline AIRR & Adjusted Internal Rate of Return \\
\hline AISC & American Institute for Steel Construction \\
\hline AP & Application Protocol \\
\hline ASHRAE & American Society of Heating, Refrigerating, and Air-Conditioning Engineers \\
\hline ASTM & American Society for Testing and Materials \\
\hline BCR & Benefit-to-Cost Ratio \\
\hline BFRL & Building and Fire Research Laboratory \\
\hline BLS & Bureau of Labor Statistics \\
\hline CAD & Computer-Aided Design \\
\hline CADD & Computer-Aided Design and Drafting \\
\hline CAM & Computer-Aided Manufacturing \\
\hline CBECS & Commercial Building Energy Consumption Survey \\
\hline CDF & Cumulative Distribution Function \\
\hline CII & Construction Industry Institute \\
\hline CONSIAT & Construction Systems Integration and Automation Technologies \\
\hline CPI & Consumer Price Index \\
\hline DOE & Department of Energy \\
\hline ECS & Emissions Control System \\
\hline EDI & Electronic Data Interchange \\
\hline EMCS & Energy Management and Control System \\
\hline EPC & Engineer-Procure-Construct \\
\hline ERP & Enterprise Resource Planning \\
\hline FIAPP & Fully-Integrated and Automated Project Process \\
\hline FIATECH & Fully-Integrated and Automated Project Processes Technologies \\
\hline FY & Fiscal Year \\
\hline GPS & Global Positioning System \\
\hline GUI & Graphical User Interface \\
\hline HVAC & Heating, Ventilation, and Air-Conditioning \\
\hline IAI & International Alliance for Interoperability \\
\hline IEC & International Electrotechnical Commission \\
\hline IEEE & Institute of Electronics and Electrical Engineers \\
\hline IFC & Industry Foundation Classes \\
\hline IFMA & International Facilities Management Association \\
\hline IRS & Internal Revenue Service \\
\hline ISO & International Organization for Standardization \\
\hline
\end{tabular}




\begin{tabular}{|l|l|}
\hline IT & Information Technology \\
\hline LCC & Life-Cycle Cost \\
\hline LADAR & LAser Detection and Ranging \\
\hline LWCIR & Lost Workday Case Incidence Rate \\
\hline MARR & Minimum Attractive Rate of Return \\
\hline NIST & National Institute of Standards and Technology \\
\hline NLS & Non-Line-of-Sight \\
\hline NSTC & National Science and Technology Council \\
\hline OAE & Office of Applied Economics \\
\hline OMB & Office of Management and Budget \\
\hline PLIB & Parts LIBrary \\
\hline PVB & Present Value of Benefits \\
\hline PVC & Present Value of Non-Investment Costs \\
\hline PVC & Present Value of Combined Costs \\
\hline PVI & Present Value of Investment Costs \\
\hline PVNB & Present Value of Net Benefits \\
\hline PVNS & Present Value of Net Savings \\
\hline PVS & Present Value of Savings \\
\hline R\&D & Research and Development \\
\hline RFID & Radio Frequency Identification \\
\hline RIR & Recordable Incidence Rate \\
\hline SIR & Savings-to-Investment Ratio \\
\hline STEP & Standard for the Exchange of Product \\
\hline TV & Terminal Value \\
\hline VRML & Virtual Reality Modeling Language \\
\hline
\end{tabular}


xviii 


\section{Executive Summary}

This report focuses on measuring and documenting the economic impacts of BFRL's Construction Systems Integration and Automation Technologies (CONSIAT) program in commercial buildings. The CONSIAT program is an interdisciplinary research effort within BFRL - in collaboration with the Construction Industry Institute, the private sector, other federal agencies, and other laboratories within NIST - to develop key enabling technologies, standard communication protocols, and advanced measurement technologies needed to deliver fully-integrated and automated project process (FIAPP) products and services to the construction industry.

This case study of BFRL's CONSIAT-related research, development, and deployment effort illustrates how to apply in practice a series of standardized methods to evaluate and compare the economic impacts of alternative research investments. It is presented in sufficient detail for the reader to understand the basis for the economic impact assessment and to reproduce the results. It is based on past, ongoing, and planned research efforts. Thus, it includes CONSIAT-related investment costs that have already occurred along with estimates of future investment costs and cost savings due to the use of FIAPP products and services in commercial buildings.

Chapter 2 presents the five economic evaluation methods (i.e., economic measures) that are most appropriate for measuring the benefit and cost impacts of research programs: (1) present value of net benefits (PVNB); (2) present value of net savings (PVNS); (3) benefit-to-cost ratio (BCR); (4) savings-to-investment ratio (SIR); and (5) adjusted internal rate of return (AIRR). The PVNB (PVNS) measures the overall magnitude of the benefits (cost savings) net of the costs of undertaking the research. The BCR (SIR) measures the benefits (cost savings) per unit cost of the research. The AIRR is the annual percentage yield from a project over the study period, taking into account the reinvestment of interim receipts. All five methods apply to accept/reject decisions. Both PVNB and PVNS are appropriate for design/size decisions (selecting one among mutually exclusive alternatives). BCR, SIR, and AIRR are appropriate for ranking alternatives under a budget constraint. A format for summarizing economic impacts of research investments is presented in Exhibit 2.1.

Chapter 3 describes BFRL's CONSIAT-related research, development, and deployment effort and each of its eight key areas of research. The CONSIAT effort within BFRL is aimed at producing a suite of products and services that integrate a wide variety of planning, design, and construction activities. How these products and services perform in a "synergistic" and reliable manner is at the heart of BFRL's CONSIAT program. The goal of BFRL's CONSIAT program is to produce FIAPP products and services that will result in significant reductions in both the delivery time of constructed facilities and the life-cycle costs of those facilities. These products and services are being developed for use by building owners and operators, construction contractors, architects, engineers, and other providers of professional services. 
Chapter 4 provides a snapshot of the US construction industry. As such, it provides the context within which the scope and size of the market for FIAPP products and services is defined. Information is first presented on the value of construction put in place to show the size of the construction industry and each of its four sectors. The four sectors are residential, commercial, industrial, and public works. Information on the commercial sector is then presented to focus on its importance within the overall construction industry and to define its key components. Special emphasis is then placed on identifying and detailing the key characteristics of the commercial sector. Detailing the key characteristics of the commercial sector is crucial, because investments in FIAPP products and services affect not only new construction activities but additions and alterations as well as maintenance and repair activities.

A strategy for identifying, collecting, and measuring FIAPP-related benefits and costs is presented in Chapter 5. The strategy identifies key stakeholders (e.g., commercial building owners and managers), presents comprehensive lists of FIAPP-related benefits and costs, and documents the relationships between benefits, costs, and stakeholders. The strategy was developed through an iterative process. First, information was solicited from all of the members of the BFRL CONSIAT team. Second, the lists were refined and organized into a suite of "classification" hierarchies. Third, the classification hierarchies were distributed to the BFRL CONSIAT project leaders and, upon their review of the classification hierarchies, critiqued in a series of meetings. The meetings with the BFRL CBS project leaders also sought to identify subject matter experts for follow-on discussions. Finally, subject matter experts from industry and government were interviewed. These interviews were used to finalize the analysis strategy and the classification hierarchies as well as to collect information on current industry practices and to identify additional data sources.

Chapter 6 describes the data and assumptions used to evaluate the economic impacts of installing FIAPP products and services in commercial buildings. The goal of Chapter 6 is fourfold. First, it establishes the sources and validity of the data used in the CONSIAT economic impact assessment. Second, it defines the base case and the FIAPP alternative. Third, it produces estimated values for key sets of benefits and costs. Fourth, it documents the process by which key assumptions were established, including how the values of key parameters were set. For example, the study period over which costs and savings are measured consists of the 25 years from 1993 through 2017 . The base year is 1997, and all dollar amounts are calculated in present value 1997 dollars. The discount rate is $7 \%$ (real), which is the OMB discount rate in effect for all benefit-cost analyses of public investments that provide benefits or incur costs to the general public.

The CONSIAT economic impact assessment was carried out in two stages. In the first stage, a baseline analysis was performed. In the baseline analysis, all input variables used to calculate the economic measures are set at their likely values. It is important to recognize that the term baseline analysis is used to denote a complete analysis in all respects but one; it does not address the effects of uncertainty. In the second stage, eleven input variables were varied both singly and in combination according to an 
experimental design. Monte Carlo simulations are employed to evaluate how changing the value of these variables affects the calculated values of the economic measures.

In Chapter 7 (see Exhibit 7-1), the results of the baseline analysis demonstrate that the use of FIAPP products and services will generate substantial cost savings to commercial building owners and managers and to contractors engaged in the construction of those buildings. The present value of savings nationwide expected from the use of FIAPP products and services is almost $\$ 1.4$ billion (measured in 1997 dollars). Furthermore, because of BFRL's involvement, FIAPP products and services are expected to be commercially available in 2005. If BFRL had not participated in the development of FIAPP products and services, the commercial introduction of FIAPP products and services is expected to be delayed until 2009. Consequently, potential cost savings accruing to commercial building owners and managers and to contractors over the period 2005 through 2008 would have been foregone. The present value of these cost savings is approximately $\$ 120$ million. These cost savings measure the value of BFRL's contribution for its CONSIAT-related investment costs of approximately \$29.1 million. Stated in present value terms, every public dollar invested in BFRL's CONSIAT-related research, development, and deployment efforts is expected to generate $\$ 4.13$ in cost savings to the public (i.e., an SIR of 4.13). The annual percentage yield (AIRR) from BFRL's CONSIAT-related investments over the study period is $13.3 \%$.

Chapter 8 covers the sensitivity analysis. The objective of the sensitivity analysis was to evaluate how uncertainty in the values of each of the eleven input variables, both singly and in combination, translates into changes in each of the six economic measures. The six economic measures evaluated in the sensitivity analysis are: (1) the present value of savings nationwide, $\mathrm{PVS}_{\mathrm{ALL}}$; (2) the present value of savings due to BFRL, $\mathrm{PVS}_{\mathrm{BFRL}}$; (3) the present value of BFRL's CONSIAT-related investment costs, $\mathrm{PVC}_{\mathrm{BFRL}}$; (4) the present value of net savings due to BFRL, $\mathrm{PVNS}_{\mathrm{BFRL}} ;(5)$ the savings-to-investment ratio on BFRL's CONSIAT-related investments, $\mathrm{SIR}_{\mathrm{BFRL}}$; and (6) the adjusted internal rate of

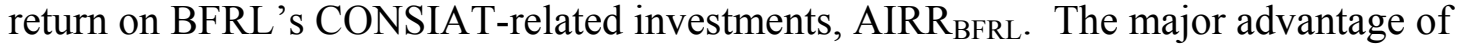
the sensitivity analysis is that it produces results that can be tied to probabilistic levels of significance for each economic measure (e.g., the probability that PVNS $\mathrm{BFRL}_{\mathrm{B}}$ is greater than or equal to zero, $\mathrm{SIR}_{\mathrm{BFRL}}$ is greater than or equal to 1.0 , or $A I R R_{\mathrm{BFRL}}$ is greater than or equal to the discount rate, each of which would indicate that BFRL's CONSIATrelated investments were cost effective).

The results of the sensitivity analysis serve to validate the results of the baseline analysis. For example, each Monte Carlo simulation in which a single input variable was varied produced 1,000 observations for each of the six economic measures. Ten of the 11 such simulations produced values for the median and mean that were nearly identical to the corresponding value calculated in the baseline analysis for that measure. The final Monte Carlo simulation, in which all eleven of the input variables were varied in combination, also produced 1,000 observations for each of the six economic measures. In this case, the median value for each economic measure was less than the corresponding value calculated in the baseline analysis for that measure. In addition, the results from this Monte Carlo simulation reveal that the present value of net savings due to BFRL, 
$\mathrm{PVNS}_{\mathrm{BFRL}}$, can be negative. This implies that there is some non-zero probability that BFRL's CONSIAT-related investments are not cost effective. On the opposite extreme,

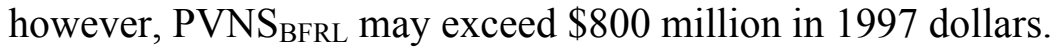

The fact that the range of values for an economic measure is so wide prompted an indepth examination of the results of the final Monte Carlo simulation for three of the six economic measures. These measures are particularly helpful in understanding BFRL's contribution, since each measure provides a different perspective. The first, the present value of net savings due to BFRL, is a magnitude measure; it shows a dollar value to the public net of BFRL's CONSIAT-related investments. The second, the savings-toinvestment ratio on BFRL's CONSIAT-related investments, is a multiplier; it shows, in present value terms, how many dollars the public receives for each public dollar spent. The third, the adjusted internal rate of return on BFRL's CONSIAT-related investments, is a rate of return; it shows the return on the public monies going into the development of FIAPP products and services throughout the 25 -year study period.

For each of the three economic measures, less than 250 observations out of 1,000 were responsible for the observed "uneconomical" outcome. Stated another way, there is at least a $75 \%$ probability that BFRL's CONSIAT-related investments are cost effective. This underscores the importance of using multiple measures in order to ensure consistency in decision making.

Chapter 9 discusses additional areas of research that might be of value to government agencies and other institutions that are concerned with an efficient allocation of their research budgets. These areas of research are concerned with: (1) the development of a standard classification of research benefits and costs; (2) factors affecting the diffusion of new technologies; (3) conducting prospective evaluations with scheduled follow-ups; and (4) evaluations based on multiattribute decision analysis. 


\section{Introduction}

\subsection{Background}

The pressures of competing in the global marketplace are affecting nearly every U.S. business. Now more than ever, U.S. businesses are finding that they must continually improve their products and services if they are to survive and prosper. Research, with its potential for incremental and breakthrough improvement, is of central importance to most businesses' continuous improvement efforts. A key component of the competitiveness problem is the "inability of American companies (or, more accurately, the U.S.-based portions of what are fast becoming global technology firms) to transform discoveries quickly into high-quality products and into processes for designing, manufacturing, marketing, and distributing such products." 1

Increasingly, the winners in the competitiveness race are those businesses that most rapidly make use of the fruits of research (e.g., new data, insights, inventions, and prototypes). Efforts underway at the National Institute of Standards and Technology (NIST) and elsewhere in the U.S. focus on speeding up the commercial application of basic and applied research results. The purpose of this report is to respond to the following question: "how do we measure the results of our investments in technology development and application?" " A case study approach is used to illustrate how standardized evaluation methods may be used to measure the economic impacts of such investments.

NIST's research laboratories assist all sectors of U.S. industry through focused research programs and standards development activities. Each laboratory has strong working relationships with industrial, trade, and professional organizations in its areas of technology concentration. The program of NIST's Building and Fire Research Laboratory (BFRL) is guided by a prioritized research agenda developed by experts from the building and fire communities. Its performance prediction and measurement technologies enhance the competitiveness of U.S. industry and public safety. Specifically, BFRL is dedicated to improving the life-cycle quality and economy of constructed facilities. BFRL studies structural, mechanical, and environmental engineering; fire science and fire safety engineering; and building materials.

To further strengthen its ties to industry, BFRL is participating in the Subcommittee on Construction and Building of the National Science and Technology Council (NSTC). The NSTC, a cabinet-level group charged with setting federal technology policy, coordinates research strategies across a broad cross-section of public and private interests. The Subcommittee on Construction and Building coordinates and defines

\footnotetext{
${ }^{1}$ Reich, Robert W. 1989. “The Quiet Path to Technological Preeminence.” Scientific American (October): pp. 41-47.

${ }^{2}$ Good, Mary, and Arati Prabhakar. 1994. "Foreword." In Mark Bello and Michael Baum, Setting Priorities and Measuring Results at the National Institute of Standards and Technology. Gaithersburg, MD: National Institute of Standards and Technology.
} 
priorities for federal research, development, and deployment related to the industries that produce, operate, and maintain constructed facilities, including, buildings and infrastructure. Seven goals to enhance the competitiveness of the U.S. construction industry are explicit in the mission of the Subcommittee. ${ }^{3}$

BFRL has long recognized the value of measuring the impacts of its research program. Previous studies have shown that even modest research efforts within BFRL are capable of producing significant impacts. ${ }^{4}$ One reason for such outcomes is the unique mix of research facilities and skills possessed by BFRL and its staff. Through many years of active collaboration with its various user communities, BFRL's research findings are highly regarded when new construction, building, and disaster mitigation technologies are considered for introduction into the U.S. market.

Information and automation technologies are core components of the strategic plans of the U.S. construction industry. Advances in information and automation technologies have been identified as key components for achieving the National Construction Goals. The U.S. chemical industry identifies information systems as a key technical discipline in its Technology Vision $2020^{5}$ and predicts achieving the smooth flow of informationfrom concept through design to construction and into plant maintenance and operationwill promote the use of automation and improve economic competitiveness. The 1999 Strategic Plan of the Construction Industry Institute (CII) identifies six major industry trends that will shape the construction industry in the next century. ${ }^{6} \mathrm{CII}$ identified fullyintegrated and automated project processes (FIAPPs) as the most significant trend and predicts it will revolutionize the construction industry. ${ }^{7}$ Characteristics of FIAPP products and services include one-time data entry; interoperability with design, construction, and operation processes (e.g., virtual construction and construction automation); and user friendly input/output techniques. Significant economic impacts are anticipated from the adoption and use of FIAPP products and services within the construction industry.

\subsection{Purpose}

This report is the fifth in a series of impact studies prepared by BFRL. ${ }^{8}$ It focuses on BFRL's Construction Systems Integration and Automation Technologies (CONSIAT)

\footnotetext{
${ }^{3}$ For a detailed description of these goals and how the Subcommittee on Construction and Building is approaching them, see Wright, Richard N., Arthur H. Rosenfeld, and Andrew J. Fowell. 1995. Construction and Building: Federal Research and Development in Support of the U.S. Construction Industry. Washington, DC: National Science and Technology Council.

${ }^{4}$ Marshall, Harold E., and Rosalie T. Ruegg. 1979. Efficient Allocation of Research Funds: Economic Evaluation Methods with Case Studies in Building Technology. NBS Special Publication 558. Gaithersburg, MD: National Bureau of Standards.

${ }^{5}$ American Chemical Society. 1996. Technology Vision 2020. Washington, DC: American Chemical Society.

${ }^{6}$ Construction Industry Institute. 1999. 1999 Strategic Plan. Austin, TX: Construction Industry Institute.

${ }^{7}$ Ibid. p. 15.

${ }^{8}$ The first report in the series focuses on two building technology applications: (1) ASHRAE Standard 9075 for residential energy conservation; and (2) 235 shingles, an improved asphalt shingle for sloped roofing (see Chapman, Robert E., and Sieglinde K. Fuller. 1996. Benefits and Costs of Research: Two Case
} 
program. The CONSIAT program is an interdisciplinary research effort within BFRLin collaboration with CII, the private sector, other federal agencies, and other laboratories within NIST - to develop key enabling technologies, standard communication protocols, and advanced measurement technologies needed to deliver FIAPP products and services to the construction industry.

BFRL's CONSIAT program is aimed at producing a suite of products and services that integrate a wide variety of planning, design, and construction activities. How these products and services perform in a "synergistic" and reliable manner is at the heart of BFRL's CONSIAT program.

The goal of BFRL's CONSIAT program is to produce products and services that will result in significant reductions in both the delivery time of constructed facilities and the life-cycle costs of those facilities. These products and services are being developed for use by building owners and operators, construction contractors, architects, engineers, and other providers of professional services.

\subsection{Scope and Approach}

FIAPP products and services help all four construction industry sectors - industrial, commercial, public works, and residential. This report employs standardized methods to evaluate the expected economic impacts of the adoption and use of FIAPP products and services in commercial buildings (e.g., office buildings, educational facilities, and hospitals).

The "case study" approach employed here illustrates how to evaluate and compare the economic impacts of research investments. Standardized methods are used in this report and others in the series to ensure consistency in the measurement of economic impacts. The measurement methods employed here are applicable to other programs in BFRL, in NIST, and in other research laboratories.

The report has eight chapters in addition to the Introduction. The methodology and the standardized methods employed in the study to measure the CONSIAT program's economic impacts are described in Chapter 2. Standardized methods are used to define

Studies in Building Technology. NISTIR 5840. Gaithersburg, MD: National Institute of Standards and Technology). The second report focuses on a fire technology application: the Fire Safety Evaluation System for health care facilities (see Chapman, Robert E., and Stephen F. Weber. 1996. Benefits and Costs of Research: A Case Study of the Fire Safety Evaluation System. NISTIR 5863. Gaithersburg, MD: National Institute of Standards and Technology). The third report focuses on the research, development, deployment, and use of cybernetic building systems in office buildings (see Chapman, Robert E. 1999. Benefits and Costs of Research: A Case Study of Cybernetic Building Systems. NISTIR 6303.

Gaithersburg, MD: National Institute of Standards and Technology). The fourth report focuses on the research, development, deployment, and use of construction systems integration and automation technologies in industrial facilities (see Chapman, Robert E. 2000. Benefits and Costs of Research: A Case Study of Construction Systems Integration and Automation Technologies in Industrial Facilities. NISTIR 6501. Gaithersburg, MD: National Institute of Standards and Technology). 
the key measures of the economic impacts of research investments. A format for summarizing the economic impacts of research investments is also presented.

The body of this report, Chapters 3 through 8, consists of a case study of fully-integrated and automated project process systems and technologies in commercial buildings. The approach is to present all CONSIAT-related information in sufficient detail for the reader both to understand the basis for the economic impact assessment and make it possible to reproduce the results of the economic impact assessment. The CONSIAT case study is ex ante (i.e., prospective) in that it estimates impacts from on-going and planned research as well as past research.

The CONSIAT case study estimates the economic impacts to the commercial buildings sector of the construction industry from BFRL's research effort aimed at the development and introduction of a suite of FIAPP products and services. Chapter 3 describes BFRL's CONSIAT program. Both the overall CONSIAT research and development effort and the eight key areas of research, which are its constituent parts, are described. Chapter 4 provides an overview of the construction industry. The overview provides the context within which the market for FIAPP products and services is defined. A strategy for measuring FIAPP-related benefits and costs is presented in Chapter 5. The strategy identifies key stakeholders (e.g., building owners and managers), presents comprehensive lists of FIAPP-related benefits and costs, and documents the relationships between benefits, costs, and stakeholders. Assumptions about those years over which costs and savings are tabulated, the appropriate discount rate, and the rate and level of adoption of FIAPP products and services in commercial buildings are necessary to measure the economic impacts of fully-integrated and automated project process systems and technologies. These assumptions, and the supporting data upon which these assumptions are based, are described in Chapter 6. In addition, Chapter 6 develops estimates of the key benefits and costs that are the focus of the ex ante impact assessment. These "significant few" benefits and costs are well-defined subsets of the comprehensive lists presented in Chapter 5. Estimates of the cost savings from using FIAPP products and services in commercial buildings are the focus of Chapter 7 . In addition, that part of dollar savings that appears attributable specifically to BFRL's research and development effort is estimated. A two-page summary of the CONSIAT case study is given in Section 7.1. Chapter 8 includes a sensitivity analysis to provide the reader with additional background and perspective on the economic impacts of BFRL's CONSIAT program in commercial buildings. The purpose of the sensitivity analysis is to evaluate the impact of changing the values of a number of key variables whose values are uncertain. Monte Carlo techniques are employed to evaluate how changing the values of these key variables in combination affects the calculated values of the key measures of the economic impacts of fully-integrated and automated project process systems and technologies in commercial buildings. Chapter 9 concludes the report with a summary and suggestions for further research. 


\section{A Methodology for Analyzing Economic Impacts}

This chapter focuses on laying out a methodology for conducting and summarizing an economic impact assessment. The methodology is based on two types of analysis, five measures of economic performance, and a format for summarizing the results of an economic impact assessment. The two types of analysis are baseline analysis and sensitivity analysis. They are described in Section 2.1. The five measures of economic performance are present value of net benefits, present value of net savings, benefit-to-cost ratio, savings-to-investment ratio, and adjusted internal rate of return. They are described in Section 2.2. The format for summarizing the results of the economic impact assessment is described in Section 2.3.

\subsection{Types of Analysis}

\subsubsection{Baseline Analysis}

A baseline analysis is the starting point for conducting an economic impact assessment. In the baseline analysis, all data (i.e., all input variables and any functional relationships among these variables) entering into the benefit, cost, and savings calculations are set at their likely values. For selected types of data, the input values are fixed (e.g., a physical constant or a value that is mandated by legislation). The input values associated with these data types are considered to be known with certainty. For other types of data, the likely values reflect the fact that some information associated with these data is uncertain. In that case, the values of any data subject to uncertainty are set based on some measure of central tendency. ${ }^{9}$ Throughout this report, likely value and baseline value are used interchangeably. Baseline data represent a fixed state of analysis based on likely values. For this reason, the results and the analysis of these results are referred to as the baseline analysis. Throughout this report, the term baseline analysis is used to denote a complete analysis in all respects but one; it does not address the effects of uncertainty.

\subsubsection{Sensitivity Analysis}

Sensitivity analysis measures the impact on project outcomes of changing the values of one or more key input variables about which there is uncertainty. Sensitivity analysis can be performed for any measure of economic performance (e.g., present value of net benefits, present value of net savings, benefit-to-cost ratio, savings-to-investment ratio, adjusted internal rate of return). Since sensitivity analysis is easy to use and understand, it is widely used in the economic evaluation of government and private-sector applications. Office of Management and Budget Circular A-94 recommends sensitivity

\footnotetext{
${ }^{9}$ Two common measures of central tendency are the mean (e.g., the sum of the individual values of the items divided by the number of items in the sample) and the median (e.g., the middle value in a rank ordering of the individual values of the items in the sample). In most cases in this report, the mean is used as the measure of central tendency. Any case where the median is used as the measure of central tendency is clearly indicated in the text. Consequently, if no explicit reference is made to the measure of central tendency, the measure used is the mean.
} 
analysis to federal agencies as one technique for treating uncertainty in input variables. ${ }^{10}$ Therefore, a sensitivity analysis complements the baseline analysis by evaluating the changes in output measures when selected key sets of data vary about their baseline values. Readers interested in a comprehensive survey on methods for dealing with uncertainty for use in government and private-sector applications are referred to the study by Marshall $^{11}$ and the subsequent video ${ }^{12}$ and workbook. ${ }^{13}$

\subsection{Overview of Evaluation Methods}

Several methods of economic evaluation are available to measure the economic performance of a research program, a new technology, a building, a building system, or like investment, over a specified time period. These methods include, but are not limited to, present value of net benefits, present value of net savings, benefit-to-cost ratio, savings-to-investment ratio, and the adjusted internal rate of return. These methods differ in the way in which they are calculated and, to some extent, in their applicability to particular types of investment decisions. The five methods described in this section are based on American Society for Testing and Materials (ASTM) standard practices. ${ }^{14}$ Detailed descriptions of each of the standardized methods are given in Chapman and Fuller. ${ }^{15}$ Readers interested in an excellent, in-depth survey covering these as well as other methods are referred to Ruegg and Marshall. ${ }^{16}$

In order to describe each of the five standardized methods, it is necessary to first introduce and define a series of terms. These terms are used to define each of the standardized methods. Throughout this section the following terms are used as the basis for defining the standardized methods:

$$
\begin{aligned}
& a^{*}=\quad \text { the alternative under analysis; } \\
& t \quad \begin{array}{l}
\text { a unit of time, where }-t^{a} \text { is the earliest point (i.e., beginning of the } \\
\text { study period) before the base year (i.e., } t=0 \text { ) and } T \text { is the last point } \\
\text { after the base year (i.e., end of the study period); }
\end{array}
\end{aligned}
$$

$L \quad=\quad$ the length of the study period (e.g., $\left.t^{a}+T\right)$

\footnotetext{
${ }^{10}$ Executive Office of the President. 1992. OMB Circular A-94. Washington, DC: Office of Management and Budget.

${ }^{11}$ Marshall, Harold E. 1988. Techniques for Treating Uncertainty and Risk in the Economic Evaluation of Building Investments. NIST Special Publication 757. Gaithersburg, MD: National Institute of Standards and Technology.

${ }^{12}$ Marshall, Harold E. 1992. Uncertainty and Risk-Part II in the Audiovisual Series on Least-Cost Energy Decisions for Buildings. Gaithersburg, MD: National Institute of Standards and Technology.

${ }^{13}$ Marshall, Harold E. 1993. Least-Cost Energy Decisions for Buildings-Part II: Uncertainty and Risk Video Training Workbook. NISTIR 5178. Gaithersburg, MD: National Institute of Standards and Technology.

${ }^{14}$ American Society for Testing and Materials (ASTM). Fourth Edition, 1999. ASTM Standards on Building Economics. West Conshohocken, PA: American Society for Testing and Materials.

${ }^{15}$ Chapman and Fuller, Two Case Studies in Building Technology, pp. 27-37.

${ }^{16}$ Ruegg, Rosalie T. and Harold E. Marshall. 1990. Building Economics: Theory and Practice. New York: Chapman and Hall.
} 


$$
\begin{array}{ll}
B_{t}^{a^{*}} & =\quad \text { the benefits for alternative } a^{*} \text { in year } t \\
I_{t}^{a^{*}} & =\quad \text { the investment costs for alternative } a^{*} \text { in year } t \\
C_{t}^{a^{*}} & =\quad \text { the non-investment costs for alternative } a^{*} \text { in year } t \\
\underline{C}^{a^{*}} & =\quad \text { the combined cost for alternative } a^{*} \text { in year } t \text { (i.e., } \\
S_{t}^{a^{a^{*}}} & =\quad \text { the savings for alternative } a^{*} \text { in year } t \\
d & =\text { the discount rate expressed as a decimal. }
\end{array}
$$

Throughout this section the prefix, $P V$, is used to designate dollar denominated quantities in present value terms. The present value is derived by discounting (i.e., using the discount rate) to adjust all benefits, costs, and savings - past, present, and future - to the base year (i.e., $t=0$ ). The dollar denominated quantities defined above and their associated present value terms are: the present value of benefits $(P V B)$, the present value of investment costs $(P V I)$, the present value of non-investment costs $(P V C)$, the present value of combined costs $(P V \underline{C})$, and the present value of savings $(P V S)$.

\subsubsection{Present Value of Net Benefits and Present Value of Net Savings}

The present value of net benefits (PVNB) method is reliable, straightforward, and widely applicable for finding the economically efficient choice among alternatives (e.g., building systems). It measures the amount of net benefits from investing in a given alternative instead of investing in the foregone opportunity (e.g., some other alternative or maintenance of the status quo).

PVNB is computed by subtracting the time-adjusted costs of an investment from its timeadjusted benefits. If PVNB is positive, the investment is economic; if it is zero, the investment is as good as the next best investment opportunity; if it is negative, the investment is uneconomical. Emphasis is on economic efficiency because the method is appropriate for evaluating alternatives that compete on benefits, such as revenue or other advantages that are measured in dollars, in addition to costs.

The present value of net savings (PVNS) method is the PVNB method recast to fit the situation where there are no significant benefits in terms of revenue or the like, but there are reductions in future costs (e.g., reductions in the cost of ownership to consumers). ${ }^{17}$ By treating savings like revenue benefits, the PVNB method may be reformulated as the PVNS method.

\footnotetext{
${ }^{17}$ If there are any benefits, say in the form of revenues or other positive cash flows; add them to the cost savings associated with the alternative under analysis.
} 
The PVNB for a given alternative, $a^{*}$, may be expressed as:

$$
\begin{aligned}
P V N B^{a^{*}} & =P V B^{a^{*}}-P V \underline{\mathbf{C}^{a^{*}}} \\
& =\sum_{t=-t^{a}}^{T}\left(B_{t}^{a^{*}}-\underline{\mathbf{C}_{t}^{a^{*}}}\right) /\left(1+d^{t}\right)
\end{aligned}
$$

If there are no important benefits in terms of revenue or the like, but there are reductions in future costs, then, the PVNS for a given alternative, $a^{*}$, may be expressed as:

$$
\begin{aligned}
P V N S^{a^{*}} & =P V S^{a^{*}}-P V I^{a^{*}} \\
& =\sum_{t=-t^{a}}^{T}\left(S_{t}^{a^{*}}-I_{t}^{a^{*}}\right) /(1+d)^{t}
\end{aligned}
$$

If the decision maker anticipates revenues from the investment, then use the PVNB measure. If the decision maker expects costs to be reduced, then use the PVNS measure. The PVNS measure is one of the methods used in the construction systems integration and automation technologies (CONSIAT) case study (see Chapters 7 and 8).

\subsubsection{Benefit-to-Cost Ratio and Savings-to-Investment Ratio}

The benefit-to-cost ratio (BCR) and the savings-to-investment ratio (SIR) are numerical ratios whose sizes indicate the economic performance of an investment. The BCR is computed as benefits, net of future non-investment costs, divided by investment costs. The SIR is savings divided by investment costs. The SIR is the BCR method recast to fit the situation where the investment's primary advantage is lower costs. SIR is to BCR as PVNS is to PVNB.

A ratio less than 1.0 indicates an uneconomic investment; a ratio of 1.0 indicates an investment whose benefits or savings just equal its costs; and a ratio greater than 1.0 indicates an economic project. A ratio of, say, 4.75 means that the investor (e.g., the general public for a public-sector research program) can expect to receive $\$ 4.75$ for every $\$ 1.00$ invested (e.g., public funds expended), over and above the required rate of return imposed by the discount rate.

The BCR for a given alternative, $a^{*}$, may be expressed as: 


$$
\begin{aligned}
B C R^{a^{*}} & =\left(P V B^{a^{*}}-P V C^{a^{*}}\right) / P V I^{a^{*}} \\
& =\frac{\sum_{t=-t^{a}}^{T}\left(B_{t}^{a^{*}}-C_{t}^{a^{*}}\right) /(1+d)^{t}}{\sum_{t=-t^{a}}^{T} I_{t}^{a^{*}} /(1+d)^{t}}
\end{aligned}
$$

The SIR for alternative $a^{*}$ may be expressed as:

$$
\begin{aligned}
\operatorname{SIR}^{a^{*}} & =P V S^{a^{*}} / P V I^{a^{*}} \\
& =\frac{\sum_{t=-t^{a}}^{T} S_{t}^{a^{*}} /(1+d)^{t}}{\sum_{t=-t^{a}}^{T} I_{t}^{a^{*}} /(1+d)^{t}}
\end{aligned}
$$

As was the case for the PVNB and PVNS measures, use the BCR if the decision maker anticipates revenues from the investment, and use the SIR if the decision maker anticipates costs to be reduced. The SIR measure is the second method used in the CONSIAT case study (see Chapters 7 and 8).

\subsubsection{Adjusted Internal Rate of Return}

The adjusted internal rate of return (AIRR) is the annual yield from a project over the study period, taking into account reinvestment of interim receipts. Because the AIRR calculation explicitly includes the reinvestment of all net cash flows, it is instructive to introduce a new term, terminal value (TV). The terminal value of an investment, $a^{*}$, is the future value (i.e., the value at the end of the study period) of reinvested net cash flows excluding all investment costs. The terminal value for an investment $a^{*}$, is denoted as $T V^{a^{*}}$.

The reinvestment rate in the AIRR calculation is equal to the minimum attractive rate of return (MARR), which is assumed to equal the discount rate, $d$, a constant. When the reinvestment rate is made explicit, all investment costs are easily expressible as a time equivalent initial outlay (i.e., a value at the beginning of the study period) and all noninvestment cash flows (e.g., benefits, non-investment costs, savings) as a time equivalent terminal amount. This allows a straightforward comparison of the amount of money that comes out of the investment (i.e., the terminal value) with the amount of money put into the investment (i.e., the time equivalent initial outlay).

The AIRR is defined as the interest rate, $r^{*}$, applied to the terminal value, $T V^{a^{*}}$, which equates (i.e., discounts) it to the time equivalent value of the initial outlay of investment 
costs. It is important to note that all investment costs are discounted to a time equivalent initial outlay (i.e., to the beginning of the study period) using the discount rate, $d$.

Several procedures exist for calculating the AIRR. These procedures are derived and described in detail in the report by Chapman and Fuller. ${ }^{18}$ The most convenient procedure for calculating the AIRR is based on its relationship to the BCR (SIR). This procedure results in a closed-form solution for $r^{*}$. The AIRR - expressed as a decimalis that value of $r^{*}$ for which:

$$
\begin{aligned}
r^{*} & =(1+d)\left(B C R^{a^{*}}\right)^{\frac{1}{L}}-1 \\
& =(1+d)\left(S I R^{a^{*}}\right)^{\frac{1}{L}}-1
\end{aligned}
$$

The AIRR measure is the third method used in the CONSIAT case study (see Chapters 7 and 8).

\subsubsection{Summary of Methods ${ }^{19}$}

The methods presented in the previous sections provide the basis for evaluating the economic performance of research investments. The equations underlying the methods presented earlier are all based on ASTM standard practices. All of the methods are appropriate for evaluating accept or reject type decisions. Among these methods one should recognize several distinctions that relate to the type of investment decision the decision maker is facing.

There are four basic types of investment decisions for which an economic analysis is appropriate:

(1) whether to accept or reject a given project;

(2) the most efficient project size/level, system, or design;

(3) the optimal combination of interdependent projects (i.e., the right mix of sizes/levels, systems, and designs for a group of interdependent projects); and

(4) how to prioritize or rank independent projects when the allowable budget can not fund them all.

\footnotetext{
${ }^{18}$ Chapman and Fuller, Two Case Studies in Building Technology, pp. 35-37.

${ }^{19}$ For a comprehensive treatment of how to choose among economic evaluation methods, see the NIST/BFRL video (Marshall, Harold E. 1995. Choosing Economic Evaluation Methods-Part III in the Audiovisual Series on Least-Cost Energy Decisions for Buildings. Gaithersburg, MD: National Institute of Standards and Technology) and workbook (Marshall, Harold E. 1995. Least-Cost Energy Decisions for Buildings-Part III: Choosing Economic Evaluation Methods Video Training Workbook. NISTIR 5604. Gaithersburg, MD: National Institute of Standards and Technology).
} 
Each type of investment decision is important in a research environment. First and foremost, decision makers need to know whether or not a particular project or program should be undertaken in the first place. Second, how should a particular research project/program be configured? The third type of decision builds on the second and introduces an important concept, interdependence. Many research projects/programs are multidisciplinary and are analogous to a portfolio. In addition, there may be both economies of scale (e.g., spreading out the use of specialized equipment) and of scope (e.g., packaging of staff talents). Consequently, for a given set of skills, laboratory facilities, candidate projects, and implied interdependencies, the problem becomes how to choose that combination of projects which maximizes PVNB (PVNS). The fourth type of decision introduces a budget constraint. The key here is how to get the most impact for the given budget amount.

Table 2-1 provides a summary of when it is appropriate to use each of the evaluation methods described earlier. Note that the PVNB (PVNS) method is appropriate in three of the four cases. Only in the presence of a budget constraint is the use of PVNB (PVNS) inappropriate and even in that case it plays an important role in computing the aggregate measure of performance.

Table 2-1. Summary of Appropriateness of Each Standardized Evaluation Method for Each Decision Type

\begin{tabular}{|l|c|c|c|}
\hline \multicolumn{1}{|c|}{ Decision Type } & $\begin{array}{c}\text { PVNB } \\
\text { PVNS }\end{array}$ & $\begin{array}{c}\text { BCR } \\
\text { SIR }\end{array}$ & AIRR \\
\hline Accept/Reject & Yes & Yes & Yes \\
\hline Design/Size & Yes & No & No \\
\hline $\begin{array}{l}\text { Combination } \\
\text { (Interdependent) }\end{array}$ & Yes & No & Yes \\
\hline $\begin{array}{l}\text { Priority/Ranking } \\
\text { (Independent) }\end{array}$ & No & Yes & \\
\hline
\end{tabular}

In summary, there are several reasons why multiple measures of economic performance are necessary. First and foremost, managers want to know if a particular research project is economic. Reference to Table 2-1 shows that all of the evaluation methods address this type of decision. Furthermore, these evaluation methods may be used ex ante for emerging technologies as well as ex post for past research projects. Second, as issues of design, sizing, and packaging combinations of projects become the focus of attention-as often occurs in conjunction with budget reviews - the PVNB (PVNS) method emerges as the principle means for evaluating a project's or program's merits. ${ }^{20}$ Finally, the tightening budget picture involves setting priorities. Consequently, decision makers need both measures of magnitude, provided by PVNB (PVNS), and of return, provided by either the BCR (SIR) or the AIRR, to assess economic performance. Multiple measures, when used appropriately, ensure consistency in both setting priorities and selecting

\footnotetext{
${ }^{20}$ If incremental values of the BCR (SIR) or AIRR are computed, they can be used to make design/size and packaging decisions. See Ruegg and Marshall, Building Economics, pp. 54-58 and 85-87.
} 
projects for funding. The results from the CONSIAT case study presented in Chapters 7 and 8 illustrate the importance of multiple measures of economic performance.

\subsection{Presentation and Analysis of the Results of an Economic Impact Assessment}

The presentation and analysis of the results of an economic impact assessment are central to understanding and accepting its findings. If the presentation is clear and concise, and if the analysis strategy is logical, complete, and carefully spelled out, then the results will stand up under close scrutiny. The purpose of this section is to outline a generic framework for economic impact studies that meets the two previously cited conditions. The generic framework is built upon the following three factors: (1) the significance of the research effort; (2) the analysis strategy; and (3) the calculation of key benefit and cost measures. A specific framework, tailored to BFRL, is given in Exhibit 2-1; it is also used as the basis for summarizing the CONSIAT case study (see Section 7.1).

The discussion that follows relates the three factors for the generic framework referenced above to the specific framework given in Exhibit 2-1. Exposition of the generic framework serves two purposes. First, it provides a means for organizing the way to present material associated with an in-depth economic impact assessment. Second, it provides a vehicle for clearly and concisely presenting the salient results of the analysis. Such a short summary is appropriate for use by senior research managers (e.g., laboratory directors) as the basis for statements on the benefits of the research project or program to the public. A two-page summary of the CONSIAT case study is provided at the beginning of Chapter 7.

\subsubsection{Significance of Research Effort}

This section of an economic impact assessment sets the stage for the results that follow. The goal at this point is to clearly describe:

(1) why the research is important and how the organization conducting the research became involved; and

(2) why some or all of the changes brought about were due to the research organization's contribution.

Emphasis is placed on providing dollar estimates to define the magnitude of the problem. If any non-financial characteristics are of key importance to senior management, list and describe them briefly. A clear tie into the research organization's mission or vision is included to demonstrate why the organization conducting the research is well qualified and well positioned to participate in the research effort. The section concludes with a statement of the research organization's contribution. 


\section{Exhibit 2-1. Format for Summarizing the Economic Impacts of BFRL Research Efforts}

\begin{tabular}{|l|l|}
\hline 1.a Significance of Research Effort: & 1.b Key Points: \\
$\begin{array}{l}\text { Describe why the research is important and how BFRL } \\
\text { became involved. }\end{array}$ & $\begin{array}{l}\text { Highlight two or three key points which } \\
\text { convey why this research effort is } \\
\text { important. }\end{array}$ \\
$\begin{array}{l}\text { Describe the changes brought about by the BFRL } \\
\text { research effort. }\end{array}$ &
\end{tabular}

\section{Analysis Strategy:}

Describe how the present value of total benefits (savings) to the nation stemming from all contributions to the research effort was determined.

Describe how the present value of total costs to the nation stemming from all contributors to the research effort was determined.

Describe how the present value net benefits (savings) to the nation was determined.

Describe how the present value of total benefits (savings) attributable to BFRL's research effort was determined.

Describe how the present value of total costs attributable to BFRL's research effort was determined.

Describe how the present value of net benefits (savings) attributable to BFRL's research effort was determined.

Describe how any additional measures were calculated and how BFRL's contribution was determined.

Summarize key data and assumptions: (a) Base year; (b) Length of study period; (c) Discount rate or minimum acceptable rate of return; (d) Data; and (e) other.

\section{3.a Calculation of Benefits, Costs, and Additional} Measures:

Total Benefits (Savings):

Report the present value of the total benefits (savings) attributable to BFRL's research effort.

\section{Total Costs:}

Report the present value of the total costs attributable to BFRL's research effort.

\section{Net Benefits (Savings):}

Report the present value of net benefits (savings) attributable to BFRL's research effort.

\section{Additional Measures:}

Report the values of any additional measures calculated.

3.b Key Measures:
Report the calculated value of the
Present Value of Net Benefits (PVNB)
or the Present Value of Net Savings
(PVNS) attributable to BFRL and at
least one of the following:
Benefit-to-Cost Ratio (BCR) or
Savings-to-Investment Ratio (SIR)
Adjusted Internal Rate of Return
(AIRR)
3.c Traceability
Cite references to specific ASTM
standard practices, ASTM adjuncts, or
any other standards, codes, or regulations
used.




\subsubsection{Analysis Strategy}

This section of an economic impact assessment focuses on documenting the steps taken to ensure that the analysis strategy is logical and complete. Particular emphasis is placed on summarizing the key assumptions, including any constraints that limited the scope of the study. Responses are provided for key assumptions concerning: (a) the base year for the study; (b) the length of the study period; and (c) the discount rate or minimum acceptable rate of return used.

Special emphasis is placed on documenting the sources and validity of any data used to make estimates or projections of key benefit and cost measures. This section establishes an audit trail from the raw data, through data manipulations (e.g., represented by equations and formulae), to the results which describe how to determine:

(1) the present value of total benefits (savings) to the nation stemming from all contributors to the research effort under study, any benefits (savings) to users of products (materials, equipment, software, or procedures) stemming from the research effort under study, and any third parties affected positively by either the research effort or the use of products stemming from the research effort;

(2) the present value of total costs for all contributors to the research effort under study, any costs to users of products stemming from the research effort under study, and any third parties affected negatively by either the research effort or the use of products stemming from the research effort;

(3) the present value of net benefits (savings) to the nation stemming from all contributors to the research effort under study, any users of products stemming from the research effort under study, and any third parties affected by either the research effort or the use of products stemming from the research effort;

(4) the present value of total benefits (savings) attributable to the research organization's contribution;

(5) the present value of total costs attributable to the research organization's contribution;

(6) the present value of net benefits (savings) attributable to the research organization's contribution; and

(7) the way in which any additional measures were calculated and how the research organization's contribution was determined. 


\subsubsection{Calculation of Benefits, Costs, and Additional Measures}

This section of an economic impact assessment focuses on reporting the calculated values of the key benefit and cost measures, as well as any additional measures that are deemed appropriate, and establishing traceabilty to standardized practices or, where appropriate, to statutory documents or procedures. It consists of three subsections, designated as 3.a, 3.b, and 3.c. Subsection 3.a includes descriptive information as well as calculated values. Subsection 3.b reports calculated values for key summary impact measures. Subsection 3.c is included to ensure traceability to appropriate national standards, codes, or regulations.

In subsection 3.a, report summaries (e.g., using text, mathematical expressions, tables, graphs, comparative statistics) of the following information:

(1) the present value of the total benefits attributable to the research organization's contribution;

(2) the present value of the total costs attributable to the research organization's contribution;

(3) the present value of net benefits attributable to the research organization's contribution; and

(4) the values of any additional measures calculated.

In subsection 3.b, report the calculated value of the present value of net benefits or the present value of net savings attributable to the research organization's contribution and at least one of the following:

(a) the benefit-to-cost ratio or the savings-to-investment ratio; or

(b) the adjusted internal rate of return.

In subsection 3.c, cite references to specific ASTM standard practices, ASTM adjuncts, or any other standards, codes, or regulations used. 


\section{Building and Fire Research Laboratory's CONSIAT Program}

\subsection{Fully-Integrated and Automated Project Processes: What They Are and What They Will Do}

Information technologies have transformed many aspects of our daily lives and revolutionized industries in both the manufacturing and service sectors. Within the construction industry, the changes have so far been less radical. However, the use of information technologies offers a clear potential for revolutionary change in the effectiveness with which construction-related processes are executed and the value they add to construction industry stakeholders. Recent exponential growth in computer, network, and wireless capabilities, coupled with improved 3D CAD (computer-aided design) and object-oriented software tools, have made it possible to apply information technologies in all aspects of the facility life cycle - design, construction, commissioning, operation, and decommissioning.

Computer, automobile, and aircraft manufacturers have taken the lead in improving the integration of design and manufacturing, harnessing automation technology, and in using electronic standards to replace paper for many types of documents. Unfortunately, the construction industry has not yet used information technologies as effectively to improve and automate its design, construction, and operational processes. There is still widespread use of paper as a medium to capture and exchange information among project participants, and relatively little use of design and automation tools that depend on computer-readable product descriptions.

The Construction Industry Institute (CII) predicts that fully-integrated and automated project processes (FIAPPs) will be a vehicle for transforming the way construction projects are designed, built, and operated. ${ }^{21}$ FIAPPs will result in significant reductions in both the delivery time and life-cycle costs of constructed facilities. FIAPPs are also expected to result in reductions in construction-related accidents. Characteristics of FIAPP products and services include one-time data entry; interoperability with design, construction, and operation processes (e.g., virtual construction and construction automation); and user friendly input/output techniques.

The context within which FIAPP products and services are defined is shown schematically in Figure 3-1. Figure 3-1 is a stylized information flows model for a typical commercial building or industrial facility; it spans the entire building/facility life cycle-from concept through disposition.

The information flows model is configured as a four-tiered set of activities. Each activity is represented by a rectangle. Interactions between activities (i.e., information flows) are represented by arrows. It is important to note that each activity shown in Figure 3-1 can be subdivided into sub-activities and used to highlight information flows between sub-

\footnotetext{
${ }^{21}$ Construction Industry Institute. 1999. 1999 Strategic Plan. Austin, TX: Construction Industry Institute.
} 
activities. These information flows, although not shown, are treated as implicit in Figure 3-1. In several cases, interactions with feedback are made explicit. This is done to highlight the most significant feedback loops between activities. In principle, there is substantial feedback between many of the activities shown in Figure 3-1.

Business need provides the impetus for planning, designing, constructing, operating, and disposing of a building/facility. Consequently, business need is placed at the left-hand side of the uppermost tier (i.e., the first tier). Project management activities are placed on the first tier because they span all phases in the life cycle of the building/facility. Regulatory bodies are also placed on the first tier.

The activities on the second and third tiers are laid out in sequential order. Interactions between these two tiers are closely coupled. A dashed line is placed between the second and third tier; it is used to separate functions performed by the two major groups of participants: (1) owners and operators - the first and second tiers; and (2) architects and engineers, constructors, and suppliers and fabricators - the third and fourth tiers. The key participants are designated in bold face font. The fourth tier is limited to suppliers and fabricators; it spans most of the phases in the building/facility life cycle.

A closer examination of Figure 3-1 reveals an interesting outcome. The entire construction phase is shown as a single activity in Figure 3-1: Prepare Site, Construct Facility, Pre-Commission. As will be seen in Sections 3.2 and 3.3, much of the interest in FIAPP products and services is concerned with the construction phase. However, as is shown in Figure 3-1, there are many information flows going into or coming out of the construction phase. Thus, to better understand the value of FIAPP products and services, it is useful to review what these information flows represent.

The information flows model is a mapping of project processes during a building's/ facility's life cycle. Integrating and automating these project processes involves managing and manipulating information flows within and between the activities shown in Figure 3-1. Thus, a FIAPP consists of a data warehouse with a real-time capability enabling information to be passed, operated upon, and retained for future reference. This information could be used to control the position of construction equipment, specify a set of work tasks, or electronically store the "as built" status of a building element. The data warehouse component of a FIAPP includes design data, supplier data, project data, site data, resource data, and codes and standards data. The real-time capability is supported through two key enabling technologies - the Construction Site Measurement System and the Project Information Management System. Linkages between the enabling technologies, the data warehouse, and other FIAPP components rely on standard interoperability and communication protocols and advanced measurement technologies (see Section 3.3). 
Figure 3-1. Information Flows Model for Commercial Buildings and Industrial Facilities

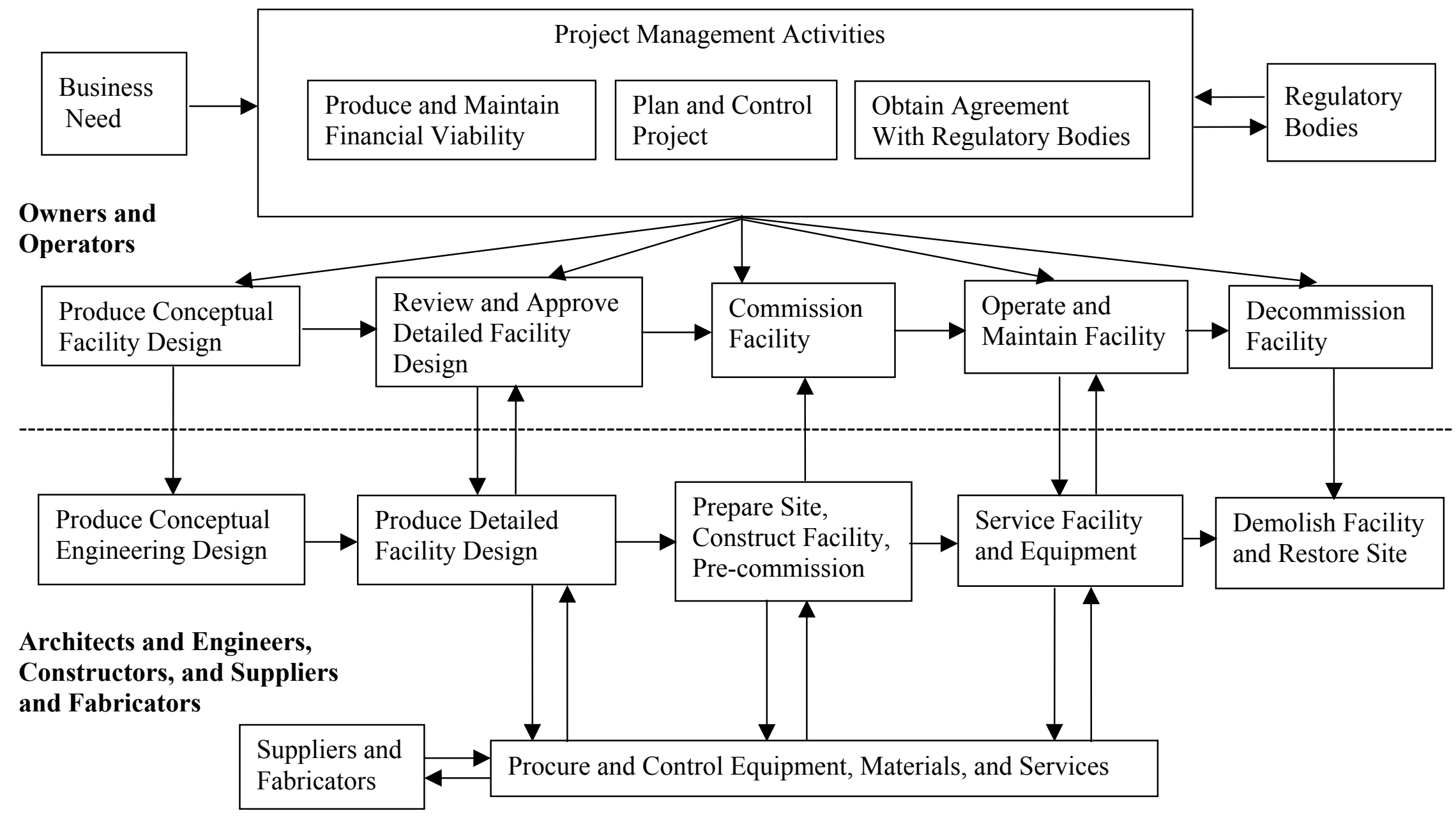




\subsection{The FIATECH Consortium: A Vehicle for Delivering Fully-Integrated and Automated Project Processes to the Construction Industry}

The FIATECH Consortium is envisioned as a CII affiliated, collaborative, not-for-profit, research consortium established to conduct leveraged research and development to accelerate the deployment of FIAPP products and services in the commercial marketplace. Specifically, the FIATECH Consortium is needed to make FIAPP real for $\mathrm{CII}$ members and the rest of the construction industry.

The construction industry faces special challenges in reaping the full benefits of the information technology revolution that has brought and continues to bring rich rewards to many industries. These challenges include low $\mathrm{R} \& \mathrm{D}$ investment, fragmentation, and its unique project-oriented character. Recognizing these challenges, CII has made FIAPP a top priority.

The FIATECH Consortium will seek to achieve breakthrough, technology-intensive process changes. First, it will enable the seamless integration and management of project information within the context of an entire building/facility life cycle and enterprise-wide resource planning system. And second, it will bring live wireless data from the construction site into the project management information loop.

The FIATECH Consortium will conduct leveraged R\&D in partnership with suppliers, with firms in the software/information technology industries, and within the public sector. In addition to NIST, likely public sector partners include the Department of Transportation, the U.S. Army Corps of Engineers, and the General Services Administration.

NIST's participation in the FIATECH Consortium focuses on providing the measurements, standard interoperability and communication protocols, and information technology tools to enable FIAPP along with economic assessments to quantify its impact. Consortium-developed products and services will be tested and demonstrated in a distributed testbed environment.

The Consortium-developed products and services, when fully deployed, will enable significant cycle time and life-cycle cost reductions in the delivery of capital projects by digitally linking all facets of the design, fabrication, and construction process. Drawing on documented economic success in industries such as manufacturing, the FIATECH Consortium will develop and adopt open interoperability and communication standards to achieve significant cycle time and life-cycle cost reductions.

Specifically, the goals of the FIATECH Consortium are to:

- Reduce design changes and rework through concurrent engineering;

- Enable better control of project schedule and cost;

- Improve supply chain management, including tracking of materials, components, and labor; 
- Rapidly detect and rectify differences between intended design and actual construction; and

- Capture the "as-built" status of a project for later use in building/facility operation, maintenance, and renovation.

To achieve these goals, the FIATECH Consortium has established a framework of guiding principles and primary purposes. The guiding principles of the Consortium are twofold. First, the Consortium will be an industry-driven, not-for-profit, collaborative research consortium with dues-paying member companies. Second, it will maintain a "safe harbor" environment with third party independence where companies can come together to achieve mutually beneficial results by pooling talent, substantially leverage their scarce R\&D dollars, spread risks, and achieve robust solutions. The Consortium will collaborate broadly with diverse partners - public, private, and academe - and create alliances.

The primary purposes of the Consortium are to:

- Conduct, sponsor, fund, direct, and otherwise promote research, development, and demonstration of technologies and practices for significant cycle time and life-cycle cost reductions in the delivery, operation, and maintenance of capital projects;

- Assist in the implementation of such technologies and practices;

- Provide a forum for the examination and discussion of technical issues having a significant impact on cycle time and life-cycle costs of capital projects;

- Serve as a national clearinghouse, library, and data source for information in these areas; and

- Publish or sponsor articles, press releases, newsletters, and other publications on these topics.

\subsection{Key Components of BFRL's CONSIAT Program}

BFRL is working towards a prototype suite of FIAPP systems and technologies being tested and deployed by 2004. To achieve this goal, BFRL is working with building/ facility owners, contractors, equipment and systems manufacturers and service providers, software developers, building/facility operators, trade associations, professional societies, standards organizations, university researchers, and other government agencies. Strategic partnerships for the overall CONSIAT research, development, and deployment effort will employ the FIATECH Consortium (see Section 3.2).

BFRL's CONSIAT-related research, development, and deployment effort is multi-year and multi-tiered. Throughout this effort, BFRL will employ field demonstration projects. These projects are by design collaborative activities, since they seek to gain early involvement of key construction industry stakeholders to ensure that the products and services developed are focused on stakeholder needs and address explicitly any potential barriers to adoption. BFRL's major milestones for these collaborative activities include field demonstrations of: (1) key FIAPP system components and associated information technology (IT) protocols/tools; (2) FIAPP subsystems and associated IT protocols/tools 
for earthwork, foundation, and the structural steel delivery process and the pipe spools and piping systems delivery process; (3) first-generation prototype FIAPP system and associated IT protocols/tools based largely on the innovative use of proven technologies; (4) advanced site measurement systems and innovative uses of information technologies; and (5) second-generation prototype FIAPP system and associated IT protocols/tools that build on advanced site measurement systems and innovative uses of information technologies.

The first generation prototype FIAPP system, targeted for completion in 2002, will demonstrate feasibility, focusing on innovative process changes based largely on the integration of robust/proven technologies. The second generation prototype system, targeted for completion in 2004, will integrate advanced functional capabilities, building on new measurement systems and innovative uses of information technology.

The overall CONSIAT research, development, and deployment effort is built around eight key projects (see Sections 3.3.1 through 3.3.8). In addition, the overall effort includes a Virtual FIAPP Testbed and a series of full-scale field demonstration projects.

A schematic for how the eight key projects fit together and how BFRL will work with industry to develop FIAPP products and services is shown in Figure 3-2. Each of the eight key projects is represented by a rectangle in the figure. These activities are undertaken and funded primarily by NIST. Those activities undertaken by private sector entities are represented by ovals in the figure. The Virtual FIAPP Testbed and the field demonstration projects are a hybrid activity, involving a broad cross-section of participants; they are represented in the figure by the rectangles with rounded edges. Unidirectional arrows or bi-directional arrows (i.e., including a feedback mechanism) represent information flows between activities. Coordination of and feedback between the BFRL projects and the private sector entities is facilitated by BFRL's CONSIAT program manager.

Figure 3-2 includes a user/vendor tier. Owners and contractors are classified as users of FIAPP products and services. Vendors include equipment and systems manufacturers and service providers and software developers. Because many different users will adopt and install FIAPP products and services and many different vendors will develop and offer commercial products and/or services, the figure uses an ellipsis (...) to reflect the indeterminacy of the number of users and the number of vendors in the user/vendor tier.

Figure 3-2 shows the importance of the field demonstration projects to BFRL's efforts. Once the field demonstration projects are completed, the private sector moves into a fullscale market adoption process. This process will evolve over a number of years as FIAPP products and services diffuse throughout the marketplace. 
Figure 3-2. Schematic Diagram of BFRL's CONSIAT Program

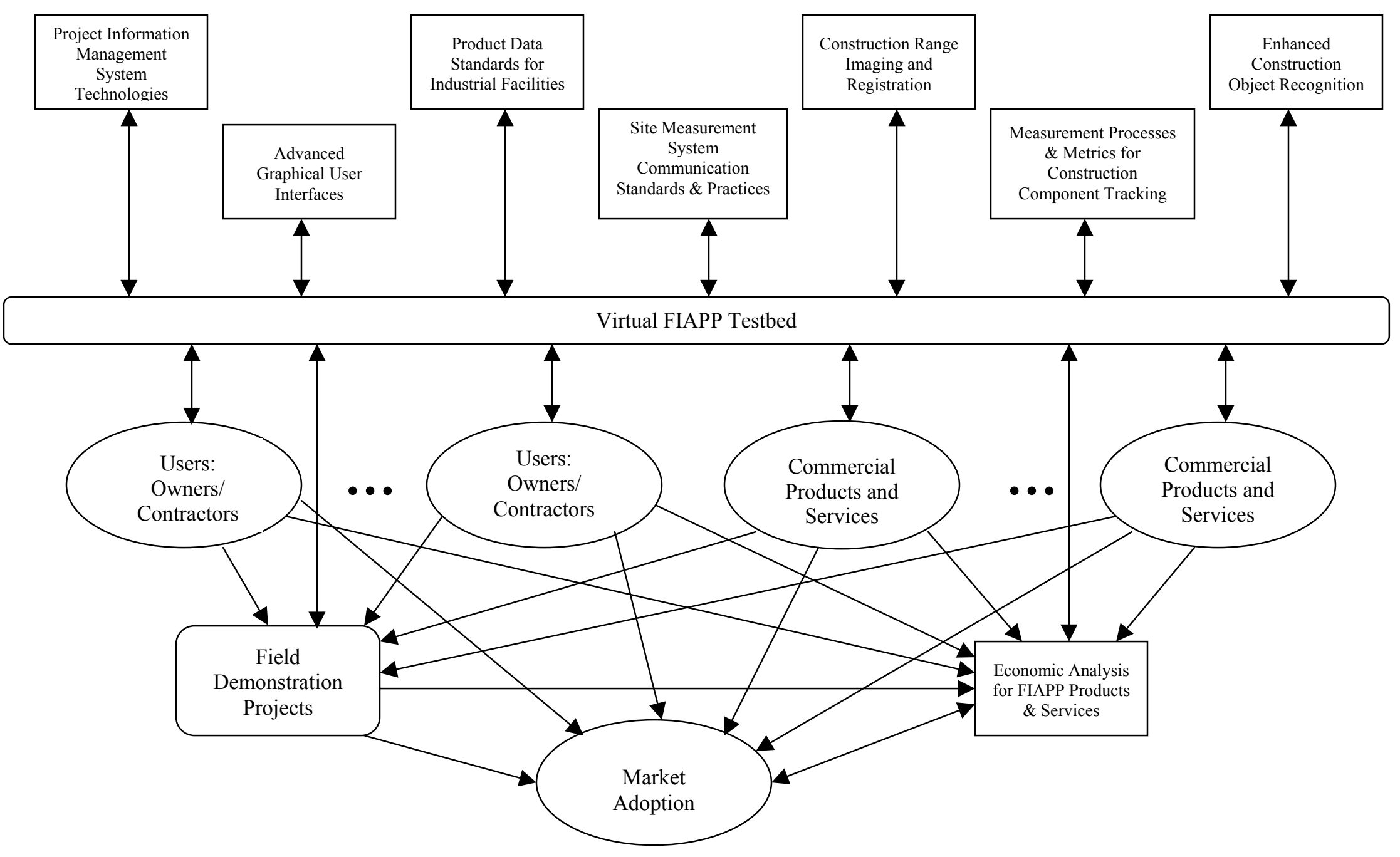


BFRL will produce a series of intermediate outputs prior to the deployment of a prototype suite of FIAPP products and services. These outputs are described briefly in the series of bullets that follow:

- Develop enabling technologies aimed at producing a Construction Site Measurement System and a Project Information Management System.

- Develop standard interoperability and communication protocols for the open exchange of information among building/facility owners, designers, construction products and equipment manufacturers and suppliers, contractors, and building/ facility managers. Protocols being developed include:

- Data exchange protocol for piping design, fabrication, installation, and inspection;

- Identification and fiducial marking protocols for discrete components; and

- LiveView construction site management system interoperability protocols.

- Develop advanced measurement technologies, including:

- Ability to compare "as-is" and "as-designed" geometry, location, and orientation of construction objects incorporating advanced VRML (Virtual Reality Modeling Language) techniques;

- Ability to characterize LADAR (LAser Detection And Ranging) measurement accuracy as a function of range, surface texture, and reflectivity for a range of conditions anticipated at construction sites;

- Mobile scanning system with wireless transport of range data to a remote site;

- Robust post-processing technique for registration and volumetric calculations of LADAR-acquired terrain data; and

- Integration of project information management system with construction metrology systems using LiveView to enable all data communications.

- Construct a Virtual FIAPP Testbed - an open, distributed system environment with modular (plug-and-play) architecture - in the laboratory to facilitate the development and evaluation of new products and systems by manufacturers and external service providers.

- Develop a Consortium of building/facility owners, contractors, construction products and equipment manufacturers, and service providers interested in producing, testing, demonstrating, and buying and selling FIAPP products and services.

- Conduct a prospective economic impact assessment of BFRL's CONSIAT-related research, monitor outcomes, and conduct a follow-up economic impact assessment.

- Demonstrate the integration of FIAPP products, services, and concepts in real construction projects. 


\subsubsection{Project Information Management System Technologies}

An effective project delivery process depends on the availability of current and correct information for all the participants, wherever they are and whenever they need it.

Achieving the seamless integration of project information has become a primary goal for many organizations associated with the building and construction industries, ranging from CII to the Construction and Building Subcommittee of the President's National Science and Technology Council. Ongoing benchmarking studies by organizations like the Business Roundtable and CII confirm the business stake in this goal.

BFRL's CONSIAT program envisions a number of technology developments that will make more and richer information available to project participants. These developments, and the information resources associated with them, include: (1) more complete descriptions of the project design itself and of the products and services procured for the project; (2) large amounts of previously unavailable spatio-temporal information supporting the realization of the project design on the construction site; and (3) comprehensive commissioning procedures tied to the "as-built" condition of the resulting facility.

Integrating and managing these information resources presents significant technical challenges. Two very different approaches have emerged during this decade. The first is a data-driven approach based on the evolution of computer-aided design systems. Open system standards such as the International Organization for Standardization's STandard for the Exchange of Product model data (ISO/STEP) and Parts LIBrary (ISO/PLIB) and the International Alliance for Interoperability's Industry Foundation Classes (IAI/IFC) are being developed to capture the complex, deep-structured technical data created using computerized tools. These standards allow the exchange and sharing of information in such a way that it remains as functional in the receiving system as it was in the originating system, with integration taking place at the level of individual information elements.

However, neither the standards nor the systems based on them yet cover all the functionality needed in a typical project, and especially not throughout the entire delivery process. This has led to a second, document-driven approach based on the evolution of the Internet and the World Wide Web. Frequently called project extranets, systems based on this approach collect and distribute project information, ranging from long-lived design drawings to transitory email requests, as configuration-controlled documents, with integration taking place at the level of hyperlinks among the documents. Compared to the first approach, the information exchanged in this approach is shallow-structured and superficially integrated. Because the basic unit of information is a document, however, these systems automatically cover all the functionality needed in a traditional documentcentric project. Consequently, their use is beginning to make a difference in the U.S. construction industry.

As the technologies envisioned in the CONSIAT program emerge, the need to merge 
these two approaches to the integration and management of project information will become acute. The objective of this project is to develop the standards-based opensystem technologies needed in next-generation project information management systems and demonstrate them in prototype systems.

To enable the capture of technical project information, BFRL will implement selected portions of emerging product data standards in experimental databases. The ISO/STEP and PLIB standards suites and the IAI/IFC are relevant starting points. Because several CONSIAT projects share an interest in the fabrication, delivery, and erection of structural steelwork, BFRL will collaborate in this project with the American Institute for Steel Construction (AISC) as its members begin implementing the CIMSteel Integration Standard CIS(2), which is based on STEP technology and is the precursor of the STEP Application Protocol 230 on structural steelwork. In following years, this project will widen its focus to include other systems, such as piping and HVAC, and their associated controls.

To deal with the spatial-temporal information envisioned to be streaming to the project information system from on-site construction metrology systems, this project will document candidate use cases in collaboration with the companion project (see Section 3.3.4); assess the state of the art in temporal database research; and implement a suitable data model in experimental databases. Many such models are available, and none is considered to be universally applicable, so this task is expected to be an iterative implement-and-test cycle that continues over several years.

Initially, this project dealt only with the information needed by other CONSIAT projects to track certain work processes relating to the fabrication and erection of steelwork, and the creation of experimental supporting databases. In following years, BFRL will install a commercial project extranet system and couple it with the experimental databases. In addition, coupling and integration mechanisms will be developed to account for additional work processes and other systems.

NIST construction projects, most notably the addition of a new emissions control system (ECS) to Building 205 at the NIST Gaithersburg site, will be used as the source of information for populating and testing the experimental databases coupled to a project extranet system. The resulting system will be used to provide information management support for other CONSIAT projects as they test emerging construction metrology systems.

\subsubsection{Advanced Graphical User Interfaces for Construction Project Delivery Systems}

The technical challenges faced in integrating and managing project information were addressed in the previous subsection. Once available, however, accessing and viewing this information presents additional technical challenges. Traditional presentation

mechanisms are based on static views of tabular data extracted from databases and stored 
two-dimensional drawings and documents. These mechanisms have been carried directly into the graphical user interface (GUI), based on Web browser technology, used in document-based project extranet systems. While the industry has a decade of experience in developing graphical user interfaces for 3-dimensional project models, these were typically based on proprietary CAD-system data structures and presented static design models with only limited access to non-geometric information.

As the technologies envisioned in the CONSIAT program emerge, the user will be challenged to deal with increasing volumes of increasingly complex information, and the need for facile and intuitive graphical user interfaces will increase dramatically. The objective of this project is to develop standards-based, open-system technologies for accessing and viewing construction project information and demonstrate them in prototype systems.

BFRL will build on the work begun in fiscal year (FY) 1999 to model typical construction products using the Virtual Reality Modeling Language (VRML) 97 specification developed by the Web3D Consortium and promulgated as ISO/IEC 14772. The use of VRML continues to offer an advantage because any user can employ widely available Web browser technology to access and display the results. The construction object definitions that were developed using VRML programming capabilities will be extended and enhanced to include more functionality. Techniques for improving performance will be explored, for example, by reimplementing critical JavaScript code as Java applets. Additional Java applets tied to the VRML External Authoring Interface will be used to import project information to the VRML model from external information sources based on standard data representations. Techniques for creating intuitive links from the VRML model to non-geometric information will be explored, as well as innovative techniques for accessing and displaying non-geometric information using VRML directly. Techniques for dealing with spatio-temporal information (e.g., time sequences of equipment movements on the construction site) will be explored. Techniques for comparing different geometry models representing, for example, the asdesigned and as-built conditions of some item of interest, will be explored. The emerging third-generation VRML specification, called X3D, will be reviewed and critiqued for its applicability to construction applications.

Because several CONSIAT projects share an interest in the fabrication, delivery, and erection of structural steelwork, BFRL will collaborate in this project with the AISC as its members begin implementing the CIMSteel Integration Standard CIS(2), which is based on ISO/STEP technology and is the precursor of the STEP Application Protocol 230 on structural steelwork. A mapping between VRML data structures and CIS(2) geometry representations has been developed. A transfer between VRML and CIS(2) provides for the seemless conversion of CIS(2) files to VRML.

Exemplary models will be built using NIST construction projects, most notably the Building 205 ECS at the NIST Gaithersburg site, as the source of information. The results will be evaluated in terms of their ability to support typical user work processes. 


\subsubsection{Product Data Standards for Industrial Facilities}

The U.S. capital facilities industry is seeking to improve the design and delivery of constructed facilities through advanced uses of information technologies - CADD, CAM, ERP (computer-aided design and drafting, computer-aided manufacturing, enterprise resource planning) - and the integration of information systems (e.g., automation of the exchange and sharing of information among systems). Although many of the leading engineering organizations have adopted 3D modeling and information integration technologies, the capabilities and benefits of these technologies are not being exploited fully in the fabrication, inspection, and construction phases of projects.

The many computerized systems in use for the design and construction of facilities can be integrated only at great cost because of their incompatible proprietary representations of information. Standard, neutral information representations and exchange methods are needed that allow system vendors to be innovative and yet allow system users to exchange and share information about industrial facilities automatically. The evolving international standard ISO 10303, Product Data Representation and Exchange, known as STEP, is providing a base technology for developing information exchange protocols.

Leading organizations in the U.S. process plant industries recognize the potential benefits of STEP application protocols (APs) and are working with NIST to develop protocols that meet the needs of the process plant industries. The shipbuilding industry has adopted CAM technologies for improvements in the fabrication and assembly of piping. These CAM successes and lessons from improvements in ship piping fabrication could be useful to advancing the capabilities of the U.S. process plant industries. Additionally, the piping and HVAC delivery process could be improved with the use of advanced component tagging technologies. U.S. industry needs data exchange protocols, test cases, and guidance for fully leveraging CAD, CAM, and eBusiness technologies and progressing toward achievement of FIAPP capabilities. This project works with the chemical, pharmaceutical, power, semiconductor, leverage, engineering and construction, $\mathrm{CADD} / \mathrm{CAM}$, shipbuilding, and pipe fabrication industries to resolve these challenges.

Many of the current applications of CADD/CAM tools focus on automating the documentation of engineering decisions. These applications have improved the productivity of the engineering phase of industrial projects, but have not been used to improve the fabrication, inspection, installation, and commissioning phases of industrial projects.

Beyond documenting procedures for reducing potential rework costs, this project will investigate improvements in the fabrication, delivery, and installation of piping systems. The primary use of CADD for piping fabrication is still focused on replicating the drafting of isometric drawings and spool drawings to illustrate the configuration, shapes, and connections of piping components. Large savings in labor, time, and errors are possible by reducing the need for the piping engineer to develop intermediate isometric drawings for the piping fabricator. Rather, this project will develop a piping fabrication protocol for conveying the piping $3 \mathrm{D}$ design information directly to the piping fabricator 
for automated pipe spool definition and materials management. This protocol will also be useful for conveying spool and installation information to the project information systems and back to the piping engineer, when necessary. PlantSTEP, PIEBASE, and the CII Research Team 152 (3D CADD in the Fully-Integrated and Automated Project Process) identified piping fabrication and installation as construction tasks which could be improved with the reliable exchange of 3D piping model information.

This project will provide to the CONSIAT program insights on the needs and uses of piping design and delivery information as part of the project delivery process and insights on eBusiness for capital facilities. This project will use prior CONSIAT results in component tracking and placement for steel construction in investigating the utility of similar improvements in piping material tracking and installation.

\subsubsection{Site Measurement System Communication Standards and Practices}

There is presently little in the way of live information from a construction job site that flows back into the design, planning, fabrication, and transportation stages of a project. Because these facets of project management are not automatically linked, it is extremely difficult to take advantage of recent advances in information technology to speed construction delivery time through concurrent engineering. Lack of information closure with the job site specifically precludes: (1) comparison of "as-is" with "should-be" to avoid or rapidly rectify differences between the intended design and the actual construction; (2) construction site control and resource management to avoid delays by tracking material, equipment, and labor to meet schedule while ensuring quality; and (3) capturing "as-built" status of a completed project for use in operation and maintenance over the building/facility life cycle. In order to bring construction into the information loop, a myriad of real-time sensors and human feedback must find a means to be wirelessly brought from the job site to a digital storehouse - a temporal database - that can be mined and used to facilitate work process modeling and construction management.

One of the significant problems facing developers of new construction metrology systems is the difficulty of interfacing to a wide variety of subsystems and integrating them into a useful whole. Furthermore, the subsystems are often numerous, and the "best" for any task can change rapidly. At present, there is no generally accepted approach for software subsystems in a construction site measurement system to use for exchanging data with one another. As a result, significant effort in implementing such systems goes into creating different software interfaces for each sensor, actuator, GUI, and database. Since there is often little prospect of interface-software reuse (because there is so little standardization), system developers are often hesitant to change, upgrade, or experiment with new subsystems. To avoid this productivity loss, a standard, broadly accepted means to communicate information between construction site measurement subsystems is needed. Ideally, this interface should work whether the subsystems reside on the same computer, or on different ones. Also, ideally, this protocol should be designed to provide maximum flexibility of physical networks capable of realizing the protocol. 
Research at NIST is predicated on the availability of live spatial data - the position and orientation of all objects on site. This includes the geometry of amorphous ${ }^{22}$ objects, which are not neatly classified as "components," as well as task and component-specific knowledge. We are using many state-of-the-art and emerging sensing technologies to achieve this, including phase differential GPS (global positioning system), fanning lasers, NLS (non-line-of-sight) tracking systems, and LADAR. We must consider how one is to mine this wealth of chronological data and present it to the various consumers: project/ construction managers, crew foremen, laborers, engineers, fabricators, building owners, and automated machinery.

The intent at NIST is to develop OSI Application Level protocols applicable to a variety of lower-level layers, for example wireless and wired technology as the site conditions permit. There are envisioned to be two protocols, one to facilitate the exchange of raw sensory data (SensorView) and one to facilitate the exchange of object state information (LiveView). These protocols are envisioned to be promulgated through standards setting bodies such as IEEE or ISO.

Work on SensorView revolves around solving issues in: (1) packet standards (including speed, and reliability) needed in meeting OSI communications assumptions necessary for use and development of LiveView; (2) data representation standards (e.g. STEP); (3) interoperability assessment and evaluation testing and standards; (4) representation of uncertainty of sensed quantities of field sensors; and (5) support for data fusion applications. Current plans call for a sample implementation of SensorView to be developed to support structural steel tracking and excavation activities. Trial testing of SensorView will demonstrate the transfer of data relevant to structural steel tracking and excavation. This extends the capability of the previous LiveView demonstration with regard to de-coupling of raw sensor data from the model changes implied by the data.

BFRL has already begun looking at the issues surrounding object state communication from the construction site with the LiveView protocol. Yet significant issues remain to be addressed in LiveView such as interfacing with SensorView and integration into a larger Site Measurement System. This larger system is more than simply having two protocols and applications that utilize them. Such a larger system includes expected behaviors of applications, typical networking configurations and services, practices for quality assurance of the entire system, and practices to enable easy integration of additional applications.

A set of standard practices will be developed and documented that will enable applications to be generated that turn raw sensor data from SensorView into object states that can be reported to construction management applications over LiveView. To state this explicitly, SensorView is a protocol for transmission of field sensor data to an intermediate-processing agent. LiveView is a protocol that transports processed registered object states (e.g. global positions and orientations of manufactured parts; registered

\footnotetext{
${ }^{22}$ Amorphous objects are items which do not fall under the category of engineered components. They include such things as excavation topography; status of a concrete pour; piles of raw materials; and the status of a paving operation.
} 
terrain models, etc.) to a project database. Since the suite of potential types of measurements is large, no single solution can be provided, however, a set of standard practices and standard system architecture can reduce the cost of development of metrology systems for construction metrology companies. Such practices are envisioned to be promulgated via interoperability protocols, as a separate standard, or as an annex to the protocol standards.

\subsubsection{Procedures and Metrics for Construction Range Imaging and Registration}

This project focuses on the use of new fast laser ranging technologies and threedimensional analysis to non-intrusively scan a construction site and to extract useful information from these data for project planning purposes. This versatile capability will directly address both the BFRL CONSIAT program and the National Construction Goal of reducing delivery time by $50 \%$.

BFRL's Construction Metrology and Automation Group in collaboration with NIST's Information Technology Laboratory and BFRL's Computer Integrated Construction Group has made strides in the use of LADAR for rapidly assessing the status and quantitative change of amorphous objects on a construction site.

Specifically, BFRL has succeeded in live acquisition of 3D earthmoving topography, transmission of this data to a remote host, combining the live data with extant data from other, previous LADAR sweeps, and developed the subsequent post-processing technology to produce both a 3D representation of the changed state of the terrain following excavation and quantitative information concerning such measures as the amount of material removed and the amount remaining.

Current efforts focus on the evaluation of registration and surface generation methods/algorithms. This evaluation involves a three-part process. In the first part, the characteristics (accuracy, noise, and related uncertainties) of the sensor would be determined. This "calibration" would be performed in an indoor facility, which allows for a controlled environment. In the second part, mathematical procedures are used to determine the statistical uncertainties of particular calculations (e.g., volume) based on the results of the instrument calibration. In the third part, the characteristics of the methods/algorithms used to generate the 3D model would be determined (how well does it handle missing points, outliers, discontinuities, vertical surfaces, etc.).

In the first and third parts of the process, a set of metrics has to be established to measure the accuracy. In the first part (sensor evaluation), the metrics depend largely on the sensor characteristics and are relatively straightforward for range calibration. However, determination of the angular accuracy of the scanner is more complicated for scanning sensors due to divergence of the laser beam and because some scanners use lasers outside of the visible range. In the third part (evaluation of surface generation methods/ algorithms), these metrics are harder to establish. One way to evaluate the method/ algorithm is to compare it with a reference surface (ground truth). Initially, simple 
objects of known shape and volume will be used to evaluate the method/algorithm in an indoor controlled environment. This effort will be followed by using objects with more complex shapes. The accuracy of the method/algorithm will be evaluated based on how well known volumes are reproduced.

The same data gathered for the evaluation of the accuracy of surfaces may be used to develop methods for automatic registration. In addition, the protocols for target-based registration need to be developed. These protocols will include target size, shape, and material. Comparison between target-based and automatic registration will be conducted. Performance measures for registration will be needed for that purpose. To some extent, the protocol for the evaluation of surface generation method/algorithms will already provide some indication of the ability to register separate scans. However, additional testing protocols are needed to assess the uncertainties caused by the registration process.

Future work will focus on a demonstration of a complete prototype information management system integrated with automated earthwork tracking systems and a subsequent field demonstration of a second-generation prototype project information management system incorporating advanced earthwork tracking techniques, including real-time extraction of in-scene machinery.

\subsubsection{Measurement Processes and Metrics for Construction Component Tracking}

Significant amounts of time are spent every day on construction sites across the United States in efforts to locate and identify components, sub-assemblies, and tools. Finding a needed item is only part of the problem. Once a component or assembly has been incorporated into the building or plant, other questions need to be answered: (1) was the component the right one for that location? (2) where was it finally positioned and what was its orientation? (3) were there any problems associated with the component or with its placement into the structure? and (4) do the appropriate managers, engineers, and planners know this information? Knowledge of this information, in a quick and accurate fashion, would dramatically improve productivity and lower construction costs. The goals of this project are to develop standards for part ID and tracking that the construction industry will adopt; to develop means for real-time tracking of these items and wirelessly transmitting that information to a construction project database; and, finally, to demonstrate the utility of these techniques on full-scale construction sites.

This project will address the problem of identifying, registering, and tracking discrete construction components and sub-assemblies on a construction site, specifically steel frame components. BFRL's approach uses a customized, interactive web-based graphical user interface operating on a field-portable computer as the field agent interface. Automated field data collection via peripherals, such as a laser-based real-time spatial positioning system, bar code and RFID scanning systems, and wireless data links, are integrated seamlessly through the browser. The field inspector uses either the bar code scanner or RFID reader to acquire the part identification. Then an interactive session begins in which the field computer queries, by means of the wireless link, a remote job 
site database that then returns information concerning the part. The returned information also includes a three-dimensional model of the component indicating available fiducial point locations to help guide the user through the spatial $(\mathrm{x}, \mathrm{y}, \mathrm{z})$ data collection process. In the current NIST laboratory work, the new component location data is sent to a virtual site simulator that allows contractors, engineers, and owners to independently view the job site in 3D and to observe the status of construction, including the current position and orientation of components. In this fashion an automated "as-built" database is constructed in the course of routine quality control tracking. The system is powerful enough to permit real-time tracking of construction machinery as well as other mobile capital assets.

Prior year work on this project has produced a prototype system of integrated hardware and software to measure the position and orientation of steel frame components and subassemblies at the job site and to allow for web-based interactive information entry and query while at a component's location. The prototype system was field-tested at the Building 205 ECS project on the NIST, Gaithersburg campus. A subset of the ECS structural steel framework was tracked, addressing integration and implementation issues, including: locating, mounting and registering fanning laser transmitters on the site, tagging steel for identification, developing a simple methodology for identifying fiducial point locations, defining and transforming local-to-world coordinate systems, and testing the LiveView wireless data transmission protocol. The data collected at the ECS site was post-processed for integration with the project information database and 3D virtual site simulator.

Current research focuses on the development of standard methods of practice and performance metrics that are needed to assure interoperability and accuracy in this class of field metrology. Three specific areas of research are being addressed.

1. Metrics for Registration of Multiple Fanning Laser Transmitters: This work is essential to providing the standards needed to enable uniform and accurate coordinate registration of large-scale laser-based coordinate measurement systems used to track components on construction sites.

2. Standard Methods for Automatic Fiducial Point Identification: At present, fiducial points are manually identified for each part on a project in a time consuming process. Standard methods are needed to automatically mine this information from existing (CIS(2)) data representations. Visual advisories need to be provided to the inspector so that available fiducial points are quickly identifiable and easily located.

3. Measures of Performance for Part Locator Algorithms: This work seeks to develop standard NIST-traceable measures of performance for pose determination (i.e. its position and orientation) based on 3D large-scale coordinate measurement system input.

This project will work with industry to develop realistic business cases for deployment of the technologies based on the standards. Collaborations will be sought with construction 
industry partners to ensure that the standards being developed are responsive to industry needs and are compatible with other industry standardization efforts.

\subsubsection{Enhanced Construction Object Recognition Through Sensor Fusion}

Imaging sensors such as LADARs are used to rapidly acquire data of a scene to generate $3 \mathrm{D}$ models. Increased interest in this technology is due to the substantial growth in applications for real-time scene updates created by advances in imaging sensor software and hardware. Current applications include site surveillance, map/terrain update/bathymetry/recognizance, indoor/outdoor visual inspection, collision avoidance, and generating "as-builts."

Imaging sensors are used to obtain two- or three-dimensional arrays of values such as range, intensity, or other characteristics of a scene. Currently available LADARs can gather two pieces of information - namely range to an object and strength of the returned signal (intensity). Various methods are used to convert the data, which are collected in the form of point clouds, into meaningful 3D models of the actual environment for visualization and scene interpretation. The need for accurate representations varies with the purpose of the application. In the construction industry, an accurate representation aids in determining payment for completed work, determining if errors are being made, and in tracking work progress on a project.

The points within a point cloud are indistinguishable from each other with regards to their origin (i.e., there is no way to tell if a point is reflected from a tree or from a building). As a result, the methods used to generate the models treat all points identically and the results are indistinguishable "humps/bumps" in the scene. Current surface generation methods using LADAR data require intensive manual intervention to recognize, replace, and/or remove objects within a scene. As a result, aids to object identification have been recognized by the end users as a highly desirable feature and a high priority area of research.

To that end, a hybrid LADAR is needed - a LADAR that can simultaneously acquire "intelligent" information about an object in addition to existing generic point cloud data when conducting a scan of a scene such as a construction site. The combined information from this type of sensor would be a major step towards automatic object identification. In addition, there is a growing need for metrics that can determine the accuracy of the various object identification methods that currently exist and/or are under development.

This project focuses on investigations of: (1) the ability of using a LADAR to acquire information (such as color, type of material, distinct patterns, and fiducial point identifiers) about an object in addition to range data, and (2) the fusion of LADAR and other sensors. These "other sensors" could be (a) RFID tags that contain encrypted data about the scanned object (e.g., beam, column, part number), (b) micro-reflective sensors arranged in a standardized pattern or at pre-determined fiducial locations on an object to 
allow for identification, and/or (c) a camera to provide a concurrent image of a scanned scene.

The additional information from the hybrid LADAR does not identify objects per se, but is used to aid in object identification. Additional intelligence will have to be supplied/ added to (a) pick out and extract the data (points) from a point cloud for further processing, and (b) correctly identify the object. In the first instance, user intervention is the most likely source of this intelligence. In the latter instance, the intelligence could be in the form of user intervention, image processing algorithms (if a camera is used), and/or a database containing objects that would most likely be found in a particular scene.

Image processing algorithms are currently research tools that have been successfully used to identify a limited number of objects in a scene. A standard protocol (point density; object size, shape, and placement; partial obstruction; etc.) and test environment will have to be developed to measure the accuracy of these algorithms. If a database is utilized to provide the intelligence, probability analyses will have to be performed to determine confidence limits.

The project will be divided into four phases. The first phase will involve investigating various technologies that can be combined with LADAR to yield additional information about a scene to aid in object identification. The second phase will involve developing a sensor that combines the capabilities of a LADAR with the most promising technology(s) identified in the first phase. The third phase involves developing a standard protocol and measures of performance for the various object recognition algorithms. The fourth phase will be testing the hybrid LADAR at a construction site.

\subsubsection{Economic Analysis of FIAPP Products and Services}

FIAPP products and services are one means to improve the performance of the project delivery process by reducing cycle time, construction costs, and construction-related accidents. But investments in and the use of FIAPP products and services will be forthcoming only if industry perceives that the economic benefits outweigh the costs of using such products and services. Being able to demonstrate net economic savings from using FIAPP products and services will encourage their acceptance and use. Economic support for the overall CONSIAT effort addresses the need for information on the economic consequences of investing in FIAPP products and services in two distinct ways.

First, the Office of Applied Economics (OAE) is conducting ex ante (i.e., prospective) economic impact assessments of BFRL's CONSIAT-related research, will monitor outcomes, and will conduct a follow-up economic impact assessment. The subject of this report is the ex ante economic impact assessment of one segment of the market for FIAPP products and services_commercial buildings. 
Second, OAE will develop user-friendly, decision-support software to facilitate the economic evaluation of FIAPP products and services and the identification of costeffective levels of investment in these products and services. To make cost-effective choices for investments in FIAPP products and services, decision makers must have data on benefits and costs associated with these products and services, information on who bears the costs and reaps the benefits, and tools (methods and software) for measuring those benefits and costs. Having a package of economic tools that helps users and stakeholders identify and measure the benefits and costs of choosing between FIAPP products and services and traditional products and services will accelerate the introduction and acceptance of FIAPP products and services in the U.S. and abroad. Thus, OAE will produce an integrated software package providing life-cycle cost (LCC) measurement capabilities for evaluating FIAPP products and services. To assure industry acceptance of the software package, it will be made consistent with ASTM's LCC standard practice, E $917 .^{23}$

${ }^{23}$ American Society for Testing and Materials. 1999. Standard Practice for Measuring Life-Cycle Costs of Buildings and Building Systems. E 917. West Conshohocken, PA: American Society for Testing and Materials. 


\section{Market for FIAPP Products and Services}

The construction industry is a key component of the US economy and is vital to its continued growth. Investment in plant and facilities, in the form of construction activity, provides the basis for the production of products and the delivery of services. Investment in infrastructure promotes the smooth flow of goods and services and the movement of individuals. Investment in housing accommodates new households and allows existing households to expand or improve their housing. Clearly, construction activities affect nearly every aspect of the US economy. ${ }^{24}$

This chapter provides a snapshot of the US construction industry. As such, it provides the context within which the scope and size of the market for FIAPP products and services is defined. The chapter contains three sections.

Section 4.1 presents information on the value of construction put in place to show the size of the construction industry and each of its four sectors. The four sectors, which taken together define the construction industry, are residential, commercial, industrial, and public works. Data from the seven-year period 1994 through 2000 are used to highlight the magnitude of construction-related investments in each sector. Data from 1997 are then used to establish the relative shares of construction-related investments for each sector.

Section 4.2 uses information on the commercial sector both to focus on its importance within the overall construction industry and to define its key components. Information on investment activity, the number of commercial buildings, and the amount of commercial floorspace is used to identify both those characteristics that are changing and those that are remaining constant. Information showing the relative share of construction-related investments in the key components of the commercial sector is also presented.

Section 4.3 places special emphasis on identifying and detailing the key characteristics of the commercial sector. Information detailing key characteristics (e.g., building floorspace and year of construction) is needed to define the scope and size of the market for FIAPP products and services in the commercial sector. Detailing the key characteristics of the commercial sector is crucial, because investments in FIAPP products and services affect not only new construction activities but additions and alterations as well as maintenance and repair activities. Ways in which these key characteristics affect the calculation of FIAPP-related benefits and costs are discussed in Chapter 6.

\footnotetext{
${ }^{24}$ Readers interested in learning more about construction statistics, their sources and interpretation, are referred to the document by Rogers (Rogers, R. Mark. 1994. Handbook of Key Economic Indicators. Burr Ridge, IL: Irwin Professional Publishing).
} 


\subsection{Value of Construction Put in Place}

This section provides information on a key indicator of construction activity; the value of construction put in place. Data published by the US Bureau of the Census are used to establish the composition of construction expenditures by type of construction/function (e.g., non-residential/office building). These expenditures are then assigned to the four key construction industry sectors. The reference document used throughout this section is the Current Construction Reports series C30 publication Value of Construction Put in Place. ${ }^{25}$ A brief description of the "C30 report" follows. Special attention is given to the organization of the data in the $\mathrm{C} 30$ report and how these data map into the four key construction industry sectors. The section concludes with tabular and graphical summaries of the value of construction put in place.

Construction expenditures data are published monthly in the Current Construction Reports series C30 publication Value of Construction Put in Place. Construction expenditures refer to actual construction rather than planned or just initiated activity. It is noteworthy that the $\mathrm{C} 30$ report covers both private residential and non-residential construction activities and public sector construction activities.

The value of construction put in place is a measure of the value of construction installed or erected at a site during a given period. For an individual project, this includes: (1) cost of materials installed or erected; (2) cost of labor and a proportionate share of construction equipment rental; (3) contractor's profit; (4) cost of architectural and engineering work; (5) miscellaneous overhead and office costs chargeable to the project on the owner's books; and (6) interest and taxes paid during construction. Expenses do not include the cost of land nor do they include maintenance and repairs to existing structures or service facilities.

The C30 data are compiled via survey and through indirect estimation. In the context of the C30 survey, construction includes the following: (1) new buildings and structures; (2) additions, alterations, conversions, expansions, reconstruction, renovations, rehabilitations, and major replacements (e.g., the complete replacement of a roof or a heating system); (3) mechanical and electrical installations (e.g., plumbing, heating, electrical work, and other similar building services); (4) site preparation and outside construction of fixed structures or facilities (e.g., sidewalks, highways and streets, water supply lines, sewers, and similar facilities which are built into or fixed to the land); (5) installation of boilers, overhead hoists and cranes, and blast furnaces; (6) fixed, largely site-fabricated equipment not housed in a building (e.g., petroleum refineries and chemical plants); and (7) cost and installation of construction materials placed inside a building and used to support production machinery (e.g., concrete platforms, overhead steel girders, and pipes).

\footnotetext{
${ }^{25}$ US Department of Commerce. 2001. Current Construction Reports: Value of Construction Put in Place. C30. Washington, DC: US Bureau of the Census.
} 
The data presented in the $\mathrm{C} 30$ report are summarized in Tables 4-1 and 4-2. To facilitate comparisons between this report and the C30 report, Tables 4-1 and 4-2 use the same row and column headings as are used in the $\mathrm{C} 30$ report.

Tables 4-1 and 4-2 record annual values for the years 1994 through 2000. Table 4-1 records annual values in millions of constant 1997 dollars. Table 4-2 records annual values in millions of current dollars. ${ }^{26}$ Reference to Table 4-1 reveals that total construction expenditures in real terms have increased modestly over the seven-year period (i.e., from $\$ 571.3$ billion to $\$ 727.5$ billion). When the effects of inflation are included, the rate of increase appears more pronounced. Table 4-2 shows total construction expenditures in current dollars.

Tables 4-1 and 4-2 are organized to allow for in-depth analyses of the components/ subcomponents of total construction expenditures. To facilitate such analyses, the data presented in Tables 4-1 and 4-2 are initially divided into two parts: (1) private construction; and (2) public construction.

Private construction contains two major components - residential buildings and nonresidential buildings - plus a number of subcomponents. Both the two major components and the subcomponents are shown as headings in the first column of Tables 4-1 and 4-2.

The residential buildings component includes new private housing and improvements. New private housing includes new houses, apartments, condominiums, and town houses. New private housing units are classified as " 1 unit" or " 2 or more units." The value of improvements put in place are a direct measure of the value of residential additions and alterations activities.

The non-residential buildings component includes industrial, office buildings, hotels and motels, and "other commercial" (e.g., shopping centers, banks, service stations, warehouses, and other categories). Also falling under the non-residential buildings component are religious, educational, hospital and institutional, and "miscellaneous" nonresidential buildings.

\footnotetext{
${ }^{26}$ Inflation reduces the purchasing power of the dollar over time; deflation increases it. When amounts are stated in actual prices as of the year in which they occur, they are said to be in current dollars. Current dollars are dollars of any one year's purchasing power, inclusive of inflation/deflation. That is, they reflect changes in purchasing power of the dollar from year to year. In contrast, constant dollars are dollars of uniform purchasing power, exclusive of inflation/deflation. Constant dollars indicate what the same good or service would cost at different times if there were no change in the general price level to change the purchasing power of the dollar. For additional information on conducting economic analyses using either constant dollars or current dollars, see Fuller, Sieglinde K., and Stephen R. Petersen. 1996. Life-Cycle Costing Manual for the Federal Energy Management Program. NIST Handbook 135. Gaithersburg, MD: National Institute of Standards and Technology.
} 
Table 4-1. Value of Construction Put in Place in Millions of Constant 1997 Dollars

\begin{tabular}{|c|c|c|c|c|c|c|c|}
\hline \multirow{2}{*}{ Type of Construction } & \multicolumn{7}{|c|}{ Millions of Constant (1997) Dollars } \\
\hline & 1994 & 1995 & 1996 & 1997 & 1998 & 1999 & $2000^{e}$ \\
\hline Total Construction & 571,271 & 586,538 & 633,670 & 656,630 & 692,876 & 715,203 & 727,462 \\
\hline Private Construction & 439,110 & 449,367 & 489,838 & 501,749 & 537,585 & 553,609 & 562,131 \\
\hline Residential Buildings & 262,659 & 261,129 & 290,341 & 289,014 & 306,260 & 326,447 & 322,704 \\
\hline New Housing Units & 184,639 & 180,951 & 197,385 & 198,063 & 218,041 & 233,527 & 233,647 \\
\hline 1 Unit & 169,156 & 162,066 & 176,395 & 175,179 & 194,119 & 208,020 & 208,632 \\
\hline 2 Units or more & 15,483 & 18,885 & 20,991 & 22,883 & 23,922 & 25,507 & 25,015 \\
\hline Improvements & 78,020 & 80,177 & 92,956 & 90,951 & 88,220 & 92,920 & 89,058 \\
\hline Nonresidenti & 132,262 & 144,146 & 158,963 & 172,990 & 185,651 & 183,216 & 196,098 \\
\hline Industrial & 31,829 & 35,919 & 37,409 & 36,739 & 39,410 & 32,655 & 36,618 \\
\hline Office & 24,386 & 27,040 & 28,801 & 34,305 & 41,106 & 43,582 & 48,530 \\
\hline Hotel, motels & 5,111 & 7,508 & 11,270 & 12,898 & 14,423 & 14,916 & 14,674 \\
\hline Other commercial & 41,290 & 45,030 & 49,769 & 51,809 & 52,176 & 53,477 & 55,056 \\
\hline Religious & 4,254 & 4,567 & 4,683 & 5,777 & 6,419 & 7,016 & 7,170 \\
\hline Educational & 5,302 & 5,799 & 6,963 & 8,693 & 9,441 & 9,156 & 10,686 \\
\hline Hospital and institutional & 13,490 & 11,875 & 12,167 & 13,546 & 13,427 & 12,750 & 13,950 \\
\hline Miscellaneous & 6,600 & 6,409 & 7,901 & 9,223 & 9,249 & 9,664 & 9,415 \\
\hline Farm nonresidential & 3,547 & 3,182 & 3,778 & 3,815 & 4,170 & 4,165 & 4,237 \\
\hline Public L & 37,464 & 37,856 & 34,244 & 33,638 & 38,966 & 37,066 & 37,702 \\
\hline nications & 11,129 & 11,711 & 12,198 & 12,416 & 12,974 & 14,246 & 14,491 \\
\hline Other public & 26,335 & 26,145 & 22,047 & 21,222 & 25,992 & 22,820 & 23,211 \\
\hline Railroads & 3,673 & 3,704 & 4,542 & 4,922 & 5,584 & 4,602 & $\mathrm{n} / \mathrm{a}$ \\
\hline Electric light and power & 16,403 & 14,832 & 11,579 & 11,325 & 12,053 & 13,155 & $\mathrm{n} / \mathrm{a}$ \\
\hline Gas & 5,161 & 6,629 & 4,877 & 4,006 & 7,124 & 3,669 & $\mathrm{n} / \mathrm{a}$ \\
\hline Petroleum pipelines & 1,097 & 981 & 1,048 & 969 & 1,231 & 1,393 & $\mathrm{n} / \mathrm{a}$ \\
\hline All other private & 3,178 & 3,054 & 2,511 & 2,292 & 2,537 & 2,715 & 2,884 \\
\hline Public Construction & 132,161 & 137,170 & 143,833 & 154,882 & 155,291 & 161,595 & 165,330 \\
\hline Buildings & 54,370 & 60,971 & 65,554 & 71,867 & 71,333 & 72,706 & 78,155 \\
\hline Housing an & 4,217 & 4,960 & 5,214 & 5,230 & 4,988 & 5,258 & 4,865 \\
\hline Industrial & 1,611 & 1,592 & 1,435 & 999 & 983 & 866 & 972 \\
\hline Education & 22,388 & 27,219 & 29,528 & 34,385 & 35,273 & 37,176 & 41,868 \\
\hline Hospital & 4,344 & 4,472 & 4,769 & 5,152 & 3,802 & 3,713 & 3,763 \\
\hline Other & 21,809 & 22,727 & 24,608 & 26,100 & 26,288 & 25,693 & 26,687 \\
\hline Higl & 41,145 & 39,711 & 40,759 & 44,105 & 47,228 & 50,098 & 46,566 \\
\hline Military fa & 2,549 & 3,179 & 2,676 & 2,556 & 2,462 & 1,976 & 2,028 \\
\hline Conservation and development & 6,997 & 6,659 & 6,205 & 5,739 & 5,302 & 5,618 & 5,379 \\
\hline Sewer systems & 9,566 & 8,889 & 10,120 & 10,392 & 9,898 & 10,464 & 10,155 \\
\hline Water supply facilities & 5,110 & 4,971 & 5,802 & 6,419 & 6,649 & 7,114 & 6,907 \\
\hline Miscellaneous public & 12,426 & 12,791 & 12,717 & 13,803 & 12,417 & 13,621 & 16,141 \\
\hline
\end{tabular}

${ }^{\mathrm{e}}$ Estimated. n/a Not available. 
Table 4-2. Value of Construction Put in Place in Millions of Current Dollars

\begin{tabular}{|c|c|c|c|c|c|c|c|}
\hline \multirow{2}{*}{ Type of Construction } & \multicolumn{7}{|c|}{ Millions of Current Dollars } \\
\hline & 1994 & 1995 & 1996 & 1997 & 1998 & 1999 & $2000^{e}$ \\
\hline Total Construction & 519,539 & 555,591 & 613,535 & 656,630 & 711,759 & 764,233 & 807,850 \\
\hline Private Construction & 399,346 & 425,658 & 474,273 & 501,749 & 552,236 & 591,561 & 624,249 \\
\hline Residential Buildings & 238,874 & 247,351 & 281,115 & 289,014 & 314,607 & 348,826 & 358,365 \\
\hline New Housing Units & 167,919 & 171,404 & 191,113 & 198,063 & 223,983 & 249,536 & 259,466 \\
\hline 1 Unit & 153,838 & 153,515 & 170,790 & 175,179 & 199,409 & 222,280 & 231,687 \\
\hline 2 Units or more & 14,081 & 17,889 & 20,324 & 22,883 & 24,574 & 27,256 & 27,779 \\
\hline Improvements & 70,955 & 75,947 & 90,002 & 90,951 & 90,624 & 99,290 & 98,899 \\
\hline Nonresidenti & 120,285 & 136,541 & 153,912 & 172,990 & 190,711 & 195,776 & 217,768 \\
\hline Industrial & 28,947 & 34,024 & 36,220 & 36,739 & 40,484 & 34,894 & 40,665 \\
\hline Office & 22,178 & 25,613 & 27,886 & 34,305 & 42,226 & 46,570 & 53,893 \\
\hline Hotel, motels & 4,648 & 7,112 & 10,912 & 12,898 & 14,816 & 15,939 & 16,295 \\
\hline Other commercial & 37,551 & 42,654 & 48,188 & 51,809 & 53,598 & 57,143 & 61,140 \\
\hline Religious & 3,869 & 4,326 & 4,534 & 5,777 & 6,594 & 7,497 & 7,962 \\
\hline Educational & 4,822 & 5,493 & 6,742 & 8,693 & 9,698 & 9,784 & 11,867 \\
\hline Hospital and institutional & 12,268 & 11,248 & 11,780 & 13,546 & 13,793 & 13,624 & 15,492 \\
\hline Miscellaneous & 6,002 & 6,071 & 7,650 & 9,223 & 9,501 & 10,327 & 10,455 \\
\hline Farm nonresidential & 3,226 & 3,014 & 3,658 & 3,815 & 4,284 & 4,451 & 4,705 \\
\hline Public L & 34,071 & 35,859 & 33,156 & 3,638 & 40,028 & 39,607 & 41,868 \\
\hline nications & 10,121 & 11,093 & 11,810 & 12,416 & 13,328 & 15,223 & 16,092 \\
\hline Other public utilities & 23,950 & 24,766 & 21,346 & 21,222 & 26,700 & 24,384 & 25,776 \\
\hline Railroads & 3,340 & 3,509 & 4,398 & 4,922 & 5,736 & 4,918 & $\mathrm{n} / \mathrm{a}$ \\
\hline Electric light and power & 14,918 & 14,049 & 11,211 & 11,325 & 12,381 & 14,057 & $\mathrm{n} / \mathrm{a}$ \\
\hline Gas & 4,694 & 6,279 & 4,722 & 4,006 & 7,318 & 3,920 & $\mathrm{n} / \mathrm{a}$ \\
\hline Petroleum pipelines & 998 & 929 & 1,015 & 969 & 1,265 & 1,489 & $\mathrm{n} / \mathrm{a}$ \\
\hline All other private & 2,890 & 2,893 & 2,431 & 2,292 & 2,606 & 2,901 & 3,203 \\
\hline Public Construction & 120,193 & 129,933 & 139,263 & 154,882 & 159,523 & 172,673 & 183,600 \\
\hline Buildings & 49,446 & 57,754 & 63,471 & 71,867 & 73,277 & 77,690 & 86,792 \\
\hline Housing an & 3,835 & 4,698 & 5,048 & 5,230 & 5,124 & 5,618 & 5,403 \\
\hline Industrial & 1,465 & 1,508 & 1,389 & 999 & 1,010 & 925 & 1,079 \\
\hline Education & 20,361 & 25,783 & 28,590 & 34,385 & 36,234 & 39,725 & 46,495 \\
\hline Hospital & 3,951 & 4,236 & 4,617 & 5,152 & 3,906 & 3,968 & 4,179 \\
\hline Other & 19,834 & 21,528 & 23,826 & 26,100 & 27,004 & 27,454 & 29,636 \\
\hline Hight & 37,419 & 37,616 & 39,464 & 44,105 & 48,515 & 53,532 & 51,712 \\
\hline Military fa & 2,318 & 3,011 & 2,591 & 2,556 & 2,529 & 2,111 & 2,252 \\
\hline Conservation and development & 6,363 & 6,308 & 6,008 & 5,739 & 5,447 & 6,003 & 5,973 \\
\hline Sewer systems & 8,700 & 8,420 & 9,798 & 10,392 & 10,168 & 11,181 & 11,277 \\
\hline Water supply facilities & 4,647 & 4,709 & 5,618 & 6,419 & 6,830 & 7,602 & 7,670 \\
\hline Miscellaneous public & 11,301 & 12,116 & 12,313 & 13,803 & 12,755 & 14,555 & 17,925 \\
\hline
\end{tabular}

${ }^{\mathrm{e}}$ Estimated. n/a Not available. 
Rounding out the private construction component are farm non-residential, public utilities, and "all other private." These are generally of a non-residential nature, but are not part of non-residential buildings. Farm non-residential construction includes structures such as barns, storage houses, and fences. Land improvements such as leveling, terracing, ponds, and roads are also a part of this subcomponent. Privately owned public utilities construction is categorized by industry rather than function of the building or structure. This subcomponent includes expenditures made by utilities for telecommunications, railroads, petroleum pipelines, electric light and power, and natural gas. "All other private" includes privately owned streets and bridges, sewer and water facilities, airfields, and similar construction.

For public construction, there are two major components-building and non-building. Both the two major components and the various subcomponents are shown as headings in the first column of Tables 4-1 and 4-2. The building component contains subcomponents similar to those for private construction, with educational buildings being the largest subcomponent. Expenditures for the non-building component overwhelmingly consist of outlays for highways and streets, with sewer systems being a distant second subcomponent.

To get the sector totals, each subcomponent was assigned to a sector and summed. The sector assignments are identical to those used in Chapman and Rennison. ${ }^{27}$ The sector totals and the overall total are recorded in Tables 4-3 and 4-4. Reference to the tables reveals that sector totals vary considerably, with residential being the largest and industrial the smallest.

Table 4-3. Value of Construction Put in Place: Sector Totals and Sum Total in Millions of Constant 1997 Dollars $^{28}$

\begin{tabular}{|l|r|r|r|r|r|r|r|}
\hline \multirow{2}{*}{ Sector } & \multicolumn{7}{|c|}{ Value of Construction Put in Place (\$ Millions) } \\
\cline { 2 - 9 } & 1994 & 1995 & 1996 & 1997 & 1998 & 1999 & $2000^{\mathrm{e}}$ \\
\hline Residential & 266,876 & 266,089 & 295,555 & 294,244 & 311,248 & 331,705 & 327,569 \\
\hline Commercial & 152,521 & 165,828 & 184,237 & 205,703 & 215,774 & 221,308 & 236,036 \\
\hline Industrial & 33,440 & 37,511 & 38,844 & 37,738 & 40,393 & 33,521 & 37,590 \\
\hline Public Works & 118,434 & 117,111 & 115,034 & 118,944 & 125,459 & 128,671 & 127,762 \\
\hline Sum Total & 571,271 & 586,539 & 633,670 & 656,629 & 692,874 & 715,205 & 728,957 \\
\hline
\end{tabular}

${ }^{\mathrm{e}}$ Estimated.

\footnotetext{
${ }^{27}$ Chapman, Robert E., and Roderick Rennison. 1998. An Approach for Measuring Reductions in Operations, Maintenance, and Energy Costs: Baseline Measures of Construction Industry Practices for the National Construction Goals. NISTIR 6185. Gaithersburg, MD: National Institute of Standards and Technology.

${ }^{28}$ Note that due to rounding the values entered in the "Sum Total" row in Table 4-3, differ slightly from the values entered in the "Total Construction" row in Table 4-1.
} 
Table 4-4. Value of Construction Put in Place: Sector Totals and Sum Total in Millions of Current Dollars ${ }^{29}$

\begin{tabular}{|l|r|r|r|r|r|r|r|}
\hline \multirow{2}{*}{ Sector } & \multicolumn{7}{|c|}{ Value of Construction Put in Place (\$ Millions) } \\
\cline { 2 - 8 } & \multicolumn{1}{c|}{1994} & \multicolumn{1}{c|}{1995} & 1996 & \multicolumn{1}{c|}{1997} & \multicolumn{1}{c|}{1998} & \multicolumn{1}{c|}{1999} & \multicolumn{1}{c|}{$2000^{\mathrm{e}}$} \\
\hline Residential & 242,709 & 252,049 & 286,163 & 294,244 & 319,731 & 354,444 & 363,768 \\
\hline Commercial & 138,710 & 157,078 & 178,383 & 205,703 & 221,654 & 236,482 & 262,119 \\
\hline Industrial & 30,412 & 35,532 & 37,609 & 37,738 & 41,494 & 35,819 & 41,744 \\
\hline Public Works & 107,709 & 110,932 & 111,379 & 118,944 & 128,878 & 137,492 & 141,880 \\
\hline Sum Total & 519,540 & 555,591 & 613,534 & 656,629 & 711,757 & 764,237 & 809,511 \\
\hline
\end{tabular}

${ }^{\mathrm{e}}$ Estimated.

Reference to Table 4-3 reveals that the commercial sector is the only sector to have grown consistently in real terms over the entire seven-year period. In real terms, expenditures in the commercial sector grew from $\$ 152.5$ billion in 1994 to $\$ 236.0$ billion in 2000, an increase of almost $55 \%$. Real expenditures for two of the four sectors, industrial and public works, were essentially constant over the same seven-year period. Real expenditures for the residential sector exhibited a cyclical pattern.

The data contained in Tables 4-3 and 4-4 provide the basis for calculating each sector's relative share of total construction expenditures. Each sector's relative share of total construction expenditures is shown graphically in pie chart form in Figure 4-1. It was constructed using 1997 data from Table 4-4 (i.e., current dollar expenditures). Reference to Figure 4-1 reveals that in 1997 the commercial sector accounted for $31 \%$ of total construction expenditures (i.e., $31 \%$ of $\$ 656.6$ billion). The commercial sector's relative share of total construction expenditures is exceeded only by the residential sector, which constitutes $45 \%$ of the total. In addition, the commercial sector's relative share exceeds the combined total for the industrial and public works sectors.

Figure 4-1 provides a useful perspective on the potential market for FIAPP products and services. Consider the four following issues in developing a statement of market scope. First, the use of FIAPP products and services is more likely in the non-residential sectors, where construction establishments tend to be larger. Thus, slightly more than half of the U.S. construction industry serves as a potential market for FIAPP products and services. However, the relatively larger size of construction establishments engaged in nonresidential construction activities is only an indicator of market potential. Second, the "owner" plays a vital role in choosing whether or not to employ FIAPP products and services. In fact, the ultimate choice of which technologies to use-traditional or

\footnotetext{
${ }^{29}$ Note that due to rounding the value entered in the "Sum Total" row in Table 4-4 differ slightly from the values entered in the "Total Construction" row of Table 4-2.
} 
FIAPP — rests with the owner. Third, the relative importance of cost—both first costs and life-cycle costs - and schedule considerations are key drivers of whether or not to use FIAPP products and services. These considerations tend to reflect more of an owner perspective than a contractor perspective. However, much has been done in recent years to bring these two perspectives into alignment. This brings us to the fourth issue. Finally, the method of contracting and the use of strategic alliances between owners and contractors affect the efficacy with which new technologies can be deployed. Specifically, the engineer-procure-construct (EPC) method of contracting that is used broadly within the industrial sector and, more recently, the design-build method of contracting used in all three non-residential sectors promote a "partnership" environment rather than the adversarial environment that often prevailed under the traditional designbid-build method of contracting. Furthermore, large industrial organizations (e.g., many of the members of the Construction Industry Institute) have actively pursued strategic alliances to promote increased cooperation and reduced confrontation between owners and contractors.

Figure 4-1. 1997 Breakdown of \$657 Billion Construction Market

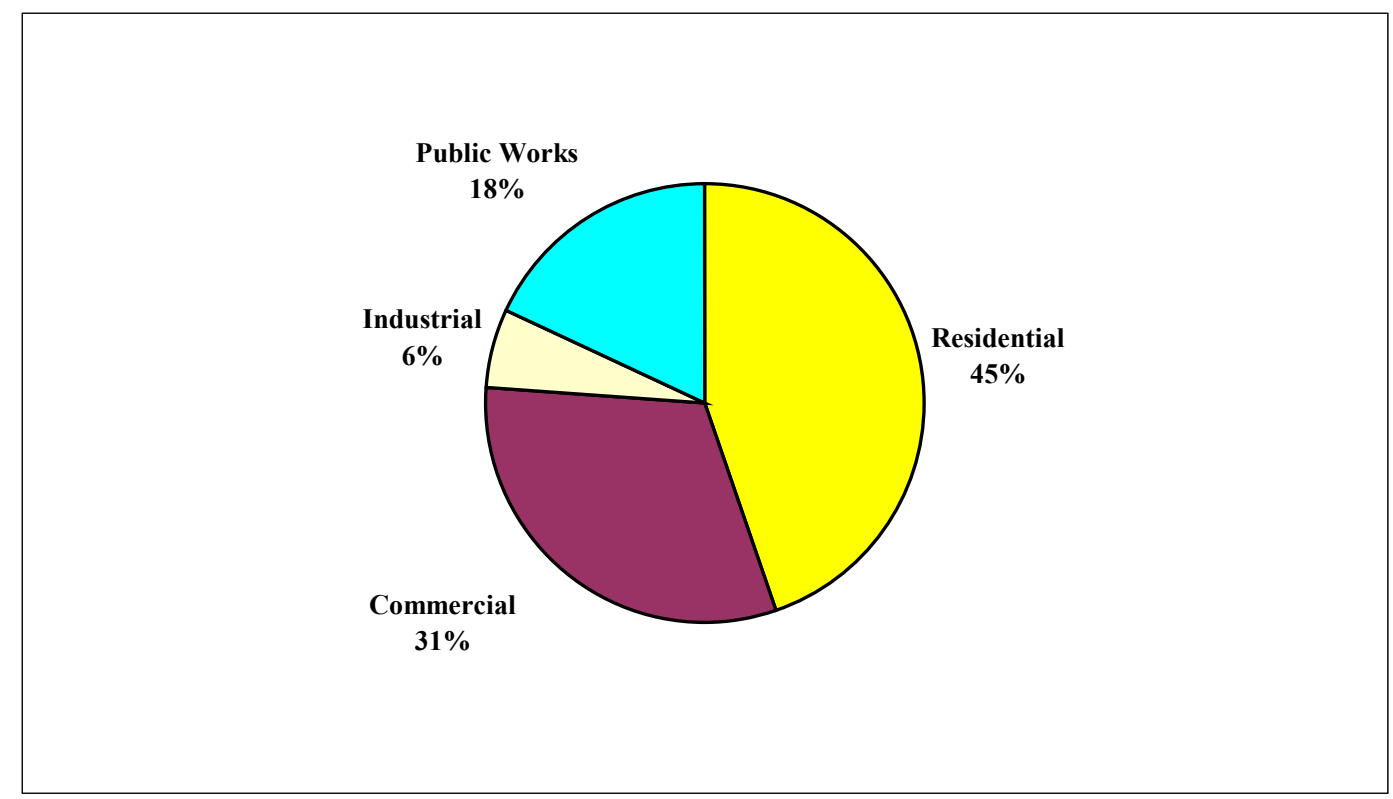

\subsection{Overview of the Commercial Sector}

The commercial sector, defined economically, consists of establishments that provide services. Defined in this way, the commercial sector is extremely varied. It includes office buildings, service businesses (e.g., retail and wholesale stores, hotels and motels, restaurants, and hospitals), as well as a wide range of facilities that would not be considered "commercial" in a traditional sense (e.g., public schools, correctional institutions, and religious and fraternal organizations). 
Expenditures by establishments in the commercial sector for the built environment include construction expenditures (e.g., new construction and additions and alterations) as well as expenditures for maintenance and repair activities, and for energy. The market for FIAPP-related products and services both affects and is affected by each type of expenditure. Consequently, it is instructive to first define what is included in each type of expenditure and then examine the characteristics of commercial buildings that affect these expenditures. This approach is aimed at producing a better understanding of the market for FIAPP-related products and services within the commercial sector.

Construction expenditures include both new construction activities and additions and alterations.

New construction activities include the complete original building of structures and essential service facilities and the initial installation of integral equipment (e.g., elevators and plumbing, heating, and air-conditioning supplies and equipment).

Additions and alterations include construction work that adds to the value or useful life of an existing building or structure, or which adapts a building or structure to a new or different use. Included are major replacements of building systems (e.g., installation of a new roof or heating system).

Maintenance and repair activities include incidental construction work that keeps a building or structure in ordinary working condition.

Energy is defined as including all non-process or end-product related energy consumption required to operate a building or structure. Energy consumption can be categorized by energy source (e.g., electricity, gas, and oil) and by end-use (e.g., space heating, cooling, and lighting).

Construction expenditures in 1997 for the commercial sector were $\$ 205.7$ billion in current dollars (see Table 4-4). Total expenditures include expenditures from subcomponents classified by the Census under their headings of "private construction" and "public construction." The subcomponents that the Census classifies under the private construction heading are: office, hotels and motels, other commercial, religious, educational, hospital and institutional (i.e., health care), miscellaneous, and farm nonresidential. The subcomponents included under the public sector heading are: educational, hospital, and other. Because the commercial sector is so varied, it is useful to group these subcomponents into a small number of key components. For convenience, these subcomponents are grouped into four key components, three of which are fairly homogeneous. The four key components are: office, educational, health care, and other. The relative share of the overall commercial sector's construction expenditures for each of the four key components is shown graphically in pie chart form in Figure 4-2. Figure 4-2 was constructed using 1997 data from Table 4-4 (i.e., current dollar expenditures). Reference to Figure 4-2 reveals that in 1997 the office buildings component accounted 
for $17 \%$ of the commercial sector's construction expenditures. Educational and health care account for $21 \%$ and $9 \%$, respectively.

Although there are a number of data sets which allow in-depth analyses of the commercial sector, the data associated with the Department of Energy's (DOE's) Commercial Building Energy Consumption Survey (CBECS) is the source of preference for summarizing the characteristics of the commercial sector's stock of buildings. The CBECS collects information on physical characteristics of commercial buildings, building use and occupancy patterns, equipment use, conservation features and practices, and types and uses of energy in buildings. The survey is conducted in two stages, the Building Characteristics Survey and the Energy Suppliers Survey. Our focus is on the Building Characteristics Survey. The types of buildings covered by the CBECS are far more detailed than those appearing in the $\mathrm{C} 30$ publication. This enables us to examine the commercial sector in greater detail than the breakdown shown in Figure 4-2.

\section{Figure 4-2. 1997 Breakdown of \$206 Billion Commercial Sector}

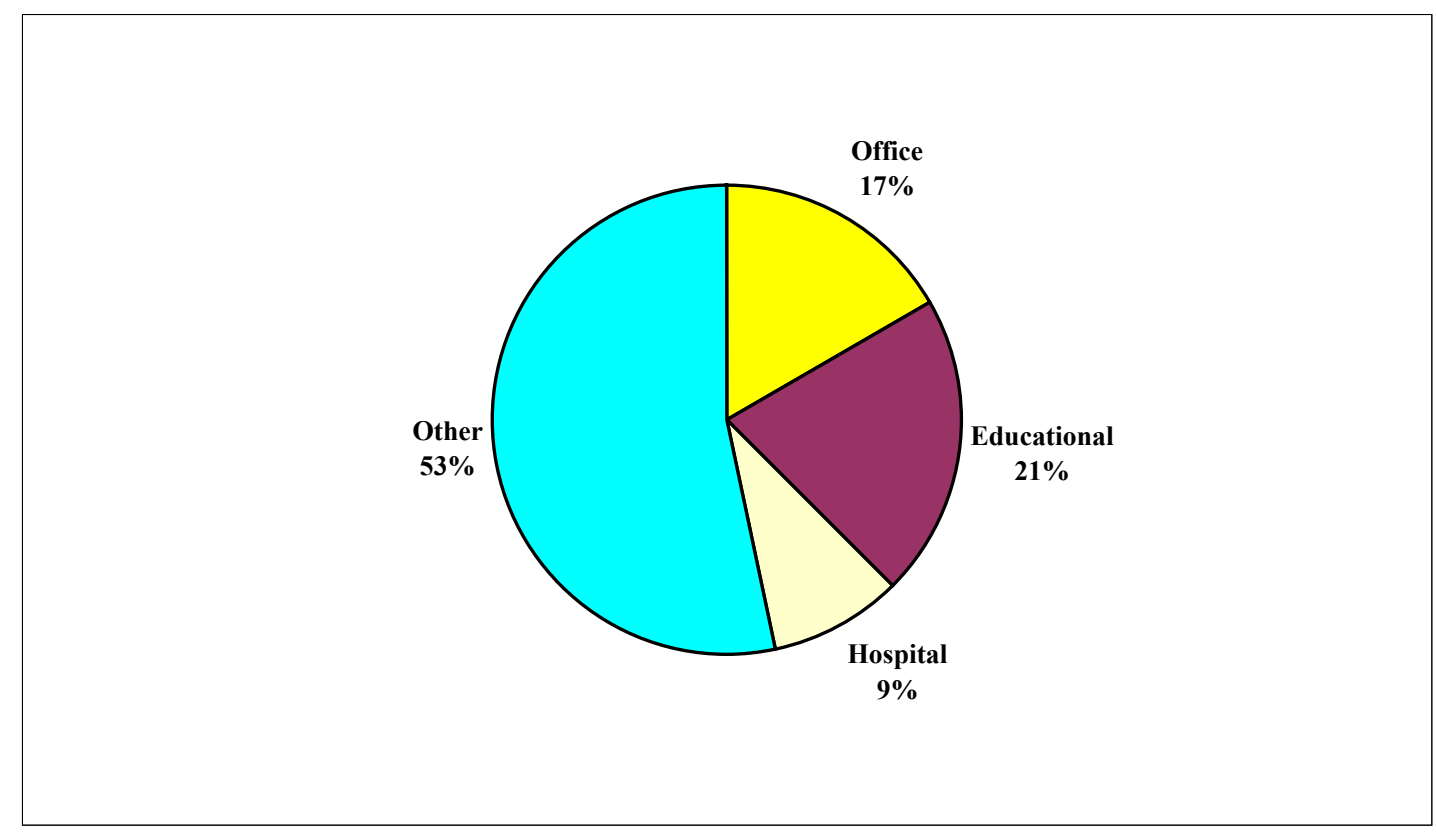

The most recent DOE Commercial Buildings Characteristics report ${ }^{30}$ provides detailed information on the size, age, and other characteristics of commercial buildings. In 1995, there were 4.58 million commercial buildings and 5.46 billion square meters (58.77 billion square feet) of commercial floorspace in the United States. ${ }^{31}$ The mean size of all commercial buildings was $1,193 \mathrm{~m}^{2}\left(12,840 \mathrm{ft}^{2}\right)$. The DOE report grouped buildings into eight size categories and into eight age categories. The vast majority of commercial

\footnotetext{
${ }^{30}$ US Department of Energy. 1997. Commercial Buildings Characteristics 1995. DOE/EIA-E024695. Washington, DC: Energy Information Administration.

${ }^{31}$ Values expressed in square feet are denoted by $\mathrm{ft}^{2}$. Values expressed in square meters are denoted by $\mathrm{m}^{2}$.
} 
buildings were found in the smallest size categories, with more than half in the smallest category and three-quarters in the two smallest categories. Most commercial buildings, once constructed, are expected to last for decades or longer. New buildings are constructed each year and older buildings are demolished, but the commercial buildings stock at any point in time is dominated by older buildings. More than $70 \%$ of all commercial buildings and total floorspace were constructed prior to 1980 , and more than $50 \%$ of buildings and floorspace were constructed prior to 1970 .

The DOE report also examined whether any changes in major characteristics had occurred between 1989 and 1995. The report concluded that the profiles of major characteristics of commercial buildings showed no statistically significant changes from 1989 to 1992 to 1995 , the years in which the last three surveys were conducted. ${ }^{32}$ Significant changes between surveys would occur if characteristics in the newest buildings (i.e., those constructed since the previous survey) were quite different, or if changes were made to buildings in the existing stock. However, each three-year increment of new buildings and floorspace was generally small compared to all buildings and floorspace in a given category and the changes that did occur were not great enough to be statistically significant.

The profiles of major characteristics which showed no significant changes included the total number of buildings, the total amount of floorspace, the distribution of floorspace by principal building activity (e.g., office buildings), the distribution of buildings by size of building, and the distribution of floorspace by census region. The findings presented in the DOE report and the characteristics just referenced are of particular importance in defining the market for FIAPP-related products and services in the commercial sector for two reasons.

First, the market for FIAPP-related products and services, or any new technology intended for use in the built environment, is dominated by the characteristics of the current building stock. Thus, the diffusion of new technologies in general, and FIAPP technologies in particular, must include explicit reference to the current building stock and not just to new construction. This statement is consistent with the assumption that FIAPP-related products and services will be employed both as part of additions and alterations to existing buildings and as part of new construction.

Second, DOE's findings imply that both total floorspace for the entire commercial sector and total floorspace by principal building activity have remained constant for an extended period of time. If this trend continues, as seems likely, then total floorspace for each key component will continue to remain constant. It is important to note that during the period covered by the last survey the commercial sector experienced steady growth in construction expenditures relative to the rest of the construction industry. Even during this period of growth, total floorspace in the commercial sector remained constant.

\footnotetext{
${ }^{32}$ DOE, Commercial Buildings Characteristics 1995, p. vii and p.10.
} 
The choice to adopt a new technology is driven by a number of factors. However, two factors that are of particular importance to decision makers considering investments in new technologies in the commercial sector is the ability of those technologies to either reduce costs or reduce cycle time. Clearly, cost reductions have an immediate impact on the bottom line and thus are reflected on the "corporate" balance sheet. Cycle time reductions bring the building into an income generating status sooner, thus impacting profits. Although all owners and managers of commercial buildings are interested in the potential for cost and/or cycle time reductions, those with the greatest incentive are the owners/managers of relatively large buildings. Thus, large commercial buildings are considered more likely candidates for early adoption of FIAPP technologies. Consequently, this impact assessment adopts a conservative approach in defining the scope of the market for FIAPP-related products and services to be the "large" buildings component of the commercial sector. For purposes of this report, a large building is defined as one whose floor area exceeds $4,645 \mathrm{~m}^{2}\left(50,000 \mathrm{ft}^{2}\right)$. The next section defines the size of the market for FIAPP-related products and services by detailing information on the key characteristics of commercial buildings.

\subsection{Characteristics of Commercial Buildings}

The previous section concluded with a market scope statement. This section demonstrates how that market scope statement is translated into a specific statement of market size. To better understand both the scope and size of the CONSIAT market, it is useful to examine in some detail the characteristics of commercial buildings.

In 1995, there were 4,579,000 commercial buildings in the United States. Collectively, these 4,579,000 buildings had 5,460 million $\mathrm{m}^{2}\left(58,772\right.$ million $\left.\mathrm{ft}^{2}\right)$ of floorspace. Commercial buildings in the United States had a mean size of $1,193 \mathrm{~m}^{2}\left(12,840 \mathrm{ft}^{2}\right)$.

Figures 4-3 through 4-8 provide detailed snapshots of the nation's stock of commercial buildings. In each figure, information is classified along one of two major dimensions, either by building size, measured in terms of total floorspace, or by building age, measured in terms of year of construction. Each set of figures (e.g., Figures 4-3, 4-4, and 4-5) uses the same bar chart format to facilitate comparisons of characteristics.

Figures 4-3, 4-4, and 4-5 record the distribution of the number of commercial buildings and total floorspace by building size. All three figures use the same eight size categories specified in the DOE report. The DOE size categories are specified in customary units; they range from 1,001 to $5,000 \mathrm{ft}^{2}\left(93.0\right.$ to $\left.464.5 \mathrm{~m}^{2}\right)$ for the smallest size category to over $500,000 \mathrm{ft}^{2}$ (over $46,451.5 \mathrm{~m}^{2}$ ) for the largest size category. The eight size categories, as defined in this section, are used throughout this report.

Figure 4-3 records the distribution of the number of commercial buildings by building size. Figure 4-3 shows clearly that smaller buildings dominate the key category of commercial buildings. More than half of the stock of commercial buildings $(2,399,000$ of 
the $4,579,000$ ) is contained in the smallest size category and almost three-fourths $(3,434,000$ of the $4,579,000)$ in the two smallest size categories. By contrast, only four percent or 188,000 buildings are contained in the four largest size categories; the four size categories deemed most likely to use CONSIAT products and services.

Figure 4-4 shows the distribution of total floorspace by building size. The floorspace of commercial buildings first increases for the three smallest size categories and then trends downward for the four largest size categories. Total floorspace for the four largest size categories is 2,379 million $\mathrm{m}^{2}\left(25,610\right.$ million $\left.\mathrm{ft}^{2}\right)$. Figure 4-4 shows that the largest amount of floorspace is in the third smallest size category. The largest size category contains the smallest number of buildings and the least amount of floorspace.

Figure 4-5 introduces an additional characteristic, the number of floors in the building. This characteristic serves to sharpen the distinctions between the buildings in each size category. Figure 4-5 uses the same classification scheme as employed in the DOE report. DOE grouped commercial buildings into one of five categories, based on the number of floors. These categories are one floor, two floors, three floors, four to nine floors, and ten or more floors. Each floor category is coded by shading; a legend is provided on the figure to match the floor category to a specific bar in each of the eight size categories. Figure 4-5 shows clearly that commercial buildings with one and two floors dominate the smaller size categories. Commercial buildings with one floor tend to decrease as the building size gets larger. Figure 4-5 shows that buildings in the three smallest size categories, which contain the largest number of commercial buildings as shown in Figure 4-3, are constructed largely with one and two floors. For the three smallest size categories, the ratio of buildings with one floor to those with two floors is about 2:1.

Figures 4-6, 4-7, and 4-8 record the distribution of the number of commercial buildings and total commercial floorspace by year of construction. All three figures use seven year of construction (i.e., age) categories. It is important to note that these seven year of construction categories differ from the eight year of construction categories specified in the DOE report. This is because the last two DOE year of construction categories have been combined. The last two DOE year of construction categories were 1990 to 1992 and 1993 to 1995 . These categories were combined to form the 1990 to 1995 year of construction category. The year of construction categories used are 1919 or before, 1920 to 1945,1946 to 1959,1960 to 1969,1970 to 1979,1980 to 1989 , and 1990 to 1995 . The seven years of construction categories, as defined in this section, are used throughout this report.

Figure 4-6 records the distribution of the number of commercial buildings by year of construction. Figure 4-6 shows that most of the commercial buildings were constructed between 1946 and $1989(3,244,000$ of 4,579,000) with the largest number in the 1946 to 1959 category $(867,000$ of $4,579,000)$. Approximately one-fifth of the stock was constructed prior to 1946 . The smallest number of commercial buildings was constructed prior to $1920(353,000$ of $4,579,000)$. 
Figure 4-3. Total Number of Commercial Buildings by Size Category: 1995

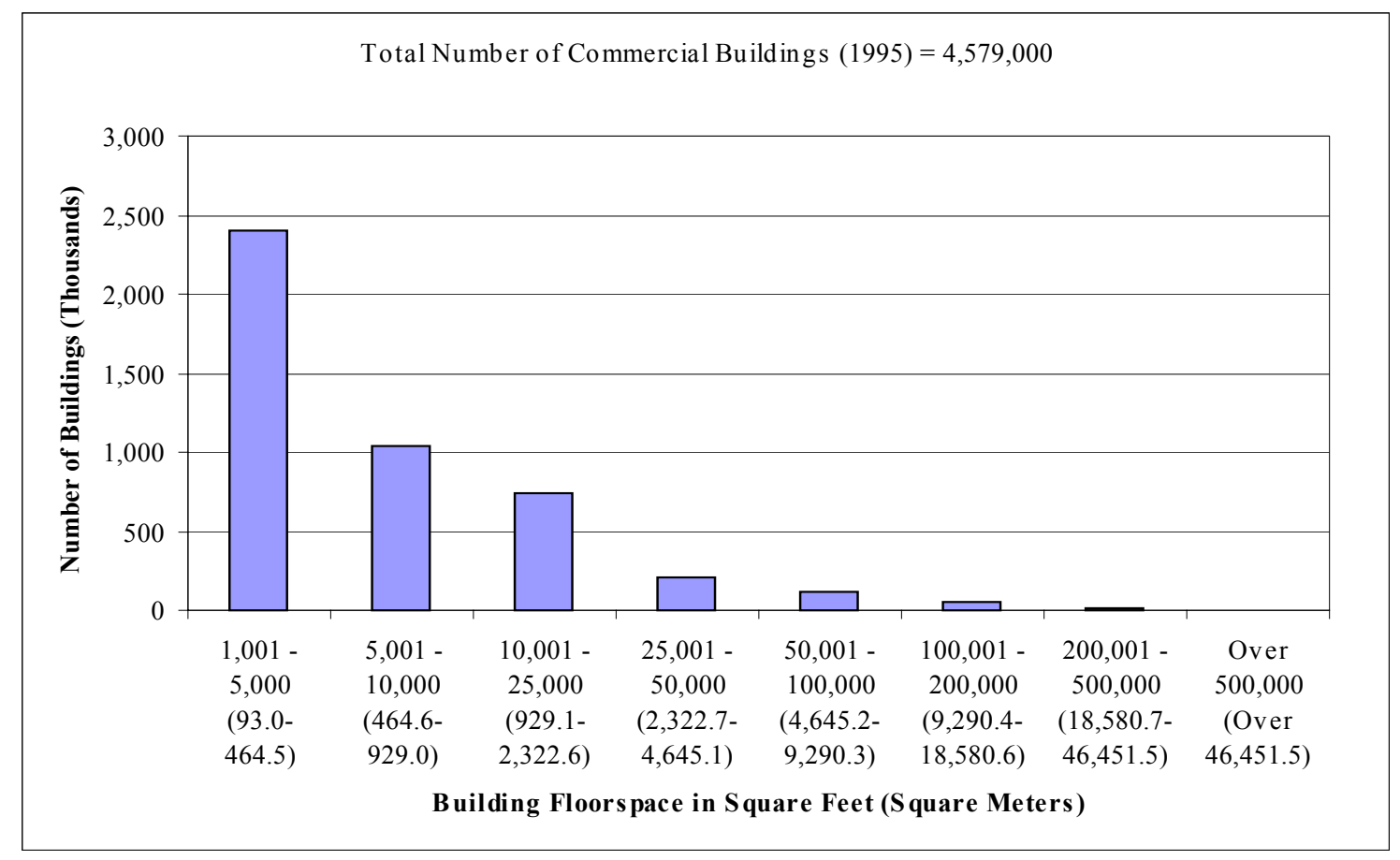

Figure 4-4. Total Commercial Floorspace by Building Size Category: 1995

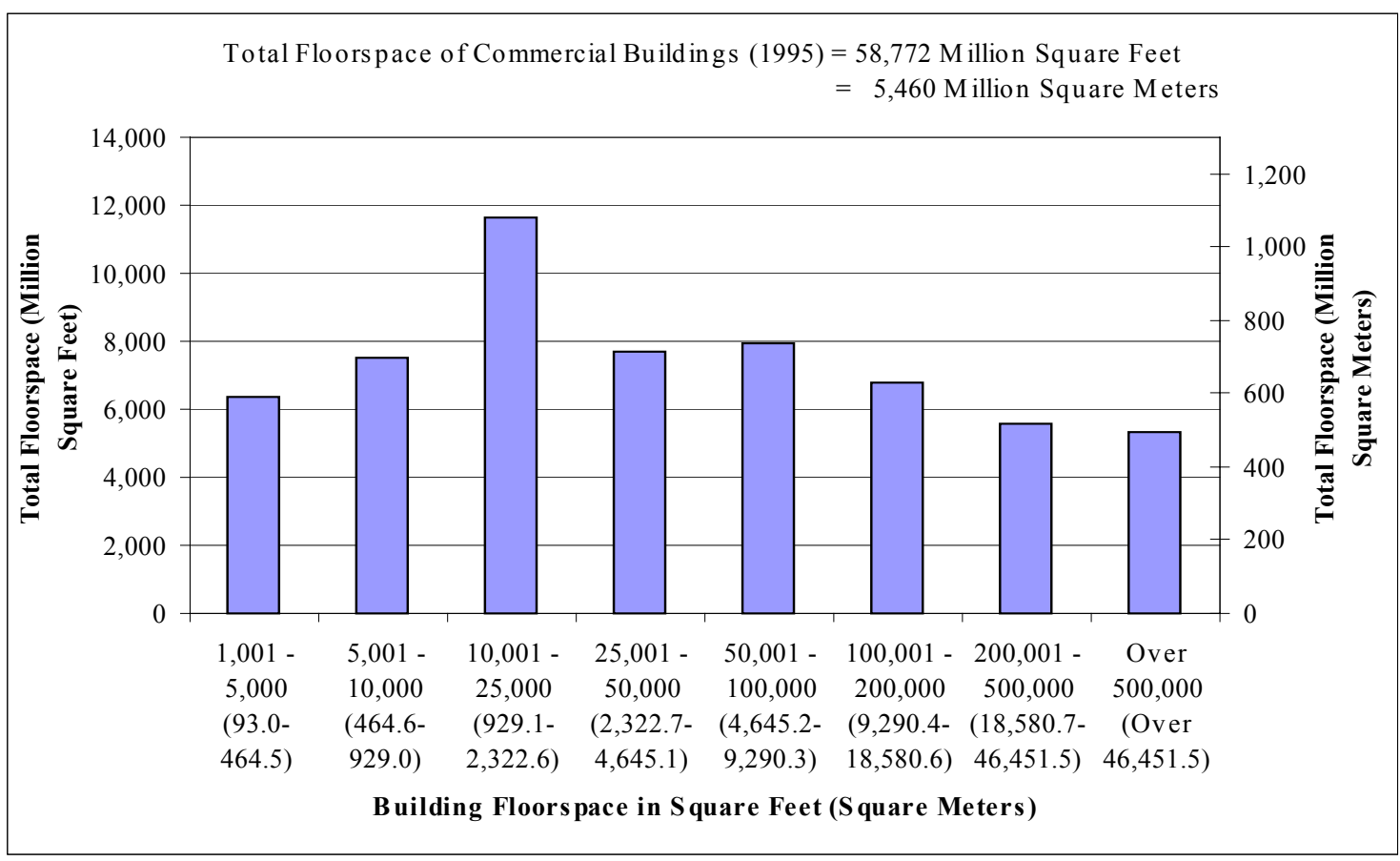


Figure 4-5. Total Commercial Floorspace by Building Size Category and Number of Floors: 1995

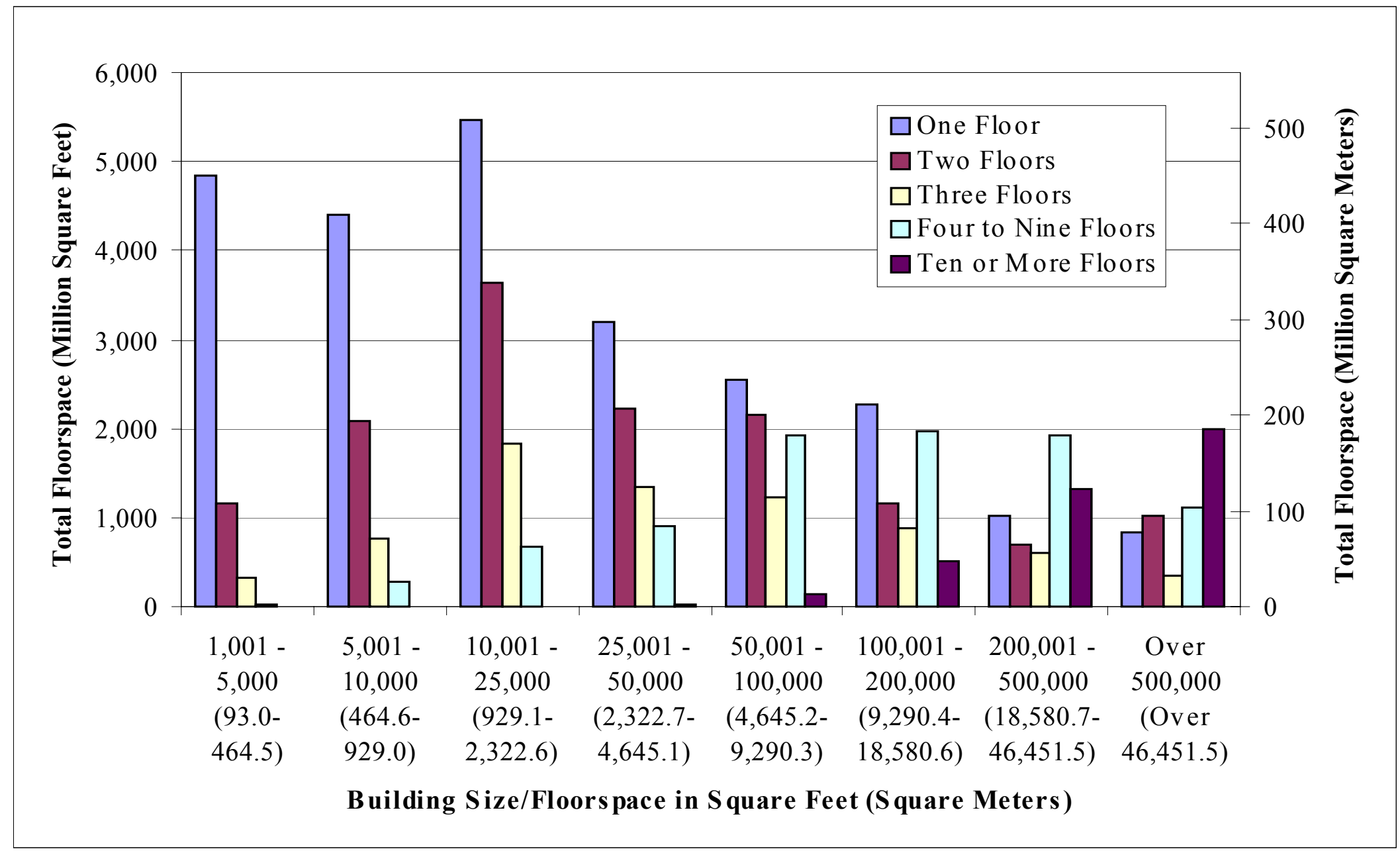


Figure 4-6. Total Number of Commercial Buildings by Year of Construction: 1995

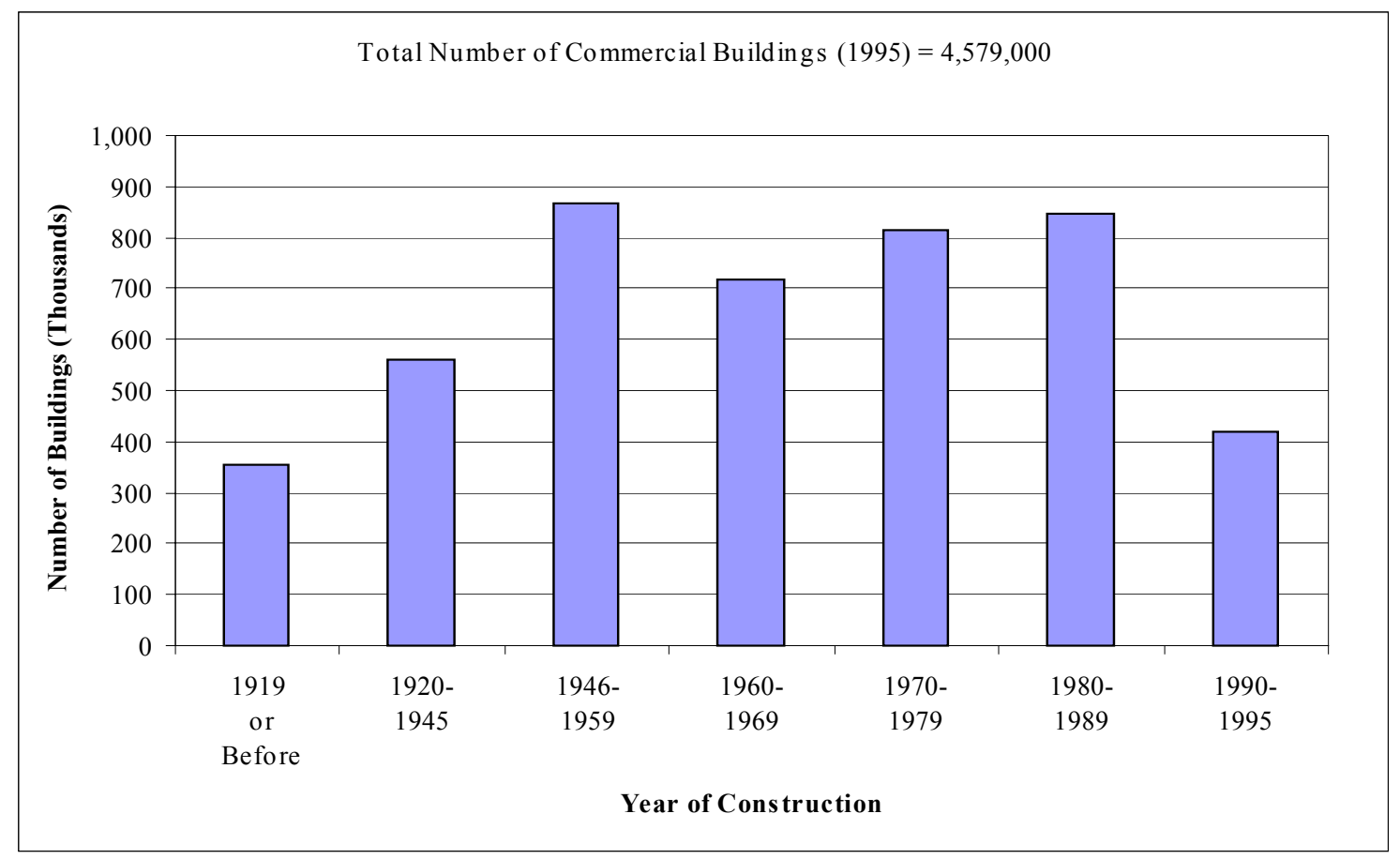

Figure 4-7. Total Commercial Floorspace by Year of Construction: 1995

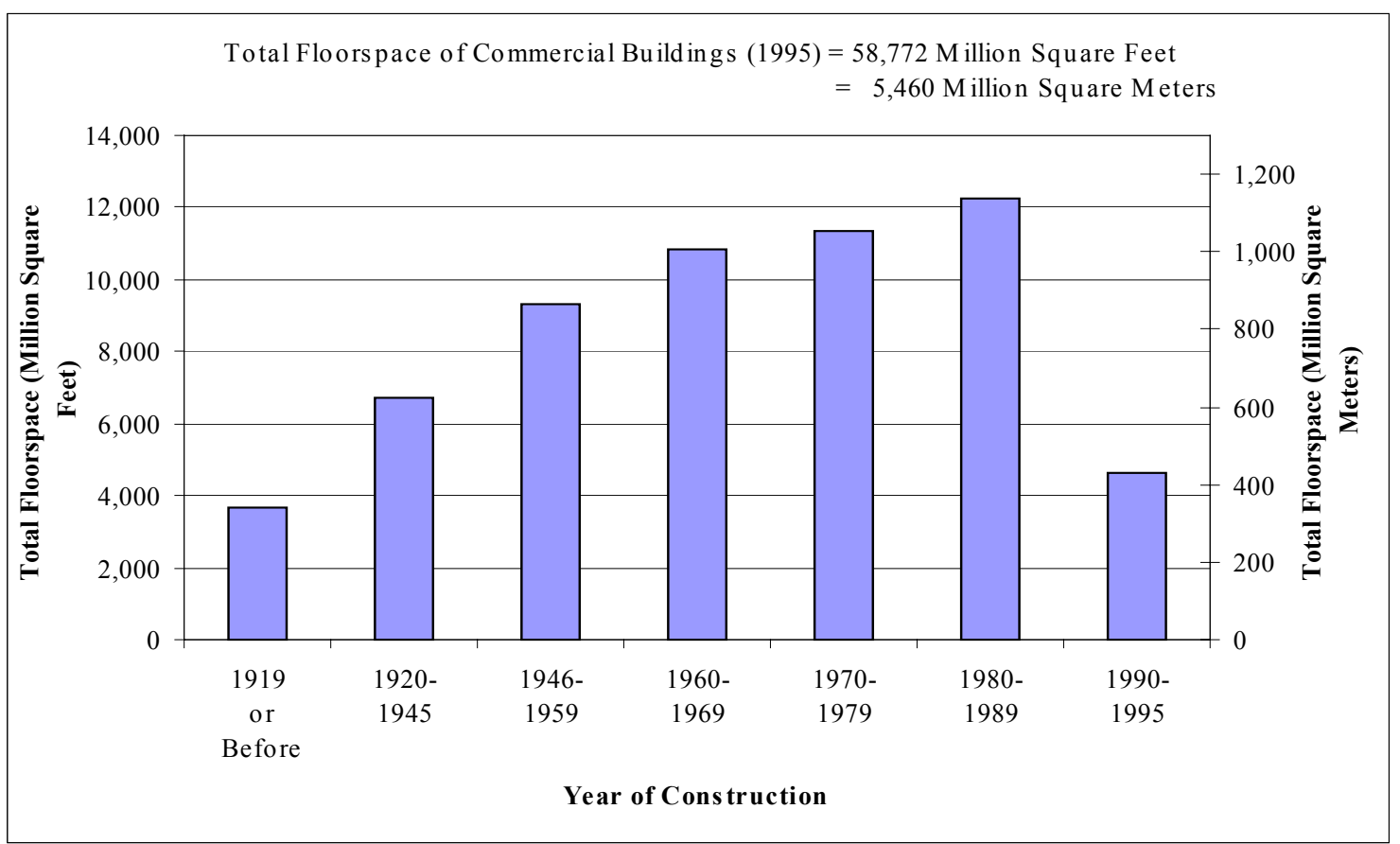


Figure 4-8. Total Commercial Floorspace by Year of Construction and Number of Floors: 1995

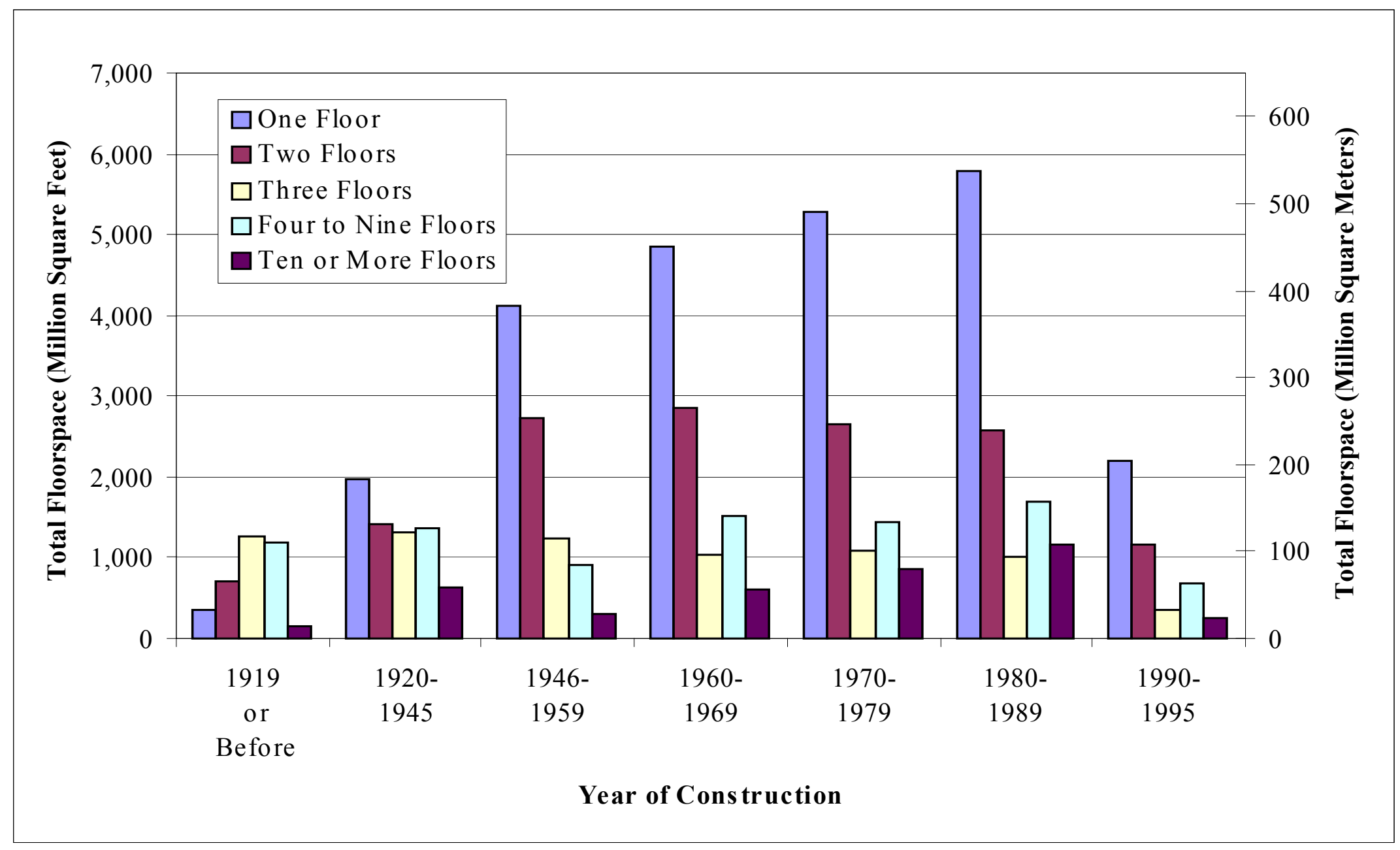


Figure 4-7 records the distribution of floorspace by year of construction. Note that approximately $75 \%$ of the total floorspace was constructed between 1946 and 1989 . Approximately $18 \%$ of the building stock was constructed prior to 1946 . As clearly shown in Figure 4-7, the amount of floorspace by year of construction increases from 1919 through 1989.

Figure 4-8 introduces information on the number of floors. As shown in Figure 4-8, commercial buildings were constructed mainly with one and two floors during the 1946 to 1989 time period. The number of commercial buildings with one floor shows a tendency to increase during this same time period. The floorspace of commercial buildings with one floor is almost double the floorspace of commercial buildings with two floors. Total floorspace in commercial buildings having ten or more floors tends to increase from 1946 through 1989. Figure 4-8 shows that a large proportion of commercial buildings constructed prior to 1920 were built with three to nine floors.

The material presented in this section demonstrated several ways in which the nation's 5.46 billion $\mathrm{m}^{2}$ ( 58.77 billion $\left.\mathrm{ft}^{2}\right)$ of commercial floorspace can be characterized. This section's approach to characterizing the market for FIAPP-related products and services and detailing the market in terms of total floorspace of large commercial buildings, those whose floor area exceeds $4,645 \mathrm{~m}^{2}\left(50,000 \mathrm{ft}^{2}\right)$, sets the stage for the impact assessment. These buildings account for 2.38 billion $\mathrm{m}^{2}\left(25.61\right.$ billion $\left.\mathrm{ft}^{2}\right)$ or approximately $44 \%$ of the nation's commercial floorspace. By focusing on total floorspace of large commercial buildings as the potential target market, the calculation of FIAPP-related costs and benefits is driven by floorspace-related considerations. This is fortuitous because the commercial sector of the construction industry is geared towards processing information presented in terms of per unit costs (e.g., $\$ / \mathrm{m}^{2}$ or $\left.\$ / \mathrm{ft}^{2}\right)$. As a consequence, most published information on commercial construction expenditures for facility construction, for maintenance and repair activities, and for energy is presented on a per unit basis. 


\section{Strategy for Identifying, Collecting, and Measuring FIAPP-Related Benefits and Costs}

The strategy outlined in this chapter was developed through an iterative process. First, information was solicited from members of the BFRL CONSIAT team. This information was used to develop candidate lists of key stakeholder classes (e.g., building owners) and general types of FIAPP-related benefits and costs. Second, the lists were refined and organized into a suite of "classification" hierarchies. Third, the classification hierarchies were distributed to each of the BFRL CONSIAT project leaders and, upon their review of the classification hierarchies, critiqued in a series of meetings with the project leaders. The meetings with the BFRL CONSIAT project leaders also sought to identify subject matter experts for follow-on discussions. Finally, subject matter experts from industry and government were interviewed. These interviews were used to finalize the analysis strategy and the classification hierarchies presented in this chapter as well as to collect information on current industry practices and to identify additional data sources.

\subsection{Identification of Key Stakeholders}

Because individual stakeholders are affected in different ways by the introduction, adoption, and use of FIAPP products and services, it is useful to first identify classes of individual stakeholders and then classify them into stakeholder groups. By developing a classification hierarchy of stakeholders, we are better able to understand and identify both potential opportunities (i.e., real or perceived benefits and cost savings accruing to that stakeholder) and potential barriers (i.e., real or perceived additional costs and benefit reductions borne by that stakeholder) to the adoption of FIAPP products and services.

Since individual stakeholder classes evaluate the benefits and costs of FIAPP products and services purely from their "stakeholder" viewpoint, it is important to reflect not only that viewpoint, but the viewpoints of aggregations of stakeholder classes (i.e., a single stakeholder group or a collection of stakeholder groups) and all stakeholder groups as well. The viewpoint of the individual stakeholder is important because they make the decision of whether or not to invest in FIAPP products and services. Examples of individual stakeholder classes are building owners, engineering consultants, and trade associations. A single stakeholder group is a special aggregation of individual stakeholders classified according to a common theme. An example of a stakeholder group is construction and associated support services. This stakeholder group contains five classes of individual stakeholders: construction workers, general contractors, specialty trade contractors, trade associations, and wholesale/retail trade/supply. A collection of stakeholder groups is important because an individual stakeholder class may be a key player in several stakeholder groups. The overall picture (i.e., all stakeholder groups) is important because it reflects the benefits and costs of FIAPP products and services to society. BFRL's assessment of FIAPP-related impacts is undertaken from society's frame of reference. Thus, it includes all benefits and costs to whomsoever they accrue. 
Tables 5-1 and 5-2 identify the classes of individual stakeholders and the corresponding stakeholder group(s) used in the assessment of FIAPP-related benefits and costs. Both tables provide the same information, but are organized in different ways.

Table 5-1 is a hierarchy of stakeholders; it lists stakeholder groups with their corresponding classes of individual stakeholders. It shows how the stakeholder groups are formed. In Table 5-1, the six stakeholder groups are listed in a bold-italics typeface. The classes of individual stakeholders are listed in alphabetical order beneath each stakeholder group.

Table 5-2 is arranged as a checklist; it assigns each of the 31 classes of individual stakeholders to its corresponding stakeholder group(s). Table 5-2 lists the classes of individual stakeholders in alphabetical order to facilitate cross-referencing of individual stakeholders and stakeholder groups. Note that an individual stakeholder class may be associated with more than one stakeholder group. For example, trade associations are associated with three stakeholder groups.

The analysis conducted in this report encompasses all stakeholder groups. However, if analyses from the perspective of a single stakeholder or stakeholder group were desired, Tables 5-1 and 5-2 could be used to structure these analyses (see Section 5.4). In such cases, either Table 5-1 or Table 5-2 may be used to select which class (classes) of individual stakeholders is (are) appropriate.

\subsection{Classification of FIAPP-Related Benefits and Cost Savings}

Stakeholders invest in FIAPP products and services because they anticipate receiving, in present value terms, benefits or cost savings in excess of the costs or benefit reductions associated with these investments. Table 5-3 provides a framework for one side of the stakeholders investment decision problem. Namely, how to identify FIAPP-related benefits and cost savings from society's frame of reference (i.e., across all stakeholder groups).

Table 5-3 is organized as a three-tiered hierarchy. Table 5-3 represents the culmination of the Office of Applied Economics CONSIAT project team's efforts to produce a consensus on a comprehensive list of FIAPP-related benefits and cost savings.

The first tier of the hierarchy lists generic types of FIAPP-related benefits and cost savings. Although the types of benefits and cost savings appearing in the first tier are generic, the list is considered to be exhaustive. In addition, the generic types of benefits and cost savings listed in the first tier are considered to be self-evident. The 15 first tier elements are listed in a bold-italics typeface. Examples of first tier benefits and cost savings are increased/new sales for system design/integration/optimization services, lower first costs, and lower operations and maintenance costs. 
Table 5-1. Hierarchy of FIAPP Stakeholders by Groups and Classes of Individual FIAPP Stakeholders

\section{Building Owners and Managers}

- Building Managers

- Building Owners

Codes, Standards, and Support Services

- Building Owners

- Building Permitting and Inspection

- Code Officials

- Code Organizations

- Construction Products/Equipment Manufacturers

- Professional Societies

- Product Certification Services

- Product Evaluation Services

- Research Organizations

- Standards Organizations

- Trade Associations

\section{Construction and Associated Support Services}

- Construction Workers

- General Contractors

- Specialty Trade Contractors

- Trade Associations

- Wholesale/Retail Trade/Supply

\section{Other}

- Building Occupants

- Special Interest Groups

- Third Parties

\section{Manufacturing Interest Group}

- Construction Products/Equipment Manufacturers

- Customer Service Operations

- Product/Equipment/Software Designers

- Product/Equipment/Software Innovators

- Product/Equipment/Software Marketing, Sales, and Distribution Services

- Professional Societies

- Research Organizations

- Testing Laboratories

- Testing Services

- Trade Associations

\section{Professional and Financial Services}

- Architects

- Designers

- Engineering Consultants

- Insurance Companies

- Investment Banking Services

- Warranty Companies 
Table 5-2. Assignment of Classes of Individual FIAPP Stakeholders to FIAPP Stakeholder Groups

\begin{tabular}{|c|c|c|c|c|c|c|}
\hline \multirow[b]{2}{*}{ Individual Stakeholder Class } & \multicolumn{6}{|c|}{ Stakeholder Group } \\
\hline & $\begin{array}{c}\text { Building } \\
\text { Owners \& } \\
\text { Managers }\end{array}$ & $\begin{array}{c}\text { Codes, } \\
\text { Standards, \& } \\
\text { Support } \\
\text { Services }\end{array}$ & $\begin{array}{l}\text { Manufacturing } \\
\text { Interest Group }\end{array}$ & $\begin{array}{l}\text { Construction } \\
\text { \& Associated } \\
\text { Support } \\
\text { Services }\end{array}$ & $\begin{array}{c}\text { Professional } \\
\text { \& Financial } \\
\text { Services }\end{array}$ & Other \\
\hline Architects & & & & & $\checkmark$ & \\
\hline Building Managers & $\checkmark$ & & & & & \\
\hline Building Occupants & & & & & & $\checkmark$ \\
\hline Building Owners & $\checkmark$ & $\checkmark$ & & & & \\
\hline $\begin{array}{l}\text { Building Permitting and } \\
\text { Inspection }\end{array}$ & & $\checkmark$ & & & & \\
\hline Code Officials & & $\checkmark$ & & & & \\
\hline Code Organizations & & $\checkmark$ & & & & \\
\hline $\begin{array}{l}\text { Construction Products/Equipment } \\
\text { Manufacturers }\end{array}$ & & $\checkmark$ & $\checkmark$ & & & \\
\hline Construction Workers & & & & $\checkmark$ & & \\
\hline Customer Service Operations & & & $\checkmark$ & & & \\
\hline Designers & & & & & $\checkmark$ & \\
\hline Engineering Consultants & & & & & $\checkmark$ & \\
\hline General Contractors & & & & $\checkmark$ & & \\
\hline Insurance Companies & & & & & $\checkmark$ & \\
\hline Investment Banking Services & & & & & $\checkmark$ & \\
\hline Product Certification Services & & $\checkmark$ & & & & \\
\hline $\begin{array}{l}\text { Product/Equipment/Software } \\
\text { Designers }\end{array}$ & & & $\checkmark$ & & & \\
\hline
\end{tabular}


Table 5-2. Assignment of Classes of Individual FIAPP Stakeholders to FIAPP Stakeholder Groups (Continued)

\begin{tabular}{|l|c|c|c|c|c|c|}
\hline \multirow{2}{*}{ Individual Stakeholder Class } & \multicolumn{5}{c|}{ Stakeholder Group } \\
\cline { 2 - 7 } & $\begin{array}{c}\text { Building } \\
\text { Owners \& } \\
\text { Managers }\end{array}$ & $\begin{array}{c}\text { Codes, } \\
\text { Standards, } \\
\text { Support } \\
\text { Services }\end{array}$ & $\begin{array}{c}\text { Manufacturing } \\
\text { Interest Group }\end{array}$ & $\begin{array}{c}\text { Construction } \\
\text { \& Associated } \\
\text { Support } \\
\text { Services }\end{array}$ & $\begin{array}{c}\text { Professional } \\
\text { \& Financial } \\
\text { Services }\end{array}$ & Other \\
\hline $\begin{array}{l}\text { Product/Equipment/Software } \\
\text { Innovators }\end{array}$ & & $\checkmark$ & $\checkmark$ & & & \\
\hline $\begin{array}{l}\text { Product/Equipment/Software } \\
\text { Marketing, Sales, and } \\
\text { Distribution Services }\end{array}$ & & & & & & \\
\hline Product Evaluation Services & & $\checkmark$ & & & & \\
\hline Professional Societies & & $\checkmark$ & $\checkmark$ & & & $\checkmark$ \\
\hline Research Organizations & & & & & & \\
\hline Special Interest Groups & & $\checkmark$ & & & & \\
\hline Specialty Trade Contractors & & & $\checkmark$ & & & \\
\hline Standards Organizations & & & $\checkmark$ & & & $\checkmark$ \\
\hline Testing Laboratories & & & & & & \\
\hline Testing Services & & & & & & \\
\hline Third Parties & & & & $\checkmark$ & & $\checkmark$ \\
\hline Trade Associations & & & & & \\
\hline Warranty Companies & & & & & \\
\hline Wholesale/Retail Trade/Supply & & & & & \\
\hline
\end{tabular}


Table 5-3. FIAPP-Related Benefits (or Cost Savings) for All Stakeholders

Improved Company Capabilities and Flexibility for New Project Opportunities

- Access to Live Data Stream from Construction Site Allows Construction Management to be Conducted Remote from the Job Site

- Automated Generation of Material Orders and Payments

- Pre-Programming and Simulating the Following Day's Activities for Optimum Efficiency

- Tele-Present Machine Operation Allows for Remote Operation of Machinery

Improved Feedback Mechanisms on Performance of New Tools and Processes

Increased/New Sales for System Design/Integration/Optimization Services

- Automated Construction Machine Maintenance and Fleet Management

- Automated Construction Machine Programming and Task Execution

- Construction Simulation/Visualization

- Facility Operations

- Materials Management, Tracking, and Scheduling

Increased Net Income for Contractors

- Better Control of Cost Growth

- Better Design Evaluation and Checking

- Better Document Control

- Better Materials Management

- Better Scheduling of Construction-Site Operations

- Improvements in Productivity

- Smoother Start-Up Operations

Increased Revenues Due to Earlier Start-Up of Primary Functions

- Earlier Revenue Stream from Sale of Products/Services

- Faster Return on Investment

Increased Sales of Selected Product/Equipment Lines and Associated Services

Increased Sales of Construction Products/Equipment/Services with New Features 
Table 5-3. FIAPP-Related Benefits (or Cost Savings) for All Stakeholders (Continued)

Lower First Costs

- Better Control of Cost Growth

- Earlier Bill of Materials and Procurement Analysis Reduces Risks of Non-Availability of Parts

- Fewer Project Development and Scope Changes

- Less Design Rework

- Less Field Rework

- Better Component Selection Process

- Better Design Evaluation and Checking

- Better Document Control

- Better Materials Management

- Better Scheduling of Construction-Site Operations

- Early Payment on Bill of Materials Gets Discount Price

- Lower Financing Costs Due to Earlier Start-Up of Primary Functions

- Optimization of Project Team and Plan

- Better Coordination Between Owner, Prime Contractor, and Subcontractors

- Better Opportunity for Supply Chain Management

- Earlier Optimization of Design and Project Plan

- Improved Procurement, Supply, and Contractor Management

- Smoother Start-Up Operations

\section{Lower Operations and Maintenance Costs}

- Availability of Electronic "As Built” Information Saves Time in TroubleShooting Maintenance Problems

- Availability of Online Information on the Building's Characteristics Promotes Use of Fact-Based Operations and Maintenance Programs

- Facilitates Cross-Training of Support Staff for Multi-Building Operations

- Improvements in Compliance Monitoring

- Increased Functionality and Performance

- Reduced Down Time

- Use of On-Part Information Systems (RFID) Reduces Certification and Calibration Costs 
Table 5-3. FIAPP-Related Benefits (or Cost Savings) for All Stakeholders (Continued)

Lower Repair, Replacement, and Decommissioning Costs

- Availability of Electronic "As Built" Information Enables Faster Response to and Resolution of Many Repair Problems

- Availability of Electronic "As Built" Information Reduces the Costs of Addition and Modernization Projects

- Availability of Electronic "As Built" Information Reduces the Costs of Decommissioning "Out-of-Date" Plant and Equipment

- Longer Equipment Life Due to Better Operating Conditions

- On-Part Information Systems (RFID) Identify “Generic" Replacement Components and Sources

- Reduced Down Time

- Use of Electronic Data Interchange Promotes Faster Delivery of "Out-ofStock" Parts

\section{Reductions in Construction-Related Accidents and Injuries}

- Availability of Electronic “As Built” Information Increases Safety During Normal Operations and Emergency Situations

- Fewer Lost Workdays

- Fewer Recordable Incidents

- Improved Safety Through Automated Tracking and Event Logging

- Fewer Machine-Worker Accidents

- Identification of High-Risk Employees

- Identification of High-Risk Machinery

- Less Down Time

- Lower Medical Costs

- Lower Workman's Compensation Insurance Premiums

Reductions in Costs of Code Compliance Due to New Ways of Designing, Constructing, and Maintaining Buildings

- New Ways of Communicating With Code Officials

- Automated Inspection Requests

- New Ways of Demonstrating Code Compliance

- Pre-Certified Automated Procedures

- Remote Certification (Tele-Presence Inspection)

- New Ways of Demonstrating Operating Compliance

- Autonomous Remote Sensing to Code Official 
Table 5-3. FIAPP-Related Benefits (or Cost Savings) for All Stakeholders (Continued)

\section{Reductions in Delivery Time}

- Better Control of Schedule Growth

- Automated Field Inspection Reports

- Automated Utility Avoidance

- Fewer Project Development and Scope Changes

- Less Design Rework

- Less Field Rework

- Earlier Bill of Materials and Procurement Analysis Reduces Risks of Non-Availability of Parts

- Better Document Control

- Automated Updates of As-Built Information

- Better Scheduling of Construction-Site Operations

- Dynamic Database Allows for Identification of Non-Obvious Critical Path Activities and Automated Rescheduling

- New Ideas/Task Sequencing Can be Explored with 3D Simulations

- Output of 3D Simulations Can be Used to Drive Machinery for Automated Processes

- Earlier Start-Up of Primary Functions

- Faster Task Completion

- Ability to Employ Automated Processes and "Measureless" Construction

- Automated Tracking of Parts and Processes

- Optimization of Project Team and Plan

- Better Coordination Between Owner, Prime Contractor, and Subcontractors

- Better Opportunity for Supply Chain Management

- Earlier Optimization of Design and Project Plan

- Improved Procurement, Supply, and Contractor Management

- Smoother Start-Up Operations

Reductions in Warranty Costs

Reductions in Waste and Pollution 
The second tier lists specific types of benefits and cost savings associated with its "parent" first tier element. The second tier elements are listed in alphabetical order as a series of bullets under the parent first tier element. An example of a second tier element for lower first costs is better control of cost growth. Not all generic types of benefits and cost savings have a second tier (e.g., reductions in warranty costs).

The third tier lists specific types of benefits and cost savings associated with its "parent" second tier element. The third tier elements are listed in alphabetical order as a series of bullets under the parent second tier element. Two of the third tier elements, fewer project development and scope changes and less field rework, are concerned with better control of cost growth. These cost savings are of central importance to BFRL and its industry collaborators.

The classification hierarchy presented as Table 5-3 has been limited to three tiers. Because Table 5-3 and Table 5-4 (see Section 5.3) are used to measure the "benefits" and "costs" sides of FIAPP-related impacts, the end product of these classification hierarchies is a collection of economic data. In the case of FIAPP-related benefits and cost savings, the depth of the hierarchy (i.e., the number of tiers) is equal to three. In principle, the depth of these data-related classification hierarchies could be equal to one, two, three, or some number greater than three. The rule governing the depth of the hierarchy is how far down in the hierarchy one must go until all lowest level elements in the hierarchy are indicative of economic data. For FIAPP-related benefits and cost savings, three tiers were considered adequate.

It is important to recognize that the benefits and cost savings listed in Table 5-3 might accrue to any individual stakeholder (i.e., they are aggregated according to society's frame of reference). Thus, Table 5-3 is structured from "society's" frame of reference rather than from the perspective of a single stakeholder or stakeholder group. The main purpose of Table 5-3 is to illustrate how BFRL approaches the assessment of the "benefits" side of FIAPP-related impacts. Specifically, BFRL used this table to identify the data needed to measure these impacts. For the impact assessment presented in this report, Table 5-3 identifies the potential "benefits" data links. However, if the focus is on an individual stakeholder or stakeholder group, it will be necessary to develop a crosswalk between the generic types of benefits and cost savings listed in Table 5-3 and the stakeholder groups listed in Table 5-1. This crosswalk is the subject of Section 5.4.

\subsection{Classification of FIAPP-Related Cost Increases and Benefit Reductions}

Costs are at the heart of any investments in new products. ${ }^{33}$ For the CONSIAT economic impact assessment, costs are incurred at several points in the "product" life cycle. Specifically, FIAPP-related costs include research costs, product development costs, production costs, dissemination costs, and installation costs. In addition, a particular vendor may experience benefit reductions due to reduced sales of some of its more

\footnotetext{
${ }^{33}$ The word product is used generically to represent technologies, hardware (e.g., building systems, subsystems, components, piece parts, and support equipment), software, and services.
} 
"traditional" products. These cost increases and benefit reductions are summarized in Table 5-4; they are organized as a three-tiered hierarchy.

The first tier of the hierarchy lists generic types of FIAPP-related cost increases and benefit reductions. The list is considered to be exhaustive and self-evident. The six first tier elements are listed in a bold-italics typeface. Examples of first tier cost increases and benefit reductions are increased costs for new standards development, increased investments by construction products/equipment manufacturers and hardware/software developers, and new-technology introduction costs.

The last element, new-technology introduction costs, merits a closer examination. Ehlen and Marshall ${ }^{34}$ define new-technology introduction costs as those costs covering the activities that bring the material/product from the research laboratory to full field implementation. New-technology introduction costs include the extra time and labor to design, test, monitor, and use the new technology. Ehlen's and Marshall's research on new-technology introduction costs is particularly relevant for this economic impact assessment because they demonstrate that new-technology introduction costs disappear once the designer is satisfied with the technology's performance and service life, the technology enters full implementation, and its application has become routine. ${ }^{35}$

The second tier lists specific types of cost increases and benefit reductions associated with its "parent" first tier element. The second tier elements are listed in alphabetical order as a series of bullets under the parent first tier element. One example of a second tier element for increased investments by construction products/equipment manufacturers is increased research and development costs. Another example of a second tier element for new-technology introduction costs is increased training costs. Not all generic types of costs and benefit reductions have a second tier (i.e., increased costs for new standards development and reduced sales of selected product/equipment lines and associated services).

The third tier elements are concerned with increased research and development costs and with two of the four second tier elements for new-technology introduction costsincreased marketing, advertising, and distribution costs by construction products/ equipment manufacturers and hardware/software developers and increased training costs. The costs associated with these three second tier elements are of central importance to both BFRL and its industry collaborators. Consequently, it was desirable to increase the depth of the FIAPP-related costs and benefit reductions classification hierarchy to three. Information on increased research and development costs is presented and discussed in Section 6.3.2.1. Examples of increased research and development costs are increased costs for product development and increased costs for product testing/simulation. Information on new-technology introduction costs is presented and discussed in Section 6.3.2.2.

\footnotetext{
${ }^{34}$ Ehlen, Mark A., and Harold E. Marshall. 1996. The Economics of New-Technology Materials: A Case Study of FRP Bridge Decking. NISTIR 5864. Gaithersburg, MD: National Institute of Standards and Technology.

${ }^{35}$ Ibid., p. 15.
} 
Table 5-4. FIAPP-Related Cost Increases (or Benefit Reductions) for All Stakeholders

Increased Costs for New Standards Development

Increased Costs of Hardware and Software Installation to Provide

Infrastructure Support

- Additional Construction-Site Systems Infrastructure Needed to Monitor and Control Systems and Components

- Additional Information Technology Costs for Program Management and Procurement

- Increased Costs of Installing Hardware and Software for Use by Building Owners and Managers

- Increased Costs of Installing Hardware and Software in Building Code Offices

- Increased Costs to Modify the Current Inspection/Certification Process to Accommodate New Hardware/Software Capabilities

Increased Costs to Properly Maintain Hardware and Software

- Additional Costs Associated with Parts Replacement and Software Upgrades

- Additional Costs Associated with Periodic Calibration and Certification of New Technology Products

- Additional Costs to Insure that the Current Information Transfer Protocols Are Being Used

- Additional Costs to Insure that the Hardware and Software Incorporate the Most Recent Set of Building Code Information

\section{Increased Investments by Construction Products/Equipment Manufacturers}

and Hardware/Software Developers

- Additional Costs for New Intellectual/Material Inputs

- Conversion Costs for Installing New Production Processes in Existing Facilities

- Increased Costs for Copyright/Trademark Registration/Defense

- Increased Research and Development Costs

- Increased Costs for Product Development

- Increased Costs for Product Testing/Simulation 
Table 5-4. FIAPP-Related Cost Increases (or Benefit Reductions) for All Stakeholders (Continued)

\section{New-Technology Introduction Costs}

- Increased Costs of Adapting New Construction Technologies, Products, Equipment, and Practices to Industry Use

- Increased Marketing, Advertising, and Distribution Costs by Construction Products/Equipment Manufacturers and Hardware/Software Developers

- Increased Costs Associated with Market Positioning Efforts

- Increased Costs to Develop New Distribution and Service Channels

- Intermediate Requirement to Maintain Redundant Services and Distribution Channels

- Increased Risk Exposure and Uncertainty Due to Construction with New Technologies, Products, Equipment, or Practices

- Increased Training Costs

- Increased Costs for Instruction on How to Incorporate New Technologies, Products, Equipment, and Practices into the Design Process

- Increased Costs for Training Building Owners and Managers on New Operations and Maintenance Processes and Techniques

- Increased Costs for Training Construction Workers on New Construction Processes and Techniques

- Increased Costs for Training Public Officials on Hardware/Software Capabilities

Reduced Sales of Selected Product/Equipment Lines and Associated Services 


\subsection{How FIAPP-Related Benefits and Costs Accrue to Stakeholders}

Recall that BFRL's assessment of FIAPP-related impacts is undertaken from society's frame of reference. Thus, it includes all benefits and costs to whomsoever they accrue. Although this is the traditional approach for public-sector economic impact studies, it is too broad for most stakeholder groups. This is because most stakeholder groups want to evaluate the pros and cons of "their" investments in FIAPP products and services. In addition, the traditional approach employed in public-sector studies complicates the data collection effort. Basically, the higher the level of abstraction, the more difficult it becomes to define data "categories" and collect the types of data that lead to meaningful results. Consequently, this study develops crosswalks between stakeholder groups and FIAPP-related benefits and cost savings and FIAPP-related cost increases and benefit reductions. The two crosswalks are presented as Table 5-5 and Table 5-6. Table 5-5 lists key types of benefits and cost savings by stakeholder group; Table 5-6 lists key types of costs and benefit reductions by stakeholder group.

The two crosswalks serve three purposes. First, they define in an unambiguous manner all of the potential data categories from which to collect economic data. In fact, each data category may be specified as a unique combination of stakeholder group and type of benefit or type of cost. Second, the crosswalks promote a priority-setting process for identifying what specific types of data to collect and where to collect them. For example, if we know that two stakeholder groups - building owners and managers and professional and financial services - are beneficiaries of lower operations and maintenance costs (see the cells beneath the "stakeholder group" column headings in Table 5-5 with check marks $(\checkmark)$ ), then we can focus our "operations and maintenance cost" data collection effort on these two stakeholder groups. Thus, the data collection strategy, stated in its simplest terms, is to limit the data collection effort to those cells of Table 5-5 and Table 5-6 with check marks $(\checkmark)$. This priority-setting approach to data collection is employed throughout the next three chapters. Finally, the crosswalks provide the means through which an individual stakeholder or stakeholder group may evaluate the pros and cons of investing in FIAPP products and services. Thus, the crosswalks not only greatly simplify the current economic impact assessment they also provide the framework for identifying key data elements and for specifying a data collection strategy for individual stakeholders.

The third purpose of the crosswalks is best understood by considering a specific stakeholder group, say building owners and managers. If building owners and managers are considering investing in a specific FIAPP product versus a traditional product, they need to know if the life-cycle cost over the proposed study period of the FIAPP product is less than that of the traditional product.

The first step in this "decision problem" is to identify the types of benefits and the types of costs. The "benefits" accruing to and the "costs" borne by building owners and managers are recorded in the first "stakeholder group" column of Tables 5-5 and 5-6, 
respectively. Reference to Table 5-5 shows that building owners and managers benefit from all but six of the 15 types of benefits and cost savings. Examples of specific types of benefits and cost savings accruing to building owners and managers are lower first costs, lower operations and maintenance costs, and reductions in delivery time. Reference to Table 5-6 shows that building owners and managers bear four types of increased costs. They are the costs associated with new standards development, increased costs of hardware and software to provide infrastructure support, increased costs to properly maintain hardware and software, and new-technology introduction costs. The second step is to compile a list of the types of benefits and the types of costs for which data are available and are relevant (i.e., data that allow comparisons between the products being considered). The third step is to collect the economic data. The economic data collected in the third step are used to support a life-cycle cost analysis of the products being considered. Finally, evaluate the economic performance of each product being considered. This is done by calculating the life-cycle cost for each product and selecting the one that minimizes the life-cycle cost over the proposed study period.

The same procedure can be used for an individual stakeholder class. First, select the individual stakeholder class. Then, refer to Table 5-2 to identify the appropriate stakeholder group(s). Finally, follow the procedure just described to determine whether or not that stakeholder should invest in the FIAPP product under consideration. 
Table 5-5. Types of FIAPP-Related Benefits (or Cost Savings) Classified by Stakeholder Group

\begin{tabular}{|c|c|c|c|c|c|c|}
\hline \multirow[b]{2}{*}{$\begin{array}{l}\text { Type of Benefit or } \\
\text { Cost Saving }\end{array}$} & \multicolumn{6}{|c|}{ Stakeholder Group } \\
\hline & $\begin{array}{l}\text { Building } \\
\text { Owners \& } \\
\text { Managers }\end{array}$ & $\begin{array}{l}\text { Codes, } \\
\text { Standards, \& } \\
\text { Support } \\
\text { Services } \\
\end{array}$ & $\begin{array}{l}\text { Manufacturing } \\
\text { Interest Group }\end{array}$ & $\begin{array}{l}\text { Construction } \\
\text { \& Associated } \\
\text { Support } \\
\text { Services } \\
\end{array}$ & $\begin{array}{c}\text { Professional } \\
\text { \& Financial } \\
\text { Services }\end{array}$ & Other \\
\hline $\begin{array}{l}\text { Improved Company Capabilities and } \\
\text { Flexibility for New Project Opportunities }\end{array}$ & & & $\checkmark$ & $\checkmark$ & $\checkmark$ & \\
\hline $\begin{array}{l}\text { Improved Feedback Mechanisms on } \\
\text { Performance of New Tools and Processes }\end{array}$ & & & $\checkmark$ & $\checkmark$ & $\checkmark$ & \\
\hline $\begin{array}{l}\text { Increased/New Sales for System Design/ } \\
\text { Integration/Optimization Services }\end{array}$ & & & $\checkmark$ & $\checkmark$ & $\checkmark$ & \\
\hline Increased Net Income for Contractors & & & & $\checkmark$ & $\checkmark$ & \\
\hline $\begin{array}{l}\text { Increased Revenues Due to Earlier Start-Up } \\
\text { of Primary Functions }\end{array}$ & $\checkmark$ & & & & & \\
\hline $\begin{array}{l}\text { Increased Sales of Selected Product/ } \\
\text { Equipment Lines and Associated Services }\end{array}$ & & & $\checkmark$ & $\sqrt{ }$ & $\sqrt{ }$ & \\
\hline $\begin{array}{l}\text { Increased Sales of Construction Products/ } \\
\text { Equipment/Services with New Features }\end{array}$ & & $\checkmark$ & $\checkmark$ & $\checkmark$ & $\checkmark$ & \\
\hline Lower First Costs & $\checkmark$ & $\checkmark$ & $\checkmark$ & $\checkmark$ & $\checkmark$ & \\
\hline Lower Operations and Maintenance Costs & $\checkmark$ & & & & $\checkmark$ & \\
\hline $\begin{array}{l}\text { Lower Repair, Replacement, and } \\
\text { Decommissioning Costs }\end{array}$ & $\checkmark$ & & $\checkmark$ & $\checkmark$ & $\checkmark$ & \\
\hline $\begin{array}{l}\text { Reductions in Construction-Related Accidents } \\
\text { and Injuries }\end{array}$ & $\checkmark$ & & & $\checkmark$ & $\checkmark$ & $\checkmark$ \\
\hline $\begin{array}{l}\text { Reductions in Costs of Code Compliance Due } \\
\text { to New Ways of Designing, Constructing, and } \\
\text { Maintaining Buildings }\end{array}$ & $\sqrt{ }$ & $\sqrt{ }$ & $\checkmark$ & $\sqrt{ }$ & $\sqrt{ }$ & $\checkmark$ \\
\hline Reductions in Delivery Time & $\checkmark$ & $\checkmark$ & $\checkmark$ & $\checkmark$ & $\checkmark$ & $\checkmark$ \\
\hline Reductions in Warranty Costs & $\checkmark$ & & $\checkmark$ & $\checkmark$ & & \\
\hline Reductions in Waste and Pollution & $\checkmark$ & & $\checkmark$ & $\checkmark$ & & $\checkmark$ \\
\hline
\end{tabular}


Table 5-6. Types of FIAPP-Related Cost Increases (or Benefit Reductions) Classified by Stakeholder Group

\begin{tabular}{|c|c|c|c|c|c|c|}
\hline \multirow[b]{2}{*}{$\begin{array}{l}\text { Type of Cost Increase or } \\
\text { Benefit Reduction }\end{array}$} & \multicolumn{6}{|c|}{ Stakeholder Group } \\
\hline & $\begin{array}{c}\text { Building } \\
\text { Owners \& } \\
\text { Managers } \\
\end{array}$ & $\begin{array}{c}\text { Codes, } \\
\text { Standards, \& } \\
\text { Support } \\
\text { Services } \\
\end{array}$ & $\begin{array}{l}\text { Manufacturing } \\
\text { Interest Group }\end{array}$ & $\begin{array}{c}\text { Construction } \\
\text { \& Associated } \\
\text { Support } \\
\text { Services } \\
\end{array}$ & $\begin{array}{c}\text { Professional } \\
\text { \& Financial } \\
\text { Services }\end{array}$ & Other \\
\hline $\begin{array}{l}\text { Increased Costs for New Standards } \\
\text { Development }\end{array}$ & $\checkmark$ & $\checkmark$ & $\checkmark$ & $\checkmark$ & $\checkmark$ & $\checkmark$ \\
\hline $\begin{array}{l}\text { Increased Costs of Hardware and Software to } \\
\text { Provide Infrastructure Support }\end{array}$ & $\checkmark$ & $\sqrt{ }$ & & $\checkmark$ & $\checkmark$ & \\
\hline $\begin{array}{l}\text { Increased Costs to Properly Maintain } \\
\text { Hardware and Software }\end{array}$ & $\checkmark$ & $\checkmark$ & $\checkmark$ & $\checkmark$ & $\checkmark$ & \\
\hline $\begin{array}{l}\text { Increased Investments by Construction } \\
\text { Products/Equipment Manufacturers }\end{array}$ & & & $\checkmark$ & & & \\
\hline New-Technology Introduction Costs & $\checkmark$ & $\checkmark$ & $\checkmark$ & $\sqrt{ }$ & $\checkmark$ & $\checkmark$ \\
\hline $\begin{array}{l}\text { Reduced Sales of Selected Product Lines and } \\
\text { Services }\end{array}$ & & & $\checkmark$ & $\checkmark$ & $\checkmark$ & $\checkmark$ \\
\hline
\end{tabular}




\section{Data and Assumptions for the CONSIAT Economic Impact Assessment}

This chapter describes the data and assumptions used to evaluate the economic impacts expected from the adoption and use of FIAPP products and services in commercial buildings. The goal of this chapter is fourfold. First, it establishes the sources and validity of the data used in the CONSIAT economic impact assessment. Second, it defines the base case and the FIAPP alternative. Third, it produces estimated values for key sets of benefits and costs. Fourth, it documents the process by which key assumptions were established, including how the values of key parameters were set.

\subsection{Data Sources}

Establishing the sources and validity of the data used in the CONSIAT economic impact assessment is essential if readers are to be able to follow the analysis, gain insights useful for their own applications, and reproduce our results. This section describes the three groups of data upon which the economic impact assessment is based. The material presented in this section is intended to establish an audit trail which readers can follow to gain access to the same information used in the CONSIAT economic impact assessment.

\subsubsection{Baseline Measures of Construction Industry Practices}

The Construction and Building Subcommittee of the National Science and Technology Council has established seven National Construction Goals in collaboration with a broad cross section of the construction industry. ${ }^{36}$ Data describing current practices of the US construction industry are needed to establish baselines against which the industry can measure its progress towards achieving the seven National Construction Goals. The seven Goals are: (1) reductions in the delivery time of constructed facilities; (2) reductions in operations, maintenance, and energy costs; (3) increases in occupant productivity and comfort; (4) reductions in occupant-related illnesses and injuries; (5) reductions in waste and pollution; (6) increases in the durability and flexibility of constructed facilities; and (7) reductions in construction worker illnesses and injuries.

Baseline measures and measures of progress will be produced for each National Construction Goal in each of the four key construction industry sectors. The four sectors are: (1) residential; (2) commercial; (3) industrial; and (4) public works. Industry performance in 1994 is used as the reference point from which the values of the baseline measures are calculated.

\footnotetext{
${ }^{36}$ Wright, Richard N., Arthur H. Rosenfeld, and Andrew J. Fowell. 1995. Construction and Building: Federal Research and Development in Support of the US Construction Industry. Washington, DC: National Science and Technology Council.
} 
Two reports by Chapman and Rennison provide detailed sets of baseline measures for National Construction Goal $1,{ }^{37}$ reductions in delivery time, and National Construction Goal 2, ${ }^{38}$ reductions in operations, maintenance, and energy costs. A third report by Chapman provides a detailed set of baseline measures for National Construction Goal 7,, reductions in construction worker illnesses and injuries. Goals 1, 2, and 7 were identified as the highest priority National Construction Goals by the construction industry.

The baseline measures for Goals 1, 2, and 7 for the commercial sector were the starting point for collecting the data and information needed to conduct the CONSIAT economic impact assessment. Specifically, the values of the baseline measures are reference data against which the values contained in this report can be compared. In addition, all three reports provided extensive cross-referencing of data to sources. This enabled the current effort to quickly and efficiently retrieve data and information focused exclusively on the commercial sector. The remainder of this section is devoted to the description of these data sources and the key data sets associated with these data sources.

\subsubsection{The CII Benchmarking and Metrics Database}

Information from CII is used to produce estimates for four key data items: (1) reductions in first costs; (2) reductions in delivery time; (3) reductions in construction-related accidents; and (4) higher net income for contractors. The first data item is needed to estimate the percent cost savings for a typical commercial sector project. The second data item provides the basis for estimating the potential for increased revenues due to earlier start-up of operations. The third data item is needed to estimate cost savings resulting from improved safety performance. The fourth data item provides the basis for estimating the effects on contractor margins due to better control over cost growth during the project delivery process. Anecdotal information is also presented which is useful in estimating a fifth data item-reductions in maintenance and repair costs.

CII is an internationally-recognized research consortium focused on advancing the capital projects industry. CII draws its membership primarily from companies involved in the operation or construction of industrial facilities. CII membership is nearly equally split between owner members and contractor members. CII data are used in this document because CII has committed itself to an annual cycle of surveying its member companies, collecting data on an individual project basis, analyzing these data, and publishing its findings. Many projects for which data are being collected are commercial buildings.

\footnotetext{
${ }^{37}$ Chapman, Robert E., and Roderick Rennison. 1998. An Approach for Measuring Reductions in Delivery Time: Baseline Measures of Construction Industry Practices for the National Construction Goals. NISTIR 6189. Gaithersburg, MD: National Institute of Standards and Technology.

${ }^{38}$ Chapman, Robert E., and Roderick Rennison. 1998. An Approach for Measuring Reductions in Operations, Maintenance, and Energy Costs: Baseline Measures of Construction Industry Practices for the National Construction Goals. NISTIR 6185. Gaithersburg, MD: National Institute of Standards and Technology.

${ }^{39}$ Chapman, Robert E. 2000. An Approach for Measuring Reductions in Construction Worker Illnesses and Injuries: Baseline Measures of Construction Industry Practices for the National Construction Goals. NISTIR 6473. Gaithersburg, MD: National Institute of Standards and Technology.
} 
Research by the author indicates that CII is one of the few organizations in the US that is systematically collecting construction project data in a manner conducive to estimating the benefits and costs of employing innovative methods for using existing design and information technologies. CII has agreed to provide NIST with aggregated data from its database, which will enable NIST to develop an extensive set of benefit and cost measures associated with the use of design and information technologies. ${ }^{40}$ At the same time, NIST's analyses of the CII data will provide CII with valuable insights into the performance of its member companies, which will be of direct benefit to its membership.

All information presented in this subsection is based on the results of a research collaboration between NIST and CII. ${ }^{41}$ The focus of this research collaboration was on quantifying the value of using design/information technologies within the non-residential sectors of the construction industry. Although the evolution and deployment of design/ information technologies will undoubtedly play an important role in the future of the construction industry, many stakeholders are unsure of the economic value of using these technologies. A detailed, authoritative, and readily accessible set of information is needed to enable construction industry stakeholders to make cost-effective investment decisions among established, new, and innovative design/information technologies. The CII Benchmarking and Metrics database, which is composed exclusively of actual project execution experiences, is the product from which this set of information was developed.

This collaborative research effort uses the CII Benchmarking and Metrics database to evaluate the use of design/information technology and relate its use to project performance. Results from this collaborative research effort are used to identify, document, and develop estimates for the benefits and costs of using FIAPP products and services in commercial buildings.

The CII Benchmarking and Metrics Committee ${ }^{42}$ established the CII Benchmarking and Metrics database in 1996. The CII Benchmarking and Metrics database is based on survey data collected from CII member companies. The Benchmarking and Metrics Committee is responsible for the design of the survey instrument, the training of benchmarking associates from member companies, and the compilation and analysis of respondent data.

The survey instrument focuses on information on project size, cost, schedule, overall performance, as well as on details of project execution. The survey instrument is designed to collect information both on performance metrics - cost, schedule, and safety - and on the use of CII-endorsed best practices. Perhaps most importantly, CII's

\footnotetext{
${ }^{40}$ All data provided to NIST by CII have been aggregated in a manner that precludes identification of an individual company's or project's performance.

${ }^{41}$ Thomas, Stephen R., Candace L Macken, and Sang-Hoon Lee. 2001. Impacts of Design/Information Technology on Building and Industrial Projects. NIST GCR 01-828. Gaithersburg, MD: National Institute of Standards and Technology.

${ }^{42}$ The Benchmarking and Metrics Committee was chartered by CII's Board of Advisors in November 1993. The Benchmarking and Metrics Committee is composed of representatives from both owner and contractor companies; it met for the first time in February 1994.
} 
analysis of respondent data seeks to quantify the impacts of best practice usage on the values of performance metrics (e.g., how the use of best practices translates into reductions in project delivery time). Detailed information is collected on 6 CII-endorsed best practices: (1) safety; ${ }^{43}$ (2) pre-project planning ${ }^{44}$ (3) team building; ${ }^{45}$ (4) constructability; ${ }^{46}(5)$ project change management; ${ }^{47}$ and (6) design/information technology. ${ }^{48}$ These data are used to construct a series of indices for measuring the degree of usage both for individual best practices (e.g., design/information technology) and for the overall set. Having data which links best practice use (e.g., design/ information technology) to project outcomes (e.g., reductions in project delivery time) is a valuable tool for identifying performance improvement opportunities.

Information from 566 projects totaling $\$ 35.7$ billion (installed cost) has been collected, compiled, analyzed, and made available to NIST. ${ }^{49}$ Figure 6-1 summarizes the project data received from both CII owners and contractors. Note that nearly two-thirds of the projects came from owners.

The project data analyzed in this report are classified into two construction industry groups: (1) commercial buildings and (2) industrial facilities. ${ }^{50}$ Figure 6-2 reports the distribution of projects in the database by industry group. Data on both owner respondent projects and contractor respondent projects are shown in Figure 6-2. The industrial facilities group comprises approximately $80 \%$ of the database. In all, there are 473 projects in the industrial facilities group. The remaining 93 projects are commercial buildings.

\footnotetext{
${ }^{43}$ Safety practices include the site-specific program and efforts to create a project environment and state of consciousness embracing the concept that all accidents are preventable and that zero accidents is an obtainable goal.

${ }^{44}$ Pre-project planning involves the process of developing sufficient strategic information with which owners can address risk and decide to commit resources to maximize the chance for a successful project.

${ }^{45}$ Team building is a process that brings together a diverse group of project participants and seeks to resolve differences, remove roadblocks, and proactively build and develop the group into an aligned, focused, and motivated work team that strives for a common mission for shared goals, objectives, and priorities.

${ }^{46}$ Constructability practices seek to achieve overall project objectives through the optimum use of construction knowledge and experience in planning, design, procurement, and field operations. Constructability is achieved through the effective and timely integration of construction input into planning and design as well as field operations.

${ }^{47}$ Project change management practices seek to promote a balanced change culture, recognize change, evaluate change, implement change, and continuously improve from lessons learned.

${ }^{48}$ Design/information technology practices involve the use of data integration programs, 3D CAD modeling, electronic data interchange (EDI), and bar coding.

${ }^{49}$ Contractor data was used only for those projects on which contractors performed both design and construction tasks. Although the CII Benchmarking and Metrics database contains data for four versions of its questionnaire, only data from versions $2.0,3.0$, and 4.0 were included. The version 1.0 questionnaire did not address design/information technology use.

${ }^{50}$ The data used in this report have been aggregated to promote a more straightforward analysis of the impacts of design/information technology use. CII classifies project data into four categories: (1) buildings; (2) heavy industrial; (3) light industrial; and (4) infrastructure. This report combines data on heavy and light industrial projects and excludes data on infrastructure projects. The infrastructure project grouping has been excluded due to its small sample size.
} 
Figure 6-1. CII Database by Respondent Type

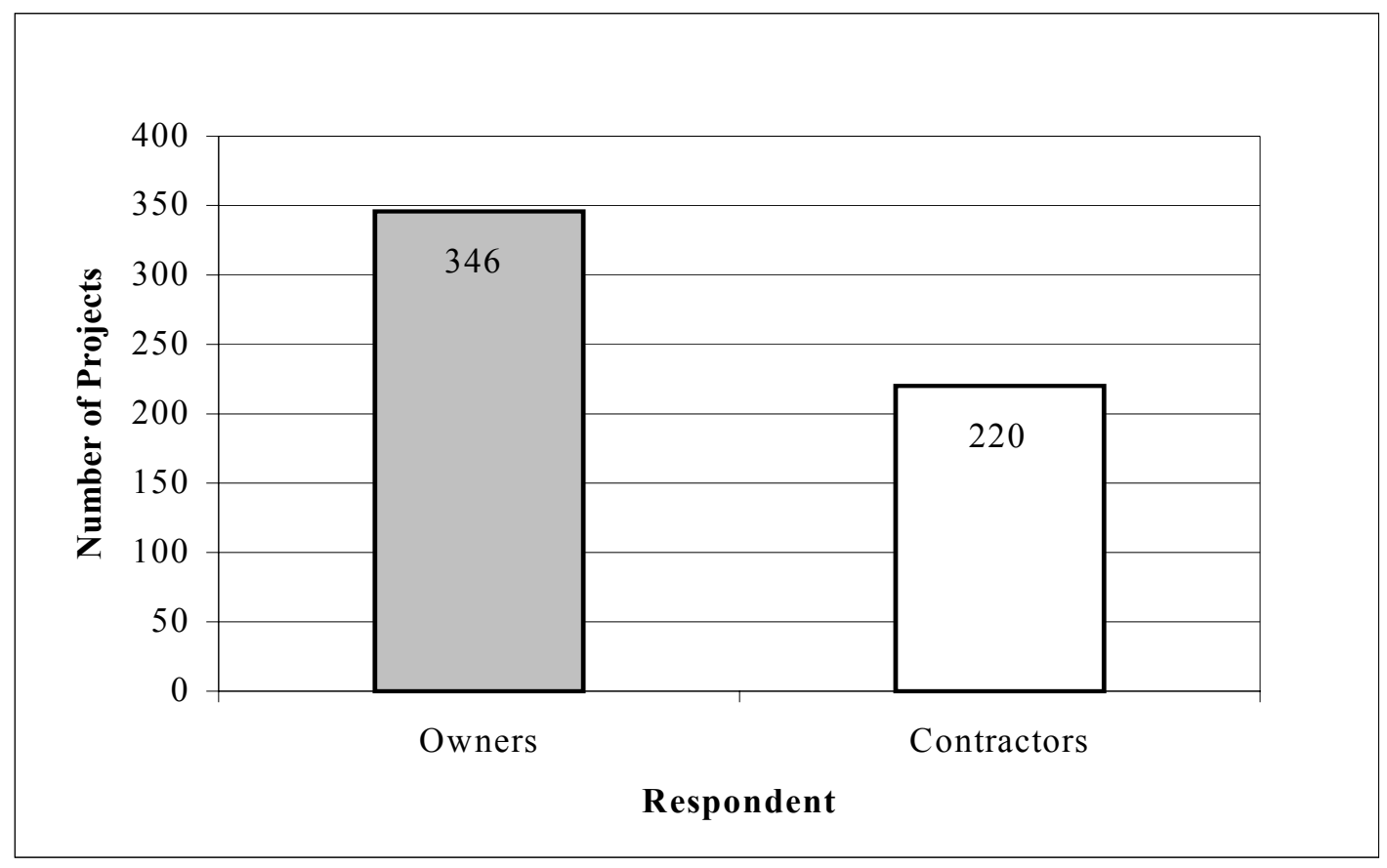

Figure 6-2. CII Database by Industry Type

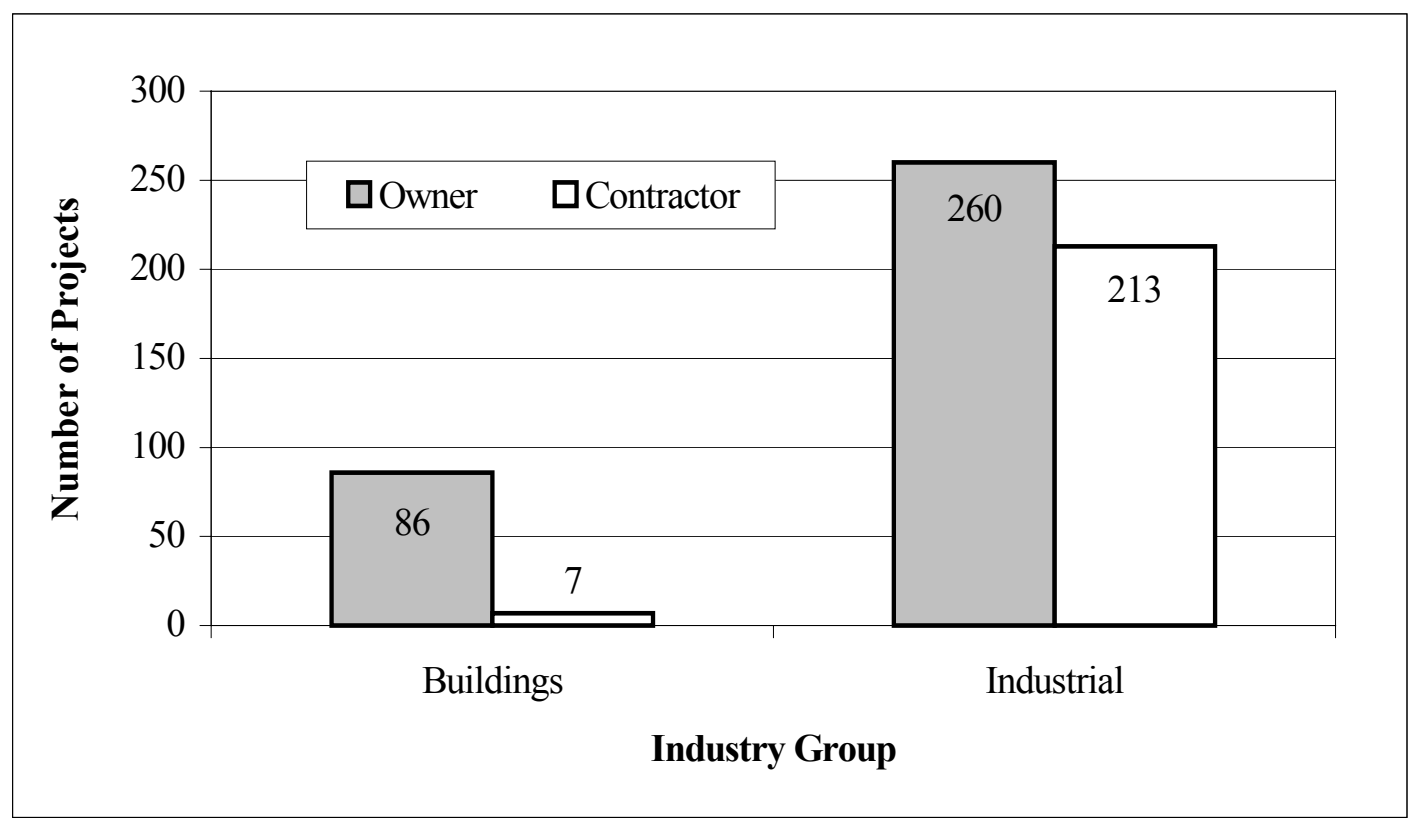


The CII database currently represents a broad range of project size as measured by cost. As shown in Figure 6-3, approximately one-half of the projects have a cost of less than $\$ 15$ million, slightly more than one-fourth have a cost between $\$ 15$ and $\$ 50$ million, and slightly less than one-fourth have a cost in excess of $\$ 50$ million. The individual project costs range from slightly below $\$ 5$ million to in excess of $\$ 500$ million, with an average cost of approximately $\$ 63$ million. Data on both owner and contractor respondent projects are shown in Figure 6-3.

Projects in the CII database can be identified and categorized by the nature of the project. Project nature indicates to which of the three categories a project belongs: (1) grassroots; (2) addition; and (3) modernization. The survey instrument defined grass roots as a new facility. An addition was defined as a new facility component that ties in to an existing facility, often intended to expand capacity or commercial floorspace. Modernization was defined as a facility for which a substantial amount of the equipment or structure is replaced or modified, and which may expand commercial floorspace. For purposes of this document, grassroots projects are classified under the heading of new construction, and addition and modernization projects are classified under the heading of additions and alterations. Figure 6-4 shows how the projects in the database are distributed among the three categories of project nature. The projects are approximately equally distributed among all three categories. Data on both owner respondent projects and contractor respondent projects are shown in Figure 6-4.

The results of the statistical analyses of the CII project data are summarized in Table 6-1. The table records two cost metrics, two schedule metrics, two safety metrics, and a project budget factor. The two cost metrics are project cost growth ${ }^{51}$ and construction cost growth; they are calculated for owner projects only. The two cost metrics provide the basis for estimating reductions in first costs. The two schedule metrics are total project duration $^{52}$ (in weeks) and construction phase duration (in weeks); they provide the basis for estimating the potential for increased revenues due to early start-up. The two safety metrics are the recordable incidence rate $^{53}$ (RIR) and the lost workday case incidence rate $^{54}$ (LWCIR); they provide the basis for estimating cost savings due to improvements in safety performance. The project budget factor ${ }^{55}$ is calculated for contractor projects only; it is used to estimate the effects on contractor margins due to better control over cost growth during the project delivery process.

\footnotetext{
${ }^{51}$ Project cost growth equals $\{$ (actual total project cost - initial predicted project cost $)$ / initial predicted project cost $\}$, where actual total project cost equals total installed cost at turnover to the user (excluding land costs), and initial predicted project cost equals the project's budget at the start of detailed design.

${ }^{52}$ Total project duration equals the elapsed time from the start of detailed design to turnover to the user.

${ }^{53}$ The RIR represents the number of injuries and illnesses per 100 full-time workers. It is calculated as $(\mathrm{N} / \mathrm{EH}) \times 200,000$, where $\mathrm{N}=$ the number of injuries and illnesses, $\mathrm{EH}=$ the total hours worked by all employees during the calendar year, and 200,000 = the base for 100 full-time workers (working 40 hours per week, 50 weeks per year).

${ }^{54}$ The LWCIR is a measure of more serious injuries; it records those cases which result in days away from work or restricted work activity.

${ }^{55}$ Project budget factor equals $\{$ (actual total project cost)/(initial predicted project cost + approved changes)\}, where actual total cost equals the total cost of the final scope of work, initial predicted project cost equals the cost estimate used as the basis for the contract award, and approved changes equal the estimated cost of owner-approved changes.
} 
Figure 6-3. CII Database by Cost Category

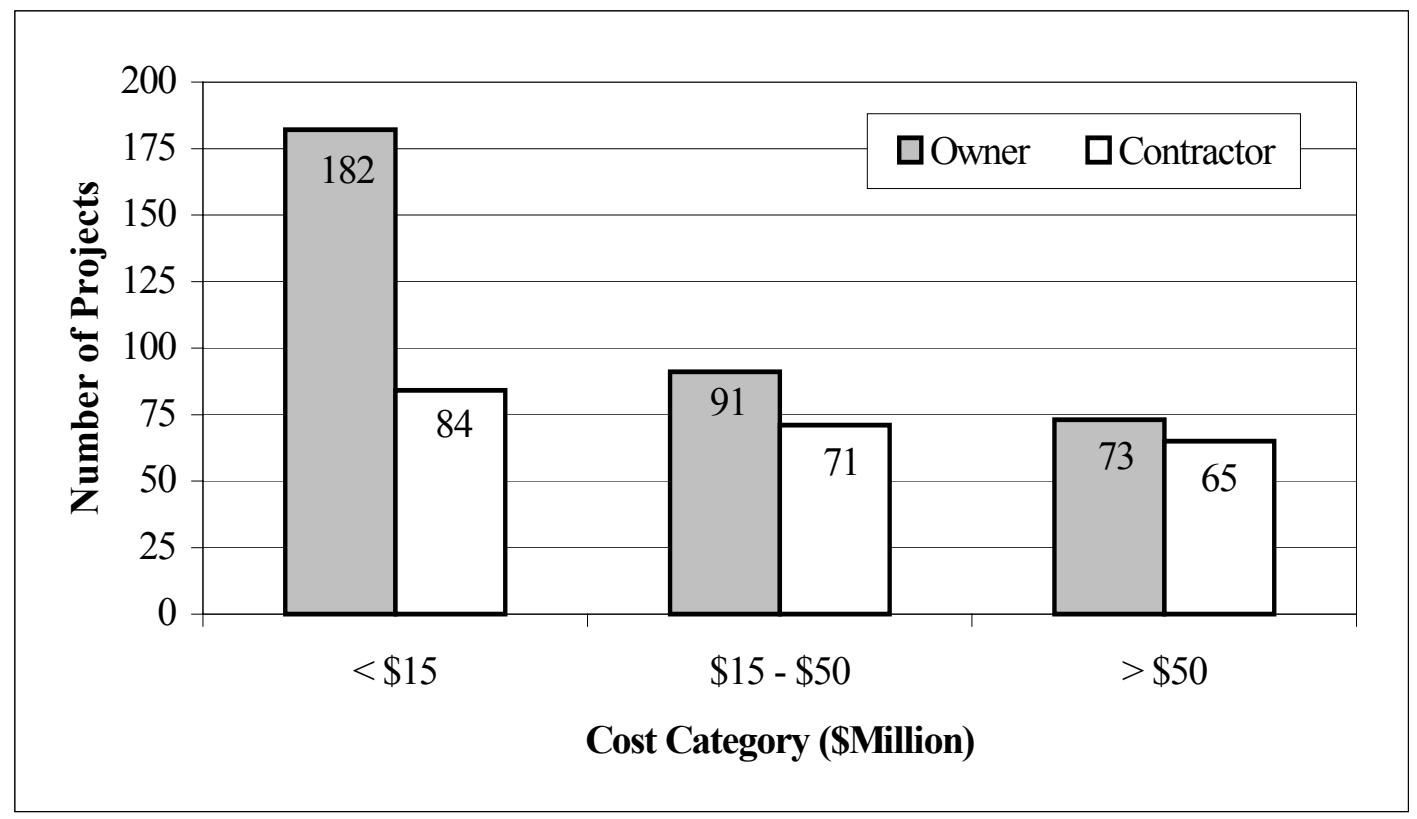

Figure 6-4. CII Database by Project Nature

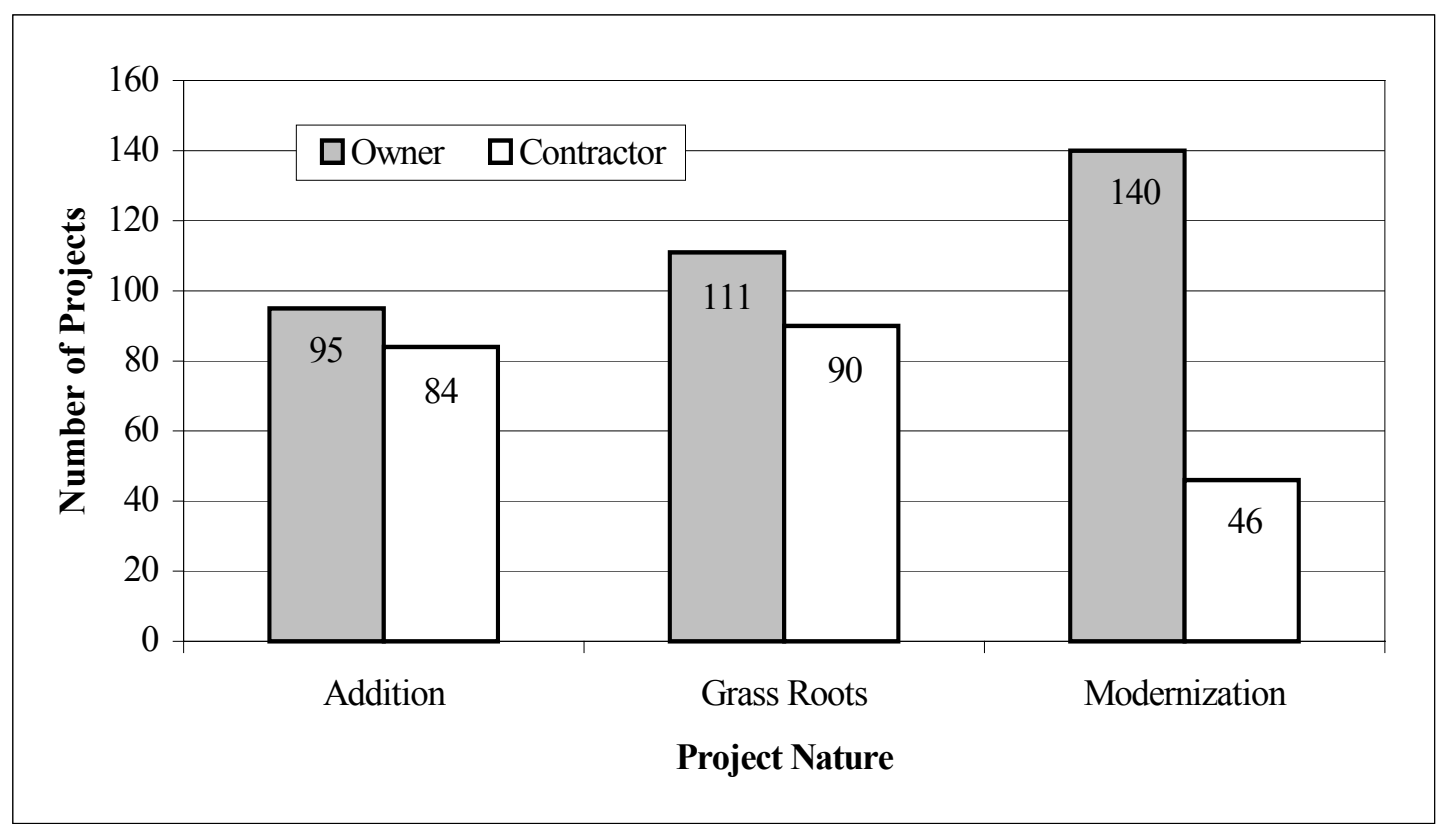


Performance improvements due to the extensive use of design/information technology practices (Column 3) are computed as the difference between average project performance for that metric (Column 1) and the value of that metric for that subset of projects which made extensive use of design/information technology practices (Column 2). The calculated values recorded in Column 3 of Table 6-1 provide the starting point for estimating FIAPP-related benefits and cost savings derived in Subsection 6.3.1. Anecdotal information collected as part of a series of in-depth analyses of a select set of exemplary projects provided the basis for estimating reductions in maintenance and repair costs (see Subsection 6.3.1). These data were collected as part of a previous research collaboration between NIST and CII. ${ }^{56}$

Table 6-1. Summary of Selected Results from the Statistical Analyses of the CII Project Data

\begin{tabular}{|l|c|c|c|}
\hline \multirow{2}{*}{ Metric } & \multicolumn{2}{|c|}{ Design/Information Technology Use } & $\begin{array}{c}\text { Measured } \\
\text { Performance } \\
\text { Improvement } \\
\text { Col. (3) }\end{array}$ \\
\cline { 2 - 3 } & $\begin{array}{c}\text { Average } \\
\text { Col. (1) }\end{array}$ & $\begin{array}{c}\text { Extensive } \\
\text { Col. (2) }\end{array}$ & $2.0 \%$ \\
\hline $\begin{array}{l}\text { Project Cost } \\
\text { Growth }\end{array}$ & $1.0 \%$ & $-1.0 \%$ & $3.5 \%$ \\
\hline $\begin{array}{l}\text { Construction Cost } \\
\text { Growth }\end{array}$ & $5.3 \%$ & $1.8 \%$ & 22 weeks \\
\hline $\begin{array}{l}\text { Total Project } \\
\text { Duration }\end{array}$ & 147 weeks & 125 weeks & 7 weeks \\
\hline $\begin{array}{l}\text { Construction Phase } \\
\text { Duration }\end{array}$ & 87 weeks & 80 weeks & 0.932 \\
\hline $\begin{array}{l}\text { Recordable } \\
\text { Incidence Rate }\end{array}$ & 3.520 & 2.588 & 0.311 \\
\hline $\begin{array}{l}\text { Lost Workday Case } \\
\text { Incidence Rate }\end{array}$ & 0.718 & 0.407 & 0.014 \\
\hline $\begin{array}{l}\text { Project Budget } \\
\text { Factor }\end{array}$ & 0.959 & 0.945 & \\
\hline
\end{tabular}

\subsubsection{Other Data Sources}

In addition to the information extracted from the CII Benchmarking and Metrics database, information on the value of construction put in place, maintenance and repair costs, safety statistics, and commercial sector net income figures were needed. The focus of this subsection is on identifying the data sources for these key data items. How this information is used to develop estimates of benefits and cost savings in the commercial sector is described in detail in Subsection 6.3.1.

\footnotetext{
56 Thomas, Stephen R. 1999. Impacts of Design/Information Technology on Project Outcomes. NIST GCR 99-786. Gaithersburg, MD: National Institute of Standards and Technology.
} 


\section{Data from the US Bureau of the Census}

The value of construction put in place in the commercial sector is based on data published in the Current Construction Reports series C30 publication (see Table 4-3 in Section 4.1). The $C 30$ publication provides a combined estimate of the value of new construction put in place plus the value of additions and alterations put in place. This value was \$205.7 billion in 1997 for the commercial sector.

Reference to Table 4-3 reveals that the value of construction put in place in the commercial sector (measured in constant 1997 dollars) has increased steadily over the period 1994 through 2000. However, over extended periods, the value of construction put in place in the commercial sector (measured in constant 1997 dollars) fluctuates according to the business cycle. Rather than trying to model the business cycle over an extended period of time into the future, this study adopts a conservative approach. It uses a single mid-range figure for the value of construction put in place in the commercial sector. Specifically, the estimate for the value of construction put in place in the commercial sector used in this study is held constant at the 1997 level (i.e., \$205.7 billion expressed in constant 1997 dollars).

The Statistical Abstract of the United States was used as the source of data for estimating the average cost per $\mathrm{m}^{2}\left(\mathrm{ft}^{2}\right)$ for a typical commercial building. The estimate is based on published data for new construction and additions. ${ }^{57}$ Data over a 10 -year period between 1988 and 1997 were used to produce the estimate. The estimated value, expressed in 1997 dollars, is $\$ 1,050.88 / \mathrm{m}^{2}\left(\$ 97.63 / \mathrm{ft}^{2}\right)$. The estimated cost per $\mathrm{m}^{2}$ is used in conjunction with the value of construction put in place and the diffusion model (see Subsection 6.4.4) to estimate in any given year the amount of commercial floorspace employing FIAPP products and services.

\section{Data from the International Facilities Management Association}

The International Facilities Management Association (IFMA) is an association serving the facility management profession. IFMA has carried out a number of benchmarking studies covering both the commercial and industrial sectors.

IFMA's Research Report $\# 13,{ }^{58}$ published in 1994 is the result of a 1993 survey of IFMA members. The report presents benchmarking data derived from 283 questionnaires.

While the IFMA report presents summary data based on a relatively small sample size; it is one of the few reports which analyzes the relationship between maintenance and repair costs. In addition, the IFMA report contains information on both the mean values (i.e., average values) and the distribution (i.e., range of values and the ordering of these

\footnotetext{
${ }^{57}$ The Statistical Abstract of the United States reports both the value of construction and the net increase in the amount of floorspace for selected commercial building types for new construction and additions combined. Since alterations tend not to increase existing floorspace, the Statistical Abstract only reports the value of alterations.

${ }^{58}$ International Facilities Management Association. 1994. Benchmarks II. Research Report \#13. Houston, TX: International Facilities Management Association.
} 
values) of each type of cost (i.e., repair costs and maintenance costs). This information is used to estimate the annual maintenance and repair costs for commercial buildings. This value, expressed in 1997 dollars is $\$ 23.90 / \mathrm{m}^{2}\left(\$ 2.22 / \mathrm{ft}^{2}\right)$.

\section{Data from the US Bureau of Labor Statistics}

The US Bureau of Labor Statistics (BLS) disseminates data in a continuous series of annual releases from the BLS safety and health statistical series. The BLS Survey of Occupational Injuries and Illnesses provides data on injuries and illnesses that are derived from population samples. In cooperation with State agencies, BLS collects information from employers ${ }^{59}$ on the number and incidence of nonfatal work-related injuries and illnesses. Each year the Survey provides estimates by industry and by State of the number of workplace injuries and illnesses, and also by the number of injuries and illnesses that involve lost work time. The average number of days away from work and the percent distribution of days away from work by industry are also given.

By recording the days away from work, the Survey provides a measure of the "seriousness" of injuries and illnesses. For workers with injuries and illnesses involving time away from work, the Survey estimates the number and percent distribution of injuries and illnesses by occupation, sex, age, race, and length of service. Numbers, percent distributions, and incidence rates are also calculated by detailed nature of injury and illness, part of body affected, source of the injury or illness, and type of event or exposure leading to the incident. Cross tabulations of the worker characteristics and injury/illness circumstances are also available. The median and percent distribution of days away from work are estimated for each worker and case characteristic.

BLS data on the recordable incidence rate (RIR) and the lost workday case incidence rate (LWCIR) are used to construct key trends in safety performance. Information on trends is necessary because safety performance in the construction industry has been improving over the last decade. Consequently, it is necessary to separate safety improvements due to industry-wide trends from improvements due to the use of FIAPP products and services.

\section{US Internal Revenue Service}

The US Internal Revenue Service (IRS) publishes financial data for all business enterprises. These data appear in the Statistics of Income, Corporation Income Tax Returns, and the Statistics of Income Bulletin. IRS data on net income ${ }^{60}$ is used as one component in the estimation procedure for placing a dollar value on potential increases in revenues due to early start-up (i.e., reductions in delivery time). IRS data from 1997 for corporate net income for services, wholesale and retail trade, and finance, insurance, and real estate, were used to estimate the average weekly net income of $\$ 1.78 / \mathrm{m}^{2}\left(\$ 0.17 / \mathrm{ft}^{2}\right)$.

\footnotetext{
${ }^{59}$ Construction establishments with no employees (i.e., self-employed construction workers) are not covered by the Survey.

${ }^{60}$ Net income equals total taxable receipts less business deductions. Net income is before income tax.
} 


\subsection{Defining the Base Case and the FIAPP Alternative}

The purpose of this section is to define the base case and the FIAPP alternative to the base case. This "definition step" is done to draw two key distinctions between the base case and the FIAPP alternative (i.e., the two configurations). These distinctions are important because they facilitate the estimation of the benefits and costs covered in Section 6.3.

It is anticipated that FIAPP products and services will be employed in both the construction of new commercial buildings and for the renovation of existing commercial buildings. Verification that the FIAPP products and services employed are performing "as stipulated" is done as part of a formal project execution process. If the FIAPP alternative is not chosen, the same process applies for commercial buildings employing the base case. Thus, for new commercial buildings, either the base case or the FIAPP alternative is employed during "grass roots" construction. Similarly, for existing commercial buildings, either the base case or the FIAPP alternative is employed while the facility is undergoing renovation.

Both the base case and the FIAPP alternative (i.e., both configurations) have features against which costs, savings, and performance are measured. These features include the equipment and software required for design, construction, and facility operations. It is important to recognize that both configurations must meet all facility-related performance requirements. This "performance requirement" constraint is needed to ensure that both configurations are reliable, serviceable, safe, and at a minimum, neutral with regard to design aesthetics. ${ }^{61}$ The performance requirement applies both to either configuration employed during the construction of a new commercial building and to either configuration employed during the renovation of an existing commercial building.

Throughout the remainder of this report, the term base case is used to represent the configuration that maintains the status quo (i.e., the "average" use of traditional design, information, and construction technologies). The FIAPP alternative is that collection of products and services (i.e., configuration) that provides equivalent or enhanced performance for all features of the base case while satisfying the definition of a FIAPP given in Section 3.1.

Based on the definitions of the base case and the FIAPP alternative, there are two key differences between the two configurations. First, the degree to which construction activities (e.g., materials management) and facility service features (e.g., maintenance and repair procedures) are integrated, automated, and controlled is significantly higher in the FIAPP alternative. The second difference is that the FIAPP alternative has the potential to achieve enhanced performance for selected construction activities (see Table

\footnotetext{
${ }^{61}$ For more information on how to specify performance requirements, see Chapter 2 of Fuller and Petersen (Fuller, Sieglinde K., and Stephen R. Petersen. 1996. Life-Cycle Costing Manual for the Federal Energy Management Program. NIST Handbook 135. Gaithersburg, MD: National Institute of Standards and Technology).
} 
6-1) and facility service features (see Subsection 6.3.1.2). These differences, although interrelated, are crucial in structuring differences in costs (e.g., due to the installation of additional equipment and software to generate improved systems integration, automation, and control) and savings (e.g., reductions in construction-related accidents and maintenance and repair cost savings due to the availability of electronic "as-built" information) between the two configurations. Quantitative measures of these differences are developed in Section 6.3.

\subsection{Estimating Significant FIAPP-Related Benefits and Costs}

This section develops estimates of the key benefits and costs that are the focus of the CONSIAT economic impact assessment. These benefits and costs are well-defined subsets of the comprehensive lists of benefits and costs presented in Chapter 5 .

It is important to recognize that every effort has been made to capture and record any cost-related information affecting the users of FIAPP products and services. Similarly, considerable effort went into documenting and estimating BFRL's CONSIAT-related investments. Relatively less effort went into estimating the full range of FIAPP-related benefits and cost savings. We focused on what we judged the most substantial and measurable benefits, which we termed the "significant few" benefits. Thus, the return on BFRL's CONSIAT-related investments is expected to be very conservative (i.e., the values presented in this report are lower bounds on the potential range of returns on BFRL's CONSIAT-related investments).

\subsubsection{Benefits and Cost Savings}

The enhanced performance of the FIAPP alternative vis-à-vis the base case produces five types of benefits and cost savings. These benefits and cost savings are: (1) lower first costs; (2) lower maintenance and repair costs; (3) fewer construction-related accidents; (4) reductions in delivery time; and (5) higher net income for contractors. Lower first costs are registered through a reduction in total installed costs (i.e., all project-related costs with the exception of land costs). Lower maintenance and repair costs are registered through reductions in future costs. Lower first costs and lower maintenance and repair costs, as measured in this study, accrue to building owners and operators. Fewer construction-related accidents are registered through reductions in direct jobsite costs (e.g., medical costs), indirect jobsite costs (e.g., lost productivity of the crew due to the accident), and liability costs (e.g., claims costs). Reductions in delivery time are registered through increased opportunities for rental income and product sales. Higher net income is registered through the contractor's increased capability to control cost growth during the project delivery process. The first three types listed-lower first costs, lower maintenance and repair costs, and fewer construction-related accidents - are readily classified as cost savings. Reductions in delivery time are classified as a benefit, rather than as cost savings, because they create the potential for increased sales revenues 
due to earlier start-up of operations. Higher net income is classified as a benefit because it increases the contractor's profit margin.

Although the FIAPP alternative is expected to result in fewer/shorter business interruptions due to building-related problems (e.g., faster turnarounds due to the availability of electronic "as-built" information), no estimates of these, potentially significant, benefits and cost savings are included in the current CONSIAT economic impact assessment. Although subject matter experts have reached consensus on the generic types of benefits and cost savings due to fewer/shorter business interruptions (see Table 5-3 in Section 5.2), no such consensus emerged on how to quantify these benefits and cost savings. Plans for incorporating such estimates in a future economic impact assessment are described in Section 9.2. It is important to recognize that although the benefits and cost savings due to fewer/shorter business interruptions are not included in this assessment, the costs of installing, operating, and maintaining the equipment and software required to achieve these benefits and cost savings are included. This contributes to the conservative outcome of the CONSIAT economic impact assessment.

\subsubsection{Reduced First Costs}

Information compiled from the CII Benchmarking and Metrics database was used to establish values both for reductions in project cost growth and reductions in construction cost growth (see Table 6-1). These reductions were $2.0 \%$ for project cost growth and 3.5 $\%$ for construction cost growth. The data used to compute both sets of reductions are from owner projects only. This is because owners bear the full cost of the project, including the contractor's profit margin. This approach ensures that any reductions in first costs are modeled independently from contractor project data.

The value used in the CONSIAT economic impact assessment is based on the $2.0 \%$ reduction in project cost growth. There are two reasons for selecting this value. First, it is more conservative than the $3.5 \%$ reduction in construction cost growth. Thus, it is more in keeping with the conservative approach employed in this impact assessment. Second, the definition of the project cost growth metric makes use of both actual total project cost and initial predicted project cost. Recall that actual total project cost equals the project's total installed cost at turnover to the user (excluding land costs) and initial predicted project cost equals the project's budget at the start of detailed design.

The project cost growth metric, as defined by CII, may be used as an estimator of the percent reduction in total installed cost due to the use of FIAPP products and services. ${ }^{62}$

\footnotetext{
${ }^{62}$ Consider the case where all base case projects and FIAPP alternative projects have the same initial predicted project cost. In this case, all differences in project cost growth are due to differences in total installed cost. Thus, a $2.0 \%$ reduction in project cost growth between the set of FIAPP alternative projects and the set of base case projects results in a $2.0 \%$ reduction in total installed costs for the FIAPP alternative vis-à-vis the base case.
} 
Therefore, the use of FIAPP products and services is estimated to reduce total installed costs for a typical commercial sector project vis-à-vis the base case by $2.0 \%$.

The $2.0 \%$ reduction in total installed cost employed in this impact assessment is considered very conservative (i.e., cost reductions due to the use of the FIAPP alternative are likely to be significantly higher). The basis for the previous statement is due to a CII study on the impacts of information management in the engineer-procure-construct (EPC) process. ${ }^{63}$ The CII study of the EPC process used an activity-based costing approach, coupled with Monte Carlo simulation, to quantify the benefits of employing traditional methods of information management on EPC projects. The study concluded "aggressive information management strategies for design related activities may yield as much as 10 $\%$ improvement in total elapsed time (calendar time) required to fully execute a typical EPC process. These same strategies will most likely yield a reduction in overall labor costs of approximately 2 to $3 \%$. Similarly, aggressive information management strategies for materials management related activities may yield as much as $3 \%$ reduction in elapsed time and $7 \%$ reduction in execution costs. When combined, aggressive information management strategies may result in reductions as much as $14 \%$ for elapsed time and $8 \%$ for execution costs. $" 64$

It is important to note that not all commercial sector projects will employ the FIAPP alternative. Thus, the $2.0 \%$ reduction in first costs will only accrue to those commercial sector projects which actually employ the FIAPP alternative. Information on the annual proportion of commercial sector construction-related investments (i.e., expenditures for new construction projects and for additions and alterations) that employ the FIAPP alternative are based on the diffusion model (see Subsection 6.4.4). Annual estimates showing how reductions in first costs contribute to cost savings nationwide are given in Section 7.2, where all key components are laid out in a spreadsheet format.

\subsubsection{Reduced Maintenance and Repair Costs}

FIAPP products and services will lower the costs of maintaining and repairing commercial buildings. How much these costs are reduced depends on a number of factors, such as, the ability to maintain electronic "as built" information in a form that will save time in troubleshooting maintenance problems, the ability to make available online information on the building's characteristics to promote the use of fact-based maintenance programs, and the ability to use electronic data interchange to promote faster delivery of "out-of-stock" parts. The use of selected FIAPP products and services during the post "start-up" phase of the project life cycle will allow building support systems and equipment to operate and be maintained under near optimal conditions for extended periods of time. As a result, equipment life will be extended, fewer replacements will be required, and replacement costs will decline.

\footnotetext{
${ }^{63}$ Construction Industry Institute. 1998. Cost and Schedule Impacts of Information Management. Research Summary 125-1. Austin, TX: Construction Industry Institute.

${ }^{64}$ Ibid. p. 11.
} 
To develop a range of estimates for annual maintenance and repair cost savings, industry experts and building managers and operators were interviewed. The general consensus was that the use of selected FIAPP products and services during the post start-up phase would enable both smaller crew sizes and the ability to handle more building-related service requests with a given size of maintenance staff. To a certain extent, some potential maintenance and repair cost savings would be offset by expenditures for training for the building's maintenance staff. However, once trained, maintenance staff can be more easily moved from one "FIAPP" location to another - a potential cost saving. Finally, the building owner/operator would incur costs to maintain an "up-todate" set of electronic "as built" information. Since these costs are expected to rise over time, they tend to "degrade" out year cost savings. Based on these inputs, maintenance and repair cost savings were estimated to range from 5 to $15 \%$. This range of values is considered very conservative (i.e., savings are likely to be greater), since a previous study focusing on a subset of the FIAPP suite of technologies produced the same range of values. ${ }^{65}$ This range of values is used to specify the range of values for maintenance and repair cost savings in the sensitivity analysis (see Chapter 8).

The baseline value for annual maintenance and repair cost savings used in the economic impact assessment is $10 \%$. This translates into an annual maintenance and repair cost savings of $\$ 2.39 / \mathrm{m}^{2}\left(\$ 0.22 / \mathrm{ft}^{2}\right)$. Because these cost savings are expected to degrade over time, they are reduced by $10 \%$ per year following their installation. Degradation over time is modeled through the use of a deflator.

The majority of reductions in maintenance and repair costs normally do not occur in the same year in which the capital investment is made, as is the case for reductions in first costs. To address this issue, this study assumes: (1) savings accrue only to that proportion of commercial floorspace that previously employed FIAPP products and services; and (2) future FIAPP-related savings in maintenance and repair costs are brought back to the year in which the capital investment is made. Thus, the proportion of commercial floorspace that has employed FIAPP products and services will rise gradually over time, creating an opportunity for growth in savings. Similarly, for each year's set of capital investments that employ FIAPP products and services, all FIAPPrelated savings in maintenance and repair costs are brought back through the combined application of the discount rate and the deflator. Annual estimates showing how reductions in maintenance and repair costs contribute to cost savings nationwide are given in Section 7.2, where all key components are laid out in a spreadsheet format.

\subsubsection{Reductions in Construction-Related Accidents}

Information compiled from the CII Benchmarking and Metrics database (see Table 6-1) was used to establish the baseline values both for reductions in the recordable incidence rate (RIR) and the lost workday case incidence rate (LWCIR). These reductions were 0.932 for the RIR and 0.311 for the LWCIR. Because the RIR also includes cases which

\footnotetext{
${ }^{65}$ Van Tienhoven, C. J. 1996. The Benefits of STEP. Report No. IS96-014. The Hague: Shell Information Services.
} 
result in lost workdays (i.e., are included in the LWCIR calculation), it is necessary to "net out" the LWCIR to achieve a number which corresponds to cases without lost workdays. The resultant figure is 0.621 (i.e., 0.932 minus 0.311 ); it is used as the baseline value for reductions in construction-related accidents that do not result in any lost workdays. This newly defined term is referred to as the "net" RIR.

The incidence rate for construction-related accidents has been declining in recent years. Figure 6-5 shows that both the RIR and the LWCIR have declined between 1989 and 1997. During this period, the RIR has declined from 14.3 to 9.5 , a compound rate of improvement of $5.25 \%$ per annum. During the same period, the LWCIR has declined from 6.8 to 4.4, a compound rate of improvement of $5.6 \%$. Because these industry-wide trends are delivering improved safety performance, any measures of "improved" safety performance due to FIAPP products and services must incorporate these trends into its analysis of cost savings. The approach employed in this impact assessment (see Section 7.2) makes explicit these industry-wide trends. This is done by reducing the 0.621 figure for improvements in the "net" RIR by $5.25 \%$ for each year beginning in 1998 and the 0.311 figure for improvements in the LWCIR by $5.6 \%$ for each year beginning in 1998 .

Figure 6-5. Recordable Incidence Rate and Lost Workday Case Incidence Rate for Years 1989-1997

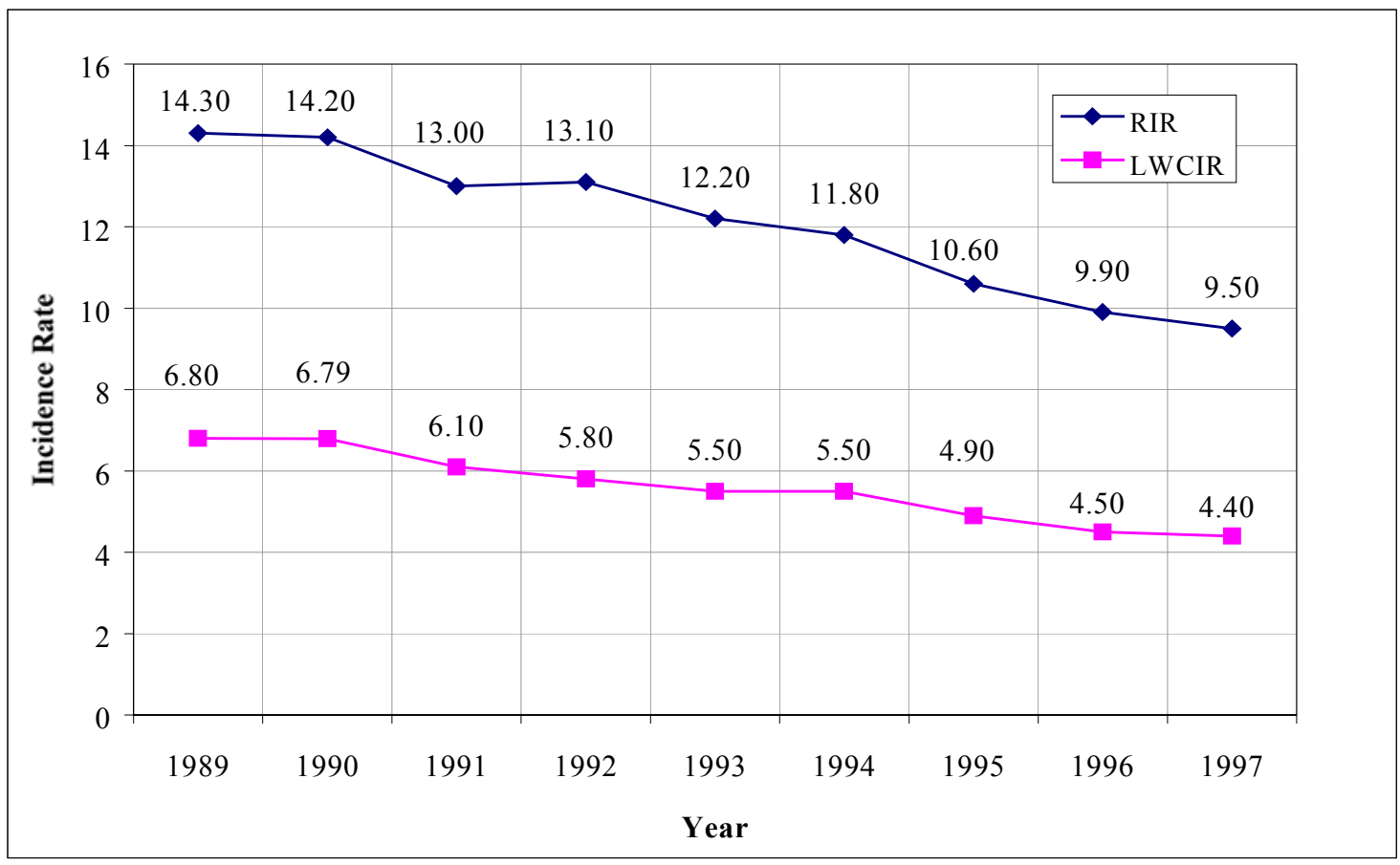

It is important to recognize that the reductions in construction-related accidents due to the FIAPP alternative are likely to be higher than the "absolute" measured performance improvement of the "net" RIR value of 0.621 and the LWCIR value of 0.311 resulting from the projects in the CII Benchmarking and Metrics database. This is because the 
"percentage" improvement in the computed value of the RIR is more than $25 \%$ (compare Columns 3 and 1 of Table $6-1$ for the RIR) and the improvement in the computed value of the LWCIR is more than $40 \%$ (compare Columns 3 and 1 of Table $6-1$ for the LWCIR). If these improvement figures are applied to the data recorded in Figure 6-5, the reductions in the RIR and LWCIR, and hence the "net" RIR, would be much greater. The reason for the differences is due to the superior safety performance of CII member organizations. Once again, the conservative approach to estimating benefits and cost savings employed in this impact assessment caused us to choose the lower values as the basis for computing cost savings due to reductions in construction-related accidents under the FIAPP alternative.

Information on the costs of construction-related accidents is needed to translate the baseline values for reductions in the "net" RIR and the LWCIR into dollar terms. Two studies which provide detailed information on the costs of construction-related accidents are Design for Safety ${ }^{66}$ and Hinze and Applegate's survey article. ${ }^{67}$ Data compiled from these studies and updated to 1997 dollars are summarized in Table 6-2. The table separates accident costs into three categories: (1) direct jobsite costs; (2) indirect jobsite costs; and (3) estimated liability costs. Direct jobsite costs include the medical costs for the injured worker and several incidental items. Direct jobsite costs are covered by worker's compensation insurance. Indirect jobsite costs include the lost productivity of the crew due to the accident, the additional cost of a replacement worker, time expended to complete forms related to the injury, and the cost for damage to materials and equipment. Liability costs are associated with any claims related to the injury. Claims costs can vary considerably. Hinze and Applegate calculated that claims costs are often 10 to 20 times the dollar value of direct jobsite costs for lost workday cases. ${ }^{68}$ The figures recorded in Table 6-2 are on the low end of the recommended ratios given in Hinze and Applegate. Thus, any FIAPP-related cost savings due to improved safety performance are likely to be very conservative.

Table 6-2. Average Costs of Construction Site Injuries: 1997

\begin{tabular}{|c|c|c|c|c|}
\hline \multirow{2}{*}{ Type of Injury } & \multicolumn{2}{|c|}{ Job Costs } & \multirow{2}{*}{$\begin{array}{l}\text { Estimated } \\
\text { Liability } \\
\text { Costs }\end{array}$} & \multirow{2}{*}{$\begin{array}{c}\text { Total Cost to } \\
\text { Employer }\end{array}$} \\
\hline & Direct & Indirect & & \\
\hline No Lost Workdays & $\$ 650$ & $\$ 550$ & $\$ 300$ & $\$ 1,500$ \\
\hline Lost Workday & $\$ 8,700$ & $\$ 2,000$ & $\$ 20,800$ & $\$ 31,500$ \\
\hline
\end{tabular}

Reference to Table 6-2 reveals that the total cost to the employer of a lost workday case is about 20 times higher than an accident which does not result in a lost workday (i.e., $\$ 31,500$ versus $\$ 1,500)$. Cost savings due to reductions in construction-related accidents

\footnotetext{
${ }^{66}$ Construction Industry Institute. 1996. Design for Safety. Research Summary 101-1. Austin, TX: Construction Industry Institute.

${ }^{67}$ Hinze, J., and L. Applegate. 1991. "Costs of Construction Accidents," Journal of Construction Engineering and Management, Vol. 117, No. 3, pp. 537-550.

${ }^{68}$ Ibid. pp. 544-545.
} 
accrue both to building owners and to contractors engaged in the construction of those buildings. Annual estimates showing how reductions in construction-related accidents contribute to cost savings nationwide are given in Section 7.2.

\subsubsection{Reductions in Delivery Time}

Information compiled from the CII Benchmarking and Metrics database was used to establish the values for reductions in delivery time. These values were 22 weeks for total project duration and 7 weeks for construction phase duration. The data used to compute both sets of reductions are from owner projects only. This is because owners participate in all phases of the project delivery process.

The value used in the CONSIAT economic impact assessment is based on the figure for reductions in the duration of the construction phase rather than for reductions in total project duration. The decision to use the 7 week figure for reductions in delivery time was motivated by a desire to maintain a conservative approach to estimating FIAPPrelated benefits.

A company's desire to reduce delivery time is driven by the potential for increased sales of its products and services in the marketplace. In the case of new products, getting to the marketplace before the competition may translate into a substantial gain in market share for that company's line of products. Because companies are assumed to be profit maximizers, reductions in delivery time offer the potential to increase profits. Therefore, to place a value on reductions in delivery time, it is necessary to employ a metric that closely approximates the profitability of the commercial sector. The "profitability" metric employed in this study is net income. This study uses net income, rather than business receipts or value added, because it best reflects profitability in the commercial sector. In addition, net income results in a more conservative estimate of the value of reductions in delivery time. The Internal Revenue Service publishes annual estimates of net income for the commercial sector. Net income for the commercial sector in 1997 was $\$ 505$ billion. ${ }^{69}$ This translates into an average weekly net income of $\$ 1.78 / \mathrm{m}^{2}\left(\$ 0.17 / \mathrm{ft}^{2}\right)$. These estimates are used to translate reductions in delivery time into a dollar denominated value.

The net income figure, expressed in 1997 dollars, is held constant throughout the study period. This assumption is very conservative because net income has tended to increase over time. The net income figure is combined with the diffusion model to estimate the benefits nationwide due to reductions in delivery time (see Section 7.2).

\subsubsection{Higher Net Income for Contractors}

Information compiled from the CII Benchmarking and Metrics database and Statistics of Income from the Internal Revenue Service was used as the basis for estimating higher net

\footnotetext{
${ }^{69}$ The $\$ 505$ billion net income figure for calendar year 1997 is based on filings by corporations only. Excluded are filings by sole proprietorships and partnerships.
} 
income for contractors. Because higher net income serves to increase a contractor's profit margin, only data from contractor projects are used. This approach ensures that any improvements in contractor performance are modeled independently from owner project data. In this way, improvements in contractor performance, say due to better cost control stemming from process improvements and increased productivity, result in improvements in profits to contractors rather than reductions in total installed cost to the owner.

Contractor data from the CII Benchmarking and Metrics database was used to construct a budget factor. The budget factor, as defined by CII, tracks deviations between the contractor's cost estimate used as the basis for the contract award for the proposed scope of work and the contractor's total cost for the final scope of work. Since changes in the scope of work sometimes occur, the CII budget metric explicitly accounts for ownerauthorized changes. Because the contractor's margin enters as a multiplicative factor, resulting in the contract award amount, reductions in the calculated value of the budget factor increase the contractor's profit margin (i.e., their costs were lower than those upon which the contract award was based). Conversely, increases in the calculated value of the budget factor reduce the contractor's profit margin. Analyses of data for CII contractors performing both design and construction tasks resulted in an average improvement of 0.014 for the computed value of the budget factor metric (see Table 6-1). This metric's performance improvement translates into an improvement of at least $1.4 \%$ in the contractor's profit margin.

In order to estimate a value for higher net income, it is first necessary to factor out an estimate of the contractor's profit margin from the value of construction put in place. This is accomplished by dividing the net income figure for the construction industry by the value of construction put in place. Based on net income figures from the most recent years available from the Statistics of Income, an average profit margin of less than $5 \%$ can be expected. Note that this figure encompasses the entire construction industry (e.g., it contains the residential sector where many firms are sole proprietorships or partnerships). According to industry experts, profit margins for the non-residential sectors of the construction industry (i.e., where most firms are corporations) tend to be very tight. This is borne out by the proportion of construction industry net income due to corporations (i.e., 0.3 to 0.4 ) versus sole proprietorships and partnerships. Thus, an assumed profit margin of $5 \%$ can be considered to be on the high side for the average commercial sector contractor. In keeping with the conservative approach of this economic impact assessment, the base against which higher net income is computed is estimated as the value of construction put in place divided by 1.05. Annual estimates of higher net income nationwide are given in Section 7.2.

\subsubsection{Cost Increases and Benefit Reductions}

Two types of costs - new-technology introduction costs and increased research and development costs - are central to this economic impact assessment. The first type of costs, new-technology introduction costs, result in higher costs to commercial building 
owners and managers and to contractors. Understanding the types of costs that affect commercial building owners, managers, and contractors is necessary in order to estimate annual values of net savings on a national level. These estimates affect not only the present value of net savings nationwide, but the estimated return on BFRL's CONSIATrelated investments as well. The second type of costs, increased research and development costs, focuses only on BFRL's CONSIAT-related investments. No estimates of the investments required to develop, test, and market FIAPP products and services by the vendor tier (see Figure 3-2) are included in this subsection. Plans for incorporating these costs in a future economic impact assessment are described in Section 9.2 .

\subsubsection{New-Technology Introduction Costs}

If commercial building owners, managers, and contractors employ the FIAPP alternative rather than the base case, they can expect to bear three types of additional costs (see Table 5-6). These costs are: (1) higher evaluation costs; (2) increased costs of adapting new building products and services to industry use; and (3) increased training costs.

These three costs may be classified as new-technology introduction costs. Ehlen and Marshall ${ }^{70}$ define new-technology introduction costs as those costs covering the activities that bring the material/product from the research laboratory to full field implementation. New-technology introduction costs include the extra time and labor to design, test, monitor, and use the new technology. Ehlen's and Marshall's research on newtechnology introduction costs is particularly relevant for this economic impact assessment because they demonstrate that new-technology introduction costs disappear once the designer is satisfied with the technology's performance, the technology enters full implementation, and its application has become routine. ${ }^{71}$

The establishment of the Virtual FIAPP Testbed will enable manufacturers to bring actual products and equipment that they have under development, obtain assistance in testing and evaluating their performance, and perform interoperability tests with other manufacturers. Thus, new-technology introduction costs are expected to decline over time. However, in keeping with the conservative approach employed in this economic impact assessment, these costs are held constant throughout the study period. An additional cost equal to $\$ 32.29 / \mathrm{m}^{2}\left(\$ 3.00 / \mathrm{ft}^{2}\right)$ is assigned when a commercial construction project employs the FIAPP alternative. As more information becomes available, the estimated cost per square meter will be revised (see Section 9.2).

\subsubsection{Increased Research and Development Costs}

BFRL launched a multidisciplinary CONSIAT research effort in Fiscal Year (FY) 1998. This effort and the eight projects that support the overall CONSIAT effort are described

\footnotetext{
${ }^{70}$ Ehlen, Mark A., and Harold E. Marshall. 1996. The Economics of New-Technology Materials: A Case Study of FRP Bridge Decking. NISTIR 5864. Gaithersburg, MD: National Institute of Standards and Technology.

${ }^{71}$ Ibid. p. 15.
} 
in Chapter 3. Because FIAPP products and services are targeted for demonstration in 2004 and commercial availability in 2005, BFRL's highest level of investment is for FY2004 through FY2006. Beginning in FY2007, BFRL's CONSIAT-related investments will decline rapidly. Beginning in 2010, BFRL moves out of the CONSIAT major product and into a long-term basic and applied research mode. Consequently, these costs are not considered part of the CONSIAT impact assessment. By 2010, BFRL's research in this area has returned to its long-term base level of funding of $\$ 2,200,000$.

It is also important to recognize that BFRL's research on the application of the ISO's Standard for the Exchange of Product (STEP) model data for the process plant industries was crucial to the establishment of its overall CONSIAT effort. Consequently, BFRL's STEP-related investments between FY1994 and FY1997 are included as part of its CONSIAT-related investments. FY1994 was chosen as the starting point, since by that time BFRL's STEP-related research had reached a high-level of maturity.

BFRL's CONSIAT-related investments are summarized in Table 6-3. The first two columns of the table record actual investments by Fiscal Year in thousands of dollars for Fiscal Years FY1994 through FY2000 and estimated investments for FY2001. The second two columns of the table record estimated investments by Fiscal Year in thousands of dollars for Fiscal Years FY2002 through FY2009. Note that all values recorded in Table 6-3 are on a Fiscal Year basis. Because the vast majority of BFRL's investment costs are staff-related costs, it is straightforward to convert Fiscal Year dollars to calendar year dollars. This conversion is necessary, because the values presented in Chapters 7 and 8 are on a calendar year basis. For example, the estimated FY2002 investment is $\$ 3,000,000$. Of the $\$ 3,000,000$ total, $25 \%$, or $\$ 750,000$, is allocated to calendar year 2001 , and $75 \%$, or $\$ 2,250,000$, is allocated to calendar year 2002 .

Table 6-3. BFRL Investment Costs by Fiscal Year

\begin{tabular}{|c|c|c|c|}
\hline $\begin{array}{c}\text { Fiscal Year } \\
\mathbf{1 9 9 4}-\mathbf{2 0 0 1}\end{array}$ & $\begin{array}{c}\text { BFRL } \\
\text { Investment Costs } \\
\text { (In \$K) }\end{array}$ & $\begin{array}{c}\text { Fiscal Year } \\
\mathbf{2 0 0 2}-\mathbf{2 0 0 9}\end{array}$ & $\begin{array}{c}\text { BFRL Estimated } \\
\text { Investment Costs } \\
\text { (In \$K) }\end{array}$ \\
\hline 1994 & $1,326^{\mathrm{a}}$ & 2002 & 3,000 \\
\hline 1995 & $1,507^{\mathrm{a}}$ & 2003 & 3,500 \\
\hline 1996 & $1,487^{\mathrm{a}}$ & 2004 & 4,000 \\
\hline 1997 & $1,733^{\mathrm{a}}$ & 2005 & 4,000 \\
\hline 1998 & $2,344^{\mathrm{a}}$ & 2006 & 4,000 \\
\hline 1999 & $2,018^{\mathrm{a}}$ & 2007 & 3,500 \\
\hline 2000 & $1,917^{\mathrm{a}}$ & 2008 & 3,000 \\
\hline 2001 & $2,256^{\mathrm{e}}$ & 2009 & 2,500 \\
\hline
\end{tabular}

$\mathrm{a}=$ actual investment costs; $\mathrm{e}=$ estimated investment costs 


\subsection{Key Assumptions and Analysis Issues}

A clear statement of the assumed values of key sets of parameters underlying the analysis is vital to understanding how the analysis was conducted. The assumptions covered in this section focus on the setting of the assumed values of the following key sets of parameters: (1) the base year; (2) the starting and ending points in the study period; (3) the discount rate; (4) the process by which FIAPP products and services diffuse into the marketplace; and (5) the process by which BFRL's contribution is measured. The assumed values of these five key sets of parameters figure prominently in evaluating the economic impacts of FIAPP products and services. Documenting the assumptions and the rationale behind the setting of the assumed values of these key sets of parameters is necessary to ensure that: (1) all costs and savings are discounted to an equivalent time basis for purpose of comparison; and (2) readers can follow the flow of the analysis, gain insights useful for their own applications, and reproduce our results.

The base year establishes the anchor point for all cost and savings calculations. The starting and ending points in the study period define both the scope of the study period-those years over which costs and savings are tabulated — and the length of the study period - a key parameter in the AIRR calculation. Because cash flows, both costs and savings, are distributed throughout the study period, the choice of the discount rate is of central importance to the analysis. The diffusion process is the critical link between potential cost savings (see Subsection 6.3.1) and cost savings nationwide (see Section 7.2). The model of the diffusion process presented in Subsection 6.4.4 provides the basis for calculating year-byyear savings following the introduction of FIAPP products and services. Because BFRL's CONSIAT-related research is expected to speed up the introduction of FIAPP products and services into the commercial marketplace, a process for evaluating the "value" of BFRL's contribution is needed. This process is described in Subsection 6.4.6.

In addition to the five key sets of parameters used to make explicit the assumptions of the economic impact assessment, there are issues linking the baseline analysis to the sensitivity analysis. These "analysis issues" are concerned with the discount rate, the diffusion process, measuring BFRL's contribution, and dealing with uncertainty. The first three analysis issues provide the necessary "direct" linkage between the baseline analysis and the sensitivity analysis. They are crucial in measuring how variations about the baseline input values affect the economic outcome measures. The last analysis issue, dealing with uncertainty, is the core concept in structuring the sensitivity analysis. This analysis issue is discussed in Subsection 6.4.5.

\subsubsection{Base Year for Computing Benefits and Costs}

The base year for computing all FIAPP-related costs and savings is 1997. There are two reasons, one primary and one secondary, why 1997 was selected as the base year. 
(1) 1997 marks the year in which BFRL formed an integrated CONSIAT project team. BFRL is working towards a prototype suite of FIAPP systems and technologies being tested and deployed in a full-scale demonstration project by 2004. Thus, by using 1997 as the base year, this economic impact study maintains its ex ante (i.e., prospective) nature while still being rooted in the present.

(2) 1997 is a year for which authoritative and comprehensive construction industry cost data are available. Thus, cost conversions for previous years may be accomplished through the use of a well-defined cost index to equate them to constant 1997 dollars.

\subsubsection{Length of the Study Period}

The study period begins in 1993 and ends in 2017. Thus, the length of the study period is 25 years. Any costs and/or savings that occur after 2017 are not included. Two factors were instrumental in determining the beginning and end of the study period.

(1) The study period begins in 1993, which is when BFRL launched its research on the application of ISO's Standard for the Exchange of Product (STEP) model data for the process plant industries. BFRL's research in this area was instrumental in the creation of PlantSTEP, Inc. in December 1994. ${ }^{72}$ However, major investments in the overall CONSIAT effort did not begin until 1997, when BFRL formed an integrated CONSIAT project team. BFRL's CONSIAT-related investments will continue at a fairly high level until 2007, at which point they will rapidly decline.

(2) The end of the study period is 2017. By 2004, BFRL will be completing a full-scale demonstration project. By 2005, the first commercial applications of FIAPP products and services are anticipated (i.e., applications other than in demonstration projects). Thus, 2005 marks the point at which FIAPP products and services penetrate the commercial marketplace. By 2017, the use of FIAPP products and services is expected to be widespread (i.e., at least $50 \%$ of the potential commercial marketplace will have been penetrated).

\subsubsection{Discount Rate}

The baseline analysis for the CONSIAT economic impact assessment uses a real rate of $7 \%$ to convert dollar amounts to present values. This rate is specified in Section 8.b of $O M B$ Circular $A-94^{73}$ as the rate for all benefit-cost analyses of public investments and regulatory programs that provide benefits or incur costs to the general public. The use of

\footnotetext{
${ }^{72}$ PlantSTEP is an industrial consortium of companies that own, design, build, operate, and maintain process plants and companies that supply equipment, materials, and information technology for the process and construction industries. The primary focus of PlantSTEP is to develop and support implementation of data exchange standards based on STEP.

${ }^{73}$ Executive Office of the President. 1992. OMB Circular A-94. Washington, DC: Office of Management and Budget.
} 
a $7 \%$ real discount rate also facilitates comparisons of the results of the CONSIAT baseline analysis with the results of the baseline analyses of the previous economic impact assessments. For purposes of this analysis, all CONSIAT-related research costs are classified as a public investment. The benefits that accrue to the public are in the form of cost savings and increased sales revenues due to reductions in delivery time.

OMB recommends that separate analyses be used to evaluate the sensitivity of key economic measures to variations in the discount rate. ${ }^{74}$ The sensitivity analysis presented in Chapter 8 evaluates the implications of raising the discount rate to $10 \%$ or lowering the discount rate to $2 \%$. The $2 \%$ to $10 \%$ range of values for the real discount rate was chosen to bracket the historical values of real treasury interest rates. These rates are periodically updated by OMB and published in Appendix C of OMB Circular A-94; they apply to government lease-purchase and cost-effectiveness analyses. Although these rates do not apply to regulatory analyses or benefit-cost analyses of public investments, they provide a useful frame of reference for establishing minimum and maximum values for the real discount rate. All values of the discount rate used in this report are real rates, since constant dollar estimates of benefits and costs are used.

\subsubsection{Diffusion Process}

Facts and data are essential components in any rigorous analysis. Factual information on the commercial sector was tabulated from published sources (see Section 4.2). These data provide the basis for estimating the "potential" benefits and cost savings associated with the use of the FIAPP products and services in commercial buildings (see Subsection 6.3.1). However, to develop realistic estimates of cost savings nationwide, it is also necessary to generate estimated values for the annual proportion of commercial buildings employing FIAPP products and services for new construction activities and for additions and alterations. To generate estimates of cost savings nationwide, information on potential benefits and cost savings and on cost increases and benefit reductions (e.g., new-technology introduction costs) must be coupled with a model of the diffusion process. Much of the discussion in this subsection and in Section 7.2 of the next chapter is aimed at establishing an audit trail for how the values of the key parameters of the diffusion process were established and employed in the economic impact assessment. The focus of this subsection is on how the diffusion process is modeled (i.e., the form of the model and its key parameter values). Section 7.2 focuses on how the diffusion model is employed in the economic impact assessment.

An economy is not affected in any material way by a new technology until the use or ownership of that technology is widespread. This spread of a new technology is a topic usually referred to as technological diffusion. It is modeled via a diffusion process. The underlying basis for the study of technological diffusion is to rationalize why, if a new technology is superior, it is not taken up immediately by all potential users.

The empirical analysis of diffusion processes is a vast and complex subject. Although a

${ }^{74}$ Ibid., p. 7. 
full treatment of the topic is beyond the scope of this report, four factors affecting the diffusion process are worth noting. Readers interested in thorough treatments of this important subject, including case studies, are referred to the books by Stoneman ${ }^{75}$ and Mansfield. $^{76}$

First, new technology and its adoption involve uncertainty. Thus, the attitude of decision makers to uncertainty needs to be considered. The degree of uncertainty may be related to the level of use of the new technology and to how learning proceeds.

Second, how learning proceeds affects the diffusion process in a number of ways. It can involve learning about the existence of a new technology or learning about its true characteristics. For example, firms might learn about how to use the new technology to produce new or current products at lower cost. For a given initial state of knowledge, the faster that learning occurs, the higher the rate of diffusion.

Third, during a diffusion process, how learning proceeds may not be the only factor changing. The good itself may be improving. This improvement may have a doubleedged effect on diffusion: a direct effect, stimulating greater use; and an indirect effect, whereby expectations of future advances may lead to the postponement of adoption.

Fourth, to a large degree the adoption decision for the firm will be related to expected profitability, which in turn will be dependent upon a number of factors. Thus differences between firms will be important, as may be the behavior of the industry supplying any new goods. The market structure of the user and supplying industries (i.e., situations involving imperfect competition) are also important.

The most widely accepted model of technology diffusion was developed by Edwin Mansfield. Consequently, the Mansfield model is employed in the CONSIAT economic impact assessment. The Mansfield model estimates the proportion of potential users who have adopted the new technology by time $t$. The mathematical representation of the model is

$$
P(t)=\left[1+e^{(\alpha-\beta t)}\right]^{-1}
$$

where
$P(t)=$ the proportion of potential users who have adopted the new technology by time $t$,
$e \quad=\quad$ Euler's number, the base of the natural system of logarithms,

\footnotetext{
${ }^{75}$ Stoneman, Paul. 1983. The Economic Analysis of Technological Change. New York: Oxford University Press.

${ }^{76}$ Mansfield, Edwin. 1995. Innovation, Technology and the Economy: Selected Essays of Edwin Mansfield. 2 vols. Economists of the Twentieth Century Series. Aldershot, UK: Elgar.
} 
$\alpha \quad=\quad$ the location parameter, and

$\beta \quad=\quad$ the shape parameter $(\beta>0)$.

A plot of $P(t)$ produces an S-shaped logistics curve, which is asymptotic to 0 as the value of $t$ gets small and to 1 as the value of $t$ gets large. Because the diffusion of a new technology may not achieve $100 \%$ penetration of the marketplace, $P(t)$ must be modified to reflect the level at which the potential market is saturated. The version of the Mansfield model employed in this report uses a subscript $\eta$ to designate the market saturation level. The mathematical representation of the model is

$$
P_{\eta}(t)=\eta\left[1+e^{(\alpha-\beta t)}\right]^{-1}
$$

where

$$
\begin{array}{lll}
P_{\eta}(t)= & \begin{array}{l}
\text { the proportion of potential users who have adopted the new technology by } \\
\text { time } t,
\end{array} \\
\eta \quad & \text { the market saturation level, } \\
e & =\quad \text { Euler's number, the base of the natural system of logarithms, } \\
\alpha \quad & =\quad \text { the location parameter, and } \\
\beta \quad & = & \text { the shape parameter }(\beta>0) .
\end{array}
$$

An extensive review of the economics literature on the diffusion process produced candidate values for $\alpha$ and $\beta$. Readers interested in case studies based on the Mansfield model that are useful in specifying values for $\alpha$ and $\beta$ are referred to Mansfield's collection of articles. ${ }^{77}$ An additional factor used to specify the values of $\alpha$ and $\beta$ is the length of time it takes for $P_{\eta}(t)$ to reach $50 \%$ of its potential market. Due to the relationship between the Mansfield model and the logistics distribution, the value at which $P_{\eta}(t)$ reaches $50 \%$ of its potential market has a closed-form relationship based solely on the values of $\alpha$ and $\beta$. If we assume $t=1$ is the time at which the technology is first introduced, then $\alpha / \beta$ is the number of years it takes that technology to reach $50 \%$ of its potential market. In order to get a meaningful value of $t$, it is necessary to constrain $\alpha$ to be positive (i.e., $\alpha>0$ ).

The values of the ratio $\alpha / \beta$ vary from 4 years to 16 years in a wide range of articles published in the economics literature (see Mansfield, ${ }^{78}$ Mansfield et al, ${ }^{79}$ and Simon ${ }^{80}$ ).

\footnotetext{
${ }^{77}$ Mansfield, Innovation, Technology and the Economy, Vol. II, pp. 3-83.

${ }^{78}$ Ibid., pp. 63-72.

${ }^{79}$ Mansfield, Edwin, John Rapoport, Anthony Romeo, Edmond Villani, Samuel Wagner, and Frank Husic. 1977. The Production and Application of New Industrial Technology. New York: W. W. Norton \& Company, Inc.
} 
Consequently, this report uses a value of 8 for the ratio $\alpha / \beta$ as its baseline value. The corresponding baseline values for $\alpha$ and $\beta$ are 4.0 and 0.5 , respectively.

The estimated value for $\eta$ was set equal to 0.4 . Thus, the baseline value for $\eta$ is 0.4 . This means that FIAPP products and services will eventually be employed in projects totaling $40 \%$ of the value of construction put in place for large commercial buildings. Recall that a large commercial building is defined as a building with more than 4,645.1 $\mathrm{m}^{2}$ of floor area $\left(50,000 \mathrm{ft}^{2}\right)$. The estimated value for $\eta$ for this class of commercial buildings is based on data contained in the 1995 CBECS. Specifically, the value of $\eta$ is set to approximate the average proportion of floorspace in large commercial buildings employing either an energy management and control system ${ }^{81}$ (EMCS) or energy efficient motors. $^{82}$ These technologies were selected because they are mature (i.e., their use is sufficiently widespread to "approximate" market saturation) and they embody a combination of hardware and software technologies that have significant information resource management requirements.

From the discussion that follows, it should be clear that this estimate is rather conservative. Thus, the estimated savings nationwide and the value of BFRL's contribution may be considered to be lower bound estimates.

Penetration of the market by FIAPP products and services for commercial sector projects will be driven by two mutually reinforcing factors. These factors are: (1) the desire of the owners of large commercial buildings to use information technology as a tool for reducing both life-cycle costs and cycle time; and (2) the need for contractors to improve their productivity and profitability in an increasingly competitive global marketplace.

The owners of commercial buildings have a tremendous incentive to improve the delivery process for construction projects. This point is underscored by a Business Roundtable report that summarizes data on over 60 major companies' project systems. ${ }^{83}$ When examining the relative performance of these systems, some important trends appear.

Most important from a business perspective, the gap between the best and the worst has widened over the past several years. Some companies have learned how to acquire consistent and significant comparative advantages from their capital project systems, while others find themselves increasingly at a disadvantage.

\footnotetext{
${ }^{80}$ Simon, P. 1975. Models of Process Diffusion and Entry in the U.S. Chemical Industry. Ph.D. dissertation, University of Pennsylvania.

${ }^{81}$ An EMCS is an energy management feature that uses mini/micro-computers, instrumentation, control equipment, and software to manage a building's use of energy for heating, ventilation, air conditioning, lighting, and/or business-related processes. These systems can also manage fire control, safety, and security.

${ }^{82}$ A demand-side management program designed to promote high-efficiency motors, adjustable speed drives, or variable speed motors to ensure that the motor's speed and size is properly matched to the load placed on the motor.

${ }^{83}$ The Business Roundtable. 1997. The Business Stake in Effective Project Systems. Washington, DC: The Business Roundtable.
} 
In relative cost performance, the best company is spending 72 cents of the industry average dollar for the same functional scope. The fastest company takes only $70 \%$ as long as the industry average to bring a project from a business idea to a facility in production. ${ }^{84}$

Although the results published by The Business Roundtable are associated with industrial facilities, research by CII has demonstrated similar trends for commercial buildings. Specifically, comparisons between the best performing $25 \%$ of commercial building projects and the worst performing $25 \%$ show differences in cost growth of $7.7 \%$ and construction phase duration of more than $30 \% .{ }^{85}$ Another CII study showed that CII owners had a significant financial incentive to partner with CII contractors in order to reduce cycle time and achieve better control over cost growth. ${ }^{86}$

Contractors who wish to survive and prosper will be pushed to employ design and information (i.e., FIAPP-like) technologies from two sources. First, the owners of large commercial buildings will increasingly demand the use of these technologies as a requirement for partnering (i.e., owners are committed to the use of these technologies both in their core business processes and in their supply chain management process). This point was touched on previously from the owner's perspective and will not be explored further here. Second, contractors have experienced a significant, sustained decline in productivity vis-à-vis the rest of the economy. ${ }^{87}$ This decline in productivity has adversely affected profitability, causing profit margins to shrink. Thus, contractors see the use of FIAPP products and services as a competitive edge for their business, enabling them to both increase net income and reduce project duration. The former directly impacts profitability, whereas the latter creates the opportunity for a greater volume of work.

Because large contractors dominate the markets for engineering design and construction of large commercial buildings, their adoption and use of FIAPP products and services are likely to be both rapid and extensive. The basis for the previous statement may be seen by noting that the top 50 contractors in 1997 installed $\$ 28.7$ billion worth of commercial sector projects. ${ }^{88}$ Although these figures represent global revenues, a significant share of these commercial sector projects was domestic.

The specification of the baseline values of the diffusion model is not complete until a time of first use is made explicit. As noted earlier, the time of first use corresponds to the value at which $t=1$. The baseline value for the time of first use is based on the assumption that the demonstration project will be completed in 2004 . Once the

\footnotetext{
${ }^{84}$ Ibid. pp. 2-3.

85 Thomas, Macken, and Lee, Impacts of Design/Information Technology on Building and Industrial Projects.

${ }^{86}$ Thomas, Stephen R. 1998. Benchmarking and Metrics Summary for 1997. BMM 97-1. Austin, TX: Construction Industry Institute.

${ }^{87}$ Teicholz, Paul M. "Reverse Productivity Declines," ENR, Vol. 243, No. 23, December 13, 1999, p. 59.

88 Tulacz, Gary J. “Top 400 Contractors,” ENR Sourcebook, November 1998, pp. 4-10.
} 
demonstration project has been completed, FIAPP products and services will become available commercially. Thus, the baseline value for the time of first use is 2005 .

The values of $\alpha$ and $\beta$ specify the rate of adoption of FIAPP products and services in commercial buildings, whereas the value of $\eta$ specifies the size of the potential market for these products and services. Consequently, once the time of first use is made explicit, it becomes possible to estimate the annual proportion of construction-related expenditures in the commercial sector covered by FIAPP products and services. For any given year, this amount is equal to the product of $P_{\eta}(t)$ for that year and the total value of construction-related expenditures in the commercial sector (i.e., $\$ 205.7$ billion) and the constant of proportionality for large commercial buildings (i.e., 0.44). Table 6-4 records the value of $P_{\eta}(t)$ for values of $t$ from 0 to 16 (i.e., from 2004 to 2020). ${ }^{89}$ Note that the years shown on the table extend past the end of the study period.

Table 6-4. Baseline Case of $P_{\eta}(t)(\alpha=4.0, \beta=0.5, \eta=0.4)$

\begin{tabular}{|l|c|c|}
\hline Year & $\mathbf{t}$ & $\mathbf{P}_{\mathbf{r}}(\mathbf{t})$ \\
\hline 2004 & 0 & 0.0000 \\
2005 & 1 & 0.0078 \\
2006 & 2 & 0.0190 \\
2007 & 3 & 0.0303 \\
2008 & 4 & 0.0477 \\
2009 & 5 & 0.0730 \\
2010 & 6 & 0.1076 \\
2011 & 7 & 0.1510 \\
2012 & 8 & 0.2000 \\
2013 & 9 & 0.2490 \\
2014 & 10 & 0.2924 \\
2015 & 11 & 0.3270 \\
2016 & 12 & 0.3523 \\
2017 & 13 & 0.3697 \\
2018 & 14 & 0.3810 \\
2019 & 15 & 0.3883 \\
2020 & 16 & 0.3928 \\
\hline
\end{tabular}

\footnotetext{
${ }^{89}$ The values of $\mathrm{P}_{\eta}(\mathrm{t})$ corresponding to years 2004 (i.e., $t=0$ ) and 2005 (i.e., $t=1$ ) have been adjusted to reflect the assumption that FIAPP products and services are not expected to be available in 2004 and may not be available at the start of 2005. This is accomplished via a multiplicative adjustment factor, see Equation 7.1 in Section 7.2, that takes on a value of 0 for $t<1$, a value of 0.667 for $t=1$, and a value of 1.0 for $\mathrm{t} \geq 2$.
} 
The diffusion model, as specified above and used in the baseline analysis, is plotted in a graphical form in Figure 6-6. The trace of $P_{\eta}(t)$ is shown as a solid line in Figure 6-6. The vertical axis of Figure 6-6 records the values of $P_{\eta}(t)$. The values on the vertical axis ranges from 0 to $\eta$. The horizontal axis of Figure 6-6 records the values of $t$ and the years for which the value of $P_{\eta}(t)$ is calculated. Recall that in the baseline analysis $t=1$ corresponds to the year 2005. ${ }^{90}$ Note that the years shown on the horizontal axis extend past the end of the study period. This is done to show that $P_{\eta}(t)$ does not approach the market saturation level, $\eta$, until well after the study period is over. Thus, substantial cost savings due to the use of FIAPP products and services will continue to accrue well after the end of the study period. Once again, this leads to the conclusion that the estimated savings nationwide are a lower-bound estimate.

\section{Figure 6-6. Baseline Case of $P_{\eta}(t)$ by $t($ year $)$}

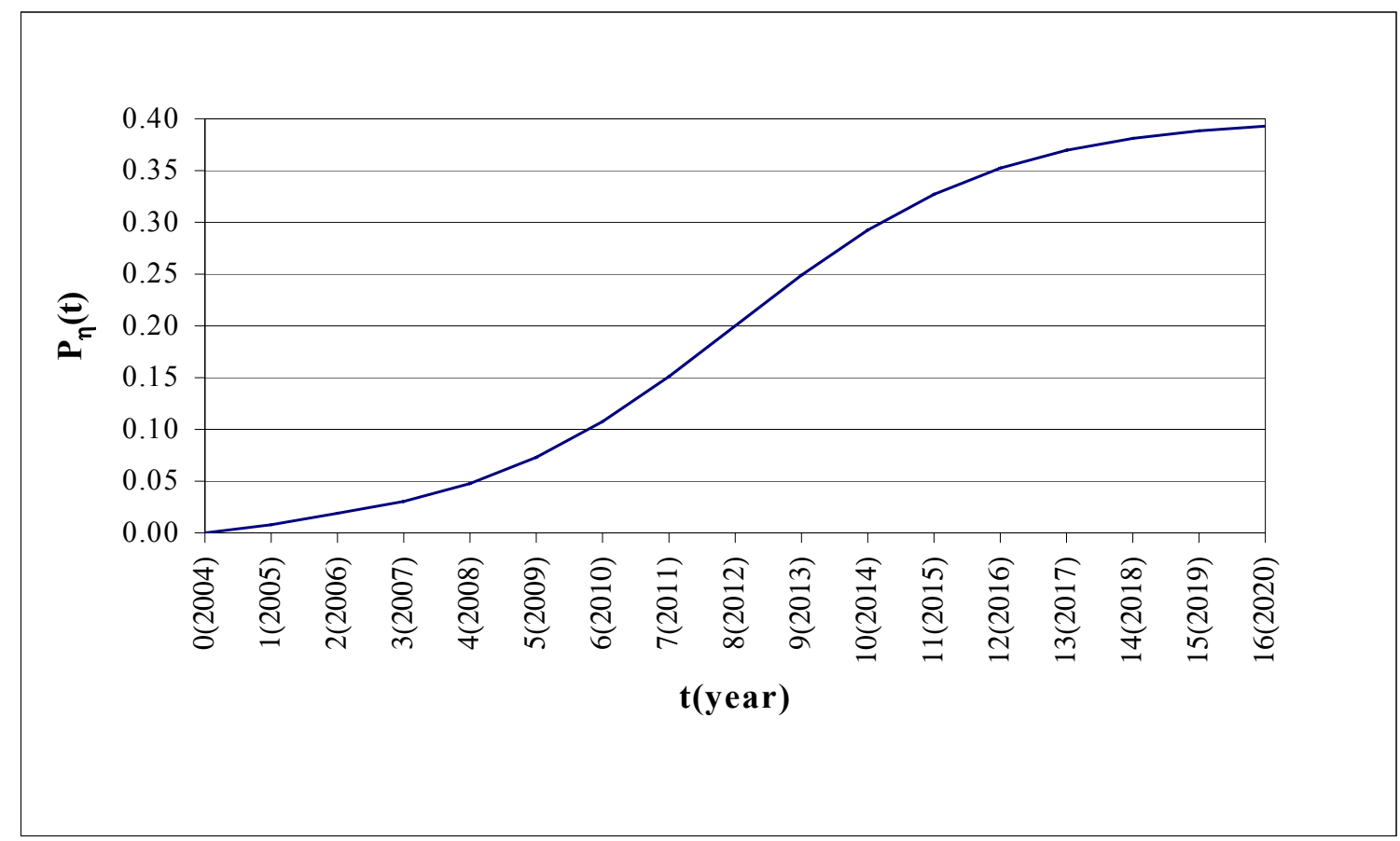

Much of the sensitivity analysis is concerned with the diffusion model (see Chapter 8). As such, ranges of values were specified for $\alpha, \beta, \eta$, and the time of first use. The ranges for $\alpha$ and $\beta$ were selected based on values of $\alpha$ and $\beta$ published in the economics literature and their implications for the values of the ratio $\alpha / \beta$ also published in the economics literature. The range of values for $\alpha$ used in the sensitivity analysis is a low of 3 and a high of 5 (i.e., $3 \leq \alpha \leq 5$ ). The range of values for $\beta$ used in the sensitivity analysis is a low of 0.4 and a high of 0.6 (i.e., $0.4 \leq \beta \leq 0.6$ ). These ranges of values for

\footnotetext{
${ }^{90}$ As noted earlier, the value of $P_{\eta}(t)$ for $t=1$ is multiplied by 0.667 to reflect the likelihood that FIAPP products and services may not be available at the start of the first year.
} 
$\alpha$ and $\beta$ result in ranges for the ratios $\alpha / \beta$ which are consistent with the values published in the economics literature (i.e., $5.0 \leq \alpha / \beta \leq 12.5$ ).

The range of values for $\eta$ is based on information published in the 1995 CBECS. These values range from a low of $30 \%$ to a high of $50 \%$ (i.e., $0.3 \leq \eta \leq 0.5$ ). The range of values for the time of first use are based on "targeted" times (i.e., years) at which FIAPP products and services will be available commercially. These times range from a low of 2004 to a high of 2007. That is, the earliest date at which FIAPP products and services are commercially available is in the year 2004 and the latest date is 2007. The alternative times of first use are specified by a discrete distribution, also known as the multinomial distribution. The discrete probabilities for each year are: $2004,0.125 ; 2005,0.5 ; 2006$, 0.25 ; and 2007, 0.125 .

\subsubsection{Dealing with Uncertainty}

Uncertainty enters into a benefit-cost analysis in three main ways. First, the value of cash flows (i.e., benefits, costs, and savings) may not be known with certainty. For example, a new technology may not be well understood by many potential users, implying that their benefits of adopting the technology may be subject to considerable variability. Consequently, decision makers are presented with a range of potential benefit values (e.g., high, moderate, and low). As the technology becomes better known, this range of values may be reduced (i.e., uncertainty, in the form of benefit variability, is being reduced with time as new information becomes available). In addition, variations in the discount rate affect the present value of any cash flows which do not occur in the base year.

Second, the timing of cash flows may not be known with certainty. In the case of a new technology, the process by which the technology diffuses to firms and households may take many time paths. ${ }^{91}$ For example, one time path might imply slow adoption at first followed by a period of rapid adoption. Such might be the case if, shortly after introduction, the technology were adopted as a standard. Alternatively, the new technology might enjoy a brief period of rapid adoption followed by a relatively long period of slow adoption. Such might be the case if, after introducing the new technology, there were a series of product improvements that caused many potential users to adopt a "wait and see" attitude.

Third, the value, timing, and magnitude of cash flows may not be known with certainty. This "composite" source of uncertainty is more complex than the two cases just

\footnotetext{
91 The time paths by which a new technology may diffuse have several characteristics that are important. First, there is a time of first use (i.e., when the technology is introduced to the market place). If the time of first use is considered fixed, then it is the same for all that technology's time paths. Second, for each time path, there is a rate of adoption; the rate of adoption affects the slope of the time path. It is important to recognize that the slope of the time path need not be the same at different points on the time path. Finally, there is a level of adoption that prevails when the market reaches saturation.
} 
discussed. It includes three issues related to the time path overlaid by variability in benefits, costs, and savings. The three time path issues are related to the time of first use (i.e., when the technology is introduced to the market place), the rate of adoption over the time path, and the level of adoption that prevails when the market reaches saturation. Although the introduction of a new technology can be expected to result in variability of benefits, costs, and savings for users which adopt it (i.e., there is some uncertainty about the values of these cash flows and, via the discount rate, their present values), the case at hand is more complex. Variations in the time of first use and the rate of adoption are the principal sources of variability in the timing of cash flows. Variations in the level of adoption enter as factors affecting both the values and the magnitudes of cash flows. This is because the level of adoption comes into play as a multiplicative factor applied to any given time path. While different times of first use and rates of adoption affect the timings of cash flows, different adoption levels affect the values (i.e., due to its being overlaid by the variability in benefits, costs, and savings) and magnitudes (i.e., due to its affect on the size of the potential market) of these cash flows. Consider the case of the direct benefits to users from adopting a new technology. Other things being equal, higher levels of adoption result in larger benefit streams and higher variability (i.e., a wider range of values) of those benefit streams across all time paths than do lower levels of adoption.

\subsubsection{Measuring BFRL's Contribution}

This section describes the process used to measure the "value" of BFRL's contribution to the development of FIAPP products and services for use in commercial buildings. It begins with a review of the nature of BFRL's contribution.

BFRL's contribution serves two vital roles. One is that of a facilitator, and the other is that of a developer of key FIAPP enabling technologies. Both roles are crucial if commercial products and services are to be developed in a timely manner.

BFRL's role as facilitator has three facets. First, BFRL is participating in a consortium of facility owners, contractors, construction product and equipment manufacturers, and service providers interested in producing, testing, demonstrating, and buying and selling FIAPP products and services. Second, BFRL is participating in the Virtual FIAPP Testbed to facilitate the development and evaluation of new products and systems by manufacturers and external service providers. Third, BFRL is working towards an operational prototype FIAPP being tested and deployed in a full-scale demonstration project by 2004.

BFRL's role as developer of key FIAPP enabling technologies is extensive and pervasive; it spans all eight projects in the integrated CONSIAT project team (see Section 3.2). However, three areas of BFRL's research and development effort are particularly important, since they provide platforms on which vendors can develop commercial products and services. First, BFRL is developing and testing standard communication protocols for the open exchange of information. Second, BFRL is developing advanced 
measurement technologies. Third, BFRL is developing interoperability testing procedures to facilitate the development and introduction of FIAPP products and services into the marketplace.

This review of the nature of BFRL's contribution makes it clear that BFRL is a catalyst in the development of FIAPP products and services. Does this mean that FIAPP products and services would not be developed without BFRL's participation? The answer to that question is an unequivocal "No." Eventually, FIAPP products and services would become commercially available. Would they have the same capabilities? The answer to that question is a qualified "Probably not." The reasoning stems from the fact that the nature of BFRL's dual role is one that few organizations can fill. Consider the case of an enabling technology. Few if any vendors will invest in enabling technologies, since they can not adequately recapture their investment. In fact, other vendors might be able to employ the enabling technology to develop their own proprietary products. BFRL and NIST do not have this problem, since a key part of their mission is to promote competitiveness through the development of enabling technologies. A similar reasoning holds for BFRL's role as a facilitator. Thus, BFRL's contribution both serves to speed up the introduction of FIAPP products and services and to result in products and services with better understood properties and, in all likelihood, better capabilities. The remainder of this section focuses on how to measure the value of BFRL's contribution in speeding up the introduction of FIAPP products and services.

Because BFRL's research effort is expected to result in a faster introduction of FIAPP products and services into the commercial marketplace, those savings which would have been foregone in the event of a delay are attributable to BFRL. Information from subject matter experts and similar economic impact assessments ${ }^{92,93}$ was used to develop an estimate of how much the commercial introduction of FIAPP products and services would have been delayed, were it not for BFRL's dual role as a facilitator and developer of key FIAPP enabling technologies. Without BFRL's involvement, the commercial introduction of FIAPP products and services is estimated to occur in 2009, a delay of four years (i.e., commercial introduction in 2009 rather than in 2005). Therefore, any savings prior to the "delayed" introduction of FIAPP products and services in 2009 would have been foregone. Such an accounting framework may be handled through use of a $0-1$ weighting factor. For those years in which savings are attributable to BFRL, the weighting factor takes on a value of 1 . For all years after the "delayed" introduction of FIAPP products and services in 2009, the weighting factor takes on a value of 0.

An important part of the sensitivity analysis is concerned with measuring changes in the value of BFRL's contribution. The value of BFRL's contribution is measured through the use of a 0-1 weighting factor tied to BFRL's efforts to speed up the commercial introduction of FIAPP products and services. These efforts vary in their funding requirements, depending on whether commercial introduction is targeted for 2004, 2005, 2006, or 2007. The estimated BFRL investment costs, as a function of the year targeted

\footnotetext{
${ }^{92}$ Chapman and Weber, A Case Study of the Fire Safety Evaluation System, pp. 31-42.

${ }^{93}$ Chapman, Robert E. 1999. Benefits and Costs of Research: A Case Study of Cybernetic Building Systems. NISTIR 6303. Gaithersburg, MD: National Institute of Standards and Technology.
} 
for first commercial use, are summarized in Table 6-5. Reference to the table shows that a very aggressive level of funding is required if FIAPP products and services are to become available in 2004. However, if these products become available in 2004, then the BFRL weighting factor takes on a value of 1 for 2004 through 2008 (i.e., a "delay" of five years is avoided) and a value of 0 from 2009 until the end of the study period. On the other hand, if funding were held constant, then commercial introduction is not expected to occur until 2007. In this scenario, the BFRL weighting factor would take on a value of 1 for 2007 and 2008 (i.e., a "delay" of two years is avoided) and a value of 0 from 2009 until the end of the study period.

Table 6-5. Estimated Investment Costs as a Function of the Year of First Commercial Use

\begin{tabular}{|c|c|c|c|c|}
\hline \multirow{2}{*}{ Fiscal Year } & \multicolumn{4}{|c|}{$\begin{array}{c}\text { BFRL Estimated Investment Costs (In \$K) as a } \\
\text { Function of the Year of First Commercial Use }\end{array}$} \\
\cline { 2 - 5 } & $\mathbf{2 0 0 4}$ & $\mathbf{2 0 0 5}$ & $\mathbf{2 0 0 6}$ & $\mathbf{2 0 0 7}$ \\
\hline 2002 & 5,000 & 3,000 & 2,500 & 2,200 \\
\hline 2003 & 6,000 & 3,500 & 3,000 & 2,200 \\
\hline 2004 & 6,000 & 4,000 & 3,500 & 2,200 \\
\hline 2005 & 6,000 & 4,000 & 4,000 & 3,000 \\
\hline 2006 & 5,000 & 4,000 & 4,000 & 4,000 \\
\hline 2007 & 3,500 & 3,500 & 4,000 & 4,000 \\
\hline 2008 & 3,000 & 3,000 & 3,500 & 4,000 \\
\hline 2009 & 2,500 & 2,500 & 3,000 & 3,000 \\
\hline
\end{tabular}

Each of the four scenarios (i.e., year targeted for first commercial use) is examined in Chapter 8. A two-stage analysis is employed. The first stage analysis focuses on measuring the return to the public from each scenario, assuming that the first commercial use of FIAPP products and services occurs in the year targeted. The second stage evaluates the consequences of targeting commercial introduction for one year but not achieving it until later. This analysis examines the critical relationship between risk and return for each scenario. The second stage analysis employs both deterministic and Monte Carlo techniques to measure the expected outcomes associated with no lag, a one year lag, and a two year lag between the year targeted for commercial introduction and the year in which commercial introduction was achieved. The alternative lags are specified by a discrete distribution. The discrete probabilities for each lag are: no lag, 0.6 ; a one year lag, 0.25; and a two year lag, 0.15 . 


\section{Baseline Analysis of Economic Impacts}

The baseline analysis presented in this chapter is the reference point for the CONSIAT economic impact assessment. Recall that in the baseline analysis, all data entering into the calculations are set at their likely values (see Section 2.1.1). Throughout this report, likely value and baseline value are used interchangeably. Thus, the baseline values represent a fixed state of analysis. The term baseline analysis is used to denote a complete analysis in all respects but one; it does not address the effects of uncertainty. Sensitivity analysis measures the impact on project outcomes of changing the values of one or more key variables about which there is uncertainty. Sensitivity analysis is the subject of Chapter 8 .

The results of the baseline analysis portion of the CONSIAT economic impact assessment are presented for two basic cases (see Exhibit 7-1). First, are the cost savings nationwide achievable through the use of FIAPP products and services in commercial buildings. Second, are the cost savings attributable to BFRL and the return on BFRL's CONSIAT-related investment costs.

Key economic measures show the present value of savings (PVS), the present value of net savings (PVNS), the savings-to-investment ratio (SIR), and the adjusted internal rate of return (AIRR) that are attributable to BFRL's CONSIAT-related research, development, and deployment efforts (see Chapter 3). These values are derived by measuring how cost savings nationwide would have been reduced if BFRL had not been involved in the development of FIAPP products and services (see Section 6.4.6).

The results of the baseline analysis demonstrate that the use of FIAPP products and services will generate substantial cost savings to commercial building owners and managers and to contractors engaged in the construction of those buildings. The present value of savings nationwide expected from the use of FIAPP products and services is nearly \$1.4 billion (measured in 1997 dollars). Furthermore, because of BFRL's involvement, FIAPP products and services are expected to be commercially available in 2005. If BFRL had not participated in the development of FIAPP products and services, the commercial introduction of FIAPP products and services is expected to be delayed until 2009. Consequently, potential cost savings accruing to commercial building owners and managers and to contractors over the period 2005 through 2008 would have been foregone. The present value of these cost savings is approximately $\$ 120$ million. These cost savings measure the value of BFRL's contribution for its CONSIAT-related investment costs of approximately $\$ 29.1$ million. Stated in present value terms, every public dollar invested in BFRL's CONSIAT-related research, development, and deployment efforts is expected to generate $\$ 4.13$ in cost savings to the public (i.e., an SIR of 4.13). The annual percentage yield (AIRR) from BFRL's CONSIAT-related investments over the study period is $13.3 \%$. 


\section{Exhibit 7-1. Summary of Economic Impacts of BFRL Research on Construction Systems Integration and Automation Technologies in Commercial Buildings}

\section{1.a Significance of Research Effort:}

Owners of commercial buildings and contractors engaged in the construction of those facilities are pressing for reductions in delivery time as a means of improving their competitive positions. Owner concerns over both the first costs and life-cycle costs of commercial buildings and tightening profit margins for contractors are also affecting the competitive positions of each stakeholder. One means of improving the competitive positions of each commercial sector stakeholder is through the development, adoption, and use of fully-integrated and automated project process (FIAPP) products and services. Characteristics of FIAPP products and services include one-time data entry; interoperability with design, construction, and operation processes; and user-friendly input/output techniques. BFRL's focused research efforts, its collaboration with the Construction Industry Institute (CII), and its participation in the FIATECH Consortium are designed to deliver FIAPP products and services to CII members and the rest of the construction industry.

BFRL's focused research on Plant STEP, construction metrology, and economic analysis led BFRL to form an integrated CONSIAT project team in 1997. In addition, BFRL is uniquely positioned to collaborate with industry on the development of FIAPP products and services and to provide a forum for conducting interoperability testing. BFRL is working towards a prototype FIAPP being tested and deployed by 2004. To achieve this goal, BFRL is working with building owners, contractors, equipment and systems manufacturers and service providers, software developers, building managers, trade associations, professional societies, standards organizations, university researchers, and other government agencies. Without BFRL's participation, it is likely that the introduction of FIAPP products and services will be delayed for at least four years.

\section{1.b Key Points:}

- Pressure to reduce delivery time and lifecycle costs has created a potential market for FIAPP products and services.

- BFRL is uniquely positioned to collaborate with industry on the development of FIAPP products and services and to provide a forum for conducting interoperability testing.

- Without BFRL's participation, it is likely that the introduction of FIAPP products and services will be delayed for at least four years.

\section{Analysis Strategy: How Key Measures are Estimated}

The objective of the study is to (1) evaluate, for the period 1993 through 2017, the net cost savings due to the adoption and use of FIAPP products and services in commercial buildings, and (2) estimate BFRL's contribution to these net cost savings. The approach is to estimate in 1997 present value (PV) dollars:

Present Value Cost Savings Nationwide in commercial buildings that employ FIAPP products and services. PV cost savings nationwide are estimated for each year from 1993 to 2017 and summed. Present Value Savings (PVS) attributable to BFRL by including the savings only for those years that accrued due to BFRL's participation (i.e., 1993 to 2008).

Present Value Net Savings (PVNS) attributable to BFRL by subtracting from BFRL PVS the present value of BFRL's investment costs (PV Costs). A PVNS $>0$ indicates an economically worthwhile project.

Two additional measures are also estimated:

Savings-to-Investment Ratio (SIR) attributable to BFRL by taking the ratio of BFRL PVS to BFRL PV Costs. A ratio $>1$ indicates an economically worthwhile project.

Adjusted Internal Rate of Return (AIRR), the annual rate of return over the study period on BFRL's investment. An AIRR $>$ the discount rate indicates that the project is economically worthwhile. 
Exhibit 7-1. Summary of Economic Impacts of BFRL Research on Construction Systems Integration and Automation Technologies in Commercial Buildings (continued)

\section{Analysis Strategy: Data and Assumptions}

- The period over which costs and savings are measured begins in 1993 and ends in 2017. Hence the length of the study period is 25 years.

- The base year is 1997, and all amounts are calculated in PV 1997 dollars.

- The discount rate is $7 \%$ (real), which is the discount rate currently in effect for government projects.

- Estimates of cost savings associated with the adoption and use of FIAPP products and services are based on construction industry data and information provided by industry experts.

- Without BFRL's participation, the introduction of FIAPP products and services will be delayed by four years.

3.a Calculation of Savings, Costs, and Additional Measures

\section{Savings and Costs}

Present Value Cost Savings Nationwide (PVCSN):

Sum from 1993 to 2017 of present value of cost savings nationwide by year

$$
=\$ 1,377.9 \text { million }
$$

Present Value Savings (PVS) Attributable to BFRL:

Sum from 1993 to 2008 of present value of cost savings nationwide by year

$$
=\$ 120.5 \text { million }
$$

Present Value Investment Costs (PV Costs) to BFRL:

Sum from 1993 to 2017 of present value of investment cost to BFRL by year

$$
=\$ 29.144 \text { million }
$$

Present Value Net Savings (PVNS) Attributable to BFRL:

Difference between present value savings (PVS) attributable to BFRL and present value of investment costs (PV Costs) to BFRL

$$
=\$ 120.5-\$ 29.144 \quad=\$ 91.3 \text { million }
$$

\section{Additional Measures}

SIR of BFRL Contribution:

Savings-to-Investment Ratio on BFRL investment

$$
=\$ 120.5 / \$ 29.144 \quad=4.13
$$

AIRR of BFRL Contribution:

Adjusted Internal Rate of Return on BFRL investment $=(1+0.07) * 4.13^{1 / 25}-1 \quad=0.133$ 3.b Key Results:

1997 Dollars

(\$ amounts in millions)

Cost Savings Nationwide:

$\$ 1,377.9$

Savings Attributable to BFRL:

PVS

$\$ 120.5$

PV Costs

$\$ 29.144$

PVNS

$\$ 91.3$

SIR 4.13

AIRR $13.3 \%$

3.c Traceability:

ASTM Discount Factor Tables (PVCSN and PVS)

ASTM E 917 (PV Costs)

ASTM E 1074 (PVNS)

ASTM E 964 (SIR)

ASTM E 1057 (AIRR) 


\subsection{BFRL Summary Impact Statement}

Exhibit 7-1 is a summary impact statement, covering the background, approach, and results of the baseline analysis. Exhibit 7-1 utilizes the framework introduced in Chapter 2 (see Exhibit 2-1).

\subsection{Cost Savings Nationwide}

This section combines three types of information presented in Sections 6.3 and 6.4 to generate a baseline estimate of cost savings nationwide. These three types of information are related to: (1) the diffusion model developed in Section 6.4.4; (2) the cost savings due to reductions in first costs, maintenance and repair costs, and construction-related accidents and the increases in net income for owners and contractors due to reductions in delivery time and higher contractor profit margins; and (3) new-technology introduction costs. These three types of information are combined via three sets of calculations to estimate "annual" cost savings to the nation. Estimates are produced for each year from 1993 to 2017. Each year's cost savings is then discounted to a present value and summed to get the present value of cost savings nationwide. The present value of cost savings nationwide is a key indicator of the merits of employing FIAPP products and services in commercial buildings. The results of the baseline analysis show that cost savings nationwide are nearly $\$ 1.4$ billion ( $\$ 1,378$ million in present value 1997 dollars). Each set of calculations used to produce the estimate of cost savings nationwide is summarized through a table and described in the text that follows.

Table 7-1 summarizes information derived from the diffusion model. To help readers reproduce the values recorded in Columns 2 through 5 of Table 7-1, the formula used to estimate the annual value for each column heading is given (see Equations 7.1 through 7.4). In each formula, $t$ corresponds to the Year (see Column 1 of Table 7-1) for which values are calculated (i.e., $t=1$ corresponds to Year $=2005$ ). Terms used in each formula are defined the first time they appear. Note that several equations use the same term (e.g., the value of commercial sector construction employing FIAPP products and services, $V I P_{C F}(t)$, appears in Equations 7.2, 7.3, and 7.4).

Column 1 of Table 7-1 lists each year of the study period from 1993 through 2017. Column 2 of Table 7-1 records information on the calculated values of the diffusion model, $P_{\eta}(t)$, for each year. Recall that $t=1$ corresponds to the year in which FIAPP products and services are expected to become commercially available (i.e., $t=1$ corresponds to the year 2005). Thus, $P_{\eta}(t)=0$ for all values of $t$ less than 1 . Recall that in the first year (i.e., $\mathrm{t}=1$ ) the "unadjusted" value of $P_{\eta}(t)$ is multiplied by 0.667 to reflect the likelihood that FIAPP products and services may not be available at the start of the first year. No adjustments are made to the values of $P_{\eta}(t)$ for values of $t \geq 2$. In Column 3, the diffusion model is combined with information on the 1997 value of construction put in place for the commercial sector as a whole and the proportion of commercial sector floorspace associated with large commercial buildings (i.e., those 
whose floorspace exceeds $\left.4,645.1 \mathrm{~m}^{2}\left(50,000 \mathrm{ft}^{2}\right)\right)$ to generate annual estimates of the value of commercial sector construction put in place which employs FIAPP products and services. Estimates are given for each year from 1993 to 2017. To get the annual value of construction put in place which employs FIAPP products and services, $V I P_{C F}(t)$, the value of $P_{\eta}(t)$ in Column 2 is multiplied by the 1997 value of construction put in place for the commercial sector as a whole and the proportion of commercial floorspace associated with large commercial buildings. The value of commercial sector construction put in place, expressed in 1997 dollars, is held constant at \$205.7 billion throughout the period during which FIAPP products and services diffuse into the marketplace (i.e., 2005 through 2017). The proportion of commercial floorspace associated with large commercial buildings is held constant at 0.44 (i.e., $44 \%$ ) throughout the period during which FIAPP products and services diffuse into the marketplace (i.e., 2005 through 2017). Columns 4 and 5 record estimates of the amount of commercial floorspace receiving FIAPP installations in millions of $\mathrm{m}^{2}, U_{C M}(t)$, (Column 4) and millions of $\mathrm{ft}^{2}$, $U_{C F}(t)$, (Column 5).

\section{Proportion of Commercial Sector Investments Covered by FIAPP Products and Services}

$P_{\eta}(t)=\left\{\eta\left[1+e^{(\alpha-\beta t)}\right]^{-1}\right\}^{*} A(t)$

where

$\eta\left[1+e^{(\alpha-\beta t)}\right]^{-1}=\quad$ the "unadjusted" value of $P_{\eta}(t)$; and

$A(t) \quad=\quad$ the adjustment factor, where $A(t)=0$ for $t<1$, $A(t)=0.667$ for $t=1$, and $A(t)=1.0$ for $t \geq 2$.

Value of FIAPP-Related Investments In Millions of 1997 Dollars

$V I P_{C F}(t)=P_{\eta}(t) * V I P_{C}(t) * F_{C}(t)$

where

$V I P_{C}(t)=$ the value of commercial sector construction put in place in millions of 1997 dollars $(\$ 205,703)$; and

$F_{C}(t)=$ the proportion of commercial floorspace associated with large commercial buildings (0.44). 


\section{New FIAPP Installations in Millions of Square Meters}

$$
U_{C M}(t)=V I P_{C F}(t) / C P S M
$$

where

CPSM = the average cost per square meter for commercial floorspace $\left(\$ 1,050.88 / \mathrm{m}^{2}\right)$.

\section{New FIAPP Installations in Millions of Square Feet}

$U_{C F}(t)=V I P_{C F}(t) / C P S F$

where

CPSF $=$ the average cost per square foot for commercial floorspace $\left(\$ 97.63 / \mathrm{ft}^{2}\right)$.

Table 7-2 summarizes how baseline cost savings by category and in total are calculated. The years for which cost savings are calculated are listed in Column 1 of Table 7-2. The years run from 1993 until 2017 (i.e., the entire study period). The table records information on five categories of cost savings: (1) first cost savings; (2) maintenance and repair cost savings; (3) savings due to reductions in two types of construction-related accidents; (4) reductions in delivery time; and (5) higher net income for contractors. Annual values for each category of cost savings are recorded in Column 2 for first costs, Column 3 for maintenance and repair costs, Column 4 for accidents avoided which do not result in any lost workdays, Column 5 for accidents avoided which do result in lost workdays, Column 6 for reductions in delivery time, and Column 7 for higher net income for contractors. Note that no cost savings for any category occur until 2005, the year in which FIAPP products and services first become commercially available.

To help readers reproduce the values recorded in Table 7-2, the formula used to estimate the annual cost savings for each category of cost savings is given (see Equations 7.5 through 7.10). In each formula, $t$ corresponds to the Year (see Column 1 of Table 7-2) for which savings are calculated (i.e., $t=1$ corresponds to Year $=2005$ ). The nature of the anticipated cost savings for each category is designated with a subscript, depending on whether they result in cost avoidance (i.e., savings) or in higher net income (i.e., benefits). The subscript $S$ is used to denote savings; these values appear in Columns 2 through 5. They are calculated through application of Equations 7.5 through 7.8. The subscript $B$ is used to denote benefits; these values appear in Columns 6 and 7. They are calculated through application of Equations 7.9 and 7.10. 
Table 7-1. Baseline Values for the Diffusion Models and of FIAPP-Related Investments and Installations by Year: $1993-2017$

\begin{tabular}{|c|c|c|c|c|}
\hline \multirow[b]{2}{*}{ Year } & \multirow{2}{*}{$\begin{array}{c}\text { Proportion of } \\
\text { Commercial } \\
\text { Sector } \\
\text { Investments } \\
\text { Covered by } \\
\text { FIAPP Products } \\
\text { and Services } \\
\mathbf{P}_{\eta}(\mathbf{t})\end{array}$} & \multirow{2}{*}{$\begin{array}{l}\text { Value of FIAPP- } \\
\text { Related } \\
\text { Investments (In } \\
\text { Millions of } 1997 \\
\text { Dollars) }\end{array}$} & \multicolumn{2}{|c|}{$\begin{array}{c}\text { New FIAPP Installations in } \\
\text { Millions of }\end{array}$} \\
\hline & & & Square Meters & Square Feet \\
\hline Col. (1) & Col. (2) & Col. (3) & Col. (4) & Col. (5) \\
\hline 1993 & 0 & 0 & 0 & 0 \\
\hline 1994 & 0 & 0 & 0 & 0 \\
\hline 1995 & 0 & 0 & 0 & 0 \\
\hline 1996 & 0 & 0 & 0 & 0 \\
\hline 1997 & 0 & 0 & 0 & 0 \\
\hline 1998 & 0 & 0 & 0 & 0 \\
\hline 1999 & 0 & 0 & 0 & 0 \\
\hline 2000 & 0 & 0 & 0 & 0 \\
\hline 2001 & 0 & 0 & 0 & 0 \\
\hline 2002 & 0 & 0 & 0 & 0 \\
\hline 2003 & 0 & 0 & 0 & 0 \\
\hline 2004 & 0 & 0 & 0 & 0 \\
\hline 2005 & 0.0078 & 707.8 & .7 & 7.3 \\
\hline 2006 & 0.0190 & $1,717.0$ & 1.6 & 17.6 \\
\hline 2007 & 0.0303 & $2,746.3$ & 2.6 & 28.1 \\
\hline 2008 & 0.0477 & $4,315.6$ & 4.1 & 44.2 \\
\hline 2009 & 0.0730 & $6,604.5$ & 6.3 & 67.6 \\
\hline 2010 & 0.1076 & $9,736.7$ & 9.3 & 99.7 \\
\hline 2011 & 0.1510 & $13,668.4$ & 13.0 & 140.0 \\
\hline 2012 & 0.2000 & $18,101.9$ & 17.2 & 185.4 \\
\hline 2013 & 0.2490 & $22,535.3$ & 21.4 & 230.8 \\
\hline 2014 & 0.2924 & $26,467.0$ & 25.2 & 271.1 \\
\hline 2015 & 0.3270 & $29,599.2$ & 28.2 & 303.2 \\
\hline 2016 & 0.3523 & $31,888.1$ & 30.3 & 326.6 \\
\hline 2017 & 0.3697 & $33,457.4$ & 31.8 & 342.7 \\
\hline
\end{tabular}


To facilitate cross-referencing between Table 7-2 and Equations 7.5 through 7.10, a short hand notation for each column heading is used. Specifically, the year-by-year savings (benefits) for each category are: $R F C_{S}(t)$ for Column $2 ; R M R C_{S}(t)$ for Column 3; $N E T R I R_{S}(t)$ for Column 4; $L W C I R_{S}(t)$ for Column $5 ; R D T_{B}(t)$ for Column 6 ; and $H_{C N I_{B}}(t)$ for Column 7. Terms used in each formula are defined the first time they appear. Note that several equations use the same term.

\section{Reductions in First Costs}

$R F C_{S}(t)=V I P_{C F}(t) * 0.02$

where

$0.02=$ the expected reduction in first costs expressed as a decimal.

\section{Reductions in Maintenance and Repair Costs}

$$
R M R C_{S}(t)=U_{C \#}(t) * M R C_{C \#}(t) * U P V^{m}(t) * 0.1
$$

where

\# $\quad=\quad \mathrm{M}$ for $\mathrm{m}^{2}$ and $\mathrm{F}$ for $\mathrm{ft}^{2}$;

$M R C_{C \#}(t)=$ the per unit maintenance and repair cost in the commercial sector in year $\mathrm{t}$ (in 1997 dollars);

$U P V^{m}(t)=$ the "modified" uniform present value factor ${ }^{94}$ for year $t$; and

$0.1=$ the expected reduction in maintenance and repair costs expressed as a decimal.

${ }^{94} U P V^{m}(t)=\left(\frac{1+g}{d-g}\right) *\left[1-\left(\frac{1+g}{1+d}\right)^{N-t}\right]$

where

$d \quad=\quad$ the real discount rate of $7 \%$ expressed as a decimal $(0.07)$;

$g=$ the negative escalation rate of $10 \%$ expressed as a decimal $(-0.10)$ - it is used to model how

$N=\begin{aligned} & \text { cost savings are expected to degrade over time; } \\ & \text { the value of } t \text { corresponding to the year } 2018 \text {. }\end{aligned}$

Including an escalation rate is the reason for "modifying" the uniform present value factor. The term $g$ is used to designate the escalation rate in the formula for the "modified" uniform present value factor that appears above. The engineering economics literature uses the term $e$ to designate the escalation rate (see Fuller and Petersen, Life-Cycle Costing Manual, p. D-4.). The term $g$ is used here instead of $e$ to avoid confusion with Euler's number, which appears in Equation 7.1. 


\section{Reductions in Construction-Related Accidents \\ Resulting in No Lost Workdays: NETRIR}

$$
\begin{aligned}
\operatorname{NETRIR}_{S}(t)= & {\left[0.621 *(1.0525)^{-y} * P_{\eta}(t) * F_{C}(t) * C W H_{C}(t) *(200,000)^{-1}\right] } \\
& * 0.0015
\end{aligned}
$$

where

$0.621=$ the expected reduction in "NETRIR" expressed as a decimal;

$1.0525=$ deflator used to adjust for improved RIR-related safety performance of $5.25 \%$ per year;

$y=$ Year -1997 ;

$C W H_{C}(t)=$ the number of craft workhours in the commercial sector ${ }^{95}$ in year $t$;

$200,000=$ the base for computing safety-related measures (100 full time workers working 40 hours per week, 50 weeks per year); and

$0.0015=$ the value of avoiding an accident which results in no lost workdays (in millions of 1997 dollars).

Reductions in Construction-Related Accidents Resulting in One or More Lost Workdays: LWCIR

$$
\begin{aligned}
\operatorname{LWCIR}_{S}(t)= & {\left[(0.311) *(1.056)^{-y} * P_{\eta}(t) * F_{C}(t) * C W H_{C}(t) *(200,000)^{-1}\right] } \\
& * 0.0315
\end{aligned}
$$

where

$0.311=$ the expected reduction in LWCIR expressed as a decimal;

$1.056=$ deflator used to adjust for improved LWCIR-related safety performance of $5.6 \%$ per year; and

$0.0315=$ the value of avoiding an accident which results in one or more lost workdays (in millions of 1997 dollars).

\footnotetext{
${ }^{95}$ The estimated number of craft workhours in the commercial sector assumes that craft workhours are directly proportional to the value of construction put in place. Since the value of commercial construction put in place is approximately $31 \%$ of the total for the entire construction industry, the number of craft workhours in the commercial sector was taken to be $31 \%$ of the construction industry total in 1997.
} 
Table 7-2. Baseline Cost Savings by Category and in Total in Millions of 1997 Dollars by Year: 1993-2017

\begin{tabular}{|c|c|c|c|c|c|c|c|}
\hline \multirow{3}{*}{ Year } & \multicolumn{6}{|c|}{ Annual Cost Savings By Category } & \multirow{3}{*}{$\begin{array}{c}\text { Total Cost Savings by } \\
\text { Year (In Millions of } 1997 \\
\text { Dollars) }\end{array}$} \\
\hline & \multirow{2}{*}{$\begin{array}{c}\text { Savings Due to } \\
\text { Reductions in First } \\
\text { Costs (In Millions of } \\
1997 \text { Dollars) }\end{array}$} & \multirow{2}{*}{$\begin{array}{c}\text { Savings Due to } \\
\text { Reductions in } \\
\text { Maintenance and } \\
\text { Repair Costs (In } \\
\text { Millions of } 1997 \\
\text { Dollars) } \\
\end{array}$} & \multicolumn{2}{|c|}{$\begin{array}{c}\text { Savings Due to Reductions in } \\
\text { Construction-Related Accidents (In } \\
\text { Millions of } 1997 \text { Dollars) }\end{array}$} & \multirow{2}{*}{$\begin{array}{l}\text { Benefits Due to } \\
\text { Reductions in } \\
\text { Delivery Time (In } \\
\text { Millions of } 1997 \\
\text { Dollars) }\end{array}$} & \multirow{2}{*}{$\begin{array}{c}\text { Benefits From } \\
\text { Higher Net Income } \\
\text { for Contractors (In } \\
\text { Millions of } 1997 \\
\text { Dollars) }\end{array}$} & \\
\hline & & & $\begin{array}{c}\text { Cases With No Lost } \\
\text { Workdays }\end{array}$ & $\begin{array}{c}\text { Lost Workday } \\
\text { Cases }\end{array}$ & & & \\
\hline Col. (1) & Col. (2) & Col. (3) & Col. (4) & Col. (5) & Col. (6) & Col. (7) & $\begin{array}{c}\text { Col. (8) } \\
(2)+(3)+(4)+(5)+(6)+(7) \\
\end{array}$ \\
\hline 1993 & 0 & 0 & 0 & 0 & 0 & 0 & 0 \\
\hline 1994 & 0 & 0 & 0 & 0 & 0 & 0 & 0 \\
\hline 1995 & 0 & 0 & 0 & 0 & 0 & 0 & 0 \\
\hline 1996 & 0 & 0 & 0 & 0 & 0 & 0 & 0 \\
\hline 1997 & 0 & 0 & 0 & 0 & 0 & 0 & 0 \\
\hline 1998 & 0 & 0 & 0 & 0 & 0 & 0 & 0 \\
\hline 1999 & 0 & 0 & 0 & 0 & 0 & 0 & 0 \\
\hline 2000 & 0 & 0 & 0 & 0 & 0 & 0 & 0 \\
\hline 2001 & 0 & 0 & 0 & 0 & 0 & 0 & 0 \\
\hline 2002 & 0 & 0 & 0 & 0 & 0 & 0 & 0 \\
\hline 2003 & 0 & 0 & 0 & 0 & 0 & 0 & 0 \\
\hline 2004 & 0 & 0 & 0 & 0 & 0 & 0 & 0 \\
\hline 2005 & 14.157 & 7.622 & .035 & .354 & 8.384 & 9.438 & 39.989 \\
\hline 2006 & 34.340 & 18.078 & .080 & .813 & 20.337 & 22.893 & 96.541 \\
\hline 2007 & 54.927 & 28.132 & .121 & 1.232 & 32.530 & 36.618 & 153.560 \\
\hline 2008 & 86.312 & 42.744 & .181 & 1.833 & 51.117 & 57.541 & 239.727 \\
\hline 2009 & 132.090 & 62.752 & .263 & 2.656 & 78.228 & 88.060 & 364.049 \\
\hline 2010 & 194.734 & 87.847 & .368 & 3.709 & 115.328 & 129.822 & 531.808 \\
\hline 2011 & 273.368 & 115.533 & .491 & 4.930 & 161.898 & 182.245 & 738.465 \\
\hline 2012 & 362.037 & 140.746 & .618 & 6.183 & 214.412 & 241.358 & 965.354 \\
\hline 2013 & 450.707 & 157.072 & .731 & 7.289 & 266.925 & 300.471 & $1,183.195$ \\
\hline 2014 & 529.341 & 159.138 & .816 & 8.107 & 313.495 & 352.894 & $1,363.790$ \\
\hline 2015 & 591.985 & 144.282 & .867 & 8.585 & 350.595 & 394.657 & $1,490.970$ \\
\hline 2016 & 637.763 & 112.290 & .887 & 8.759 & 377.706 & 425.175 & $1,562.580$ \\
\hline 2017 & 669.148 & 63.991 & .884 & 8.703 & 396.293 & 446.098 & $1,585.117$ \\
\hline
\end{tabular}




\section{Reductions in Delivery Time}

$R D T_{B}(t)=U_{C \#}(t) * W N I_{C \#}(t) * 7$

where

$W N I_{C H}(t)=$ weekly net income per unit of floor area in the commercial sector in year $t$ (in 1997 dollars); and

$7=$ the expected reduction in delivery time expressed in weeks.

\section{Higher Contractor Net Income}

$\operatorname{HCNI}_{B}(t)=\left[\operatorname{VIP} P_{C F}(t) *(1.05)^{-1}\right] * 0.014$

where

$1.05=$ deflator used to translate total installed cost to contractor cost; and

$0.014=$ the expected increase in contractor net income expressed as a decimal.

In addition to annual cost savings by category, Table 7-2 also contains total cost savings by year. These cost savings are recorded in Column 8 . Total cost savings for each year equal the sum of each category's cost savings for that year. Total cost savings, denominated in millions of 1997 dollars, increase steadily between 2005 and 2017.

Table 7-3 summarizes how the present values of net cost savings nationwide by year and in total are calculated. The table also includes information on total cost savings, additional FIAPP-related installation costs, net cost savings, and the discount factor needed to translate yearly net cost savings into yearly present value cost savings nationwide. The years for which present values are calculated are listed in Column 1 of Table 7-3. The years run from 1993 until 2017 (i.e., the entire study period). Column 2 of Table 7-3 contains total cost savings by year in millions of 1997 dollars. The total cost savings for each year is transferred from the respective row of Column 8 of Table 7-2. The additional cost to install FIAPP products and services for each year is recorded in Column 3 of Table 7-3. This cost equals the product of the additional cost to building owners and contractors of $\$ 32.29 / \mathrm{m}^{2}\left(\$ 3.00 / \mathrm{ft}^{2}\right)$ for commercial buildings that employ FIAPP products and services. The amount of commercial floorspace that employs FIAPP products and services in millions of $\mathrm{m}^{2}\left(\mathrm{ft}^{2}\right)$ is contained in Column 4 (Column 5) of Table 7-1 for each year of the specific calculation. 
Table 7-3. Baseline Computation of Present Value Cost Savings Nationwide in Millions of 1997 Dollars: 1993-2017

\begin{tabular}{|c|r|r|r|r|r|}
\hline Year & $\begin{array}{c}\text { Total Cost } \\
\text { Savings by } \\
\text { Year }\end{array}$ & $\begin{array}{c}\text { New } \\
\text { Technology } \\
\text { Introduction } \\
\text { Costs }\end{array}$ & $\begin{array}{c}\text { Net Cost } \\
\text { Savings }\end{array}$ & $\begin{array}{c}\text { Single } \\
\text { Present } \\
\text { Value } \\
\text { Factor by } \\
\text { Year }\end{array}$ & $\begin{array}{c}\text { Present Value } \\
\text { of Net Cost } \\
\text { Savings } \\
\text { Nationwide } \\
\text { by Year }\end{array}$ \\
\hline Col. (1) & Col. (2) & Col. (3) & $\begin{array}{c}\text { Col. (4) } \\
\text { (2) - (3) }\end{array}$ & Col. (5) & $\begin{array}{c}\text { Col. (6) } \\
\mathbf{( 4 )} \mathbf{x}(\mathbf{5})\end{array}$ \\
\hline 1993 & 0 & 0 & 0 & 1.311 & 0 \\
1994 & 0 & 0 & 0 & 1.225 & 0 \\
1995 & 0 & 0 & 0 & 1.145 & 0 \\
1996 & 0 & 0 & 0 & 1.070 & 0 \\
1997 & 0 & 0 & 0 & 1.000 & 0 \\
1998 & 0 & 0 & 0 & 0.935 & 0 \\
1999 & 0 & 0 & 0 & 0.873 & 0 \\
2000 & 0 & 0 & 0 & 0.816 & 0 \\
2001 & 0 & 0 & 0 & 0.763 & 0 \\
2002 & 0 & 0 & 0 & 0.713 & 0 \\
2003 & 0 & 0 & 0 & 0.666 & 0 \\
2004 & 0 & 0 & 0 & 0.623 & 0 \\
2005 & 39.989 & 21.750 & 18.239 & 0.582 & 10.615 \\
2006 & 96.541 & 52.760 & 43.781 & 0.544 & 23.814 \\
2007 & 153.560 & 84.391 & 69.169 & 0.508 & 35.162 \\
2008 & 239.727 & 132.611 & 107.117 & 0.475 & 50.890 \\
2009 & 364.049 & 202.944 & 161.105 & 0.444 & 71.532 \\
2010 & 531.808 & 299.191 & 232.616 & 0.415 & 96.528 \\
2011 & 738.465 & 420.006 & 318.459 & 0.388 & 123.504 \\
2012 & 965.354 & 556.239 & 409.116 & 0.362 & 148.282 \\
2013 & $1,183.195$ & 692.472 & 490.723 & 0.339 & 166.225 \\
2014 & $1,363.790$ & 813.286 & 550.504 & 0.317 & 174.275 \\
2015 & $1,490.970$ & 909.533 & 581.437 & 0.296 & 172.026 \\
2016 & $1,562.580$ & 979.867 & 582.713 & 0.277 & 161.125 \\
2017 & $1,585.117$ & $1,028.087$ & 557.030 & 0.258 & 143.947 \\
\hline & & & & TOTAL & $\mathbf{1 , 3 7 7 . 9 2 6}$ \\
\hline
\end{tabular}


The difference between total cost savings and the additional costs to employ FIAPP products and services equals net cost savings. Column 4 of Table 7-3 records net cost savings for each year in millions of 1997 dollars. Note that net cost savings increase steadily. The calculated value of the single present value factor for each year is recorded in Column 5 of Table 7-3. All entries are calculated using a real discount rate of $7 \%$ (see Section 6.4.3). Because 1997 is the base year, the single present value factor takes on a value of 1.0 for that year. For years prior to 1997, the single present value factor is greater than 1.0. For years following 1997, the single present value factor is less than 1.0. The single present value factor for any given year, Year, equals $(1.07)^{1997-\text { Year }}$ where $1993 \leq$ Year $\leq 2017$. The present value of net cost savings nationwide by year is recorded in Column 6 of Table 7-3. It equals the product of the net cost savings, in Column 4, and the single present value factor, in Column 5, for that year. Note that the present value of net cost savings nationwide increases steadily.

Because the entries in Column 6 are in present value terms, they can be summed to get total cost savings nationwide over the entire study period. Total cost savings nationwide resulting from the three sets of baseline analysis calculations are nearly $\$ 1.4$ billion (\$1,378 million in present value 1997 dollars); see the bottom of Column 6 in Table 7-3.

Reference to Table 7-3 demonstrates the magnitude of the savings to the nation from using FIAPP products and services in the commercial sector. These cost savings nationwide also provide a basis for measuring the value of BFRL's contribution.

\subsection{Measuring the Value of BFRL's Contribution and the Return on BFRL's CONSIAT-Related Investments}

Measuring the value of BFRL's contribution to the development of FIAPP products and services and the return on its CONSIAT-related investments is the focus of this section. Information on BFRL's CONSIAT-related research, development, and deployment efforts - in terms of its dollar investments - over the 25-year period from 1993 to 2017 are first presented. These figures demonstrate not only a significant, up-front research commitment by BFRL, but also a continued effort as FIAPP products and services move into the commercial marketplace. Next, the likely delay in the commercial availability of FIAPP products and services is addressed. Because of BFRL's participation, FIAPP products and services are expected to be commercially available in 2005. If BFRL had not participated in the development of FIAPP products and services, the commercial introduction of FIAPP products and services is expected to be delayed until 2009. Finally, a full array of economic measures summarizes the importance of BFRL's contribution to the development of FIAPP products and services for use in commercial buildings. These measures include the present value of savings (PVS), the present value of net savings (PVNS), the savings-to-investment ratio (SIR), and the adjusted internal rate of return (AIRR) that are attributable to BFRL's CONSIAT-related research, development, and deployment efforts. 
Table 7-4. Summary of BFRL Research Investments: 1993-2017

\begin{tabular}{|c|c|c|c|c|c|}
\hline Year & $\begin{array}{c}\text { Annual Dollar } \\
\text { Amount (In } \\
\text { Millions of } \\
\text { Current } \\
\text { Dollars) }\end{array}$ & $\begin{array}{c}\text { Conversion } \\
\text { Factor by } \\
\text { Year } \\
\text { (Current } \\
\text { Dollars to } \\
\text { 1997 Dollars) }\end{array}$ & $\begin{array}{c}\text { Investment } \\
\text { Costs by } \\
\text { Year (In } \\
\text { Millions of } \\
\text { 1997 Dollars) }\end{array}$ & $\begin{array}{c}\text { Single } \\
\text { Present Value } \\
\text { Factor by } \\
\text { Year }\end{array}$ & $\begin{array}{c}\text { Present Value } \\
\text { of Investment } \\
\text { Costs by Year } \\
\text { (In Millions of } \\
\text { 1997 Dollars) }\end{array}$ \\
\hline Col. (1) & Col. (2) & Col. (3) & $\begin{array}{c}\text { Col. (4) } \\
\text { (2) x (3) }\end{array}$ & Col. (5) & $\begin{array}{c}\text { Col. (6) } \\
\text { (4) x (5) }\end{array}$ \\
\hline 1993 & .332 & 1.111 & .369 & 1.311 & .483 \\
1994 & 1.371 & 1.083 & 1.485 & 1.225 & 1.819 \\
1995 & 1.502 & 1.053 & 1.582 & 1.145 & 1.811 \\
1996 & 1.548 & 1.023 & 1.584 & 1.070 & 1.694 \\
1997 & 1.886 & 1.000 & 1.886 & 1.000 & 1.886 \\
1998 & 2.263 & 0.985 & 2.228 & 0.935 & 2.083 \\
1999 & 1.992 & 0.963 & 1.919 & 0.873 & 1.676 \\
2000 & 2.002 & 0.932 & 1.866 & 0.816 & 1.523 \\
2001 & 2.442 & 0.932 & 2.276 & 0.763 & 1.736 \\
2002 & 3.125 & 0.932 & 2.913 & 0.713 & 2.077 \\
2003 & 3.625 & 0.932 & 3.379 & 0.666 & 2.251 \\
2004 & 4.000 & 0.932 & 3.728 & 0.623 & 2.322 \\
2005 & 4.000 & 0.932 & 3.728 & 0.582 & 2.170 \\
2006 & 3.875 & 0.932 & 3.612 & 0.544 & 1.965 \\
2007 & 3.375 & 0.932 & 3.146 & 0.508 & 1.599 \\
2008 & 2.875 & 0.932 & 2.680 & 0.475 & 1.273 \\
2009 & 1.875 & 0.932 & 1.748 & 0.444 & .776 \\
2010 & 0 & 0.932 & 0 & 0.415 & 0 \\
2011 & 0 & 0.932 & 0 & 0.388 & 0 \\
2012 & 0 & 0.932 & 0 & 0.362 & 0 \\
2013 & 0 & 0.932 & 0 & 0.339 & 0 \\
2014 & 0 & 0.932 & 0 & 0.317 & 0 \\
2015 & 0 & 0.932 & 0 & 0.296 & 0 \\
2016 & 0 & 0.932 & 0 & 0.277 & 0 \\
2017 & 0 & 0.932 & 0 & 0.258 & 0 \\
\hline & & & & TOTAL & $\mathbf{2 9 . 1 4 4}$ \\
\hline
\end{tabular}

${ }^{\mathrm{a}}$ The dollar amounts for 1993 through 2000 are in millions of current dollars. The dollar amounts for 2001 through 2017 are in millions of 2000 dollars. 
Table 7-4 summarizes information on BFRL's CONSIAT-related investments. Column 1 of the table records the year in which CONSIAT-related investments were made.

Column 2 records the value (in millions of current dollars) by year of investment for each year between 1993 and 2017. For example, in 1993 the investment was \$332,000 (in 1993 dollars), in 1994 the investment was \$1,371,000 (in 1994 dollars), and in 1995 the investment was $\$ 1,502,000$ (in 1995 dollars). For 2001 through 2017, the entries in Column 2 are in millions of 2000 dollars. Investments over the 1991 to 1996 time period cover STEP-related and construction metrology-related research. Investments beginning in 1997 include research, development, and deployment efforts aimed at producing FIAPP products and services. Because the values for 1993 through 2000 in Column 2 are in current dollars by year and the values for 2001 through 2017 are in 2000 dollars, it is necessary to convert them to constant 1997 dollars and then convert them to present value (i.e., time equivalent) dollars. This involves a two-step process. First, each year's current dollar investment is converted to a "real" investment in 1997 constant dollars through application of the Consumer Price Index (CPI). The conversion factors, for each year, are shown in Column 3 of Table 7-4. The constant 1997 dollar values (in millions of dollars) are the year-by-year products of the entries in Column 2 and Column 3. These values are shown in Column 4. The values in Column 4 are converted into present value terms through the use of a single present value factor, based on a real discount rate of 7 $\%$. The value of each year's single present value factor is given in Column 5 . The present values in millions of 1997 dollars are recorded in Column 6; they are the year-byyear products of the entries in Column 4 and Column 5.

Because entries in Column 6 are in present value terms, they can be summed to get the present value of BFRL's CONSIAT-related investments. The present value of BFRL's CONSIAT-related investments, PV Costs, totals \$29.144 million; this value is recorded at the bottom of Column 6.

Table 7-5 provides the information needed to calculate the present value of savings attributable to BFRL. The years for which present values are calculated are listed in Column 1 of Table 7-5. The years run from 1993 until 2017 (i.e., the entire study period). The present value of cost savings nationwide by year is recorded in Column 2 of Table 7-5. The present value of cost savings nationwide for each year is transferred from the respective row of Column 6 of Table 7-3. BFRL's dual role as a facilitator and developer of key FIAPP enabling technologies is expected to speed up the introduction of FIAPP products and services into the commercial marketplace. Without BFRL's participation, the introduction of FIAPP products and services into the commercial marketplace would likely have been delayed. Information from subject matter experts and similar economic impact assessments suggest a range of values from two to five years for the likely delay. ${ }^{96}$ The selected baseline value for the delay is four years (see Section 6.4.6). Because BFRL's research, development, and deployment efforts are expected to result in faster introduction of FIAPP products and services, those savings which would have been foregone in the event of a delay are attributable to BFRL.

\footnotetext{
${ }^{96}$ Chapman, A Case Study of Construction Systems Integration and Automation Technologies in Industrial Facilities, pp. 98-101.
} 
Therefore, any savings over the first four years (starting with 2005), prior to the "delayed" introduction of FIAPP products and services in 2009, would have been foregone. Such an accounting framework may be handled through use of a 0-1 weighting factor. For those years in which savings are attributable to BFRL, the weighting factor takes on a value of 1 . The year-by-year values of the BFRL baseline weighting factor are given in Column 3 of Table 7-5. The present value of savings attributable to BFRL is the product of each year's present value of cost savings nationwide in Column 2 and the value of the BFRL baseline weighting factor in Column 3. The present value of savings attributable to BFRL on a year-by-year basis is given in Column 4 of Table 7-5.

Because entries in Column 4 are in present value terms, they can be summed to get the present value of savings attributable to BFRL. The present value of savings attributable to BFRL, PVS, totals $\$ 120.482$ million; this value is recorded at the bottom of Column 6 .

Given the values of PV Costs and PVS attributable to BFRL, it is now possible to derive three other economic impact measures. These measures are: (1) present value of net savings (PVNS) attributable to BFRL; (2) the savings-to-investment ratio (SIR) on BFRL's CONSIAT-related investments; and (3) the adjusted internal rate of return (AIRR) on BFRL's CONSIAT-related investments. Multiple measures are particularly useful because they each provide a different perspective - PVNS is a magnitude, the SIR is a ratio, and the AIRR is a rate of return - and promote consistency in evaluating BFRL's contribution.

The PVNS attributable to BFRL, expressed in millions of present value 1997 dollars and based on the approach outlined in Section 2.2.1, is equal to:

$\begin{array}{rlrl}\mathrm{PVNS} & = & \mathrm{PVS}-\mathrm{PV} \text { Costs } \\ & =\quad \$ 120.482-\$ 29.144 \\ & =\$ 91.337 \text { million }\end{array}$

Utilizing the approach outlined in Section 2.2.2, the SIR on BFRL's CONSIAT-related investments is equal to:

$\begin{array}{rlrl}\mathrm{SIR} & = & \mathrm{PVS} /(\mathrm{PV} \text { Costs }) \\ & = & \$ 120.482 / \$ 29.144 \\ & =4.13\end{array}$


Table 7-5. Estimated Cost Savings in Millions of 1997 Dollars Attributable to BFRL

\begin{tabular}{|c|c|c|c|}
\hline Year & $\begin{array}{c}\text { Present Value of } \\
\text { Cost Savings } \\
\text { Nationwide by } \\
\text { Year }\end{array}$ & $\begin{array}{l}\text { BFRL Baseline } \\
\text { Weighting Factor } \\
\text { (4-Year Delay) }\end{array}$ & $\begin{array}{l}\text { Present Value of } \\
\text { Cost Savings by } \\
\text { Year Attributable } \\
\text { to BFRL }\end{array}$ \\
\hline Col. (1) & Col. (2) & Col. (3) & $\begin{array}{l}\text { Col. (4) } \\
\text { (2) x (3) }\end{array}$ \\
\hline 1993 & 0 & 1 & 0 \\
\hline 1994 & 0 & 1 & 0 \\
\hline 1995 & 0 & 1 & 0 \\
\hline 1996 & 0 & 1 & 0 \\
\hline 1997 & 0 & 1 & 0 \\
\hline 1998 & 0 & 1 & 0 \\
\hline 1999 & 0 & 1 & 0 \\
\hline 2000 & 0 & 1 & 0 \\
\hline 2001 & 0 & 1 & 0 \\
\hline 2002 & 0 & 1 & 0 \\
\hline 2003 & 0 & 1 & 0 \\
\hline 2004 & 0 & 1 & 0 \\
\hline 2005 & 10.615 & 1 & 10.615 \\
\hline 2006 & 23.814 & 1 & 23.814 \\
\hline 2007 & 35.162 & 1 & 35.162 \\
\hline 2008 & 50.890 & 1 & 50.890 \\
\hline 2009 & 71.532 & 0 & 0 \\
\hline 2010 & 96.528 & 0 & 0 \\
\hline 2011 & 123.504 & 0 & 0 \\
\hline 2012 & 148.282 & 0 & 0 \\
\hline 2013 & 166.225 & 0 & 0 \\
\hline 2014 & 174.275 & 0 & 0 \\
\hline 2015 & 172.026 & 0 & 0 \\
\hline 2016 & 161.125 & 0 & 0 \\
\hline 2017 & 143.947 & 0 & 0 \\
\hline & & TOTAL & 120.482 \\
\hline
\end{tabular}


Utilizing the approach outlined in Section 2.2.3, the AIRR on BFRL's CONSIAT-related investments is equal to:

$$
\begin{aligned}
\mathrm{AIRR} & =(1+0.07) * 4.13^{1 / 25}-1 \\
& =0.133 \\
& =13.3 \%
\end{aligned}
$$

The values of the five economic impact measures derived in Chapter 7 are the baseline values that appear in Section 3.b of Exhibit 7-1. These values also figure in the sensitivity analysis, which is the subject of the next chapter. 


\section{Sensitivity Analysis of Economic Impacts}

The CONSIAT economic impact assessment described in this report was carried out in two stages. In the first stage, a baseline analysis was performed. The data and assumptions underlying the baseline analysis were described in Chapter 6; the results of the baseline analysis were presented in Chapter 7.

In the second stage, eleven variables were varied both singly and in combination according to an experimental design. The sensitivity analysis uses the same data and assumptions as the baseline analysis for its starting point. Information on how the deviations about the baseline values for each of the eleven input variables were specified and how the range of values for each variable was determined is described and documented in Chapter 6. The sensitivity analysis described in this chapter is based on Monte Carlo techniques. The objective of the sensitivity analysis is to evaluate how uncertainty in the values of each of the eleven input variables, both singly and in combination, translates into changes in each of six key economic measures. The six economic measures evaluated in the sensitivity analysis are: (1) the present value of savings nationwide; (2) the present value of savings due to BFRL; (3) the present value of BFRL's CONSIAT-related investment costs; (4) the present value of net savings due to BFRL; (5) the savings-to-investment ratio on BFRL's CONSIAT-related investments; and (6) the adjusted internal rate of return on BFRL's CONSIAT-related investments. Three of these measures are particularly helpful in understanding BFRL's contribution, since each measure provides a different perspective. The first, the present value of net savings due to BFRL is a magnitude measure; it shows a net dollar value to the public net of BFRL's CONSIAT-related investments. The second, the savings-to-investment ratio on BFRL's CONSIAT-related investments is a multiplier; it shows, in present value terms, how many dollars the public receives for each public dollar spent. The third, the adjusted internal rate of return on BFRL's CONSIAT-related investments is a rate of return; it shows the return on the public monies going into the development of CONSIAT products and services throughout the 25 -year study period.

\subsection{Methodology}

Because the values of many variables that enter into the CONSIAT economic impact assessment are not known with certainty, it is advisable to select a small set of variables whose impact is likely to be substantial and subject them to a sensitivity analysis. Variations in the values of these input variables translate into the value of each outcome (e.g., the SIR) in such a manner that the impacts of uncertainty can be measured quantitatively.

Sensitivity analysis may be divided into two polar cases: (1) deterministic; and (2) probabilistic. Deterministic sensitivity analyses are the most straightforward. Their advantage is that they are easy to apply and the results are easy to explain and 
understand. Their disadvantage is that they do not produce results that can be tied to probabilistic levels of significance (i.e., the probability that the SIR is less than 1.0).

For example, a deterministic sensitivity analysis might use as inputs a pessimistic value, a value based on a measure of central tendency (e.g., mean or median), and an optimistic value for the variable of interest. Then an analysis could be performed to see how each outcome (e.g., the SIR) changes as each of the three chosen values for the selected input is considered in turn, while all other input variables are maintained at their baseline values. A deterministic sensitivity analysis can also be performed on different combinations of input variables. That is, several variables are altered at once and then an outcome measure is computed. This is the approach used in two of the previous economic impact assessments. ${ }^{97}$

In a probabilistic sensitivity analysis, a small set of key input variables is varied either singly or in combination according to an experimental design. In most cases, probabilistic sensitivity analyses are based on Monte Carlo techniques, or some other form of simulation. The major advantage of probabilistic sensitivity analysis is that it permits the effects of uncertainty to be rigorously analyzed. For example, not only the expected value of each economic measure can be computed but also the variability of that value. In addition, probabilistic levels of significance can be attached to the computed values of each economic measure. The disadvantage of a probabilistic sensitivity analysis is that it requires many calculations carried out according to an experimental design, and is therefore practical only when used with a computer.

The approach selected for this study makes use of works by McKay, Conover, and Beckman ${ }^{98}$ and by Harris; ${ }^{99}$ it is based on the method of model sampling. Model sampling provides the basis for many probabilistic sensitivity analyses. Model sampling is a procedure for sampling from a stochastic process to determine, through multiple trials, the characteristics of a probability distribution. This approach was used in two of the previous economic impact assessments. ${ }^{100}$

The method of model sampling was implemented through application of the @RISK software product. ${ }^{101}$ This software product is an add-in for spreadsheets. For the case at hand, selected columns of the spreadsheet were associated with one or more of the eleven input variables. The @RISK software product allows the user to specify a unique probability distribution for each input variable. Specification of the experimental design

\footnotetext{
${ }^{97}$ See Chapman and Fuller, Two Case Studies in Building Technology, and Chapman and Weber, A Case Study of the Fire Safety Evaluation System.

${ }^{98}$ McKay, M. C., W. H. Conover, and R.J. Beckman. 1979. "A Comparison of Three Methods for Selecting Values of Input Variables in the Analysis of Output from a Computer Code." Technometrics (Vol. 21): pp. 239-245.

${ }^{99}$ Harris, Carl M. 1984. Issues in Sensitivity and Statistical Analysis of Large-Scale, Computer-Based Models. NBS GCR 84-466. Gaithersburg, MD: National Bureau of Standards.

${ }^{100}$ See Chapman, A Case Study of Cybernetic Building Systems, and Chapman, A Case Study of Construction Systems Integration and Automation Technologies in Industrial Facilities.

${ }^{101}$ Palisade Corporation. 1997. Guide to Using@RISK: Risk Analysis and Simulation Add-In for Microsoft Excel or Lotus 1-2-3. Newfield, NY: Palisade Corporation.
} 
involves defining which variables are to be simulated and the number of simulations. Throughout this sensitivity analysis, 1,000 simulations were run for each input variable or combination of input variables under analysis. The number of simulations was chosen to ensure that values in the tails of the distribution for each input variable would be selected for inclusion in the analysis. When the @RISK software product is executed, it randomly samples from the parent probability distribution for each input variable of interest (i.e., the input variable(s) specified by the experimental design).

In reality, the exact nature of the parent probability distribution for each input variable is unknown. Estimates of the parameters (e.g., mean and variance) of the parent probability distribution can be made and uncertainty can be reduced by investigation and research. However, uncertainty can never be eliminated completely. The true specification of the parent probability distribution can only be known after CONSIAT products and services have been operating in the marketplace for an extended period of time. Therefore, in order to implement the procedure without undue attention to the characterization of the parent probability distribution, it was decided to focus on only three probability distributions. These probability distributions are: (1) the triangular; (2) the uniform; and (3) the discrete or multinomial. Readers interested in learning more about these probability distributions, including variate relationships, estimation procedures, and random number generation, are referred to Evans, Hastings, and Peacock. ${ }^{102}$

One reason for using these three probability distributions is that they are all defined over a finite interval. Furthermore, the specification of each probability distribution is accomplished with as few as two data points. The triangular distribution is widely used in simulation modeling; its specification requires three data points, the minimum value, the most likely value, and the maximum value. The triangular distribution is used whenever the range of input values is continuous and a clustering about some central value is expected. Discussions with subject matter experts and reference to selected publications indicated eight input variables for which clustering about a central value was to be expected. Once the triangular distribution was selected for these eight input variables, all three values were derived through investigation and discussions with subject matter experts. The uniform distribution is also widely used in simulation modeling; its specification requires only two data points, the minimum value and the maximum value. In addition, all values between the minimum and maximum are equally likely. The uniform distribution is used whenever the range of input values is continuous but no $a$ priori reason can be given for expecting clustering about some central value. It was used for one input variable (see Section 8.2). The discrete distribution is used whenever the range of input values is discrete; it was used for two input variables (see Section 8.2).

\subsection{Key Variables}

Information on the eleven input variables that are the focus of the sensitivity analysis is presented in this section. The eleven variables are: (1) alpha, $\alpha$, the location parameter in

${ }^{102}$ Evans, Merran, Nicholas Hastings, and Brian Peacock. 1993. Statistical Distributions. New York, NY: John Wiley \& Sons, Inc. 
the diffusion model; (2) beta, $\beta$, the shape parameter in the diffusion model; (3) eta, $\eta$, the market saturation level in the diffusion model; (4) the discount rate; (5) first cost savings; (6) maintenance and repair cost savings; (7) reductions in delivery time; (8) higher contractor net income; (9) new-technology introduction costs; (10) the time of first use; and (11) the length of the delay.

Table 8-1 summarizes information on each of the eleven input variables. The table includes information on the type of probability distribution used to model variations about the baseline value for each input variable, the baseline value for each input variable, and the minimum and maximum values for each input variable.

Table 8-1. Baseline and Extreme Values of the Eleven Input Variables Used in the Sensitivity Analysis

\begin{tabular}{|l|c|c|c|c|}
\hline & Probability & \multicolumn{3}{|c|}{ Setting and Value } \\
\cline { 3 - 5 } Variable Name & Distribution & Baseline & Minimum & Maximum \\
\hline (1) Alpha & Uniform & 4 & 3 & 5 \\
\hline (2) Beta & Triangular & 0.5 & 0.4 & 0.6 \\
\hline (3) Eta & Triangular & 0.4 & 0.3 & 0.5 \\
\hline (4) Discount Rate & Triangular & 0.07 & 0.02 & 0.10 \\
\hline (5) First Cost Savings & Triangular & 0.020 & 0 & 0.035 \\
\hline $\begin{array}{l}\text { (6) Maintenance and } \\
\text { Repair Cost Savings }\end{array}$ & Triangular & 0.10 & 0.05 & 0.15 \\
\hline $\begin{array}{l}\text { (7) Reductions in } \\
\text { Delivery Time }\end{array}$ & Triangular & 7 & 0 & 22 \\
\hline $\begin{array}{l}\text { (8) Higher Contractor } \\
\text { Net Income }\end{array}$ & Triangular & 0.014 & 0 & 0.037 \\
\hline $\begin{array}{l}\text { (9) New-Technology } \\
\text { Introduction Costs }\end{array}$ & Triangular & $\begin{array}{l}\$ 32.29 \\
(\$ 3.00)\end{array}$ & $\begin{array}{l}\$ 21.53 \\
(\$ 2.00)\end{array}$ & $\begin{array}{c}\$ 43.05 \\
(\$ 4.00)\end{array}$ \\
\hline (10) Time of First Use & Discrete & 2005 & 2004 & 2007 \\
\hline (11) Delay & Discrete & 0 & 0 & 2 \\
\hline
\end{tabular}

Reference to the entries under the heading Probability Distribution shows that all but three of the eleven input variables use the triangular distribution to model variations about the baseline value for that variable. One of these variables, $\alpha$, employs the uniform distribution. The input variable, $\alpha$, is modeled with a uniform distribution because a review of the economics literature on the diffusion process produced no a priori reason for expecting a clustering of values around a value of 4.0. The economics literature was, however, useful in specifying the range about the baseline value of $\alpha$. The other two input variables, the time of first use and the length of delay, employ the discrete distribution. Both of these variables designate a year. For example, the time of first use (i.e., when CONSIAT products and services first become available commercially) either occurs in 2005 (i.e., the year corresponding to the baseline value) or in some other year. 
Thus, the discrete distribution is the most meaningful way to model when CONSIAT products and services first become available commercially.

The next three headings record, for each input variable, its setting (i.e., baseline, minimum, and maximum) and value. For each input variable, the baseline value is recorded first. For example, the baseline value for the discount rate is $7 \%$ (real); it is recorded in decimal form as 0.07 . Two other values for the discount rate, $2 \%$ and $10 \%$, are selected to bracket the baseline value. These values are recorded in decimal form as 0.02 and 0.10 , respectively.

\subsection{Sensitivity Results}

The results of the sensitivity analysis are summarized in a series of tables and figures. Two sets of results are presented. The first set covers the case where each of the eleven input variables is varied singly. The first set of results is designed to show the effect of each input on each of the economic measures. This is done by varying each input variable singly while holding the other ten input variables at their baseline values. These results are summarized in Tables 8-2 through 8-12. Table 8-13 summarizes the results of a deterministic sensitivity analysis for the combined effects of the time of first use and the length of delay. Table 8-13 has three parts: (1) Part A, where each time of first use is evaluated assuming no delay; (2) Part B, where each time of first use is evaluated assuming a one-year delay; and (3) Part C, where each time of first use is evaluated assuming a two-year delay. The second set covers the case where all eleven input variables are varied in combination. The second set of results is designed to produce a data set that facilitates an in-depth analysis of the results, and promotes an understanding of what these results mean. These results are summarized in Tables 8-14 and 8-15 and in Figures 8-1 through 8-6. To facilitate comparisons among each of the Monte Carlo simulations, Tables 8-2 through 8-12 and Table 8-14 use the same presentation format. Table 8-15 summarizes in tabular form the results plotted in Figures 8-1 through 8-6.

\subsubsection{Changing One Input}

Tables 8-2 through 8-12 report a series of statistical measures for each economic measure. To facilitate comparisons among the economic measures, a shorthand notation for each is used. The present value of savings nationwide over the entire study period is denoted by $\mathrm{PVS}_{\mathrm{ALL}}$. The present value of savings due to BFRL is denoted by $\mathrm{PVS}_{\mathrm{BFRL}}$. The present value of BFRL's CONSIAT-related investment costs is denoted by PVC $_{\text {BFRL. }}$.

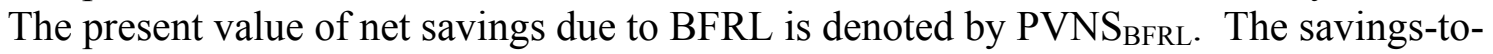
investment ratio on BFRL's CONSIAT-related investments is designated by SIR BFRL $_{\text {. }}$ The adjusted internal rate of return on BFRL's CONSIAT-related investments is

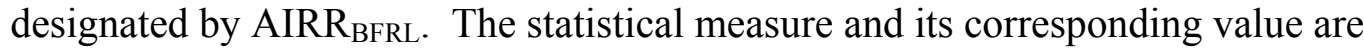
recorded under the heading Statistical Measure. Seven statistical measures are reported to characterize the results of each Monte Carlo simulation. The calculation of these statistical measures is based on a "sample of 1,000 observations" produced by each 
Monte Carlo simulation. These statistical measures are: (1) the minimum; (2) the $25^{\text {th }}$ percentile, denoted by $25 \%$; (3) the $50^{\text {th }}$ percentile (i.e., the median), denoted by $50 \%$; (4) the $75^{\text {th }}$ percentile, denoted by $75 \%$; (5) the maximum; (6) the mean; and (7) the standard deviation. The minimum and the maximum define the range of values for the results from each of the Monte Carlo simulations. The $50^{\text {th }}$ percentile and the mean are measures of central tendency. The $25^{\text {th }}$ and $75^{\text {th }}$ percentiles define the interquartile range, a range that includes the middle $50 \%$ of the observations. The interquartile range is also a crude measure of central tendency. The standard deviation measures the variability of the results from each of the Monte Carlo simulations. It is important to recognize that the values reported for $\mathrm{PVS}_{\mathrm{ALL}}, \mathrm{PVS}_{\mathrm{BFRL}}, \mathrm{PVC}_{\mathrm{BFRL}}$, and $\mathrm{PVNS} \mathrm{S}_{\mathrm{BFRL}}$ are all in millions of 1997 dollars.

The results presented in Tables 8-2, 8-3, and 8-4 are related to the values of the parameters in the diffusion model (see Section 6.4.4). Each parameter, $\alpha, \beta$, and $\eta$ is analyzed in turn.

Table 8-2 shows how variations about the baseline value for $\alpha$ (i.e., $\alpha=4.0$ ) affect each economic measure. The parameter $\alpha$ was selected for evaluation because it is the location parameter for the diffusion model. The effect of $\alpha$ is as follows: lower values of $\alpha$ produce a thicker tail immediately following the introduction of CONSIAT products and services into the marketplace (i.e., higher values of $P_{\eta}(t)$, whenever $t$ is small), whereas higher values of $\alpha$ produce a thinner tail (i.e., lower values of $P_{\eta}(t)$, whenever $t$ is small). Reference to Table 8-2 reveals that $\alpha$ exerts a strong effect on five of the six economic measures. For example, the minimum value of $\mathrm{PVS}_{\mathrm{ALL}}$ is less than one half of the highest value. Although the present value of savings nationwide is strongly affected by changes in the value of $\alpha$, the measures of BFRL's influence are affected to a far greater degree. The reason is due to the way in which BFRL's influence is measured. Because those savings occurring in the first four years are attributable to BFRL, higher values of $\alpha$ reduce these savings and lower values of $\alpha$ increase these savings over the value calculated in the baseline analysis. For example, the minimum value of SIR $\mathrm{BFRL}_{\mathrm{B}}$ is one-sixth the highest value, and PVNS $\mathrm{BFRL}_{\mathrm{B}}$ varies by more than a factor of 10 . Note that $\mathrm{PVC}_{\mathrm{BFRL}}$ is unaffected by changes in the value of $\alpha$. Thus, the standard deviation for $\mathrm{PVC}_{\mathrm{BFRL}}$ is 0.0. Consequently, the standard deviation for PVS $\mathrm{S}_{\mathrm{BFRL}}$ and the standard

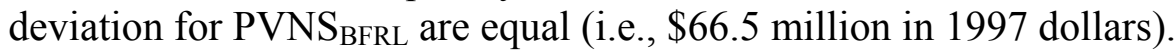

Table 8-2. Summary Statistics Due to Changes in the Input Variable Alpha

\begin{tabular}{|l|c|c|c|r|r|r|r|}
\hline \multirow{2}{*}{$\begin{array}{l}\text { Economic } \\
\text { Measure }\end{array}$} & \multicolumn{7}{|c|}{ Statistical Measure } \\
\cline { 2 - 8 } & Minimum & $\mathbf{2 5 \%}$ & $\mathbf{5 0 \%}$ & $\mathbf{7 5 \%}$ & Maximum & Mean & $\begin{array}{r}\text { Standard } \\
\text { Deviation }\end{array}$ \\
\hline PVS $_{\text {ALL }}$ & 871.406 & $1,119.611$ & $1,382.380$ & $1,655.858$ & $1,980.009$ & $1,391.566$ & 313.721 \\
\hline PVS $_{\text {BFRL }}$ & 46.898 & 76.927 & 121.359 & 184.499 & 285.684 & 134.644 & 66.544 \\
\hline PVC $_{\text {BFRL }}$ & 29.144 & 29.144 & 29.144 & 29.144 & 29.144 & 29.144 & 0.0 \\
\hline PVNS $_{\text {BFRL }}$ & 17.753 & 47.783 & 92.214 & 155.354 & 256.540 & 105.500 & 66.544 \\
\hline SIR $_{\text {BFRL }}$ & 1.609 & 2.640 & 4.164 & 6.331 & 9.802 & 4.620 & 2.283 \\
\hline AIRR $_{\text {BFRL }}$ & 0.091 & 0.112 & 0.133 & 0.152 & 0.172 & 0.132 & 0.023 \\
\hline
\end{tabular}


Table 8-3 shows how variations about the baseline value for $\beta$ (i.e., $\beta=0.5$ ) affect each economic measure. The parameter, $\beta$, was selected for evaluation because it specifies the rate of change for the diffusion model. The effect of $\beta$ is as follows: higher values of $\beta$ produce a higher rate of adoption of CONSIAT products and services in the marketplace immediately following the introduction of these products and services (i.e., higher values of $P_{\eta}(t)$, whenever $t$ is small), whereas lower values of $\beta$ produce a lower rate of adoption (i.e., lower values of $P_{\eta}(t)$, whenever $t$ is small). Reference to Table 8-3 reveals that $\beta$ exerts a moderate to strong effect on five of the six economic measures. For example, the range of values for $\mathrm{PVS}_{\mathrm{ALL}}$ is slightly in excess of $\$ 750$ million in 1997 dollars.

Although the present value of savings nationwide is strongly affected by changes in the value of $\beta$, the measures of BFRL's influence are affected to a much lesser degree than for changes in $\alpha$. The reason is due to the way in which BFRL's influence is measured. Because those savings occurring in the first four years are attributable to BFRL, lower values of $\beta$ reduce these savings and higher values of $\beta$ increase these savings over the value calculated in the baseline analysis. However, these differences are less than those associated with $\alpha$, because $\alpha$ affects the thickness of the lower tail of $P_{\eta}(t)$, whereas $\beta$ only affects the rate of change of the slope of the tail in the period immediately following the introduction of CONSIAT products and services. For example, the minimum value

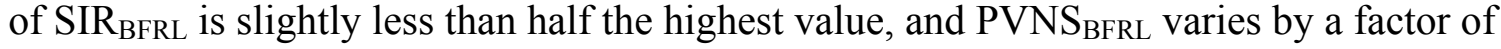
slightly more than two. Note that $\mathrm{PVC}_{\mathrm{BFRL}}$ is unaffected by changes in the value of $\beta$. Thus, the standard deviation for $\mathrm{PVC}_{\mathrm{BFRL}}$ is 0.0 . Consequently, the standard deviation for $\mathrm{PVS}_{\mathrm{BFRL}}$ and the standard deviation for $\mathrm{PVNS}_{\mathrm{BFRL}}$ are equal (i.e., $\$ 13.7$ million in 1997 dollars).

Table 8-3. Summary Statistics Due to Changes in the Input Variable Beta

\begin{tabular}{|l|r|r|r|r|r|r|r|}
\hline \multirow{2}{*}{$\begin{array}{l}\text { Economic } \\
\text { Measure }\end{array}$} & \multicolumn{7}{|c|}{ Statistical Measure } \\
\cline { 2 - 8 } & Minimum & $\mathbf{2 5 \%}$ & $\mathbf{5 0 \%}$ & $\mathbf{7 5 \%}$ & Maximum & Mean & $\begin{array}{l}\text { Standard } \\
\text { Deviation }\end{array}$ \\
\hline PVS $_{\text {ALL }}$ & 973.785 & $1,258.309$ & $1,382.033$ & $1,492.397$ & $1,737.736$ & $1,373.051$ & 161.564 \\
\hline PVS $_{\text {BFRL }}$ & 91.943 & 110.950 & 120.830 & 130.782 & 158.063 & 121.205 & 13.741 \\
\hline PVC $_{\text {BFRL }}$ & 29.144 & 29.144 & 29.144 & 29.144 & 29.144 & 29.144 & 0.0 \\
\hline PVNS $_{\text {BFRL }}$ & 62.799 & 81.805 & 91.685 & 101.637 & 128.918 & 92.061 & 13.741 \\
\hline SIR $_{\text {BFRL }}$ & 3.155 & 3.807 & 4.146 & 4.487 & 5.423 & 4.159 & 0.471 \\
\hline AIRR $_{\text {BFRL }}$ & 0.120 & 0.129 & 0.133 & 0.136 & 0.145 & 0.132 & 0.005 \\
\hline
\end{tabular}

Table 8-4 shows how variations about the baseline value for $\eta$ (i.e., $\eta=0.4$ ) affect each economic measure. The parameter, $\eta$, was selected for evaluation because it specifies the level at which the market for CONSIAT products and services saturates. The effect of $\eta$ is as follows: higher values of $\eta$ produce a higher level of adoption of CONSIAT products and services in the marketplace towards the latter part of the study period (i.e., higher values of $P_{\eta}(t)$, for all values of $t$, especially whenever $t$ is large), whereas lower values of $\eta$ produce a lower level of adoption (i.e., lower values of $P_{\eta}(t)$ ). Reference to Table 8-4 reveals that $\eta$ exerts a moderate to strong effect on five of the six economic measures. For example, the range of values for $\mathrm{PVS}_{\mathrm{ALL}}$ (i.e., Maximum - Minimum) is 
slightly less than $\$ 700$ million in 1997 dollars. Although the present value of savings nationwide is strongly affected by changes in the value of $\eta$, the measures of BFRL's influence are affected to a lesser degree than for changes in $\alpha$. The reason, once again, is due to the way in which BFRL's influence is measured. Because those savings occurring in the first four years are attributable to BFRL, lower values of $\eta$ reduce these savings and higher values of $\eta$ increase these savings over the value calculated in the baseline analysis. However, these differences are less than those associated with $\alpha$, because $\alpha$ affects the thickness of the lower tail of $P_{\eta}(t)$, whereas $\eta$ affects the level at which the market saturates. Thus, the influence of $\eta$ on the years immediately following the introduction of CONSIAT products and services is modest. Consequently, the range of values for the measures of BFRL's influence due to variations about the baseline value for $\eta$ tend to be about the same as for $\beta$, and significantly narrower than for $\alpha$.

Table 8-4. Summary Statistics Due to Changes in the Input Variable Eta

\begin{tabular}{|l|r|r|r|r|r|r|r|}
\hline \multirow{2}{*}{$\begin{array}{l}\text { Economic } \\
\text { Measure }\end{array}$} & \multicolumn{7}{|c|}{ Statistical Measure } \\
\cline { 2 - 8 } & Minimum & $\mathbf{2 5 \%}$ & $\mathbf{5 0 \%}$ & $\mathbf{7 5 \%}$ & Maximum & Mean & $\begin{array}{r}\text { Standard } \\
\text { Deviation }\end{array}$ \\
\hline PVS $_{\text {ALL }}$ & $1,040.260$ & $1,277.849$ & $1,378.806$ & $1,478.809$ & $1,714.327$ & $1,380.564$ & 140.930 \\
\hline PVS $_{\text {BFRL }}$ & 90.957 & 111.731 & 120.559 & 129.302 & 149.895 & 120.712 & 12.323 \\
\hline PVC $_{\text {BFRL }}$ & 29.144 & 29.144 & 29.144 & 29.144 & 29.144 & 29.144 & 0.0 \\
\hline PVNS $_{\text {BFRL }}$ & 61.813 & 82.587 & 91.414 & 100.158 & 120.751 & 91.568 & 12.323 \\
\hline SIR $_{\text {BFRL }}$ & 3.121 & 3.834 & 4.137 & 4.437 & 5.143 & 4.142 & 0.423 \\
\hline AIRR $_{\text {BFRL }}$ & 0.120 & 0.129 & 0.133 & 0.136 & 0.142 & 0.132 & 0.005 \\
\hline
\end{tabular}

Table 8-5 shows how variations about the baseline value of the discount rate ( $7 \%$ (real)) affect each economic measure. The discount rate affects calculations in a number of ways. For example, BFRL's CONSIAT-related investment costs, $\mathrm{PVC}_{\mathrm{BFRL}}$, are affected by the discount rate. The present value of savings nationwide, $\mathrm{PVS}_{\mathrm{ALL}}$, and the present value of savings due to BFRL, PVS $\mathrm{BFRL}_{\mathrm{BF}}$, are also affected by the discount rate. Reference to Table 8-5 reveals that $\mathrm{PVS}_{\mathrm{ALL}}$ is more sensitive to changes in the discount rate than are the key measures of BFRL's influence. This is because savings do not begin until 2005, whereas the base year is 1997 . Thus, savings occurring in the out years (e.g., 2009 and beyond) benefit from a lower discount rate and are penalized by a higher discount rate. This explains the wide range in computed values for $\mathrm{PVS}_{\mathrm{ALL}}$, a range that exceeds $\$ 2.1$ billion in 1997 dollars. On the other hand, BFRL's CONSIAT-related investments are largely clustered around 1997, and BFRL's savings occur between 2005 and 2008 (i.e., much earlier than the bulk of the savings used to calculate $\mathrm{PVS}_{\mathrm{ALL}}$ ). This explains why the key measures of BFRL's influence are less sensitive to changes in the discount rate than is $\mathrm{PVS}_{\mathrm{ALL}}$.

The results presented in Tables 8-6, 8-7, 8-8, and 8-9 address the "savings/benefits" side of the analysis. Tables 8-6 and 8-7 are related to the values of percent cost savings. Tables 8-8 and 8-9 are related to increases in benefits, which in both cases are due to increases in net income. 
Table 8-5. Summary Statistics Due to Changes in the Input Variable Discount Rate

\begin{tabular}{|l|r|r|r|r|r|r|r|}
\hline \multirow{2}{*}{$\begin{array}{l}\text { Economic } \\
\text { Measure }\end{array}$} & \multicolumn{7}{|c|}{ Statistical Measure } \\
\cline { 2 - 8 } & Minimum & $\mathbf{2 5 \%}$ & $\mathbf{5 0 \%}$ & $\mathbf{7 5 \%}$ & Maximum & Mean & $\begin{array}{l}\text { Standard } \\
\text { Deviation }\end{array}$ \\
\hline PVS $_{\text {ALL }}$ & 887.466 & $1,290.033$ & $1,514.077$ & $1,874.513$ & $3,012.035$ & $1,615.876$ & 449.220 \\
\hline PVS $_{\text {BFRL }}$ & 88.427 & 115.014 & 128.762 & 149.751 & 209.877 & 133.853 & 25.984 \\
\hline PVC $_{\text {BFRL }}$ & 26.348 & 28.685 & 29.828 & 31.501 & 35.907 & 30.178 & 2.065 \\
\hline PVNS $_{\text {BFRL }}$ & 62.078 & 86.329 & 98.934 & 118.250 & 173.970 & 103.675 & 23.920 \\
\hline SIR $_{\text {BFRL }}$ & 3.356 & 4.010 & 4.317 & 4.754 & 5.845 & 4.399 & 0.540 \\
\hline AIRR $_{\text {BFRL }}$ & 0.097 & 0.118 & 0.128 & 0.136 & 0.153 & 0.127 & 0.012 \\
\hline
\end{tabular}

Table 8-6 summarizes the results of the Monte Carlo simulation of variations about the baseline value of first cost savings. Reference to Table 8-6 reveals considerable variation about the values calculated in the baseline analysis for five of the six economic measures. For example, the range of values for $\mathrm{PVS}_{\mathrm{ALL}}$ (i.e., Maximum - Minimum) exceeds \$2.2 billion in 1997 dollars. Four of the five measures of BFRL's influence are strongly affected by changes in the input variable first cost savings. More importantly, however,

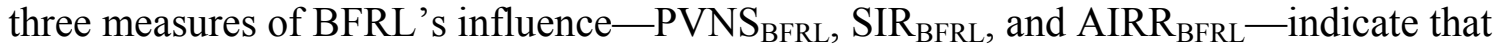
its CONSIAT-related investments may not be cost effective (i.e., cost effectiveness requires $\mathrm{PVNS}_{\mathrm{BFRL}}>0.0, \mathrm{SIR}_{\mathrm{BFRL}}>1.0$, and $\left.\mathrm{AIRR}_{\mathrm{BFRL}}>0.07\right)$. The value of $\mathrm{PVC}_{\mathrm{BFRL}}$ is not affected by the input variable first cost savings.

\section{Table 8-6. Summary Statistics Due to Changes in the Input Variable First Cost Savings}

\begin{tabular}{|l|c|c|r|r|r|r|r|}
\hline \multirow{2}{*}{$\begin{array}{l}\text { Economic } \\
\text { Measure }\end{array}$} & \multicolumn{7}{|c|}{ Statistical Measure } \\
\cline { 2 - 8 } & Minimum & $\mathbf{2 5 \%}$ & $\mathbf{5 0 \%}$ & $\mathbf{7 5 \%}$ & Maximum & Mean & $\begin{array}{l}\text { Standard } \\
\text { Deviation }\end{array}$ \\
\hline PVS $_{\text {ALL }}$ & 112.605 & 893.983 & $1,253.274$ & $1,596.071$ & $2,326.055$ & $1,241.567$ & 484.500 \\
\hline PVS $_{\text {BFRL }}$ & 28.410 & 85.267 & 111.411 & 136.355 & 189.472 & 110.559 & 35.255 \\
\hline PVC $_{\text {BFRL }}$ & 29.144 & 29.144 & 29.144 & 29.144 & 29.144 & 29.144 & 0.0 \\
\hline PVNS $_{\text {BFRL }}$ & -0.734 & 56.123 & 82.267 & 107.211 & 160.328 & 81.415 & 35.255 \\
\hline SIR $_{\text {BFRL }}$ & 0.975 & 2.926 & 3.823 & 4.679 & 6.501 & 3.794 & 1.210 \\
\hline AIRR $_{\text {BFRL }}$ & 0.069 & 0.117 & 0.129 & 0.138 & 0.153 & 0.126 & 0.016 \\
\hline
\end{tabular}

Table 8-7 summarizes the results of the Monte Carlo simulation of variations about the baseline value of maintenance and repair cost savings. Table 8-7 reveals modest variations about the values calculated in the baseline analysis for five of the six economic measures. For example, the minimum value for the $\mathrm{PVS}_{\mathrm{ALL}}$ is $\$ 1,187.9$ million, and the maximum is $\$ 1,576.7$ million, a range of slightly less than $\$ 400$ million (measured in 1997 dollars). Whereas, the minimum value for the $\mathrm{PVS}_{\mathrm{BFRL}}$ is $\$ 97.4$ million, and the maximum is $\$ 144.6$ million, a range of approximately $\$ 45$ million (measured in 1997 dollars). The value of $\mathrm{PVC}_{\mathrm{BFRL}}$ is not affected by the input variable maintenance and repair cost savings. 
Table 8-7. Summary Statistics Due to Changes in the Input Variable Maintenance and Repair Cost Savings

\begin{tabular}{|c|c|c|c|c|c|c|c|}
\hline \multirow[b]{2}{*}{$\begin{array}{l}\text { Economic } \\
\text { Measure }\end{array}$} & \multicolumn{7}{|c|}{ Statistical Measure } \\
\hline & Minimum & $25 \%$ & $50 \%$ & $75 \%$ & Maximum & Mean & $\begin{array}{l}\text { Standard } \\
\text { Deviation }\end{array}$ \\
\hline $\mathbf{P V S}_{\mathrm{ALL}}$ & $1,187.911$ & $1,318.587$ & $1,377.409$ & $1,435.741$ & $1,576.729$ & $1,376.502$ & 82.187 \\
\hline PVS $_{\text {BFRL }}$ & 97.428 & 113.282 & 120.419 & 127.496 & 144.601 & 120.309 & 9.971 \\
\hline PVC $_{\text {BFRL }}$ & 29.144 & 29.144 & 29.144 & 29.144 & 29.144 & 29.144 & 0.0 \\
\hline PVNS $_{\text {BFRL }}$ & 68.284 & 84.138 & 91.274 & 98.351 & 115.457 & 91.164 & 9.971 \\
\hline SIR $_{\text {BFRL }}$ & 3.343 & 3.887 & 4.132 & 4.375 & 4.962 & 4.128 & 0.342 \\
\hline AIRR $_{\text {BFRL }}$ & 0.123 & 0.130 & 0.132 & 0.135 & 0.141 & 0.132 & 0.004 \\
\hline
\end{tabular}

Table 8-8 summarizes the results of the Monte Carlo simulation of variations about the baseline value of reductions in delivery time. Reference to Table 8-8 reveals considerable variation about the values calculated in the baseline analysis for five of the six economic measures. The pattern of results presented in Table 8-8 is similar to the one resulting from first cost savings (see Table 8-6). For example, the range of values for PVS $_{\text {ALL }}$ (i.e., Maximum - Minimum) exceeds \$2.2 billion in 1997 dollars. As was the case for first cost savings, four of the five measures of BFRL's influence are strongly affected by changes in the input variable reductions in delivery time. For example, the value calculated in the baseline analysis for the $\mathrm{SIR}_{\mathrm{BFRL}}$ is 4.13. In Table 8-8, the minimum value for the $\mathrm{SIR}_{\mathrm{BFRL}}$ is 2.346 , and the maximum value is 8.000 , a relative difference of a factor of more than three-to-one. The value of $\mathrm{PVC}_{\mathrm{BFRL}}$ is not affected by the input variable reductions in delivery time.

Table 8-8. Summary Statistics Due to Changes in the Input Variable Reductions in Delivery Time

\begin{tabular}{|l|r|r|r|r|r|r|r|}
\hline \multirow{2}{*}{$\begin{array}{l}\text { Economic } \\
\text { Measure }\end{array}$} & \multicolumn{7}{|c|}{ Statistical Measure } \\
\cline { 2 - 8 } & Minimum & $\mathbf{2 5 \%}$ & $\mathbf{5 0 \%}$ & $\mathbf{7 5 \%}$ & Maximum & Mean & $\begin{array}{r}\text { Standard } \\
\text { Deviation }\end{array}$ \\
\hline PVS $_{\text {ALL }}$ & 661.751 & $1,275.050$ & $1,602.790$ & $2,005.168$ & $2,926.232$ & $1,652.937$ & 502.951 \\
\hline PVS $_{\text {BFRL }}$ & 68.369 & 112.996 & 136.844 & 166.123 & 233.144 & 140.493 & 36.597 \\
\hline PVC $_{\text {BFRL }}$ & 29.144 & 29.144 & 29.144 & 29.144 & 29.144 & 29.144 & 0.0 \\
\hline PVNS $_{\text {BFRL }}$ & 39.225 & 83.851 & 107.699 & 136.979 & 204.000 & 111.348 & 36.597 \\
\hline SIR $_{\text {BFRL }}$ & 2.346 & 3.877 & 4.695 & 5.700 & 8.000 & 4.821 & 1.256 \\
\hline AIRR $_{\text {BFRL }}$ & 0.107 & 0.130 & 0.138 & 0.147 & 0.163 & 0.138 & 0.012 \\
\hline
\end{tabular}

Table 8-9 summarizes the results of the Monte Carlo simulation of variations about the baseline value of higher contractor net income. Table 8-9 reveals considerable variations about the values calculated in the baseline analysis for five of the six economic measures. The value of $\mathrm{PVC}_{\mathrm{BFRL}}$ is not affected by the input variable higher contractor net income. Reference to Table 8-9 reveals that the range of values for PVS $_{\mathrm{ALL}}$ (i.e., Maximum Minimum) exceeds $\$ 2.2$ billion in 1997 dollars. Note that the ranges of values and the standard deviations for the five economic measures for which variations do occur for this 
input variable are approximately equal to those for first cost savings and less than those for reductions in delivery time (see Tables 8-6 and 8-8).

Table 8-9. Summary Statistics Due to Changes in the Input Variable Higher Contractor Net Income

\begin{tabular}{|l|r|r|r|r|r|r|r|}
\hline \multirow{2}{*}{$\begin{array}{l}\text { Economic } \\
\text { Measure }\end{array}$} & \multicolumn{7}{|c|}{ Statistical Measure } \\
\cline { 2 - 8 } & Minimum & $\mathbf{2 5 \%}$ & $\mathbf{5 0 \%}$ & $\mathbf{7 5 \%}$ & Maximum & Mean & $\begin{array}{l}\text { Standard } \\
\text { Deviation }\end{array}$ \\
\hline PVS $_{\text {ALL }}$ & 530.369 & $1,223.724$ & $1,512.503$ & $1,908.493$ & $2,766.567$ & $1,565.514$ & 481.060 \\
\hline PVS $_{\text {BFRL }}$ & 58.809 & 109.261 & 130.274 & 159.088 & 221.526 & 134.131 & 35.004 \\
\hline PVC $_{\text {BFRL }}$ & 29.144 & 29.144 & 29.144 & 29.144 & 29.144 & 29.144 & 0.0 \\
\hline PVNS $_{\text {BFRL }}$ & 29.665 & 80.117 & 101.130 & 129.944 & 192.382 & 104.987 & 35.004 \\
\hline SIR $_{\text {BFRL }}$ & 2.018 & 3.749 & 4.470 & 5.459 & 7.601 & 4.602 & 1.201 \\
\hline AIRR $_{\text {BFRL }}$ & 0.100 & 0.128 & 0.136 & 0.145 & 0.160 & 0.136 & 0.012 \\
\hline
\end{tabular}

The results presented in Table 8-10 address the "costs" side of the analysis. Table 8-10 summarizes the results of the Monte Carlo simulation of variations about the baseline value of new technology introduction costs. Table $8-10$ reveals strong variations about the values calculated in the baseline analysis for five of the six economic measures. The value of $\mathrm{PVC}_{\mathrm{BFRL}}$ is not affected by the input variable new technology introduction costs. Reference to Table 8-10 reveals that the range of values for $\mathrm{PVS}_{\mathrm{ALL}}$ (i.e., Maximum Minimum) exceeds $\$ 1.2$ billion in 1997 dollars. One of the economic measures of BFRL's influence is the SIR. For this economic measure, the value calculated in the baseline analysis is 4.13 . In Table 8-10, the minimum value for the $\operatorname{SIR}_{\mathrm{BFRL}}$ is 2.604 , and the maximum value is 5.740 (i.e., the baseline value of the $\operatorname{SIR}_{B F R L} \pm 1.5$ ). Note that the ranges of values and the standard deviations for the five economic measures for which variations do occur for the "costs" side of the analysis are less than those for three of the four input variables associated with the "savings/benefits" side of the analysis (i.e., first cost savings, reductions in delivery time, and higher contractor net income (see Tables 8$6,8-8$, and 8-9)). Thus, the economic measures are "less sensitive" to variations in the "costs" side of the analysis than they are to the "savings/benefits" side of the analysis.

Table 8-10. Summary Statistics Due to Changes in the Input Variable NewTechnology Introduction Costs

\begin{tabular}{|l|r|r|r|r|r|r|r|}
\hline \multirow{2}{*}{$\begin{array}{l}\text { Economic } \\
\text { Measure }\end{array}$} & \multicolumn{7}{|c|}{ Statistical Measure } \\
\cline { 2 - 8 } & Minimum & $\mathbf{2 5 \%}$ & $\mathbf{5 0 \%}$ & $\mathbf{7 5 \%}$ & Maximum & Mean & $\begin{array}{l}\text { Standard } \\
\text { Deviation }\end{array}$ \\
\hline PVS $_{\text {ALL }}$ & 765.223 & $1,183.489$ & $1,396.944$ & $1,596.607$ & $2,021.082$ & $1,386.715$ & 276.424 \\
\hline PVS $_{\text {BFRL }}$ & 75.898 & 106.333 & 121.865 & 136.394 & 167.281 & 121.121 & 20.114 \\
\hline PVC $_{\text {BFRL }}$ & 29.144 & 29.144 & 29.144 & 29.144 & 29.144 & 29.144 & 0.0 \\
\hline PVNS $_{\text {BFRL }}$ & 46.754 & 77.189 & 92.721 & 107.250 & 138.137 & 91.977 & 20.114 \\
\hline SIR $_{\text {BFRL }}$ & 2.604 & 3.649 & 4.181 & 4.680 & 5.740 & 4.156 & 0.690 \\
\hline AIRR $_{\text {BFRL }}$ & 0.112 & 0.127 & 0.133 & 0.138 & 0.147 & 0.132 & 0.008 \\
\hline
\end{tabular}


Table 8-11 shows how variations about the baseline value for the time of first use (i.e., $t=$ 1 in the year 2005) affect each economic measure. The alternative times of first use are specified by a discrete distribution (see Table 8-1). The discrete probabilities for each year are: 2004, 0.125; 2005, 0.5;2006, 0.25; and 2007, 0.125. The time of first use affects all six economic measures. It exerts a moderate to strong influence on the present value of savings nationwide, $\mathrm{PVS}_{\mathrm{ALL}}$, since it determines the number of years over which cost savings can accrue. This is because the end of the study period is fixed at 2017.

Thus, if the year of first use is 2007, there are fewer years over which savings can accrue than for the baseline value (i.e., 2005). Notice that the measures of BFRL's influence are strongly affected. This is because BFRL's contribution is measured in terms of the savings occurring in those years before CONSIAT products and services would become available commercially were it not for BFRL's influence (i.e., 2009). The year of first use defines when savings begin. Also, because BFRL is targeting the introduction of CONSIAT products and services for a particular year, BFRL's investment cost stream, $\mathrm{PVC}_{\mathrm{BFRL}}$, varies as a function of the target date. Thus, the differences from the value calculated in the baseline analysis are due to the timing of the savings and BFRL's investment cost stream, which, through the discount rate, affects the values of PVS $\mathrm{S}_{\mathrm{BFRL}}$ and $\mathrm{PVC}_{\mathrm{BFRL}}$. Variations in the value of $\mathrm{PVS}_{\mathrm{BFRL}}$ and $\mathrm{PVC}_{\mathrm{BFRL}}$ are responsible for variations in the values of PVNS $\mathrm{BFRL}_{\mathrm{B}}, \mathrm{SIR}_{\mathrm{BFRL}}$, and $\mathrm{AIRR}_{\mathrm{BFRL}}$.

\section{Table 8-11. Summary Statistics Due to Changes in the Input Variable Time of First Use}

\begin{tabular}{|c|c|c|c|c|c|c|c|}
\hline \multirow[b]{2}{*}{$\begin{array}{l}\text { Economic } \\
\text { Measure }\end{array}$} & \multicolumn{7}{|c|}{ Statistical Measure } \\
\hline & Minimum & $25 \%$ & $50 \%$ & $75 \%$ & Maximum & Mean & $\begin{array}{l}\text { Standard } \\
\text { Deviation }\end{array}$ \\
\hline $\mathbf{P V S}_{\mathrm{ALL}}$ & 853.341 & $1,098.833$ & $1,377.926$ & $1,377.926$ & $1,690.445$ & $1,292.270$ & 240.842 \\
\hline PVS $_{\text {BFRL }}$ & 29.310 & 64.186 & 120.482 & 120.482 & 208.436 & 108.465 & 52.134 \\
\hline PVC $_{\text {BFRL }}$ & 27.069 & 28.872 & 29.144 & 29.144 & 34.878 & 29.656 & 2.228 \\
\hline PVNS $_{\text {BFRL }}$ & 2.241 & 35.314 & 91.337 & 91.337 & 173.558 & 78.810 & 50.146 \\
\hline SIR $_{\text {BFRL }}$ & 1.083 & 2.223 & 4.134 & 4.134 & 5.976 & 3.568 & 1.468 \\
\hline AIRR $_{\text {BFRL }}$ & 0.073 & 0.105 & 0.133 & 0.133 & 0.149 & 0.121 & 0.023 \\
\hline
\end{tabular}

Table 8-12 shows how variations about the baseline value for the length of the delay affect each economic measure. The alternative numbers of years for the length of the delay are specified by a discrete distribution (see Table 8-1). The discrete probabilities for each length of delay are: 0 years, $0.6 ; 1$ year, 0.25 ; and 2 years, 0.15 . The length of delay affects five of the six economic measures. The value of $\mathrm{PVC}_{\mathrm{BFRL}}$ is not affected by the input variable length of delay. Because the baseline analysis assumed no delay, the computed value for each economic measure equals the value calculated in the baseline analysis for three of the six statistical measures (i.e., the $50^{\text {th }}$ percentile, the $75^{\text {th }}$

percentile, and the maximum). By virtue of the way the discrete distribution is specified for the length of the delay, the $25^{\text {th }}$ percentile is associated with a one-year delay and the minimum is associated with a two-year delay. Reference to Table 8-12 reveals that with the exception of first cost savings (see Table 8-6) the minimum value for four of the five 


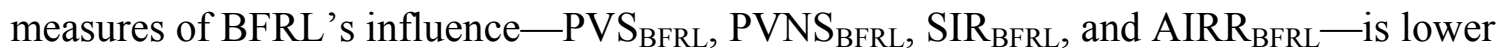
than the corresponding minimum value for each of these variables examined previously. Although the minimum values for these four measures of BFRL's influence are smaller for this input variable than for nine of the other ten, in every case BFRL's contribution is positive (i.e., $\mathrm{PVNS}_{\mathrm{BFRL}}>0.0, \mathrm{SIR}_{\mathrm{BFRL}}>1.0$, and $\mathrm{AIRR}_{\mathrm{BFRL}}>0.07$ ). The length of delay affects the calculated values of the economic measures in a way that is similar to the year of first use. This is because BFRL's contribution is measured in terms of the savings occurring in those years before CONSIAT products and services would become available commercially were it not for BFRL's influence (i.e., 2009). Thus, a two-year delay, measured against the baseline year of first use of 2005, delays the commencement of the savings/benefits stream until 2007. Reference to Table 8-11 reveals that the minimum values for PVS $\mathrm{ALL}_{\mathrm{AL}}$ and PVS $\mathrm{BFRL}_{\mathrm{BF}}$ are the same as in Table 8-12. In the case of Table 8-11, these values correspond to a "no delay" (i.e., the baseline value for the length of delay) and a year of first use of 2007.

\section{Table 8-12. Summary Statistics Due to Changes in the Input Variable Length of Delay}

\begin{tabular}{|l|r|r|r|r|r|r|r|}
\hline \multirow{2}{*}{$\begin{array}{l}\text { Economic } \\
\text { Measure }\end{array}$} & \multicolumn{10}{|c|}{ Statistical Measure } & $\begin{array}{r}\text { Standard } \\
\text { Deviation }\end{array}$ \\
\cline { 2 - 8 } & Minimum & $\mathbf{2 5 \%}$ & $\mathbf{5 0 \%}$ & $\mathbf{7 5 \%}$ & Maximum & Mean & \\
\hline PVS $_{\text {ALL }}$ & 853.341 & $1,098.833$ & $1,377.926$ & $1,377.926$ & $1,377.926$ & $1,231.876$ & 195.960 \\
\hline PVS $_{\text {BFRL }}$ & 29.310 & 64.186 & 120.482 & 120.482 & 120.482 & 93.174 & 35.500 \\
\hline PVC $_{\text {BFRL }}$ & 29.144 & 29.144 & 29.144 & 29.144 & 29.144 & 29.144 & 0.0 \\
\hline PVNS $_{\text {BFRL }}$ & 0.165 & 35.041 & 91.337 & 91.337 & 91.337 & 64.030 & 35.500 \\
\hline SIR $_{\text {BFRL }}$ & 1.006 & 2.202 & 4.134 & 4.134 & 4.134 & 3.197 & 1.218 \\
\hline AIRR $_{\text {BFRL }}$ & 0.070 & 0.104 & 0.133 & 0.133 & 0.133 & 0.116 & 0.023 \\
\hline
\end{tabular}

Table 8-13 summarizes the results of a deterministic sensitivity analysis for the combined effects of the "targeted" time of first use and the length of delay. Table 8-13 has three parts: (1) Part A, where each targeted time of first use is evaluated assuming no delay; (2) Part B, where each targeted time of first use is evaluated assuming a one-year delay; and (3) Part C, where each targeted time of first use is evaluated assuming a two-year delay. The results presented in Table 8-13 differ significantly from those presented in all but one (see Table 8-6) of the previous tables in an important way. Namely, the minimum values of four of the key measures of BFRL's influence (i.e., PVS $_{\mathrm{BFRL}}$, PVNS $\mathrm{BFRL}_{\mathrm{BF}}$, $\mathrm{SIR}_{\mathrm{BFRL}}$, and $\mathrm{AIRR}_{\mathrm{BFRL}}{ }^{103}$ ) indicate that BFRL's CONSIAT-related investments may not be cost effective. To place the previous remark in context, it is important to recognize that this outcome corresponds to situations where a non-zero delay is present. For example, reference to Part A of Table 8-13 reveals that for all targeted times of first use all economic measures indicate that BFRL's CONSIAT-related investments are cost effective. Reference to Parts B and C reveals that a delay of one year for the 2007

\footnotetext{
${ }^{103}$ The value of the AIRR is only defined for cases where the computed value of the SIR is non-negative.

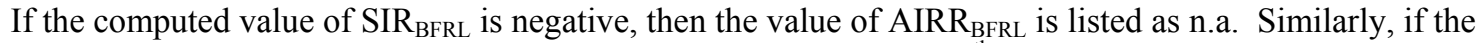
computed value of $\operatorname{SIR}_{\mathrm{BFRL}}$ is zero or positive but after taking the $1 / \mathrm{L}^{\text {th }}$ root (see Equation 2.5 ) the imputed value of $A_{I R R} R_{B F R}$ is negative, then the value of $A_{I R R} R_{B F R L}$ is listed as n.a.
} 
targeted time of first use and of two years for the 2006 targeted time of first use will result in a negative PVNS $\mathrm{BFRL}_{\mathrm{BF}}$. What Table 8-13 does not show is the probability that the computed value of an economic measure will indicate that BFRL's CONSIAT-related investment will not be cost effective. To estimate the probability that BFRL's CONSIAT-related investment will not be cost effective requires a more comprehensive analysis. Specifically, Table 8-13 demonstrates that the combined effects of the targeted year of first use and the length of the delay are sufficient to lead to "undesirable" outcomes. However, what about other combinations of input variables? Could combinations of all eleven inputs lead to more extreme outcomes or will they offset the "undesirable" outcomes illustrated in Table 8-13? This analysis "topic" is the subject of Subsection 8.3.2

\section{Table 8-13. Results of the Deterministic Sensitivity Analysis for the Combined Effects Due to Changes of the Input Variables "Targeted" Time of First Use and the Length of the Delay}

\section{Part A: No Delay}

\begin{tabular}{|l|c|c|r|r|}
\hline \multirow{2}{*}{$\begin{array}{l}\text { Economic } \\
\text { Measure }\end{array}$} & \multicolumn{4}{|c|}{ Year of First Commercial Use } \\
\cline { 2 - 5 } & $\mathbf{2 0 0 4}$ & $\mathbf{2 0 0 5}$ & $\mathbf{2 0 0 6}$ & \multicolumn{1}{|c|}{$\mathbf{2 0 0 7}$} \\
\hline PVS $_{\text {ALL }}$ & $1,690.445$ & $1,377.926$ & $1,098.833$ & 853.341 \\
\hline PVS $_{\text {BFRL }}$ & 208.436 & 120.482 & 64.186 & 29.310 \\
\hline PVC $_{\text {BFRL }}$ & 34.878 & 29.144 & 28.872 & 27.069 \\
\hline PVNS $_{\text {BFRL }}$ & 173.558 & 91.337 & 35.314 & 2.241 \\
\hline SIR $_{\text {BFRL }}$ & 5.976 & 4.134 & 2.223 & 1.083 \\
\hline AIRR $_{\text {BFRL }}$ & 0.149 & 0.133 & 0.105 & 0.073 \\
\hline
\end{tabular}

Part B: One-Year Delay

\begin{tabular}{|l|c|c|r|r|}
\hline \multirow{2}{*}{$\begin{array}{l}\text { Economic } \\
\text { Measure }\end{array}$} & \multicolumn{4}{|c|}{ Year of First Commercial Use } \\
\cline { 2 - 5 } & $\mathbf{2 0 0 4}$ & $\mathbf{2 0 0 5}$ & $\mathbf{2 0 0 6}$ & \multicolumn{1}{c|}{$\mathbf{2 0 0 7}$} \\
\hline PVS $_{\text {ALL }}$ & $1,377.926$ & $1,098.833$ & 853.341 & 646.198 \\
\hline PVS $_{\text {BFRL }}$ & 120.482 & 64.186 & 29.310 & 12.514 \\
\hline PVC $_{\text {BFRL }}$ & 34.878 & 29.144 & 28.872 & 27.069 \\
\hline PVNS $_{\text {BFRL }}$ & 85.604 & 35.041 & 0.438 & -14.555 \\
\hline SIR $_{\text {BFRL }}$ & 3.454 & 2.202 & 1.015 & 0.462 \\
\hline AIRR $_{\text {BFRL }}$ & 0.124 & 0.104 & 0.071 & 0.037 \\
\hline
\end{tabular}

\section{Part C: Two-Year Delay}

\begin{tabular}{|l|c|c|c|r|}
\hline \multirow{2}{*}{$\begin{array}{l}\text { Economic } \\
\text { Measure }\end{array}$} & \multicolumn{4}{|c|}{ Year of First Commercial Use } \\
\cline { 2 - 5 } & $\mathbf{2 0 0 4}$ & $\mathbf{2 0 0 5}$ & $\mathbf{2 0 0 6}$ & \multicolumn{1}{c|}{$\mathbf{2 0 0 7}$} \\
\hline PVS $_{\text {ALL }}$ & $1,098.833$ & 853.341 & 646.198 & 469.371 \\
\hline PVS $_{\text {BFRL }}$ & 64.186 & 29.310 & 12.514 & 0.0 \\
\hline PVC $_{\text {BFRL }}$ & 34.878 & 29.144 & 28.872 & 27.069 \\
\hline PVNS $_{\text {BFRL }}$ & 29.308 & 0.165 & -16.358 & -27.069 \\
\hline SIR $_{\text {BFRL }}$ & 1.840 & 1.006 & 0.433 & 0.0 \\
\hline AIRR $_{\text {BFRL }}$ & 0.096 & 0.070 & 0.035 & n.a. \\
\hline
\end{tabular}




\subsubsection{Changing All Eleven Inputs in Combination}

Table 8-14 summarizes the results of the Monte Carlo simulation in which all eleven of the input variables were varied in combination. Reference to Table 8-14 reveals that the

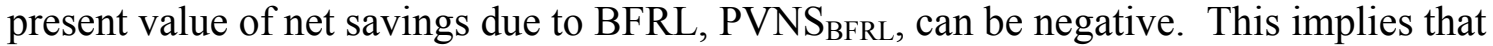
there is some non-zero probability that BFRL's CONSIAT-related investments are not cost effective. However, on the opposite extreme, $\mathrm{PVNS}_{\mathrm{BFRL}}$ may exceed $\$ 800$ million in 1997 dollars, and SIR $\mathrm{BFRL}$ reaches 26.6.

A closer examination of Table 8-14 reveals several interesting outcomes. First, the range of values - the difference between the minimum and maximum - is very wide. For example, the minimum value of $\mathrm{PVS}_{\mathrm{ALL}}$ is approximately $-\$ 1.35$ billion, whereas the maximum is almost $\$ 8.0$ billion. Second, the computed value of the mean equals or exceeds the computed value of the median for five of the six economic measures. This is because a small number of very large observations are pulling up the computed value of the mean. Third, the computed value of the standard deviation for each of the six economic measures is higher than the corresponding value for variations in a single input variable. This is also due to a small number of very large observations. Finally, the computed values of both the mean and the median of each of the five economic measures of BFRL's contribution are lower than the corresponding baseline value. This is due to the way the length of the delay enters into the calculations. In the baseline analysis, no delay was assumed. Thus, if CONSIAT products and services were targeted for commercialization in 2005, they were assumed to enter the market in 2005 . In the sensitivity analysis, CONSIAT products and services enter the market in the year targeted $60 \%$ of the time, one year after the year targeted $25 \%$ of the time, and two years after the year targeted $15 \%$ of the time. As was seen in Part C of Table 8-13, a delay of two years may lead to commercialization in 2009 , the year in which commercialization is assumed to take place without BFRL's participation. Thus, although the nation reaps substantial cost savings associated with the use of CONSIAT products and services, none of these savings are attributed to BFRL. This is due to our conservative approach to measuring BFRL's impact, in which zero weight is assigned to any savings accruing in 2009 or thereafter.

Table 8-14. Summary Statistics Due to Changes in All of the Input Variables

\begin{tabular}{|l|c|c|c|r|r|r|r|}
\hline \multirow{2}{*}{$\begin{array}{l}\text { Economic } \\
\text { Measure }\end{array}$} & \multicolumn{7}{|c|}{ Statistical Measure } \\
\cline { 2 - 8 } & Minimum & $\mathbf{2 5 \%}$ & $\mathbf{5 0 \%}$ & $\mathbf{7 5 \%}$ & Maximum & Mean & $\begin{array}{l}\text { Standard } \\
\text { Deviation }\end{array}$ \\
\hline PVS $_{\text {ALL }}$ & $-1,353.334$ & 833.362 & $1,461.006$ & $2,274.788$ & $7,979.868$ & $1,686.191$ & $1,221.494$ \\
\hline PVS $_{\text {BFRL }}$ & -38.580 & 32.322 & 78.666 & 164.442 & 860.753 & 120.427 & 124.971 \\
\hline PVC $_{\text {BFRL }}$ & 24.529 & 28.503 & 30.125 & 32.289 & 43.889 & 30.719 & 3.140 \\
\hline PVNS $_{\text {BFRL }}$ & -71.204 & 2.530 & 48.726 & 132.643 & 828.414 & 89.708 & 123.768 \\
\hline SIR $_{\text {BFRL }}$ & -1.183 & 1.076 & 2.611 & 5.258 & 26.617 & 3.810 & 3.773 \\
\hline AIRR $_{\text {BFRL }}$ & n.a. & 0.063 & 0.105 & 0.135 & 0.226 & 0.104 & 0.046 \\
\hline
\end{tabular}


The fact that the range of outcomes is so wide suggests that an in-depth examination of the results of this Monte Carlo simulation is warranted. We now turn to this in-depth examination.

The graphical results of the sensitivity analysis where all eleven input variables were varied in combination are shown in Figures 8-1 through 8-6. The figures were constructed by first sorting the values of each economic measure from smallest to largest. The resultant cumulative distribution function (CDF) was then plotted. In each figure, the vertical axis records the probability that the economic measure (e.g., $\mathrm{SIR}_{\mathrm{BFRL}}$ ) is less than or equal to a specified value. The values recorded on the horizontal axis cover the range of values encountered during this Monte Carlo simulation.

The tabular results of the sensitivity analysis are recorded in Table 8-15. The table lists each of the calculated percentiles from the resultant CDF. The range of percentiles included in the table go from the $1^{\text {st }}$ to the $99^{\text {th }}$. For purposes of this analysis, the $0^{\text {th }}$ percentile is set equal to the minimum value, and the $100^{\text {th }}$ percentile is set equal to the maximum value (see Table 8-14). This enables a close coupling of the values recorded in Table 8-15 and the values used to plot each figure.

Table 8-15 includes for each percentile the computed value for $\mathrm{PVS}_{\mathrm{ALL}}, \mathrm{PVS}_{\mathrm{BFRL}}$,

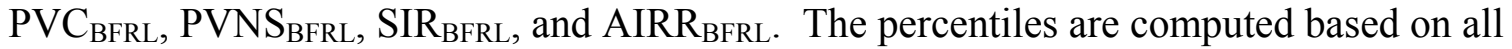
1,000 data points (i.e., observations) for each economic measure. The percentiles are estimated by first ordering each economic measure and then applying a statistical procedure. Readers interested in procedures for estimating percentiles are referred to the text by Ott. ${ }^{104}$

Figure 8-1 shows how present value cost savings nationwide, $\mathrm{PVS}_{\mathrm{ALL}}$, varies when all eleven input variables are varied in combination. In analyzing Figure 8-1, it is useful to keep in mind that the value of $\mathrm{PVS}_{\mathrm{ALL}}$ resulting from the baseline analysis was $\$ 1,377.9$ million. As was seen in Table 8-14, the median value of the 1,000 observations was $\$ 1,461.0$ million, more than $\$ 80$ million more than the value of $\mathrm{PVS}_{\mathrm{ALL}}$ calculated in the baseline analysis. What the figure shows clearly is the considerable degree to which $\mathrm{PVS}_{\mathrm{ALL}}$ varies - both above and below the median value.

To best understand the implications of these variations, it is useful to refer both to Figure 8-1 and the entries under the $\mathrm{PVS}_{\mathrm{ALL}}$ column heading of Table 8-15. First, the lower limit shown on Figure 8-1 is $-\$ 1,353.3$ million. However, the $1^{\text {st }}$ percentile for $\mathrm{PVS}_{\mathrm{ALL}}$ is $-\$ 225.7$ million. Thus, only 10 observations out of 1,000 are clustered between $-\$ 1,353.3$ and the $1^{\text {st }}$ percentile ( $\$ 225.7$ million). Second, the CDF increases at a steady, almost linear rate between the $9^{\text {th }}$ percentile ( $\$ 388.1$ million) and the $60^{\text {th }}$ percentile $(\$ 1,731.1$ million). Third, above the $60^{\text {th }}$ percentile, the CDF increases at a decreasing rate. This is shown by the way in which the CDF tails off as the calculated value of PVS $\mathrm{PLL}_{\mathrm{AL}}$ gets

\footnotetext{
${ }^{104}$ Ott, Lyman. 1984. An Introduction to Statistical Methods and Data Analysis. Boston, MA: Duxbury Press.
} 
large. Finally, the maximum value of $\mathrm{PVS}_{\mathrm{ALL}}$ is almost $\$ 8.0$ billion. However, the $99^{\text {th }}$ percentile is $\$ 5.6$ billion. Thus, only 10 observations out of 1,000 account for

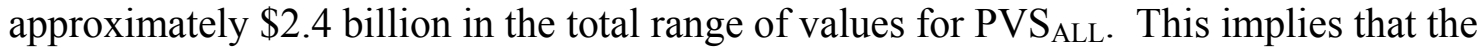
trace of the CDF for PVS $\mathrm{ALL}$ is positively skewed.

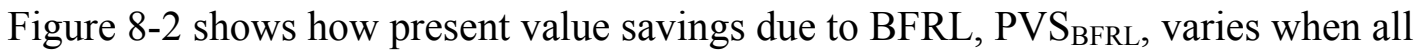
eleven input variables are varied in combination. In analyzing Figure 8-2, it is useful to

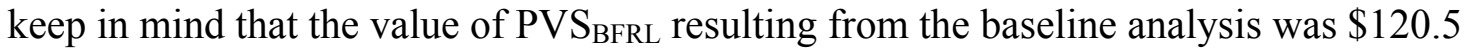
million. As was seen in Table 8-14, the median value of the 1,000 observations was more than $\$ 40$ million less than the value of PVS $\mathrm{BFRL}_{\mathrm{BF}}$ calculated in the baseline analysis. Figure 8-2 exhibits a pattern similar to the pattern seen in Figure 8-1. There is, however, one important difference between the traces of the CDFs in the two figures. Figure 8-2 is more positively skewed than Figure 8-1 (compare the upper tails of the two CDF traces).

To best understand the implications of these variations, it is useful to refer both to Figure

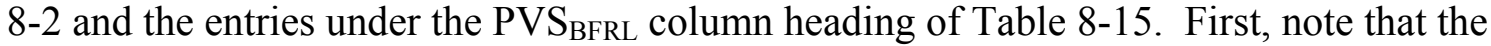
lower limit shown on Figure 8-2 extends to $-\$ 38.6$ million. Reference to Table 8-15 reveals that the $1^{\text {st }}$ percentile for $\mathrm{PVS}_{\mathrm{BFRL}}$ is still negative $(-\$ 0.006$ million) and that the $2^{\text {nd }}$ percentile becomes $\$ 0.0$. However, by the $3^{\text {rd }}$ percentile, the computed value of PVS $_{\text {BFRL }}$ becomes positive (\$3.4 million). Thus, less than 30 observations out of 1,000 result in no savings attributable to BFRL. Stated another way, there is at least a $97 \%$ probability that BFRL's CONSIAT-related efforts will produce positive and measurable cost savings to building owners, managers, and contractors. Second, the CDF increases at a steady, almost linear rate between the $3^{\text {rd }}$ percentile ( $\$ 3.4$ million) and the $50^{\text {th }}$ percentile ( $\$ 78.7$ million). Third, above the $50^{\text {th }}$ percentile, the CDF increases at a decreasing rate. This is shown by the way in which the CDF tails off as the calculated value of PVS $\mathrm{BFRL}_{\mathrm{BF}}$ gets large. Finally, the maximum value of PVS $\mathrm{S}_{\mathrm{BFRL}}$ is approximately $\$ 860$ million. However, the $99^{\text {th }}$ percentile is $\$ 564.6$ million. Thus, only 10 observations out of 1,000 account for almost $\$ 300$ million in the total range of values for PVS $\mathrm{S}_{\mathrm{BFRL}}$.

Figure 8-3 shows how the present value of BFRL's CONSIAT-related investment costs, $\mathrm{PVC}_{\mathrm{BFRL}}$, varies when all eleven input variables are varied in combination. Because the only variables that produce variations in $\mathrm{PVC}_{\mathrm{BFRL}}$ are the discount rate and the "targeted" time of first use, the shape of Figure 8-3 differs from the shapes of all of the other figures presented in this section.

Reference to the figure and to Tables 8-14 and 8-15 reveals that the CDF for $\mathrm{PVC}_{\mathrm{BFRL}}$ exhibits not only a long tail on the upper end but a significant lower tail as well. From Table 8-14 we see that the mean and median are relatively close in value, and are nearly equal to the baseline value. An examination of Figure 8-3 reveals that the trace of the $\mathrm{CDF}$ for $\mathrm{PVC}_{\mathrm{BFRL}}$ is nearly linear between the $15^{\text {th }}$ percentile ( $\$ 27.837$ million) and the $60^{\text {th }}$ percentile $\left(\$ 30.785\right.$ million). Below the $15^{\text {th }}$ percentile and above the $60^{\text {th }}$ percentile the traces exhibit similar patterns of non-linearity. 
Table 8-15. Percentiles for Statistical Measures Due to Changes in All of the Input Variables

\begin{tabular}{|c|c|c|c|c|c|c|}
\hline \multirow[b]{2}{*}{ Percentile } & \multicolumn{6}{|c|}{ Economic Measure } \\
\hline & $\mathrm{PVS}_{\mathrm{ALL}}$ & $\mathrm{PVS}_{\mathrm{BFRL}}$ & PVC $_{\text {BFRL }}$ & $\mathrm{PVNS}_{\mathrm{BFRL}}$ & $\mathrm{SIR}_{\mathrm{BFRL}}$ & $\mathrm{AIRR}_{\mathrm{BFRL}}$ \\
\hline $1^{\mathrm{ST}}$ & -225.729 & \begin{tabular}{c|c|}
-0.006 \\
\end{tabular} & 25.778 & -30.674 & 0.000 & n.a. \\
\hline $2^{\mathrm{ND}}$ & -41.299 & 0.000 & 26.177 & -28.284 & 0.000 & n.a. \\
\hline $3^{\mathrm{RD}}$ & 7.326 & 3.386 & 26.403 & -26.880 & 0.117 & n.a. \\
\hline $4^{\mathrm{TH}}$ & 60.528 & 4.453 & 26.726 & -23.490 & 0.161 & n.a. \\
\hline $5^{\mathrm{TH}}$ & 128.929 & 6.141 & 26.851 & -22.325 & 0.218 & $\overline{0.000}$ \\
\hline $6^{\mathrm{TH}}$ & 189.997 & 8.227 & 26.906 & -20.806 & 0.289 & 0.006 \\
\hline $7^{\mathrm{TH}}$ & 247.089 & 9.625 & 27.037 & -19.361 & 0.343 & 0.014 \\
\hline $8^{\mathrm{TH}}$ & 326.500 & 11.082 & 27.111 & -18.239 & 0.373 & 0.018 \\
\hline $9^{\mathrm{TH}}$ & 388.069 & 12.037 & 27.186 & -17.239 & 0.415 & 0.022 \\
\hline $10^{\mathrm{TH}}$ & 425.319 & 12.805 & 27.309 & -16.260 & 0.440 & 0.027 \\
\hline $11^{\mathrm{TH}}$ & 444.672 & 14.099 & 27.417 & -14.970 & 0.483 & 0.029 \\
\hline $12^{\mathrm{TH}}$ & 471.215 & 15.671 & 27.503 & -14.023 & 0.522 & 0.032 \\
\hline $13^{\mathrm{TH}}$ & 503.377 & 16.752 & 27.638 & -12.792 & 0.566 & 0.037 \\
\hline $14^{\mathrm{TH}}$ & 532.046 & 17.293 & 27.756 & -11.432 & 0.600 & 0.039 \\
\hline $15^{\mathrm{TH}}$ & 562.980 & 19.362 & 27.837 & -10.292 & 0.660 & 0.040 \\
\hline $16^{\mathrm{TH}}$ & 593.427 & 20.952 & 27.890 & \begin{tabular}{|c|}
-8.698 \\
\end{tabular} & 0.697 & 0.044 \\
\hline $17^{\mathrm{TH}}$ & 619.940 & 21.950 & 27.926 & \begin{tabular}{|c|}
-7.682 \\
\end{tabular} & 0.743 & 0.045 \\
\hline $18^{\mathrm{TH}}$ & 633.675 & 23.583 & 28.003 & -6.497 & 0.787 & 0.048 \\
\hline $19^{\mathrm{TH}}$ & 672.176 & 25.755 & 28.063 & -4.058 & 0.872 & 0.050 \\
\hline $20^{\mathrm{TH}}$ & 709.518 & 26.528 & 28.140 & -3.294 & 0.895 & 0.052 \\
\hline $21^{\mathrm{ST}}$ & 731.911 & 27.604 & 28.216 & -2.077 & 0.931 & 0.055 \\
\hline $22^{\mathrm{ND}}$ & 774.909 & 28.659 & 28.267 & -1.371 & 0.952 & 0.057 \\
\hline $23^{\mathrm{RD}}$ & 792.420 & 29.981 & 28.354 & \begin{tabular}{l|}
-0.039 \\
\end{tabular} & 0.999 & 0.058 \\
\hline $24^{\mathrm{TH}}$ & 814.590 & 31.189 & 28.425 & 1.246 & 1.044 & 0.061 \\
\hline $25^{\mathrm{TH}}$ & 833.362 & 32.322 & 28.503 & 2.530 & 1.076 & 0.063 \\
\hline $26^{\mathrm{TH}}$ & 859.438 & 33.460 & 28.582 & 3.650 & 1.128 & 0.065 \\
\hline $27^{\mathrm{TH}}$ & 872.718 & 34.848 & 28.659 & 6.078 & 1.194 & 0.067 \\
\hline $28^{\mathrm{TH}}$ & 887.213 & 36.567 & 28.714 & 7.581 & 1.257 & 0.068 \\
\hline $29^{\mathrm{TH}}$ & 923.801 & 38.756 & 28.785 & 8.589 & 1.287 & 0.070 \\
\hline $30^{\mathrm{TH}}$ & 952.205 & 40.061 & 28.843 & 9.357 & 1.318 & 0.072 \\
\hline $31^{\mathrm{ST}}$ & 986.646 & 42.133 & 28.893 & 11.883 & 1.388 & 0.074 \\
\hline $32^{\mathrm{ND}}$ & $1,010.696$ & 43.876 & 28.946 & 13.566 & 1.426 & 0.075 \\
\hline $33^{\mathrm{RD}}$ & $1,033.603$ & 45.176 & 28.975 & 15.100 & 1.486 & 0.076 \\
\hline
\end{tabular}


Table 8-15. Percentiles for Statistical Measures Due to Changes in All of the Input Variables (continued)

\begin{tabular}{|c|c|c|c|c|c|c|}
\hline \multirow{2}{*}{ Percentile } & \multicolumn{6}{|c|}{ Economic Measure } \\
\hline & $\mathrm{PVS}_{\mathrm{ALL}}$ & $\mathrm{PVS}_{\mathrm{BFRL}}$ & $\mathrm{PVC}_{\mathrm{BFRL}}$ & $\mathrm{PVNS}_{\mathrm{BFRL}}$ & $\mathrm{SIR}_{\mathrm{BFRL}}$ & $\mathrm{AIRR}_{\mathrm{BFRL}}$ \\
\hline $34^{\mathrm{TH}}$ & $1,046.883$ & 46.449 & 29.029 & 16.249 & 1.545 & 0.079 \\
\hline $35^{\mathrm{TH}}$ & $1,070.716$ & 47.684 & 29.063 & 17.035 & 1.585 & 0.081 \\
\hline $36^{\mathrm{TH}}$ & $1,110.502$ & 48.877 & 29.095 & 18.974 & 1.625 & 0.083 \\
\hline $37^{\mathrm{TH}}$ & $1,130.370$ & 50.126 & 29.187 & 20.422 & 1.685 & 0.084 \\
\hline $38^{\mathrm{TH}}$ & $1,164.760$ & 51.413 & 29.256 & 21.354 & 1.741 & 0.086 \\
\hline $39^{\mathrm{TH}}$ & $1,190.948$ & 54.965 & 29.312 & 23.974 & 1.806 & 0.088 \\
\hline $40^{\mathrm{TH}}$ & $1,211.380$ & 55.724 & 29.412 & 26.639 & 1.867 & 0.090 \\
\hline $41^{\mathrm{ST}}$ & $1,240.338$ & 58.498 & 29.500 & 28.712 & 1.926 & 0.091 \\
\hline $42^{\mathrm{ND}}$ & $1,249.820$ & 60.979 & 29.579 & 30.615 & 2.023 & 0.093 \\
\hline $43^{\mathrm{RD}}$ & $1,269.751$ & 62.406 & 29.659 & 32.459 & 2.081 & 0.094 \\
\hline $44^{\mathrm{TH}}$ & $1,292.194$ & 63.796 & 29.718 & 34.279 & 2.152 & 0.096 \\
\hline $45^{\mathrm{TH}}$ & $1,316.128$ & 66.401 & 29.776 & 36.296 & 2.201 & 0.097 \\
\hline $46^{\mathrm{TH}}$ & $1,354.130$ & 67.980 & 29.882 & 38.302 & 2.309 & 0.099 \\
\hline $47^{\mathrm{TH}}$ & $1,381.995$ & 70.572 & 29.964 & 40.252 & 2.350 & 0.101 \\
\hline $48^{\mathrm{TH}}$ & $1,401.785$ & 72.098 & 30.018 & 41.822 & 2.452 & 0.102 \\
\hline $49^{\mathrm{TH}}$ & $1,438.790$ & 75.518 & 30.066 & 45.152 & 2.520 & 0.103 \\
\hline $50^{\mathrm{TH}}$ & $1,461.006$ & 78.666 & 30.125 & 48.726 & 2.611 & 0.105 \\
\hline $51^{\mathrm{ST}}$ & $1,496.820$ & 82.533 & 30.179 & 52.217 & 2.702 & 0.106 \\
\hline $52^{\mathrm{ND}}$ & $1,516.942$ & 84.214 & 30.251 & 54.835 & 2.753 & 0.107 \\
\hline $53^{\mathrm{RD}}$ & $1,536.935$ & 85.979 & 30.322 & 56.218 & 2.830 & 0.109 \\
\hline $54^{\mathrm{TH}}$ & $1,563.003$ & 88.821 & 30.388 & 57.352 & 2.912 & 0.110 \\
\hline $55^{\mathrm{TH}}$ & $1,587.752$ & 91.915 & 30.442 & 60.810 & 2.999 & 0.111 \\
\hline $56^{\mathrm{TH}}$ & $1,617.477$ & 93.547 & 30.522 & 62.599 & 3.109 & 0.112 \\
\hline $57^{\mathrm{TH}}$ & $1,646.228$ & 95.526 & 30.586 & 64.991 & 3.192 & 0.113 \\
\hline $58^{\mathrm{TH}}$ & $1,674.037$ & 98.315 & 30.652 & 67.234 & 3.237 & 0.114 \\
\hline $59^{\mathrm{TH}}$ & $1,701.748$ & 101.084 & 30.707 & 71.079 & 3.299 & 0.115 \\
\hline $60^{\mathrm{TH}}$ & $1,731.099$ & 104.975 & 30.785 & 73.647 & 3.366 & 0.117 \\
\hline $61^{\mathrm{ST}}$ & $1,753.054$ & 109.272 & 30.866 & 78.204 & 3.444 & 0.117 \\
\hline $62^{\mathrm{ND}}$ & $1,801.729$ & 112.352 & 30.967 & 81.261 & 3.543 & 0.119 \\
\hline $63^{\mathrm{RD}}$ & $1,839.372$ & 114.522 & 31.052 & 84.390 & 3.760 & 0.121 \\
\hline $64^{\mathrm{TH}}$ & $1,880.123$ & 118.033 & 31.149 & 87.588 & 3.866 & 0.121 \\
\hline $65^{\mathrm{TH}}$ & $1,904.534$ & 121.706 & 31.232 & 90.902 & 3.922 & 0.123 \\
\hline $66^{\mathrm{TH}}$ & $1,939.521$ & 124.543 & 31.342 & 93.475 & 4.019 & 0.124 \\
\hline
\end{tabular}


Table 8-15. Percentiles for Statistical Measures Due to Changes in All of the Input Variables (continued)

\begin{tabular}{|c|c|c|c|c|c|c|}
\hline \multirow{2}{*}{ Percentile } & \multicolumn{6}{|c|}{ Economic Measure } \\
\hline & $\mathrm{PVS}_{\mathrm{ALL}}$ & $\mathrm{PVS}_{\mathrm{BFRL}}$ & $\mathrm{PVC}_{\mathrm{BFRL}}$ & PVNS $_{\text {BFRL }}$ & $\mathrm{SIR}_{\mathrm{BFRL}}$ & $\mathrm{AIRR}_{\text {BFRL }}$ \\
\hline $67^{\mathrm{TH}}$ & $1,985.279$ & 127.782 & 31.427 & 97.138 & 4.122 & 0.125 \\
\hline $68^{\mathrm{TH}}$ & $2,031.487$ & 132.953 & 31.544 & 102.062 & 4.238 & 0.126 \\
\hline $69^{\mathrm{TH}}$ & $2,076.201$ & 138.767 & 31.639 & 107.066 & 4.343 & 0.128 \\
\hline $70^{\mathrm{TH}}$ & $2,121.199$ & 143.661 & 31.776 & 112.370 & 4.482 & 0.129 \\
\hline $71^{\mathrm{ST}}$ & $2,159.779$ & 148.656 & 31.877 & 115.407 & 4.700 & 0.130 \\
\hline $72^{\mathrm{ND}}$ & $2,189.824$ & 151.448 & 31.962 & 121.007 & 4.858 & 0.132 \\
\hline $73^{\mathrm{RD}}$ & $2,215.715$ & 154.286 & 32.113 & 124.117 & 4.962 & 0.132 \\
\hline $74^{\mathrm{TH}}$ & $2,254.461$ & 159.857 & 32.199 & 128.528 & 5.128 & 0.134 \\
\hline $75^{\mathrm{TH}}$ & $2,274.788$ & 164.442 & 32.289 & 132.643 & 5.258 & 0.135 \\
\hline $76^{\mathrm{TH}}$ & $2,333.132$ & 170.876 & 32.352 & 140.356 & 5.449 & 0.136 \\
\hline $77^{\mathrm{TH}}$ & $2,375.492$ & 177.504 & 32.493 & 146.334 & 5.652 & 0.138 \\
\hline $78^{\mathrm{TH}}$ & $2,396.502$ & 184.394 & 32.654 & 150.944 & 5.872 & 0.140 \\
\hline $79^{\mathrm{TH}}$ & $2,455.405$ & 191.449 & 32.808 & 156.944 & 6.059 & 0.142 \\
\hline $80^{\mathrm{TH}}$ & $2,491.533$ & 196.332 & 33.029 & 166.205 & 6.258 & 0.143 \\
\hline $81^{I^{\mathrm{T}}}$ & $2,592.521$ & 202.451 & 33.193 & 171.075 & 6.477 & 0.145 \\
\hline $82^{\mathrm{ND}}$ & $2,629.810$ & 207.046 & 33.407 & 176.372 & 6.689 & 0.146 \\
\hline $83^{\mathrm{RD}}$ & $2,695.161$ & 220.082 & 33.514 & 187.193 & 6.964 & 0.148 \\
\hline $84^{\mathrm{TH}}$ & $2,752.600$ & 230.660 & 33.651 & 198.535 & 7.238 & 0.149 \\
\hline $85^{\mathrm{TH}}$ & $2,814.330$ & 239.170 & 33.958 & 206.527 & 7.427 & 0.150 \\
\hline $86^{\mathrm{TH}}$ & $2,914.070$ & 246.576 & 34.106 & 216.067 & 7.799 & 0.152 \\
\hline $87^{\mathrm{TH}}$ & $2,979.936$ & 256.283 & 34.288 & 223.212 & 8.031 & 0.153 \\
\hline $88^{\mathrm{TH}}$ & $3,055.092$ & 264.734 & 34.497 & 231.137 & 8.452 & 0.155 \\
\hline $89^{\mathrm{TH}}$ & $3,163.703$ & 270.142 & 34.838 & 237.038 & 8.702 & 0.158 \\
\hline $90^{\mathrm{TH}}$ & $3,261.409$ & 282.190 & 35.125 & 250.085 & 8.921 & 0.160 \\
\hline $91^{\mathrm{ST}}$ & $3,371.450$ & 293.051 & 35.411 & 263.269 & 9.207 & 0.163 \\
\hline $92^{\mathrm{ND}}$ & $3,493.785$ & 311.375 & 35.691 & 278.865 & 9.805 & 0.164 \\
\hline $93^{\mathrm{RD}}$ & $3,614.232$ & 328.511 & 35.950 & 295.711 & 10.474 & 0.167 \\
\hline $94^{\mathrm{TH}}$ & $3,797.795$ & 347.591 & 36.382 & 316.748 & 10.871 & 0.169 \\
\hline $95^{\mathrm{TH}}$ & $4,063.257$ & 387.208 & 36.769 & 353.696 & 11.962 & 0.173 \\
\hline $96^{\mathrm{TH}}$ & $4,298.030$ & 416.571 & 37.371 & 381.411 & 12.468 & 0.180 \\
\hline $97^{\mathrm{TH}}$ & $4,514.824$ & 451.341 & 38.179 & 420.650 & 13.230 & 0.184 \\
\hline $98^{\mathrm{TH}}$ & $5,022.385$ & 508.469 & 39.030 & 476.173 & 14.922 & 0.189 \\
\hline $99^{\mathrm{TH}}$ & $5,608.432$ & 564.584 & 40.677 & 534.159 & 16.380 & 0.197 \\
\hline
\end{tabular}


Figure 8-1. Present Value of Cost Savings Nationwide in Millions of 1997 Dollars

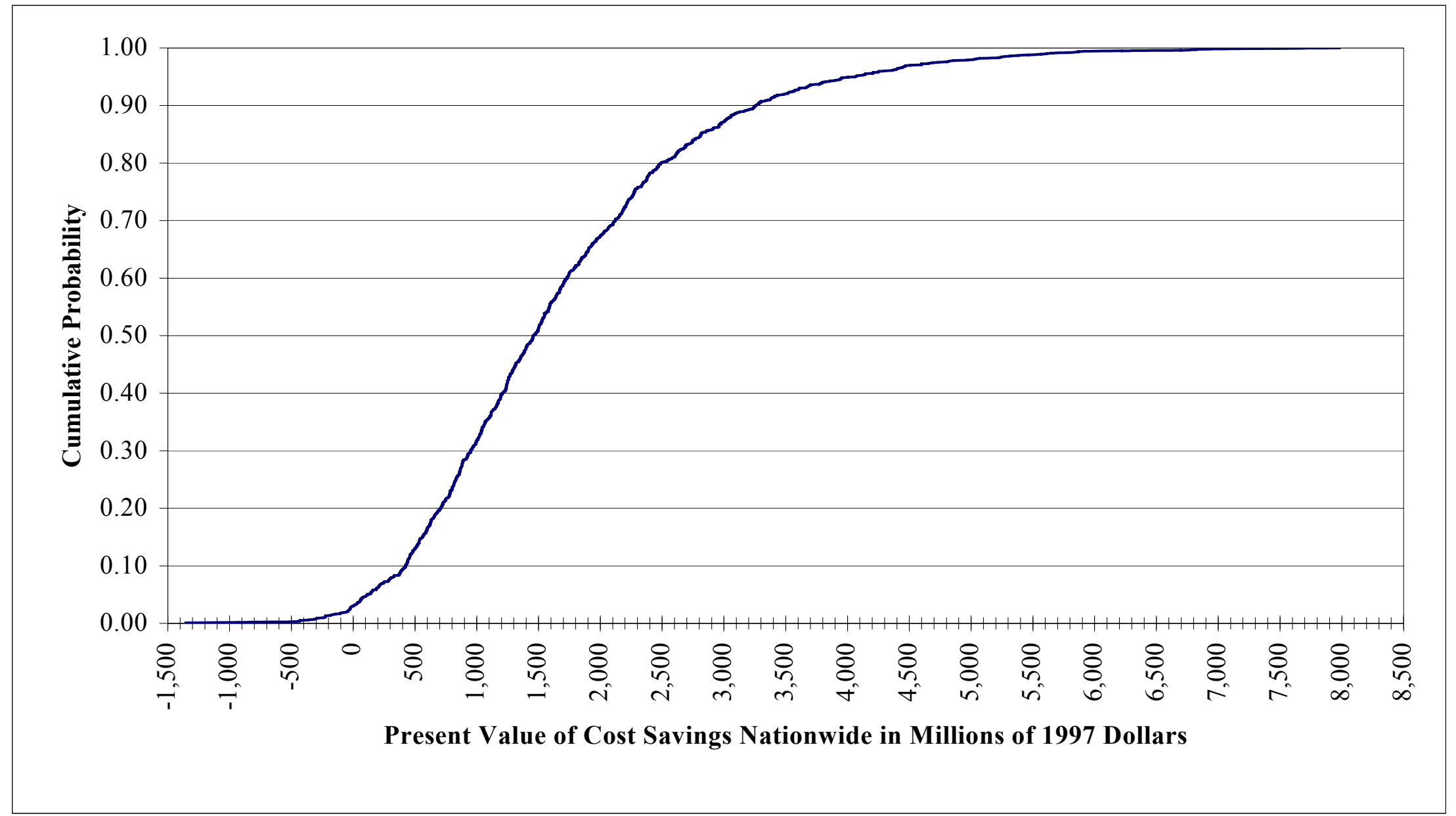


Figure 8-2. Present Value of Cost Savings Attributable to BFRL in Millions of 1997 Dollars

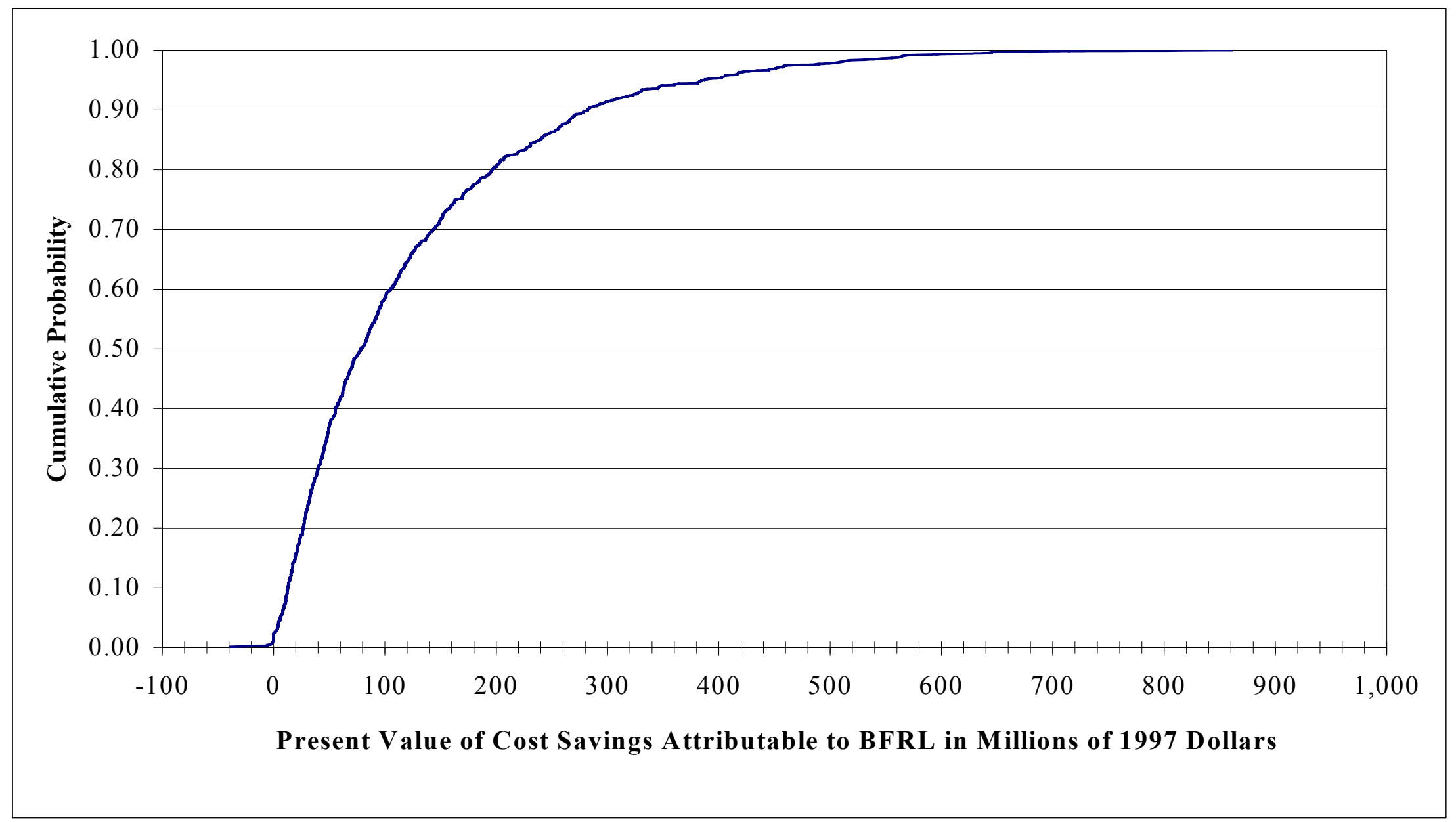


Figure 8-3. Present Value of BFRL's Investment Costs in Millions of 1997 Dollars

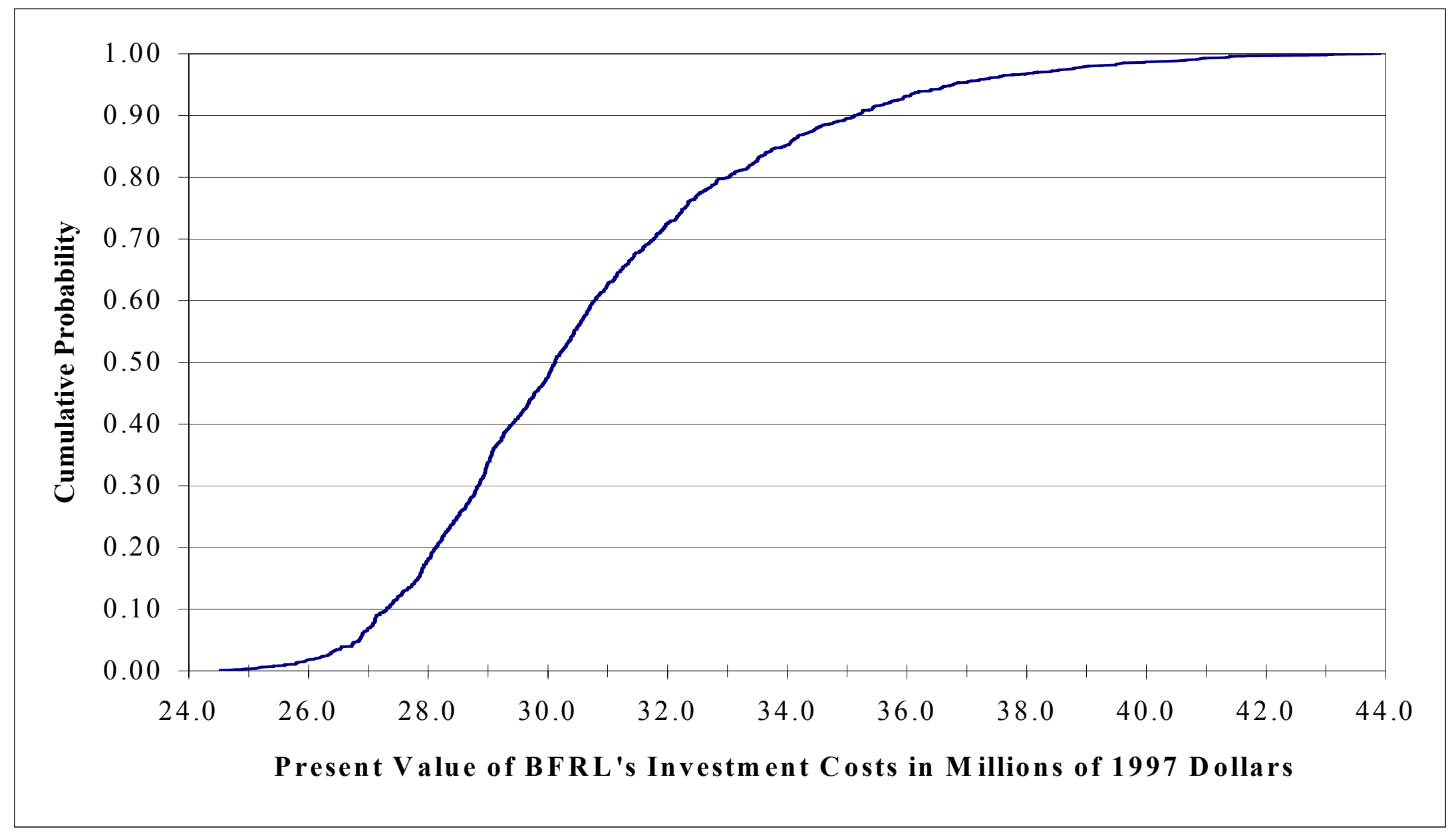




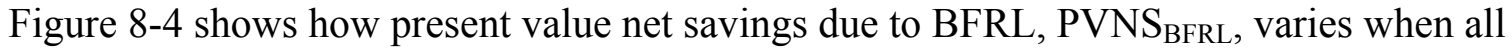
eleven input variables are varied in combination. In analyzing Figure 8-4, it is useful to

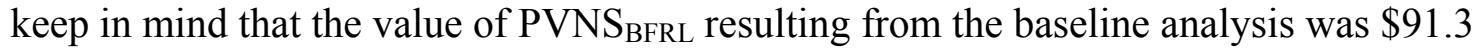
million. As was seen in Table 8-14, the median value of the 1,000 observations was

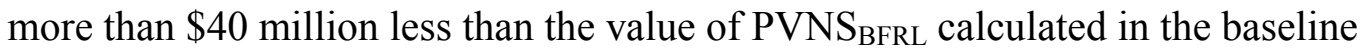
analysis. Also, Figure 8-4 exhibits a pattern similar to the pattern seen in Figure 8-2. Note that both Figure 8-2 and Figure 8-4 are highly, positively skewed (compare the upper tails of the two CDF traces). In addition, both figures are defined over nearly identical ranges of values. This similarity is to be expected since the only difference between PVS $\mathrm{B}_{\mathrm{BFRL}}$ (see Figure 8-2) and PVNS $\mathrm{BFRL}_{\text {is }}$ PVC $\mathrm{BFRL}_{\mathrm{BFR}}$ (see Figure 8-3). Recall that $\mathrm{PVC}_{\mathrm{BFRL}}$ was defined over a relatively narrow range of values. Thus, throughout the range of values over which $\mathrm{PVS}_{\mathrm{BFRL}}$ and $\mathrm{PVNS} \mathrm{BFRL}_{\mathrm{B} L}$ are defined, the value of $\mathrm{PVC}_{\mathrm{BFRL}}$ acts much like a constant term.

As was the case for the previous figures, it is useful to refer both to Figure 8-4 and the entries under the PVNS $\mathrm{BFRL}_{\mathrm{BF}}$ column heading of Table 8-15. First, note that the lower limit shown on Figure 8-4 extends below \$0.0. Reference to Table 8-15 reveals that the

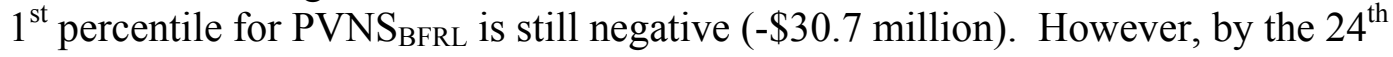
percentile, the computed value of PVNS $\mathrm{BFRL}_{\mathrm{BF}}$ becomes positive ( $\$ 1.2$ million). Thus, less than 240 observations out of 1,000 are negative. Stated another way, there is at least a 76 $\%$ probability that BFRL's CONSIAT-related investments are cost effective. Second, the CDF increases at a steady, almost linear rate between the $5^{\text {th }}$ percentile (\$-22.3 million) and the $50^{\text {th }}$ percentile ( $\$ 48.7$ million). Third, above the $50^{\text {th }}$ percentile, the CDF increases at a decreasing rate. This is shown by the way in which the CDF tails off as the calculated value of PVNS $\mathrm{BFRL}_{\text {gets large. Finally, the maximum value of PVNS }}$ BFRL is nearly $\$ 830$ million. However, the $99^{\text {th }}$ percentile is $\$ 534.2$ million. Thus, only 10 observations out of 1,000 account for approximately $\$ 300$ million in the total range of values for PVNS $\mathrm{BFRL}_{\text {. }}$

Because there are so many similarities - very low values, very high values, and the CDF traces - between the results of the sensitivity analysis for PVS $\mathrm{SFRL}_{\mathrm{BF}}$ and PVNS $\mathrm{BFRL}_{\mathrm{BF}}$, it is useful to analyze the underlying characteristics of both the upper and lower tails of the two CDF traces. This analysis was facilitated through the use of the @RISK software product. Specifically, the @RISK software product enables the random draw for each input variable for each of the 1,000 simulations to be stored in a spreadsheet. This produces a one-to-one correspondence between each simulation's input set and the resultant values of the economic measures.

As might be expected, the factors that contribute to very low values of PVS $\mathrm{S}_{\mathrm{BFRL}}$ and PVNS $_{\mathrm{BFRL}}$ differ from those that contribute to very high values of $\mathrm{PVS}_{\mathrm{BFRL}}$ and PVNS $_{\text {BFRL }}$. Consider first the very low values of PVS $\mathrm{S}_{\mathrm{BFRL}}$ and PVNS $\mathrm{P}_{\mathrm{BFRL}}$ (i.e., the 50 lowest values). Two factors, operating in combination, contribute to very low values of PVS $_{\mathrm{BFRL}}$ and PVNS $\mathrm{BFRL}$. These factors are "later" values for the "targeted" time of first use and the length of the delay. For example, of the 50 lowest values, 13 had no delay, all but four of which had a "targeted" time of first use in either 2006 or 2007, whereas 26 had a two-year delay. Five other factors had a strong influence: (1) reductions in first 
cost, if its value is less than the $10^{\text {th }}$ percentile of its parent CDF; (2) reductions in delivery time, if its value is less than the $10^{\text {th }}$ percentile of its parent CDF; (3) maintenance and repair cost savings, if its value is less than the $10^{\text {th }}$ percentile of its parent CDF; (4) higher contractor net income, if its value is less than the $10^{\text {th }}$ percentile of its parent CDF; and (5) new-technology introduction costs, if its value is greater than the $90^{\text {th }}$ percentile of its parent CDF. Very high values (i.e., the 50 highest values) were associated with two factors operating in combination- "earlier" values for the "targeted" time of first use and the length of the delay. For example, 44 of the 50 highest values had no delay and a "targeted" time of first use of 2004 or 2005 . Four other factors had a strong influence: (1) reductions in first cost, if its value is greater than the $90^{\text {th }}$ percentile of its parent CDF; (2) higher contractor net income, if its value is greater than the $90^{\text {th }}$ percentile of its parent CDF; (3); reductions in delivery time, if its value is greater than the $90^{\text {th }}$ percentile of its parent CDF; and (4) $\alpha$, if its value is less than the $10^{\text {th }}$ percentile of its parent CDF.

Figure 8-5 shows how the savings-to-investment ratio on BFRL's CONSIAT-related investments, $\mathrm{SIR}_{\mathrm{BFRL}}$, varies when all eleven input variables are varied in combination. In analyzing Figure 8-5, it is useful to keep in mind that the value of SIR $_{B F R L}$ resulting from the baseline analysis was 4.134. As was seen in Table 8-14, the median value of the 1,000 observations was 2.611. Also, Figure 8-5 exhibits a pattern similar to the pattern seen in Figure 8-2. Note that both Figure 8-5 and Figure 8-2 are highly, positively skewed (compare the upper tails of the two CDF traces). This similarity in shapes is to be expected since $\mathrm{SIR}_{\mathrm{BFRL}}$ is the ratio of PVS $\mathrm{B}_{\mathrm{BFRL}}$ to $\mathrm{PVC}_{\mathrm{BFRL}}$. Recall that PVC $\mathrm{C}_{\mathrm{BFRL}}$ was defined over a relatively narrow range of values. Thus, the value of $\mathrm{PVC}_{\mathrm{BFRL}}$ acts very much like a constant term. Although the shapes of the two distributions are similar, the ranges of values are specified in different units.

As was the case for the previous figures, it is useful to refer both to Figure 8-5 and the entries under the $\mathrm{SIR}_{\mathrm{BFRL}}$ column heading of Table 8-15. First, note that the lower limit shown on Figure 8-5 extends to -1.183 . Reference to Table $8-15$ reveals that the $1^{\text {st }}$ percentile for $\mathrm{SIR}_{\mathrm{BFRL}}$ is 0.0 . However, by the $24^{\text {th }}$ percentile, the computed value of

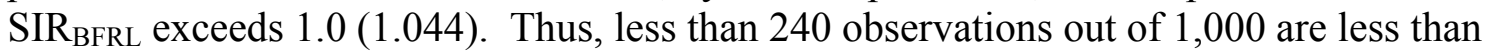
1.0. Stated another way, based on the calculated value of SIR $_{B F R L}$, there is at least a $76 \%$ probability that BFRL's CONSIAT-related investments are cost effective. Second, the CDF increases at a steady, almost linear rate between the $5^{\text {th }}$ percentile $(0.218)$ and the $40^{\text {th }}$ percentile (1.867). Third, above the $40^{\text {th }}$ percentile, the CDF increases at a decreasing rate. This is shown by the way in which the CDF tails off as the calculated value of SIR $_{\mathrm{BFRL}}$ gets large. Finally, the maximum value of $\operatorname{SIR}_{\mathrm{BFRL}}$ is 26.617 . However, the $99^{\text {th }}$ percentile is 16.380 . Thus, only 10 observations out of 1,000 account for approximately 10 units in the total range of values for SIR $_{B F R L}$.

Figure 8-6 shows how the adjusted internal rate of return on BFRL's CONSIAT-related investments, $A I R R_{B F R L}$, varies when all eleven input variables are varied in combination. In analyzing Figure 8-6, it is useful to keep in mind that the value of AIRR BFRL $_{\text {resulting }}$ from the baseline analysis was 0.133 . As was seen in Table $8-14$, both the mean $(0.104)$ and median (0.105) values of the 1,000 observations were nearly equal. Figure 8-6 
exhibits a pattern different from those seen in the other figures. Note that Figure 8-6 is negatively skewed (compare the lower and upper tails of the CDF trace). Although the values for $A_{I R R} R_{B F R}$ are a monotonic transformation of the values for SIR $_{B F R L}$, the shapes of the two CDFs are quite dissimilar. This is because the AIRR $R_{B F R L}$ is functionally related to $\left(\mathrm{SIR}_{\mathrm{BFRL}}\right)^{1 / 25}$. This relationship is highly non-linear, explaining why the two $\mathrm{CDF}$ traces are so dissimilar.

As was the case for the previous figures, it is useful to refer both to Figure 8-6 and the

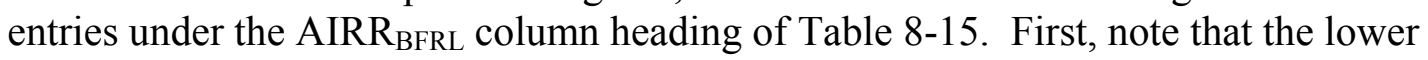
limit shown on Figure 8-6 is 0.0 . This is because a value of AIRR BFRL $_{\text {less }}$ than 0.0 has no economic meaning. Such cases are designated by the term n.a. in Tables 8-14 and 815. Reference to Table $8-15$ reveals that the $1^{\text {st }}$ percentile through the $4^{\text {th }}$ percentile for

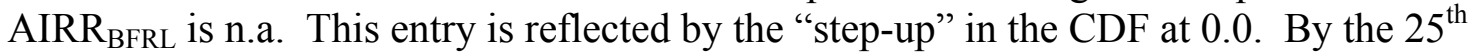
percentile, the computed value of $A$ IRR $_{B F R L}$ exceeds the average value for the 1,000 "draws" from the parent CDF for the real discount rate of 0.0619 . Thus, less than 250

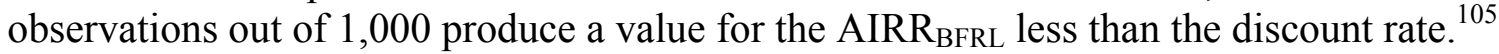

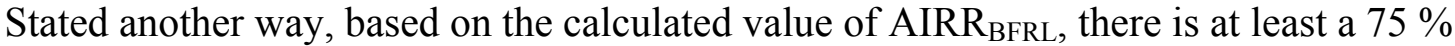
probability that BFRL's CONSIAT-related investments are cost effective. Second, the CDF increases at a steady, almost linear rate between the $15^{\text {th }}$ percentile $(0.040)$ and the $85^{\text {th }}$ percentile $(0.150)$. Third, below the $15^{\text {th }}$ percentile, the CDF increases at an increasing rate. Finally, above the $85^{\text {th }}$ percentile, the CDF increases at a decreasing rate.

Note that the values of PVNS $\mathrm{BFRL}_{\mathrm{B}}, \mathrm{SIR}_{\mathrm{BFRL}}$, and AIRR $\mathrm{BFRL}_{\mathrm{B}}$ all indicated the regions of the appropriate CDF trace where BFRL's CONSIAT-related investments were cost effective. In each case these economic measures defined very nearly the same break-even point in each of the CDF traces. The break-even point corresponds to a value of each economic measure just below the $24^{\text {th }}$ or $25^{\text {th }}$ percentile of its CDF. This point is noteworthy, since each measure provides a different perspective, but produces essentially the same end result in terms of identifying the break-even point.

\footnotetext{
${ }^{105}$ Note that the $29^{\text {th }}$ percentile had a value of 0.07 (i.e., a value that equals the baseline value for the discount rate).
} 
Figure 8-4. Present Value of Net Savings Attributable to BFRL in Millions of 1997 Dollars

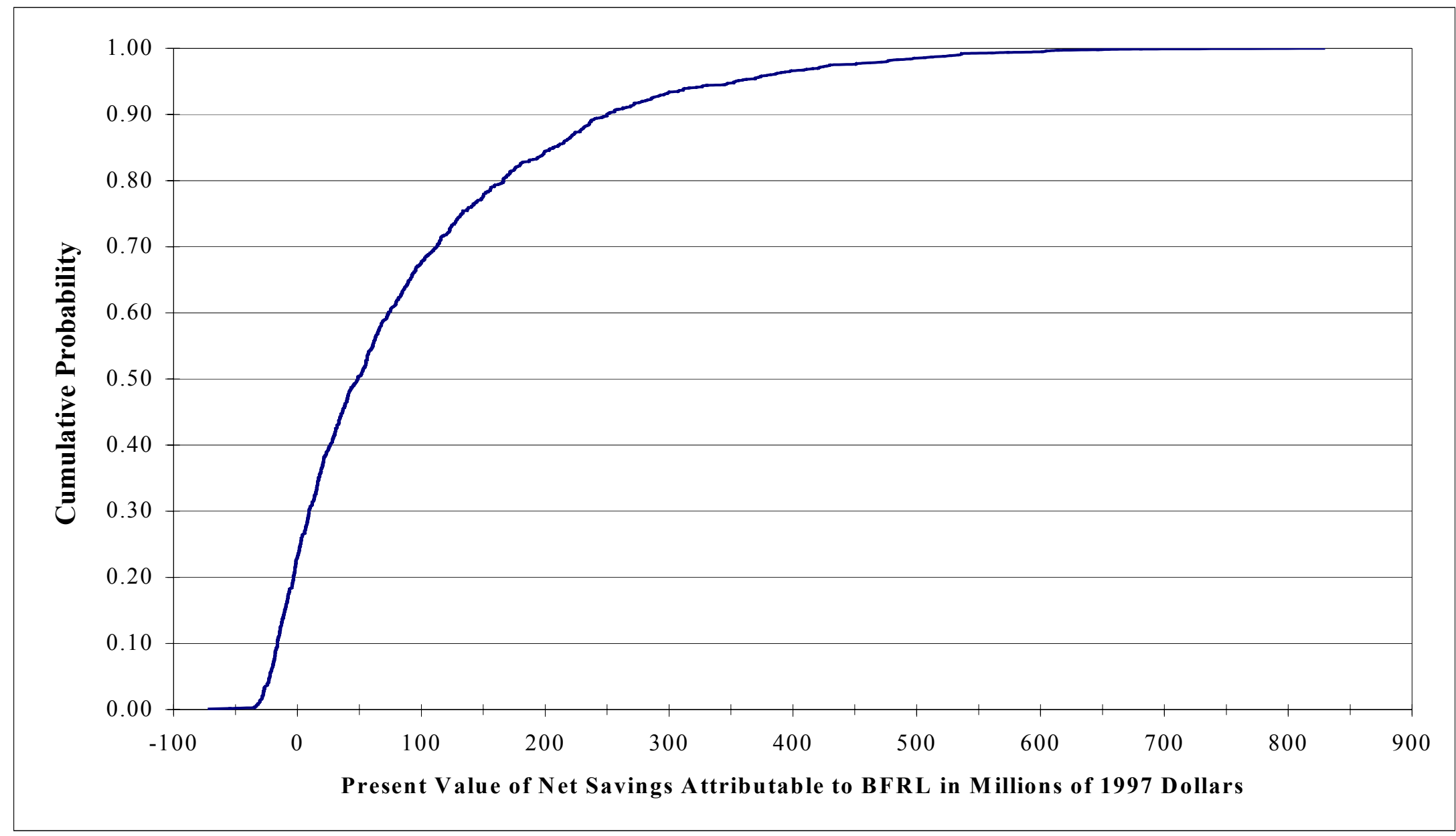


Figure 8-5. Savings to Investment Ratio on BFRL's Research and Development Investment

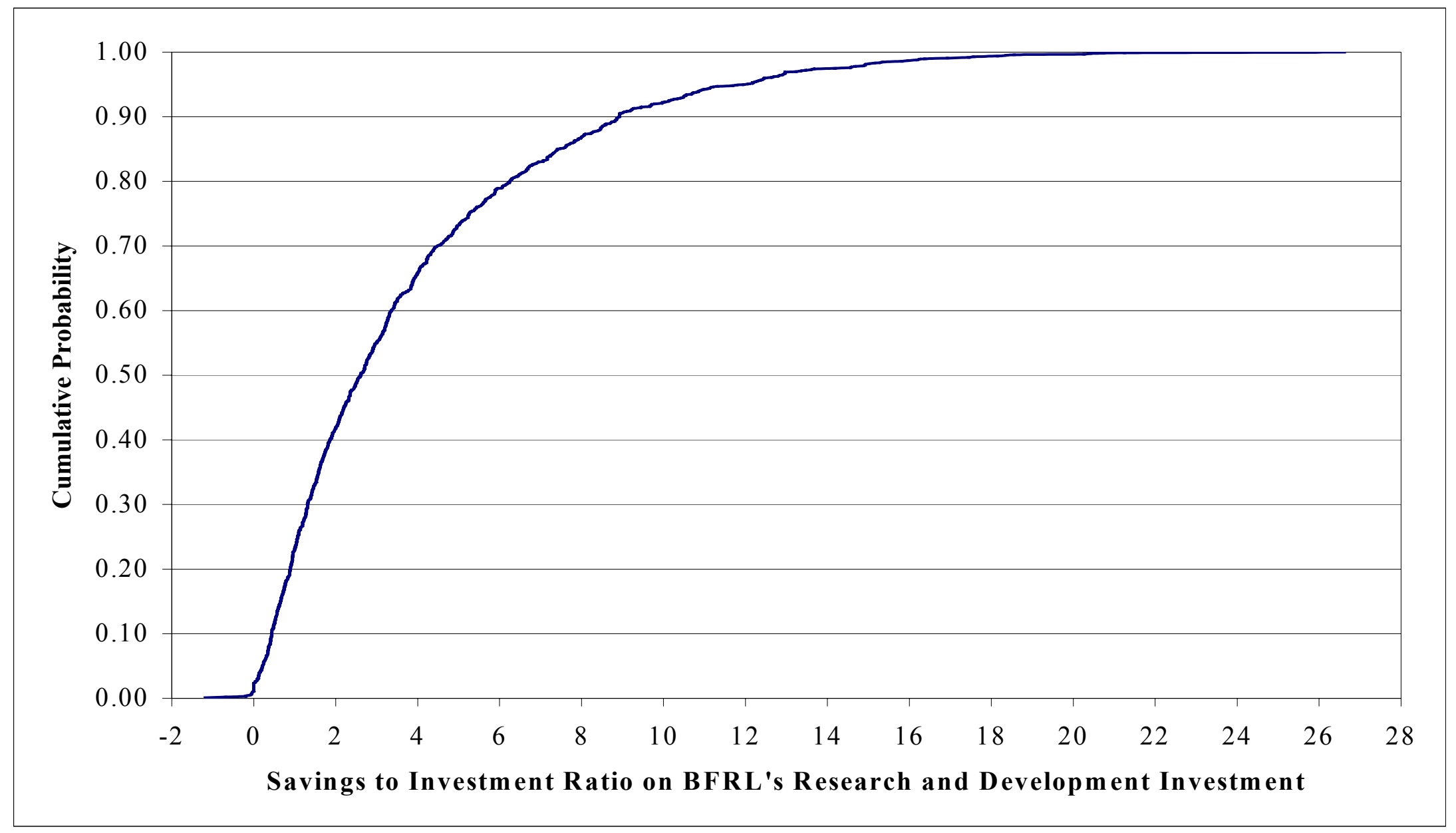


Figure 8-6. Adjusted Internal Rate of Return on BFRL's Research and Development Investment

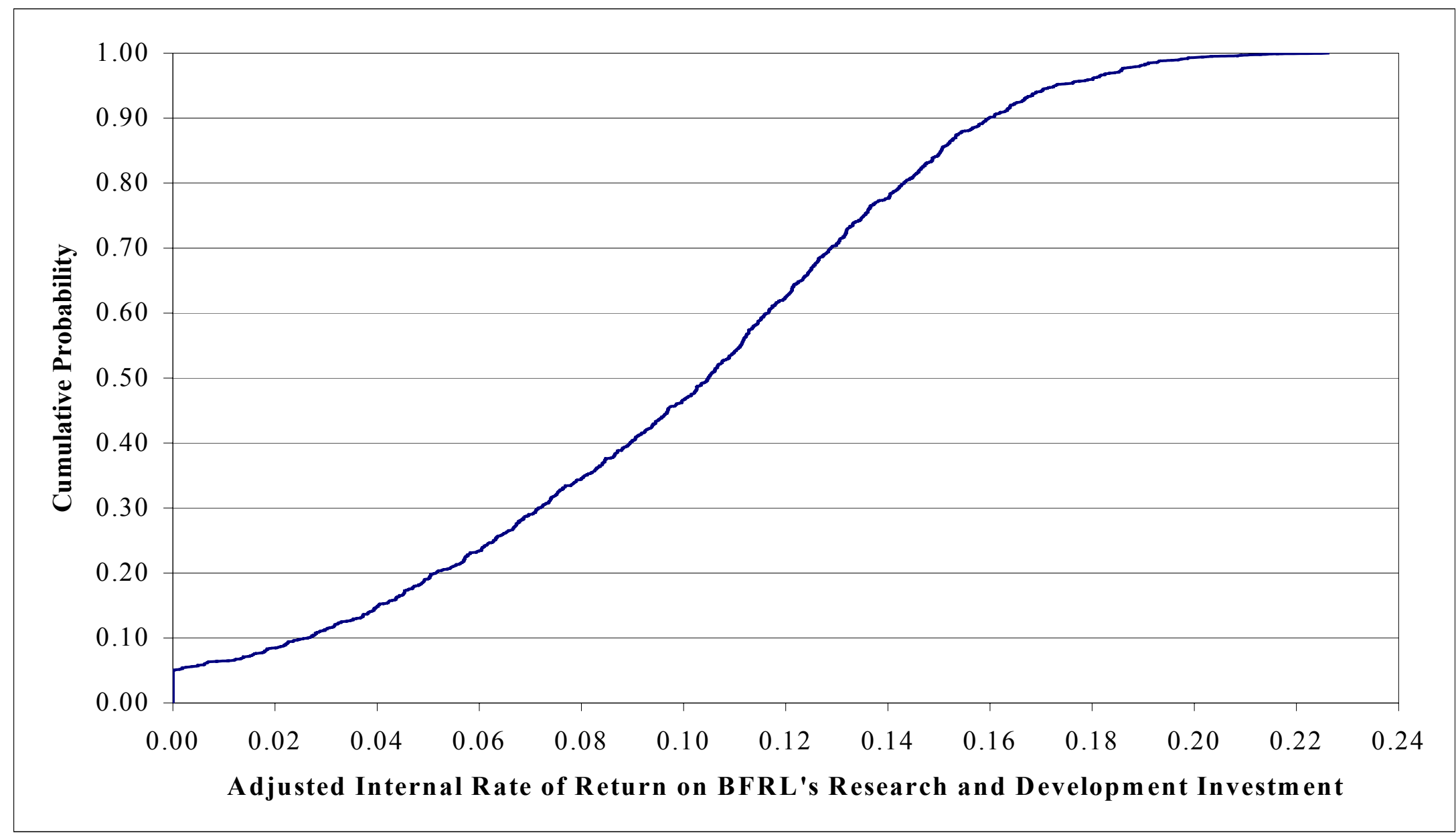




\section{Summary and Suggestions for Further Research}

\subsection{Summary}

A formal resource allocation process for funding research is needed in both the public and private sectors. Research managers need guidelines for research planning so that they can maximize the payoffs from their limited resources. Furthermore, quantitative descriptions of research impacts have become a basic requirement in many organizations for evaluating budget requests.

There are several reasons for measuring the economic impacts of a federal laboratory's research program. First, economic impact studies are a management tool; they help set priorities and point to new research opportunities. Second, as federal laboratories become more customer oriented, by revealing the "voice of the customer," such studies will strengthen the ties to industry and identify opportunities for leveraging federal research investments. Finally, changing requirements, such as the Government Performance and Results Act, will affect how federal research funds are allocated. Increasingly, federal agencies and laboratories that fail to demonstrate that their research efforts complement those of industry and that they are having a positive impact on society will be at a disadvantage when competing for federal research funds.

The National Institute of Standards and Technology (NIST), a scientific research agency of the U.S. Department of Commerce's Technology Administration, is improving its resource allocation process by doing "microstudies" of its research impacts on society. This report is the fifth in a series of impact studies prepared by BFRL. ${ }^{106}$ It focuses on BFRL's construction systems integration and automation technologies (CONSIAT) program. The CONSIAT program is an interdisciplinary research effort within BFRLin collaboration with the Construction Industry Institute, the private sector, other federal agencies, and other laboratories within NIST - to develop key enabling technologies, standard communication protocols, and advanced measurement technologies needed to

\footnotetext{
${ }^{106}$ The first report in the series focuses on two building technology applications: (1) ASHRAE Standard 9075 for residential energy conservation; and (2) 235 shingles, an improved asphalt shingle for sloped roofing (see Chapman, Robert E., and Sieglinde K. Fuller. 1996. Benefits and Costs of Research: Two Case Studies in Building Technology. NISTIR 5840. Gaithersburg, MD: National Institute of Standards and Technology). The second report focuses on a fire technology application: the Fire Safety Evaluation System for health care facilities (see Chapman, Robert E., and Stephen F. Weber. 1996. Benefits and Costs of Research: A Case Study of the Fire Safety Evaluation System. NISTIR 5863. Gaithersburg, MD: National Institute of Standards and Technology). The third report focuses on the research, development, deployment, and adoption and use of cybernetic building systems in office buildings (see Chapman, Robert E. 1999. Benefits and Costs of Research: A Case Study of Cybernetic Building Systems. NISTIR 6303. Gaithersburg, MD: National Institute of Standards and Technology). The fourth report focuses on the research, development, and deployment, and adoption and use of construction systems integration and automation technologies in industrial facilities (see Chapman, Robert E. 2000. Benefits and Costs of Research: A Case Study of Construction Systems Integration and Automation Technologies in Industrial Facilities. NISTIR 6501. Gaithersburg, MD: National Institute of Standards and Technology).
} 
deliver fully-integrated and automated project process (FIAPP) products and services to the construction industry.

BFRL's CONSIAT program is aimed at producing a suite of products and services that integrate a wide variety of planning, design, and construction activities. The goal of BFRL's CONSIAT program is to produce FIAPP products and services that will result in significant reductions in both the delivery time of constructed facilities and the life-cycle costs of those facilities. These products and services are being developed for use by building owners and operators, construction contractors, architects, engineers, and other providers of professional services.

This case study of BFRL's CONSIAT-related research, development, and deployment effort illustrates how to apply in practice a series of standardized methods, referred to as economic measures, to evaluate and compare the economic impacts of alternative research investments. It is presented in sufficient detail to understand the basis for the economic impact assessment and to reproduce the results. It is based on past, ongoing, and planned research efforts. Thus, it includes CONSIAT-related investment costs that have already occurred along with estimates of future investment costs and cost savings due to the use of FIAPP products and services.

The CONSIAT economic impact assessment was carried out in two stages. In the first stage, a baseline analysis was performed. In the baseline analysis, all input variables used to calculate the economic measures are set at their likely values. It is important to recognize that the term baseline analysis is used to denote a complete analysis in all respects but one; it does not address the effects of uncertainty. In the second stage, eleven input variables were varied both singly and in combination according to an experimental design. Monte Carlo simulations are employed to evaluate how changing the value of these variables affects the calculated values of the economic measures.

The results of the baseline analysis demonstrate that the use of FIAPP products and services will generate substantial cost savings to commercial building owners and managers and to contractors engaged in the construction of those facilities. The present value of savings nationwide expected from the use of FIAPP products and services is nearly \$1.4 billion (measured in 1997 dollars). Furthermore, because of BFRL's involvement, FIAPP products and services are expected to be commercially available in 2005. If BFRL had not participated in the development of FIAPP products and services, the commercial introduction of FIAPP products and services is expected to be delayed until 2009. Consequently, potential cost savings accruing to commercial building owners and managers and to contractors over the period 2005 through 2008 would have been foregone. The present value of these cost savings is approximately $\$ 120$ million. These cost savings measure the value of BFRL's contribution for its CONSIAT-related investment costs of approximately $\$ 29.1$ million. Stated in present value terms, every public dollar invested in BFRL's CONSIAT-related research, development, and deployment effort is expected to generate $\$ 4.13$ in cost savings to the public. The annual percentage yield (AIRR) from BFRL's CONSIAT-related investments over the study period is $13.3 \%$. 
The objective of the sensitivity analysis was to evaluate how uncertainty in the values of each of the eleven input variables, both singly and in combination, translates into changes in each of the six economic measures. The six economic measures evaluated in the sensitivity analysis are: (1) the present value of savings nationwide, $\mathrm{PVS}_{\mathrm{ALL}}$; (2) the present value of savings due to BFRL, PVS $\mathrm{BFRL}_{\mathrm{BF}}$; (3) the present value of BFRL's CONSIAT-related investment costs, $\mathrm{PVC}_{\mathrm{BFRL}} ;(4)$ the present value of net savings due to BFRL, PVNS ${ }_{\text {BFRL }}$ (5) the savings-to-investment ratio on BFRL's CONSIAT-related investments, SIR $_{\mathrm{BFRL}}$; and (6) the adjusted internal rate of return on BFRL's CONSIAT-

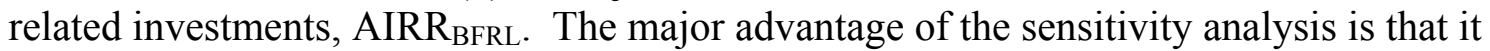
produces results that can be tied to probabilistic levels of significance for each economic measure (e.g., the probability that PVNS $\mathrm{BFRL}_{\text {is }}$ greater than or equal to zero, $\mathrm{SIR}_{\mathrm{BFRL}}$ is greater than or equal to 1.0 , or $A I R R_{B F R L}$ is greater than or equal to the discount rate, each of which would indicate that BFRL's CONSIAT-related investments were cost effective).

The results of the sensitivity analysis serve to validate the results of the baseline analysis. For example, each Monte Carlo simulation in which a single input variable was varied produced 1,000 observations for each of the six economic measures. Ten of the 11 such simulations produced values for the median and mean that were nearly identical to the corresponding value calculated in the baseline analysis for that measure. The final Monte Carlo simulation, in which all eleven of the input variables were varied in combination, also produced 1,000 observations for each of the six economic measures. In this case, the median value for each economic measure was less than the corresponding value calculated in the baseline analysis for that measure. In addition, the results from this Monte Carlo simulation reveal that the present value of net savings due to BFRL, PVNS $_{\mathrm{BFRL}}$, can be negative. This implies that there is some non-zero probability that BFRL's CONSIAT-related investments are not cost effective. However, on the opposite

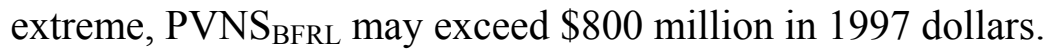

The fact that the range of values for an economic measure is so wide prompted an indepth examination of the results of this Monte Carlo simulation for three of the six economic measures. These measures are particularly helpful in understanding BFRL's contribution, since each measure provides a different perspective. The first, the present value of net savings due to BFRL, is a magnitude measure; it shows a dollar value to the public net of BFRL's CONSIAT-related investments. The second, the savings-toinvestment ratio on BFRL's CONSIAT-related investments, is a multiplier; it shows, in present value terms, how many dollars the public receives for each public dollar spent. The third, the adjusted internal rate of return on BFRL's CONSIAT-related investments, is a rate of return; it shows the annual return on the public monies going into the development of FIAPP products and services throughout the 25 -year study period.

For each of the three economic measures, less than 250 observations out of 1,000 were responsible for the observed "uneconomical" outcome. Stated another way, there is at least a $75 \%$ probability that BFRL's CONSIAT-related investments are cost effective. 
This underscores the importance of using multiple measures that ensure consistency in decision making.

\subsection{Suggestions for Further Research}

The background work for this report uncovered additional areas of research that might be of value to government agencies and other institutions that are concerned with an efficient allocation of their research budgets. These areas of research are concerned with: (1) the development of a standard classification of research benefits and costs; (2) factors affecting the diffusion of new technologies; (3) conducting ex ante evaluations with scheduled follow-ups; and (4) evaluations based on multiattribute decision analysis.

\subsubsection{The Development of a Standard Classification of Research Benefits and Costs}

A survey by the Civil Engineering Research Foundation shows that expenditures for research and development efforts in the areas of construction, building, and disaster mitigation technologies were over $\$ 2.1$ billion in $1992 .{ }^{107}$ Private industry, trade association, university, and government research bodies would like to know what are the economic impacts of these investments. The standardized evaluation methods employed in this report are appropriate for measuring these economic impacts. However, there is no systematic and comprehensive classification of research benefits and costs to guide analysts who must identify the benefits and costs associated with new construction, building, and disaster mitigation technologies that are used in these standardized evaluation methods. Such a classification, if developed, refined, and adopted as a standardized classification, could be used in several ways. ${ }^{108}$ First, the classification will help researchers and research managers identify potential benefits and costs associated with candidate research projects and thereby help them choose those with maximum net benefits (maximum net savings). Second, the classification will provide a standardized basis for identifying benefits and costs in research proposals. Finally, the classification will make possible a consistent treatment of benefits and costs in ex ante evaluations of new technologies and in ex post evaluations of completed building- and fire-related research projects.

\footnotetext{
${ }^{107}$ Civil Engineering Research Foundation. 1993. A Nationwide Survey of Civil Engineering-Related $R \& D$. Report no. 93-5006. Washington, DC: Civil Engineering Research Foundation.

${ }^{108}$ Although the standardized classification would be focused on identifying benefits and costs associated with building- and fire-related research projects, it would be generic to the extent that scientific research in general produces types of benefits and costs that are similar across technology areas. Thus the standardized classification will be applicable to many non-building- and non-fire-related technologies as well.
} 


\subsubsection{Factors Affecting the Diffusion of New Technologies}

Reliable estimates of the data input values for the standardized evaluation methods cannot be made without some relatively sound basis for predicting the rate of diffusion and the ultimate level of adoption of a new technology. The rate of diffusion and the ultimate level of adoption of a new technology depend on many factors. Uncertainty about how a new technology will perform affects both its rate of diffusion and its ultimate level of adoption.

Two factors over which a research laboratory exerts some control and which have the potential to reduce uncertainty about new technologies are: (1) the research laboratory's information dissemination efforts; and (2) the research laboratory's participation in standards-making organizations. Additional research on these two factors is warranted for a number of reasons. First, the characteristics of information are changing dramatically. With the advent of the World Wide Web and the increased acceptance of electronic media, the fruits of research may be quickly and widely disseminated. The reliance on printed reports sent to a targeted audience as the sole vehicle for communication is being eclipsed by other means of information dissemination. This transition needs to be studied to ensure that the information dissemination strategy that emerges is tailored to the needs of the research laboratory's customer base. Second, research results in the form of technical reports often provide the basis for standards. Consequently, information dissemination efforts may be used to leverage private-sector activities aimed at standardization. Finally, standards are an important means for disseminating information on expected levels of performance and for measuring key performance characteristics (e.g., through the use of standard practices, specifications, and test methods). For new technologies, acceptance by a standards-making organization should lead both to higher rates of diffusion and to higher levels of adoption. Consequently, research on how a research laboratory's participation in standards-making organizations affects the rates of diffusion and levels of adoption of new technologies will enable it to improve the efficiency with which it allocates staff and other resources to these activities.

\subsubsection{Conducting Ex Ante Evaluations with Scheduled Follow-ups}

From an analysis perspective, an ex ante evaluation of a new technology poses several challenges which are absent in an ex post evaluation of a completed research project. The biggest challenge involves the diffusion of a new technology (i.e., predicting the rate of diffusion and the ultimate level of adoption). Although two of the factors affecting the diffusion of a new technology were discussed in the previous suggestion for further research, much can be learned about the diffusion process by performing ex ante evaluations with the understanding that scheduled follow-up evaluations will be conducted.

The follow-up evaluation focuses on answering several key questions. These questions are aimed at learning more about the research laboratory's role and ability to move 
research results towards the market place and about the way in which firms and households (i.e., the intended users of the new technology) adopt and make use of the new technology. First, did the new technology become available to the intended users when anticipated in the ex ante evaluation? Second, is the new technology being adopted at the rate anticipated? Third, are the users that adopt the new technology experiencing the types of changes anticipated (e.g., cost savings, increased durability, and increased reliability)? Finally, are the types of users that adopt the new technology the same as anticipated? If these questions are asked and the answers are reviewed, critiqued, and fed back to research managers, ex ante evaluations will become a key link in the research laboratory's continuous improvement efforts.

Because ex ante evaluations are more complex than ex post evaluations, it is not always possible to quantify all of the relevant benefits and costs going into the evaluation. Such was the case in this economic impact assessment. Specifically, estimates of the cost savings due to fewer/shorter interruptions of building operations due to building-related problems (e.g., faster turnarounds due to electronic "as-built" information) are not included. Similarly, estimates of the investments required to develop, test, and market FIAPP products and services by the vendor tier (see Figure 3-2) are not included. These challenges and others (e.g., improved estimates of new-technology introduction costs) are being addressed through BFRL's Office of Applied Economics' efforts to monitor outcomes and compile information on CONSIAT-related impacts in preparation for the follow-up CONSIAT economic impact assessment.

\subsubsection{Evaluations Based on Multiattribute Decision Analysis}

Many research investment alternatives differ in characteristics that decision makers consider important but that are not readily expressed in monetary terms. Because the standardized evaluation methods employed in this report consider only monetary benefits and monetary costs associated with alternative research investments, their application does not reflect the importance of these non-financial characteristics to the decision maker. When non-financial characteristics are important, decision makers need a method that accounts for these characteristics (also called attributes) when choosing among alternative research investments. A class of methods that can accommodate nonmonetary benefits and costs is multiattribute decision analysis. ${ }^{109}$

The analytical hierarchy process (AHP) is one of a set of multiattribute decision analysis methods that considers non-financial characteristics in addition to common economic evaluation measures when evaluating project alternatives. The AHP has several important strengths: (1) it is well-known and well-reviewed in the literature; (2) it includes an efficient attribute weighting process; (3) it incorporates hierarchical descriptions of attributes; (4) its use is facilitated by available software; and (5) it has

\footnotetext{
${ }^{109}$ For more information on multiattribute decision analysis, see Norris, Gregory A., and Harold E. Marshall. 1995. Multiattribute Decision Analysis Method for Evaluating Buildings and Building Systems. NISTIR 5663. Gaithersburg, MD: National Institute of Standards and Technology.
} 
been accepted by ASTM as a standard practice for investments related to buildings and building systems. ${ }^{110}$

The AHP and its associated software represent a powerful and versatile management tool. How to apply this management tool most productively in a research environment suggests additional research in two areas. First, what will be the relationship between the AHP software and the standard classification proposed earlier? Second, how will the AHP be used to assess fit to mission, to set priorities, or to evaluate performance against some other management goal? If research is conducted on the two topics just outlined, the AHP-based tool which emerges will provide a format for: (1) efficiently and reliably screening and selecting among alternative research investments (e.g., by embedding information from the standard classification of research benefits and costs, information on fit to mission, and on research priorities); (2) selecting research projects for in-depth analyses, either of the ex ante or ex post type of evaluation; and (3) selecting and scheduling follow-up evaluations.

\footnotetext{
${ }^{110}$ American Society for Testing and Materials. 1998. Standard Practice for Applying Analytical Hierarchy Process (AHP) to Multiattribute Decision Analysis of Investments Related to Buildings and Building Systems. E 1765. West Conshohocken, PA: American Society for Testing and Materials.
} 


\section{References}

American Chemical Society. 1996. Technology Vision 2020. Washington, DC: American Chemical Society.

American Society for Testing and Materials (ASTM). Fourth Edition, 1999. ASTM Standards on Building Economics. West Conshohocken, PA: American Society for Testing and Materials.

American Society for Testing and Materials. 1999. Standard Practice for Measuring Life-Cycle Costs of Buildings and Building Systems. E 917. West Conshohocken, PA: American Society for Testing and Materials.

American Society for Testing and Materials. 1998. Standard Practice for Applying Analytical Hierarchy Process (AHP) to Multiattribute Decision Analysis of Investments Related to Buildings and Building Systems. E 1765. West Conshohocken, PA: American Society for Testing and Materials.

The Business Roundtable. 1997. The Business Stake in Effective Project Systems. Washington, DC: The Business Roundtable.

Chapman, Robert E. 2000. An Approach for Measuring Reductions in Construction Worker Illnesses and Injuries: Baseline Measures of Construction Industry Practices for the National Construction Goals. NISTIR 6473. Gaithersburg, MD: National Institute of Standards and Technology.

Chapman, Robert E. 2000. Benefits and Costs of Research: A Case Study of Construction Systems Integration and Automation Technologies in Industrial Facilities. NISTIR 6501. Gaithersburg, MD: National Institute of Standards and Technology.

Chapman, Robert E. 1999. Benefits and Costs of Research: A Case Study of Cybernetic Building Systems. NISTIR 6303. Gaithersburg, MD: National Institute of Standards and Technology.

Chapman, Robert E., and Sieglinde K. Fuller. 1996. Benefits and Costs of Research: Two Case Studies in Building Technology. NISTIR 5840. Gaithersburg, MD: National Institute of Standards and Technology.

Chapman, Robert E., and Roderick Rennison. 1998. An Approach for Measuring Reductions in Operations, Maintenance, and Energy Costs: Baseline Measures of Construction Industry Practices for the National Construction Goals. NISTIR 6185. Gaithersburg, MD: National Institute of Standards and Technology.

Chapman, Robert E., and Roderick Rennison. 1998. An Approach for Measuring Reductions in Delivery Time: Baseline Measures of Construction Industry Practices for 
the National Construction Goals. NISTIR 6189. Gaithersburg, MD: National Institute of Standards and Technology.

Chapman, Robert E., and Stephen F. Weber. 1996. Benefits and Costs of Research: A Case Study of the Fire Safety Evaluation System. NISTIR 5863. Gaithersburg, MD: National Institute of Standards and Technology.

Construction Industry Institute. 1999. 1999 Strategic Plan. Austin, TX: Construction Industry Institute.

Construction Industry Institute. 1998. Cost and Schedule Impacts of Information Management. Research Summary 125-1. Austin, TX: Construction Industry Institute.

Construction Industry Institute. 1996. Design for Safety. Research Summary 101-1. Austin, TX: Construction Industry Institute.

Construction Industry Institute. 1989. Costs of Quality Deviations in Design and Construction. RS10-1. Austin, TX: Construction Industry Institute.

Ehlen, Mark A., and Harold E. Marshall. 1996. The Economics of New-Technology Materials: A Case Study of FRP Bridge Decking. NISTIR 5864. Gaithersburg, MD: National Institute of Standards and Technology.

Executive Office of the President. 1992. OMB Circular A-94. Washington, DC: Office of Management and Budget.

Fuller, Sieglinde K., and Stephen R. Petersen. 1996. Life-Cycle Costing Manual for the Federal Energy Management Program. NIST Handbook 135. Gaithersburg, MD: National Institute of Standards and Technology.

Good, Mary, and Arati Prabhakar. 1994. "Foreword." In Mark Bello and Michael Baum, Setting Priorities and Measuring Results at the National Institute of Standards and Technology. Gaithersburg, MD: National Institute of Standards and Technology.

Hinze, J., and L. Applegate. 1991. "Costs of Construction Accidents," Journal of Construction Engineering and Management, Vol. 117, No. 3, pp. 537-550.

International Facilities Management Association. 1994. Benchmarks II. Research Report \#13. Houston, TX: International Facilities Management Association.

Mansfield, Edwin. 1995. Innovation, Technology and the Economy: Selected Essays of Edwin Mansfield. 2 vols. Economists of the Twentieth Century Series. Aldershot, UK: Elgar. 
Mansfield, Edwin, John Rapoport, Anthony Romeo, Edmond Villani, Samuel Wagner, and Frank Husic. 1977. The Production and Application of New Industrial Technology. New York: W. W. Norton \& Company, Inc.

Marshall, Harold E. 1988. Techniques for Treating Uncertainty and Risk in the Economic Evaluation of Building Investments. NIST Special Publication 757.

Gaithersburg, MD: National Institute of Standards and Technology.

Marshall, Harold E. 1992. Uncertainty and Risk-Part II in the Audiovisual Series on Least-Cost Energy Decisions for Buildings. Gaithersburg, MD: National Institute of Standards and Technology.

Marshall, Harold E. 1993. Least-Cost Energy Decisions for Buildings-Part II:

Uncertainty and Risk Video Training Workbook. NISTIR 5178. Gaithersburg, MD:

National Institute of Standards and Technology.

Marshall, Harold E. 1995. Choosing Economic Evaluation Methods-Part III in the Audiovisual Series on Least-Cost Energy Decisions for Buildings. Gaithersburg, MD: National Institute of Standards and Technology.

Marshall, Harold E. 1995. Least-Cost Energy Decisions for Buildings-Part III: Choosing Economic Evaluation Methods Video Training Workbook. NISTIR 5604. Gaithersburg, MD: National Institute of Standards and Technology.

Marshall, Harold E., and Rosalie T. Ruegg. 1979. Efficient Allocation of Research Funds: Economic Evaluation Methods with Case Studies in Building Technology. NBS Special Publication 558. Gaithersburg, MD: National Bureau of Standards.

Reich, Robert W. 1989. "The Quiet Path to Technological Preeminence." Scientific American (October): pp. 41-47.

Rogers, R. Mark. 1994. Handbook of Key Economic Indicators. Burr Ridge, IL: Irwin Professional Publishing.

Ruegg, Rosalie T. and Harold E. Marshall. 1990. Building Economics: Theory and Practice. New York: Chapman and Hall.

Simon, P. 1975. Models of Process Diffusion and Entry in the U.S. Chemical Industry. Ph.D. dissertation, University of Pennsylvania.

Stoneman, Paul. 1983. The Economic Analysis of Technological Change. New York: Oxford University Press.

Teicholz, Paul M. "Reverse Productivity Declines," ENR, Vol. 243, No. 23, December 13, 1999, p. 59. 
Thomas, Stephen R., Candace L Macken, and Sang-Hoon Lee. 2001. Impacts of Design/Information Technology on Building and Industrial Projects. NIST GCR 01-828. Gaithersburg, MD: National Institute of Standards and Technology.

Thomas, Stephen R. 1999. Impacts of Design/Information Technology on Project Outcomes. NIST GCR 99-786. Gaithersburg, MD: National Institute of Standards and Technology.

Thomas, Stephen R. 1998. Benchmarking and Metrics Summary for 1997. BMM 97-1. Austin, TX: Construction Industry Institute.

Tulacz, Gary J. “Top 400 Contractors,” ENR Sourcebook, November 1998, pp. 4-10.

US Department of Commerce. 2001. Current Construction Reports: Value of Construction Put in Place. C30. Washington, DC: US Bureau of the Census.

US Department of Energy. 1997. Commercial Buildings Characteristics 1995. DOE/EIA-E024695. Washington, DC: Energy Information Administration.

Van Tienhoven, C. J. 1996. The Benefits of STEP. Report No. IS96-014. The Hague: Shell Information Services.

Wright, Richard N., Arthur H. Rosenfeld, and Andrew J. Fowell. 1995. Construction and Building: Federal Research and Development in Support of the U.S. Construction Industry. Washington, DC: National Science and Technology Council. 